\title{
ELEMENTS OF SUSTAINABLE CANADIAN FOOD CONSUMPTION: MEASURING SELF-SUFFICIENCY.
}

\author{
by \\ Charles C. Sule \\ Bachelor of Science - Environmental Science, Royal Roads University
}

\begin{abstract}
A thesis presented to Ryerson University
in partial fulfillment of the requirements for the degree of

Master's of Applied Science in Environmental Applied Science and Management
\end{abstract}

Toronto, Ontario, Canada, 2009

(C) Charles C. Sule 2009 
I hereby declare that I am the sole author of this thesis. I authorize Ryerson University to lend this thesis to other institutions or individuals for the purpose of scholarly research.

Charles C. Sule

I further authorize Ryerson University to reproduce this thesis by photocopying or by other means, in total or in part, at the request of other institutions or individuals for the purpose of scholarly research.

Charles C. Sule 


\begin{abstract}
Elements of Sustainable Canadian Food Consumption:

Measuring Self-sufficiency.

Charles C. Sule B.Sc.

M.A.Sc. Environmental Applied Science and Management

Ryerson University

2009
\end{abstract}

One aspect of sustainable agricultural development in industrialized nations is a move towards national self-sufficiency in food production. A self-sufficiency indicator (SSI) that complements the Organization for Economic Cooperation and Development's driving force-state-response framework on which Canada's agrienvironmental indicators are based is proposed and demonstrated. A 2001 survey of Canadian household food consumption is analysed to estimate the areal measure of land required for its satisfaction exclusively by domestically produced primary agriculture. Canada is self-sufficient in field crops, which reflects its comparative advantage on the global market. The nation would require about five times the area currently under cultivation to be self-sufficient in fruit production. Vegetables consumed domestically account for just under half the area under cultivation. 


\section{Acknowledgments}

Thanks to Dr. Michal Bardecki for his critique and encouragement.

Thanks to Dr. Ron Pushchak, whose door was always open as promised.

Thanks to Dr. Mustafa Koç for his thorough review and helpful additions. Thanks to Dr. Andrew Laursen for kindly chairing my defence committee. 


\section{Dedication}

For my mother, Joan Sule, and my sister, Joanne Christopher, for supporting me through this; to my partner Christine Rahim, for her encouragement and for living with me through it; but especially for my son, Alexandre Sule, for providing the reason for all I do. 


\section{Table of Contents}

Section

Page

Author's declaration

ii

Abstract

iii

Acknowledgements

iv

Dedication

v

List of tables

viii

List of figures

xiii

List of acronyms

xiv

1.0 Introduction

01

1.1 Human carrying capacity

09

1.2 Dedication to surplus

1.3 Connecting Canadians to their land

1.4 Self-sufficiency is sustainable

2.0 Introduction to literature review

2.1 Sustainable agriculture defined 25

2.2 Approaches to sustainability

2.3 Sustainability frameworks

2.4 Sustainability indicators

3.0 Introduction to methods

3.1 Reconciling quantities in the FES

3.1.1 Meat (including poultry)

63

3.1.2 Fish and other marine products 75

3.1.3 Dairy products and eggs 77

3.1.4 Bakery and other cereal products 84

3.1.5 Fruit and nuts 99

3.1.6 Vegetables

3.1.7 Margarine, fats, and oils

3.1.8 Area for animal feed requirements $\quad 126$

3.2 Calculation of areas required to support 2001 consumption. 131 
Section

Page

4.0 Results and discussion

4.1 The areas of Canadian self-sufficiency

135

4.2 Inclusiveness of results

5.0 Conclusions

145

References

149

Appendix 1

167 


\section{List of Tables}

Table

Page

1.1 Indicator groups, AEIs and AEIs in use by AAFC.

3.1 The approximate yield of typical cuts of beef from a dressed carcass. 64

3.2 Share of listed categories supplied by ground beef.

3.3 Ground beef allocation table.

3.4 Allocation of ground beef to specific cuts.

3.5 Calculation of required slaughter cattle.

3.6 Calculation of required slaughter calves.

3.7 The yield of typical cuts of pork from a cold trimmed carcass.

3.8 Share of selected categories added to pork cuts.

3.9 Share of selected categories added to pork shoulder cuts.

3.10 Share of ham categories added to pork leg cuts.

3.11 Share of bacon added to pork loin and belly cuts.

3.12 Calculation of required slaughter pigs.

70

3.13 Share of listed categories added to lamb and mutton.

71

3.14 Calculation of required slaughter sheep.

3.15 Percent share of chicken production and average dressed weight.

3.17 Calculation of required slaughter chickens.

3.18 Share of listed categories added to turkeys.

3.19 Calculation of required slaughter turkeys.

3.20 Calculation of required farmed fish.

3.21 Calculation of milk volume required to supply butter.

3.22 Relationship between milk quantity and cheese yield.

3.23 Calculation of milk required to supply cheese consumption. 
Table

3.24 Calculation of milk required to supply evaporated milk consumption. 82

3.25 Calculation of total milk and the animals required for its supply.

3.26 Calculation of eggs and the chickens required for their supply. 83

3.27 Comparison of contributions of ingredients in bread. 88

3.28 Calculation of the mass of rolls from initial FES numerical quantity. 88

3.29 Comparison of contributions of ingredients in various rolls. $\quad 89$

3.30 Comparison of contributions of ingredients in crackers. 90

3.31 Ingredients in muffins and calculation of conversion factor. 91

3.32 Comparison of contributions of ingredients in pasta. 93

3.33 Calculation of mass of pasta from canned volume. 94

3.34 Total mass of pasta. 94

3.35 Calculation of wheat required for bread, rolls, crackers and pasta. 94

3.36 Calculation of production proportions for cereals, 2001 . 95

3.37 Calculation for rice as Canadian-grown grain. 96

3.38 Calculation of wheat required to supply flour. 96

3.39 Calculation for flour as Canadian-grown grain. 97

3.40 Calculation of the average moisture content for breakfast cereals. $\quad 97$

3.41 Calculation of grain required for breakfast cereal consumption. $\quad 98$

3.42 Calculation for breakfast cereals as Canadian-grown grain. 98

3.43 Calculation of per unit mass for selected fruits. 99

3.44 Calculation of per unit mass for melons. $\quad 100$

3.45 Calculation of the mass of fruits from initial FES numerical quantities. 101

3.46 Mass of fruit as raisins and dried fruits. 103

3.47 Calculation of mass of fruit required to make fruit juice. 104

3.48 Calculation of starting mass of fruit to make concentrated fruit juice. 105

3.49 Canned fruits consumed and $\mathrm{m} / \mathrm{v}$ ratio. 105

3.50 Other canned fruits, $\mathrm{m} / \mathrm{v}$ ratio and mean of the ratio. 106 
3.51 Mass of fruit required to provide the initial canned volume.

3.52 Mass of fruit required to manufacture the volume of jam, jelly, other preserves and fruit pie filling.

3.53 Calculation of production proportions for fruit, 2001.

3.54 Masses of domestic fruits substituting for bananas and citrus fruit. 109

3.55 Masses of domestic fruits substituting for other fresh fruit, other tropical fruit and frozen fruit.

3.56 Masses of domestic fruits substituting for dried fruit, imported fruits for juice and imported fruit for concentrated juice.

3.57 Masses of domestic fruits substituting for dried fruit, imported fruits for juice and imported fruit for concentrated juice.

3.58 Calculation of per unit mass for selected vegetables.

3.59 Calculation of mass of vegetables from FES numerical quantities.

3.60 Mass of vegetables required for frozen vegetables.

3.61 Mass of vegetables from dried potatoes and other dried vegetables. 115

3.62 Canned vegetables consumed and mass/volume ratio.

3.63 Mass of vegetables required to provide the initial canned volume.

3.64 Calculation of mass of vegetables required to make an initial volume of juice.

3.65 Calculation of starting mass of vegetables from an initial volume of pickles.

3.66 Calculation of production proportions for vegetables, 2001.

3.67 Masses of domestic vegetables substituting for other leaf and stalk vegetables, other seed and gourd vegetables, and other root vegetables. 
3.68 Masses of domestic vegetables substituting for other canned vegetables, other frozen vegetables, and other dried vegetables.

3.69 Masses of domestic vegetables substituting for other vegetable juice and pickles.

3.70 Calculation of oil density.

3.71 Calculation of extraction rate for vegetable oil.

3.72 Volume of oil from initial mass of margarine and shortening.

3.73 Calculation of masses of oilseeds from oil volumes.

3.74 Calculation of production proportions for oilseeds, 2001.

3.75 Masses of domestic oil crops used in the manufacture cooking/salad oil and margarine.

3.76 Barley, corn, and wheat grown to support 2001 Canadian meat, dairy and fish consumption..

3.77 Mixed grain and oats grown to support 2001 Canadian meat, dairy and fish consumption.

3.78 Legumes and canola grown to support 2001 Canadian meat, dairy and fish consumption.

3.79 Calculation of mass of canola and soybeans required to supply animal feed meal.

3.80 Hay, pasture and silage required to support 2001 Canadian meat and dairy consumption.

3.81 Calculation of production proportions for silage crops, 2001.

3.82 Distribution of production required for silage crops.

3.83 Final area calculations for 2001 consumption of cereals, legumes and oilseeds.

3.84 Final area calculations for 2001 fruit consumption. 
4.1 Final areas for cereals, legumes and oilseeds, 2001.

4.2 Final areas for fruits, 2001.

4.3 Final areas for vegetables, 2001.

4.4 Masses and volumes accounted by the SSI. 


\section{List of Figures}

Figure

Page

1.1 Supply of dependable agricultural land. $\quad 11$

2.1 Driving force-outcome-response framework framing Canada's AEI. $\quad 39$ 


\section{List of abbreviations}

AAFC - Agriculture and agri-food Canada

AEI - Agri-environmental indicator[s]

CC - Carrying capacity

CTW - Cold trimmed weight

DCW - Dressed carcass weight

DOJC - Department of Justice Canada

DSR - Driving force-state-response

EF - Ecological footprint

FAO - Food and Agriculture Organization

FES - Food expenditure survey, specifically for the year 2001

LQI - Land quality indicators

MPC - Manitoba Pork Council

NASS - National Agricultural Statistics Service

NPP - Net primary productivity

OECD - Organization for Economic Cooperation and Development

SD - Sustainable development

SSI - Self-sufficiency indicator

USDA - United States Department of Agriculture

WCED - World Commission on Environment and Development 


\subsection{Introduction}

Canadian people generally want to act in an environmentally responsible manner (Agriculture and Agri-Food Canada [AAFC], 2007) and more specifically have supported efforts, legislation and treaties to reduce the environmental costs of food production, both domestically and internationally (Lefebvre, 2005: 2). However, when there is no discernable impact on their local environment, people are less likely to modify their personal behaviour (Blake, 2001: 712). This has particular significance for the agricultural sector given its broad impact on the environment (Tilman, Cassman, Matson, Naylor \& Polasky, 2002: 671) and the degree of urbanization in Canada (Statistics Canada [StatsCan], 2003a), in that consumers living away from farms cannot connect their eating habits with the environmental pressures posed by the production of their food. While anecdotal evidence exists that people are becoming aware their consumption choices affect the environmental sustainability of agriculture, for instance as suggested by the growing organic and local food movements (Junkins, Clark, MacGregor \& McRae, 2005: 20), there is a lack of studies specifically connecting the two.

It is therefore proposed that a characterization of the sustainability of the agricultural-food (agri-food) system of Canada from the perspective of consumer demand be carried out in a way that is understandable and usable by producers, governments, institutions, non-governmental organizations, and consumers themselves. Establishing clear links between household food demand and the national food supply has already been proposed as a means of more firmly 
determining the sustainability of food consumption (Duchin, 2005: 103). However, simply disaggregating Canadian food consumption into the constituent crops required to supply it cannot be translated easily into environmental impacts, since not all food Canadians eat can be produced in the country.

The Canadian government, through AAFC, has set as a priority integrating sustainability concepts into agricultural practice and agri-food policy. While acknowledging rising global demand for food and arguing producers should continue trying to capture an ever-greater share, the government at the same time recognizes the uncertain long-term environmental impacts in doing so (Junkins et al., 2005: 19; Lefebvre, 2005: 2). Finding the conceptual area of Canadian land required to supply an amount equivalent to the domestic consumption of foodstuffs adds depth to assessments of sustainability because the ability of a society to continue is ultimately dependant on the self-sufficiency of the food supply, not only globally, but also nationally (Douglass, 1984: 6; Smit \& Smithers, 1993: 510). Restated, self-sufficiency is a measure of food security, as has been recognized in the Canadian context for a considerable period of time (Cowell \& Parkinson, 2003: 223; Pierce \& Furuseth, 1986: 16).

Measuring the ratio of the area of land under cultivation to the area required to furnish domestic demand for each major category of food is therefore an indicator of agricultural sustainability and food security. Of course, this is not to suggest that the nation should ignore the economic benefits of global trade, any comparative advantage possessed, and plant physiologies in a sudden 
attempt to fulfill, for example, an ideological agenda. Sustainability strategies should not require shocking overhauls of society or force people to act against their self-interest (Robèrt, Daly, Hawken, \& Holmberg, 1997: 80).

If sustainability essentially means not importing environmental goods and services in excess of our own supply or exporting wastes beyond the absorptive capacity of the domestic environment, as has been well-argued (Wackernagel \& Rees, 1996: 54-55), yet the ability to fully comprehend the impact of our consumption decisions is hampered by a lack of information (Kissinger \& Rees, 2009: 2314), a gauge of the environmental load posed by domestic agri-food demand could provide the conceptual bridge that influences producer and consumer behaviour. Although AAFC states "appropriate expectations" (Lefebvre, 2005: 3) of methods for tracking the environmental performance of the agricultural system include making scientific data accessible to the public and using the information to highlight the environmental impacts of the agri-food system to elicit behavioural change, their subsequent methodology focuses heavily on tracking environmental performance with respect to macroeconomic policy and strategy, and global trade (Lefebvre, 2005: 3-4; Junkins et al., 2005: 20). There does not appear to be a clear strategy for meeting the above-noted expectations.

The choice of data collected by AAFC to measure impacts to the ecosystems providing services for and receiving waste and bi-products from agriculture is intended to weigh environmental loading. Since Canadian agri-food 
producers and processers "are being urged to maintain acceptable levels of stewardship" (Lefebvre, 2005: 2), the real effect may be to highlight problems caused by certain production practices so that domestic farmers produce crops with lower impacts while those products associated with greater impacts are grown at a distance and imported. Interpretation of the data in this way thus causes a, albeit unintended, prescriptive effect. Further, the more Canada's agrifood system becomes integrated with the global system, the more complicated analyses of food sufficiency become (Smit \& Smithers, 1993: 510). The introduction of counteracting data linking domestic demand and supply can provide justification for the economic internalization of some environmental impacts and avoid the justification for substitution. In addition, domestic consumption disaggregated into domestically-producible commodities offers a source of innovation in agronomic practices like intercropping and integrated pest management by illuminating choices from lists of candidate crops (e.g. Boivin, Grimard \& Olivier, 2005: 86, table 12-2). Determining domestic food selfsufficiency in this way provides a direct connection between the social and environmental parameters of agricultural sustainability.

Relying on production and trade data to calculate residual domestic consumption quantities as is now the case (StatsCan, 2008a) masks the myriad sources that supply the globalized agri-food chain (Opara, 2003: 102) and thus also renders the overall environmental sustainability of Canadian food consumption blurred. Measuring the environmental impact of Canada's 
agricultural production assesses its contribution to the global total, but does not suggest the fraction posed by its citizen's demand. That Canada's contribution to the global food system is produced in ways that increasingly preserve the environment and conserve natural resources is laudable, but continuing integration with that increasingly complex system at the expense of selfsufficiency may leave Canadians vulnerable in hidden ways and thus negatively impact economic sustainability (AAFC, 1997: 7; Lefebvre, 2005: 2). Assessing the lifecycles of all the imported fresh and processed foods in the Canadian diet in order to assess the ecological cost is a daunting task (Graedel \& Allenby, 2003: 183-196).

The rationale for augmenting supply-side assessments of the sustainability of agriculture with demand-side characterization can be explained in this way:

> From the beginning societies have sought, as a general rule, to continually increase food production (Altieri, Letourneau \& Davis, 1984: 175); this has either been to support an increasing population or has spurred and supported subsequent population growth. This trend continues today.

$>$ Nonetheless, as has been globally recognized for well over 25 years (Caldwell, 1984: 307), sustainability demands limits to growth in a finite world. This is even more critical to an industry heavily reliant on scarce finite resources like soil, petro-chemicals, mineral fertilizers, and fossil fuels. 
$>$ All humans have similar, basic energy and nutrition requirements of food (Food and Agriculture Organization [FAO], 2001) and the ostensible purpose of an agri-food system is to satisfy those needs.

$>$ In a free-market economy a strong gauge of people's preference is consumer demand. However, under increasingly liberalized international trade, demand is influenced by the ever-larger choices available to the Canadian consumer. The often bewildering array of origins, even of the ingredients in an individual product, may defeat attempts to educate consumers about the environmental impact of their purchasing decisions.

There are thus two sides to the environmental impact of food: the sustainability of bulk production, which is relatable to large-scale assessment, intercession and guidance, and that of the consumer, whose capacity to relate to environmental effects may be nearer to arms-length and whose ability to react or create influence is therefore limited.

Of course modern agri-food systems have been extensively analyzed for their effects on the environment. In a review of the practices that have allowed agricultural production to double since about 1960, David Tilman (1999: 5995) noted that four grains, rice, corn, barley and wheat, annuals once considered comparatively rare, now occupy almost $40 \%$ of agricultural land and have "become the dominant plants on earth." He determined this came with an rise in nitrogen application by a factor of almost 7 and in phosphorus fertilization by 
almost 3.5 times (Tilman, 1999: 5996) that has polluted terrestrial and aquatic systems and contaminated groundwater (Tilman et al., 2002: 672). Pesticide use associated with intensive agriculture bioaccumulates and persists in the abiotic environment, while at the same time selecting for resistance amongst the pests they are designed to kill. Microbial resistance to the antibiotics used routinely in modern animal husbandry poses a risk to humans then exposed to less-treatable strains of diseases (Tilman et al., 2002: 672). Natural land converted to agricultural use shows reduced biodiversity, although agroecosystems may still be more diverse than urban ecosystems (McRae, Smith \& Gregorich, 2000: 15).

In Canada, efforts to include such environmental impacts into the agriculture industry's monitoring framework began in 1993 and mimicked the driving force-state-response (DSR) model developed by the Organization for Economic Cooperation and Development (OECD) that was adopted for international work linking food production to the environment (FAO, 1997; McRae et al., 2000). Once AAFC was directed to incorporate sustainable development principles and practices into its own management system and the way it oversees the wider industry, it generated guidance documents to provide a strategy to integrate environmental issues with economic and social interests, and suggested criteria under which environmental impacts might be assessed (AAFC, 1997: 1, 13). After criteria are established, related data are collected representing trends in environmental performance that respond to changes in policy, support and guidance, or behaviour; because of this responsiveness, 
these data are called indicators. McRae and colleagues oversaw the initial agroecosystem indicator (AEI) development and a first series of results (2000). Subsequent work expands and further operationalizes the AEI, then reports results that supplant those of the first effort (Lefebvre, Eilers, \& Chunn, 2005; Lefebvre, 2005: 6).

The groundbreaking Canadian work takes the perspective of farmers and agri-food producers (McRae et al., 2000: vii) and the "policy challenge," as they see it, is to set environmental, social and economic benefits at an "optimal and sustainable" level (McRae, et al., 2000: 1). The term "optimal" is given no immediate context by McRae and co-workers, but it suggests an attempt to assuage producers who fear their economic rights will not be respected through the imposition of environmental monitoring and controls. To that end, there is recognition later that farmers are not directly compensated for conserving environmental benefits or taking steps to manage risks (Lefebvre, 2005: 20). Also, economic and environmental optimization occurs, for example, when fertilizer or pesticide is applied such that the greatest yield is realized with the least unintended effects (i.e. nutrient run-off or pesticide overspray) (Koroluk, Piau, Grimard, Bourque \& Korol, 2005: 56, 58). The second AAFC report explicitly models its definition of sustainable development after the growth-oriented one of the UN's Brundtland Commission, and states the sustainability of agriculture is a "key aspect" of any such development (Lefebvre, 2005: 2; WCED, 1987: 8). 
This salutatory section will be followed immediately with a discussion of human carrying capacity and its relationship to land area, thereafter by an overview of agricultural development that illustrates the historical supply-side focus, the global distribution of land resources and advances in yield growth. More depth will be added to the discussion of the agri-environmental indicators before concluding with an introduction to the study methodology and an outline of the remaining work.

\subsection{Human carrying capacity}

Carrying capacity can be defined basically as the largest animal populations that can be supported by the resources of a given area without ruinous deterioration of the environment (Chambers, Simmons \& Wackernagel, 2000: 46). When applied to modern humans, carrying capacity can be interpreted as a demand on the land base and has been expressed in a variety of ways.

One simple yet useful method for determining carrying capacity is per capita arable land available for grain production, since most of the world derives nutrition largely from that source (Kendall and Pimentel, 1994: 199) and this is unlikely to change in the "foreseeable future" (Cassman, 1999: 5952). Such an approach can be expanded to include a qualitative assessment of available land, for example, as determined in the Canada Lands Inventory (CLI) classification system (AAFC, 2008a) or to illustrate the unsustainability of discrete populations, for example, dense urban centres that require far more food than the adjacent 
farmlands can provide (Wackernagel \& Rees, 1996: 86-88). Another way to broaden this approach to is to include a greater variety of foodstuffs. Such a broad scheme fits into one of six categories of methods Cohen identified as being suitable to calculate human carrying capacity (1995a: 343). Ultimately, a direct characterization of the relationship between crop area and people describes human carrying capacity in one of the most tangible ways since people must eat to survive.

In the Canada the amount of dependable agricultural land, namely CLI classes 1, 2 and 3 lands has been in decline for some time, mostly as a result of urbanization (Hofmann, Filoso \& Schofield, 2005: 10). These classes denote a range of limitations from none for the well-drained, deep soils of class 1 , to some restrictions on crop choices and conservation practices for class 2 , to the "moderately severe" restrictions that may tightly limit the choice of crops grown, "the timing and ease" of sowing, tillage, and harvesting, and conservation practices (AAFC, 2008a: 115-ף17). Figure 1.1 shows the relationship between the supply of and demand for agricultural land in Canada for a 50-year period ending in 2001.

Hofmann and colleagues noted that the excess cultivated land shown in figure 1.1 is being derived from marginal lands that suffer from inter alia erosion, slope problems and soil fertility deficiencies; in other words, limitations that are more than moderately severe (AAFC, 2008a: $118-\$ 21$ ). This is, by their definition, unsustainable (Hofmann et al., 2005: 9). To be clear, although Canada 


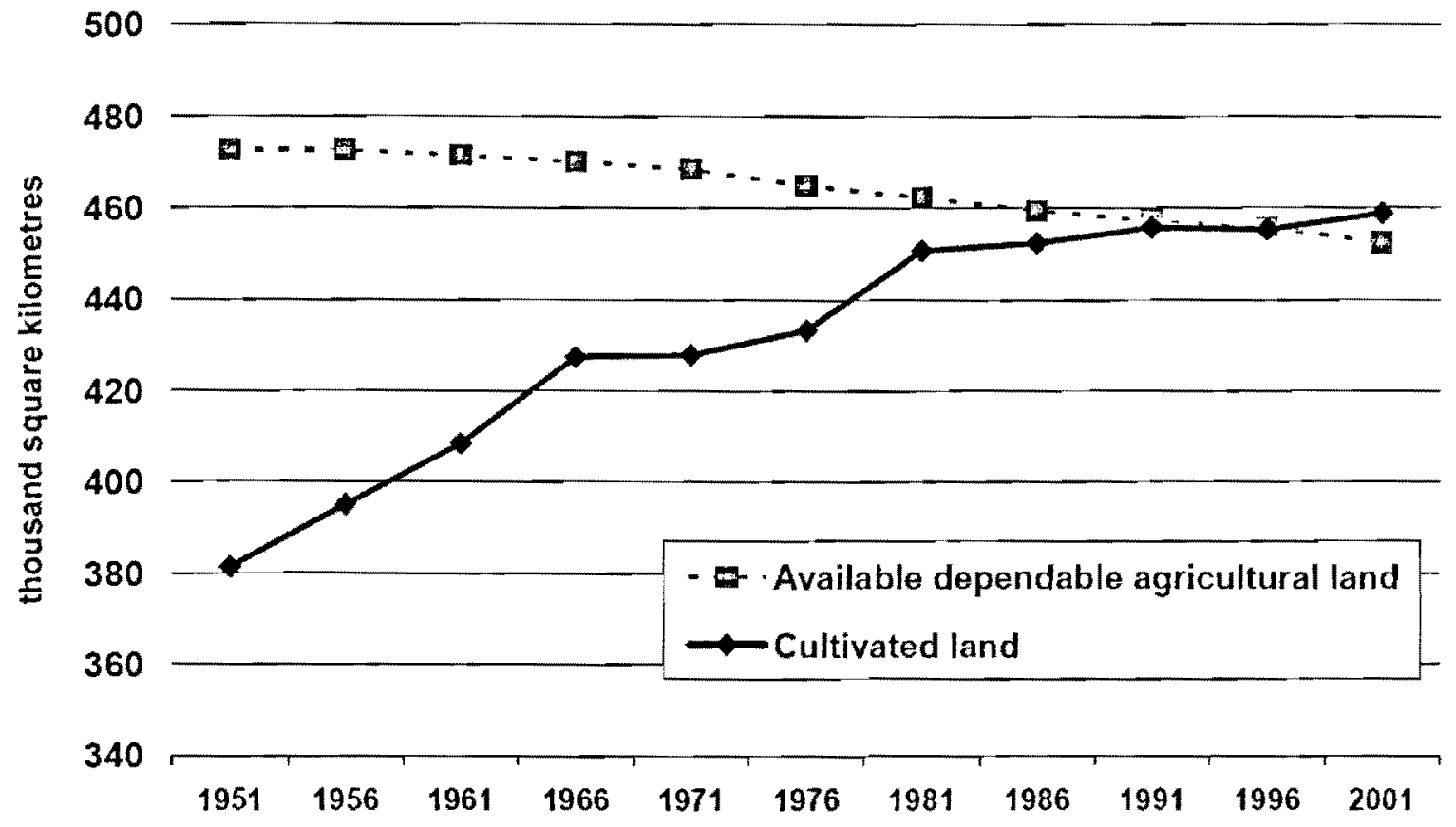

Figure 1.1: Supply of dependable agricultural land and demand for cultivated land in Canada. (Reproduced from: Hoffmann et al., 2005: 10, figure 5).

covers nearly 1 billion hectares of land and inland water (Niu \& Proux, 2005: 24), the share of dependable farmland is as little as $5 \%$ and of prime class 1 land a tenth of that. Further, since over half of class 1 land is in Ontario alone, that class may be at higher risk of loss considering Ontario is experiencing most of Canada's urban population growth (Government of Ontario, 2007: १7, १21; Hofmann et al., 2005: 5, table 1). Since in part climate and soil factors guide farmers' decisions as to what to plant, the loss of scarce land, soil types or nearby supporting natural ecosystems could translate into lost capacity to produce certain crops (Rostad \& Padbury, 2005: 98). Therefore, ensuring the continuation of elements within the greater system ensures the maintenance of overall carrying capacity and contributes to global sustainability. 
History is replete with examples of societies who tested the limits of their agri-environmental systems or were forced to rely on agricultural systems away from their populace. The record of possible outcomes upon reaching those situations is as interesting as it is varied and makes up the next section.

\subsection{Dedication to surplus: the origin and development of agriculture.}

Throughout the history of human agriculture there is evidence that maximizing production while optimizing labour has been the ultimate goal, regardless of the farmers' own needs for the products. An interaction of indeterminate origin ${ }^{1}$ (Cohen, 1995b, 37) began even before humans first tended plots: some kind of semi-permanent agriculture caused population increases, which spurred agricultural need, leading to expansion and surplus, causing further population increases, spurring further need, expansion, surplus and so on. Eventually, trading and feeding imperialist armies added to and occasionally eclipsed domestic populations as the chief users of the surplus, but even colonialism (mainly, but not only, by European nations) can ultimately be ascribed to the need for more food. In modern times, seemingly altruistic notions of finally ending world hunger led to stunning leaps in productive capacity that coincided with still more dramatic leaps in population.

Humans were likely already living in settlements year-round, or nearly so, when the practice of cultivating important plants, rather than gathering them,

\footnotetext{
'In other words, a "(w)hich came first, chicken or egg?" situation (Cohen, 1995b: 36).
} 
caught on some 10000 years ago (Smith, 1995: 51, 210). These early settlers already had extensive knowledge of the lifecycles of these plants and had developed successful methods and tools for collecting and processing the seeds (Smith, 1991: 14; Smith, 1995: 210), but had yet to face the population density pressures that made the effort of permanent agriculture worthwhile (Smith, 1991: 14). Although growth in human numbers most commonly caused density pressures, environmental perturbations had similar effects. In the Americas, for instance, the Altithermal period immediately following the last ice age was marked by a warming, drying climate that caused vegetation to vanish from historical areas along with the animals, including the Megafauna, that it fed. Thus a declining food supply for a constant population has a similar effect to that of a population growth rate that exceeds yield growth. The beginnings of agriculture in the New World can be traced to this time (Smith, 1991: 14-15).

With the inception of settlement agriculture, humans began having some success at achieving constant food production. Early agricultural settlements were some 2 to 6 times larger than their non-agricultural contemporaries and agricultural economies were more affluent, for example, as evidenced by the larger houses. Proximate endogenously produced food also afforded early settlers the time to create an infrastructure that included food storage facilities and flood protection installations (Smith, 1995: 81).

It seems then that at least some early agrarian societies produced more food than was required by the extant population. Within ancient agricultural 
catchments $^{2}$ "the human drive to secure the greatest possible amount of food for the least possible labor [sic]" that contributed to the very domestication of plants (Helbaek, 1959: 365-366) likely also meant an early tendency for surpluses. Under these conditions population levels rose to meet and exceed food production, straining the sustainability of the system. To relate an example, the so-called Cradle of Civilization, in modern-day Iraq, rose from these first agricultural settlements (Braidwood, 1954: 41). The recounting of the end of these "Old Testament societies" traditionally blamed outside invasion, but newer evidence suggests a general collapse in soil tilth and the inability of the agricultural system to support the dependant population (Douglass, 1984: 3).

In other cases production was increased to meet the needs of growing populations. In the first settlements around the Mediterranean Sea, people were clustered in river deltas. When people could no longer be fed from the deltaic farms, innovations beget terracing and other improvements, which increased yield to meet the growing demand (Semple, 1928: 62). As the Egyptian civilization gave way to the Roman Empire and more and more land was cleared of forests to make room for farmland, soil erosion compounded the problem of declining soil fertility, finally turning the North African granaries of the Roman Empire into desert and marginal land (Douglass, 1984: 3).

Other places in the world had similar experiences. In ancient Sri Lanka, farmers invented a reservoir-based irrigation system that, combined with the

\footnotetext{
${ }^{2}$ Notwithstanding obvious natural boundaries, some early nations were defined by the areas of their agricultural production, for example, Egypt in the $5^{\text {th }}$ century BCE (Semple, 1928: 66).
} 
vegetarian philosophy that accompanied Buddhism to the island in the $4^{\text {th }}$ century $\mathrm{BCE}$, gave regular surpluses that allowed for a growing kingdom. The link between this system and its dependant population was so obvious that invaders from India attacked the water tanks in order to quell the people (Senanayake, 1984: 227). Indeed, Sri Lanka is possibly only now returning to population levels first experienced almost a thousand years ago (Senanayake, 1984: 227; United Nations Population Division, 2009). In pre-Columbian America too, Mayan centres succumbed to population pressures that badly eroded soils could no longer bear (Douglass, 1984: 3).

As mentioned, evidence exists that climatic shifts, namely periods of drought, perhaps accompanied by abnormally warm or cool temperatures and lasting from a few decades to several centuries, contributed to the collapse of various societies by reducing agricultural production and the availability of game and wild plants. Thus some societies grew to what were sustainable population and agricultural production levels under the given environmental conditions. When those conditions changed rapidly and radically the peoples' technical prowess was overwhelmed and the societies collapsed or were drastically reduced (Weiss \& Bradley, 2001: 610).

Contemporaneously with one such "forced regional abandonment" by the Anasazi peoples of their North American home in the $13^{\text {th }}$ century CE as a result of an extended climate perturbation (Weiss \& Bradley, 2001: 610), Old World peoples were beginning to understand the geographical extent of the Earth 
(Osterhammel, 2005: 71). From about the $11^{\text {th }}$ to the mid- $13^{\text {th }}$ centuries, European populations rebounded at "unprecedented rates" (Smith, 1991: 47) from losses suffered under the Roman Empire and the Dark Ages that followed (Smith, 1991: 38-42), while agricultural production "expanded greatly" as more lands were cleared for cultivation (Smith, 1991: 47). The dawn of European colonialism marked the beginning of massive imports of agricultural products that augmented the limits of local production (Pfeiffer, 2006: 6). In other words, people began to import carrying capacity, on which they became dependant for survival, rather than simply trading to add value to products through variety or rarity.

In the $15^{\text {th }}$ and $16^{\text {th }}$ century, the voyages of European sailors were primarily exploratory ones also concerned with finding and obtaining spices. Many farm animals were slaughtered across Europe every fall owing to a consistent shortage of winter feed and the meat had to be preserved with salt and spices, the latter of which only grew in tropical countries (Parry, 1966: 32). Thus the initial journeys were dedicated to discovering and securing the origins of the important spices and mapping the most expeditious route by which to transport them home. Whenever the Europeans encountered other peoples, they found societies based on agriculture (Osterhammel, 2005: 73-74). In some instances, they found populous, long-standing centres of agricultural trade featuring products from distant lands; in others, they found relatively uninhabited lands. In both cases, when conquest was possible and desirable, the 
colonizers forcibly seized the land and committed it to commercialized agriculture (Caldwell, 1984: 303; Osterhammel, 2005: 74).

European overseas colonization was a relatively slow process, beginning with the American colonies in the early $17^{\text {th }}$ century ${ }^{3}$, then Australia in the $18^{\text {th }}$ and New Zealand in the $19^{\text {th }}$ centuries (Federico, 2005: 32). Throughout this time agriculture was economically paramount with respect to its contribution to national income, employment creation and generation of personal wealth (Cain \& Hopkins, 2002: 66). The willingness of citizens to immigrate to these new lands and settle was driven by population pressures in their homelands. The migrations and the pace of land clearing for farms quickened over time, not only from Europe overseas, but also as a kind of regional colonization within Russia, Eastern Europe, South America and China, as internal populations reached critical levels and were forced to find new farmland (Federico, 2005: 32).

As an example of how the rate of agricultural extensification quickened, the US began recording land area in farms in 1850 and up to that time 118 million hectares had been put under the plough. By the time the frontier was closed as the turn of the $19^{\text {th }}$ century approached, some 250 million hectares were being farmed (Federico, 2005: 32). Worldwide today there are well over 1.5 billion hectares committed to crops and cultivated trees (excluding those used for fuel, fibre and wood) and almost 3.5 billion hectares used as permanent pasture lands from the available 13 billion hectares. The remaining $50-60 \%$ of

\footnotetext{
${ }^{3}$ The pace of North American migration did quicken however and Thomas Malthus (1766-1834) believed the immigration he was observing was the exponential growth that formed one of the pillars of his population theory (Seidl \& Tisdell, 1999: 397).
} 
the Earth is unusable for agriculture short of a stunning technological breakthrough or is forested (Federico, 2005: 5). That the limit of Canada's agricultural system with respect to land area has been reached was introduced on page 7; it has stabilized at about 67 million hectares for some time (Eilers \& Hoffman, 2005: 43). That the limit has been reached should not be a shock, since increasing output has long been one of the "primary objective[s] of Canadian agricultural policy" (Junkins et al., 2005: 20).

Thus it can be seen that outgrowing lands, soil fertility problems, rising demands of growing populations, and effects of changing climate that can be observed in the world today have all been faced by farmers since the first seeds were sown. In sum, section 1.2 has shown that while the chief goal of agriculture has, or course, always been to provide adequate food, the means to that end has seemingly always involved wringing the maximum production from farms regardless of local or instant needs and frequently to the permanent detriment of the land. Even peoples who live within their carrying capacity can exceed their food supply when yields are affected by a changing environment. For most of the period since the Neolithic revolution the only way to increase production was to expand the cultivated area, either through conquering or clearing new land, but with all the available land now under cultivation at least the latter avenue is closed.

Expanding the area under cultivation is not the only way to increase production. There have been enormous gains made in yields from the mid-1960s 
into the present millenrium through the introduction of modern, hybridized varieties (MV) of rice, wheat and corn. Relying heavily on fertilizer inputs, chemical pest control, irrigation and mechanization, these advances are collectively known as the green revolution. Growers also favoured hybrids that can be planted densely to take advantage of greater nitrogen fertilization (Duvick \& Cassman, 1999: 1624). Notably though, without nitrogen fertilization MV yields are only moderately above those of the un-hybridized varieties (Khush, 1999: 646, 647-648). Yield growth has slowed over time (Khush, 1999: 650) and improved varieties of root and protein crops, mostly beans, have been slow to develop (Evenson \& Gollin, 2003: 760).

Since Canada is a net food exporter (Niu \& Proux, 2005: 24), it is not the ability of the nation to feed itself through trade that is at issue here, but rather its self-sufficiency in the range of products that constitute diet as reflected in consumer demand. Scholars have noted that global per capita caloric intake has been sufficient for some time ${ }^{4}$, mostly due to the ample supply of grain. It is nutritional balance that now concerns researchers, something hybrid cereals and the accompanying "production paradigm" cannot address (Welch \& Graham, 1999: 2). On the one hand, there is the "hidden hunger" of micronutrient (vitamin and mineral) deficiencies plaguing developing nations, while on the other there is the over-consumption of energy-rich and fatty foods causing an obesity "epidemic" in the developed world (Iyengar \& Nair, 2000: 332-333).

\footnotetext{
${ }^{4}$ Which is not to say that everyone is amply fed; wars and inequitable distribution, to give two examples, stand in the way of complete hunger prevention (Welch \& Graham, 1999: 02).
} 
Since Canadians, like all people, require a complete balance of foods for healthful sustenance (FAO, 2001) importing nutrition, as calories, is importing carrying capacity. Reducing imported agricultural carrying capacity means indentifying the gaps in the ability to supply domestic demand.

\subsection{Connecting Canadians to their land}

The AEI match "scientific knowledge and understanding with available information on resources and agricultural practice" (Eilers \& Lefebvre, 2005a: 8) and their development was set using the following approaches:

$>$ Policy relevance ensures the environmental impacts of concern to "governments and other stakeholders" are the focus.

$>$ Science-based and able to withstand the rigours of empirical analysis, though the latter may require several iterations.

$>$ Communicable to both stakeholders and the lay public.

Sensitive to trends across the whole system over time.

$>$ Economically practicable and reliant, where possible, on existing data.

The DSR-variant framework on which Canada's AEI is based has been explained by AAFC in this manner:

- Pressure: environmental stresses that may influence aspects of agricultural production such as the selection of crops and management practices used for production. 
- Outcome: ultimate impact of agricultural production on the health of the environment (soil, air, water, biodiversity).

- Response: use by producers of key management options which [sic] influence the impact of agriculture on the environment.

(Eilers \& Lefebvre, 2005a: 8; original emphasis removed).

The report further recognizes that "key gaps" exist in understanding the environmental impact of the agri-food industry. Future efforts will be addressed on the supply side through integrating economic and environmental indicators to provide a broader understanding of the effects of changing agricultural policy. There will also be an attempt to capture the economic value of the positive and negative externalities of agriculture in an effort to balance environment and economy (Lefebvre, 2005: 4). The following table 1.1 shows the five categories under which Canada's agri-environmental indicators (AEI) have been developed, the AEI, and if they are operational.

The government's stated policy objective of advancing farm income stability is supported by the AEI, especially the ones in operation now, since they are the most reflective of immediate risks to yield (Junkins et al., 2005: 20). Seemingly, the indicators that would be of more consumer or social interest but that might tend to act against the economic interests of the agri-food sector are those still under development. Take for example the water quality indicator for 
Table 1.1: Indicator groups, AEI and AEI in use by AAFC.

\begin{tabular}{|c|c|c|c|}
\hline $\begin{array}{l}\text { INDICATOR } \\
\text { GROUP } \\
\end{array}$ & \multicolumn{2}{|l|}{ INDICATOR } & $\begin{array}{l}\text { OPERATIONAL } \\
(\mathrm{Y} / \mathrm{N})\end{array}$ \\
\hline \multirow{5}{*}{$\begin{array}{l}\text { Environmental } \\
\text { farm management }\end{array}$} & \multicolumn{2}{|c|}{ Soil cover } & $\mathrm{Y}$ \\
\hline & \multicolumn{2}{|c|}{ Nitrogen use efficiency } & $\bar{Y}$ \\
\hline & \multicolumn{2}{|c|}{$\begin{array}{l}\text { Energy use efficiency } \\
\text { (energy output/energy input) }\end{array}$} & $Y$ \\
\hline & \multicolumn{2}{|c|}{ Water use efficiency: irrigation } & $\mathrm{N}$ \\
\hline & \multicolumn{2}{|c|}{ Integrated pest management } & $\mathrm{N}$ \\
\hline \multirow[t]{6}{*}{ Soil quality } & \multirow[t]{3}{*}{ Soil erosion } & Water erosion & $\bar{Y}$ \\
\hline & & Wind erosion & $\bar{Y}$ \\
\hline & & Tillage erosion & $\bar{Y}$ \\
\hline & \multicolumn{2}{|c|}{ Soil organic carbon } & $\bar{Y}$ \\
\hline & \multicolumn{2}{|c|}{ Soil salinity } & Y \\
\hline & \multicolumn{2}{|c|}{ Trace elements } & $\mathrm{N}$ \\
\hline \multirow{4}{*}{ Water quality } & \multicolumn{2}{|c|}{ Nitrogen } & $\bar{Y}$ \\
\hline & \multicolumn{2}{|l|}{ Phosphorus } & $\bar{Y}$ \\
\hline & \multicolumn{2}{|l|}{ Pesticides } & $\mathrm{N}$ \\
\hline & \multicolumn{2}{|l|}{ Pathogens } & $\bar{N}$ \\
\hline \multirow[t]{3}{*}{ Air quality } & \multicolumn{2}{|c|}{ Greenhouse gases } & Y \\
\hline & \multicolumn{2}{|c|}{ Ammonia } & $\mathrm{N}$ \\
\hline & \multicolumn{2}{|c|}{ Particulate matter } & $\mathrm{N}$ \\
\hline \multirow[t]{4}{*}{ Biodiversity } & \multicolumn{2}{|c|}{ Wild life habitat on farmland } & $\bar{Y}$ \\
\hline & \multicolumn{2}{|c|}{ Wildlife damage to crops and livestock } & $\mathrm{N}$ \\
\hline & \multicolumn{2}{|c|}{ Invasive alien species } & $\mathrm{N}$ \\
\hline & \multicolumn{2}{|c|}{ Soil biodiversity } & $N$ \\
\hline
\end{tabular}

Source: (Lefebvre, Eilers, \& Chunn, 2005)

pathogens that recognizes manure storage and application poses a direct risk to the health of the surrounding population from runoff to surface waters or groundwater infiltration. Prospective responses to adverse levels of risk include increasing manure storage capacities and ensuring optimum timing for its application (Topp, van Bochove, Thériault, Dechmi \& Lapin, 2005: 138, 139). Responding this way fails to recognize that intensive livestock operations frequently generate manure in excess of the capacity of the nearby land base to receive it (Carpenter et al., 1998: 8). 


\subsection{Self-sufficiency is sustainable}

Utilizing the pressure-outcome-response framework to structure agricultural environmental monitoring, Canada is developing indicators to connect environmental states to agri-food system responses. This will not necessarily lead to sustainable agricultural development, which requires the continuation of each of the environmental, social and economic components of the system. Since the social component of the system comprises the nation's citizens and their continuation requires an adequate food supply, sustainable agricultural development requires the self-sufficiency of the nation's food supply.

It is hypothesized that a self-sufficiency indicator (SSI) connecting the ability of a nation to supply food with the demand for it posed by its citizens adds to assessments of sustainability of the national agri-food system. The goal of this work is to express the ratio between existing areas of primary food production (i.e. crops) and that conceptually required to supply Canadian household consumption and show how this information can influence potential agri-food system responses and wider agricultural policy considerations. It is asserted that such an indicator can incorporate additional aspects of sustainability into the Canadian agri-food system without necessarily impairing its interconnections with globalized trade or otherwise interfering with stated Canadian agricultural policy objectives.

Chapter 2 contains a review of literature establishing the nature of sustainable agriculture and agricultural development. It also presents views on 
agri-indicators and their use in characterizing sustainability. Land-area indicators and indicators and indices of carrying capacity are also reviewed. Chapter 3 introduces the Canadian household consumption dataset for 2001 and provides the method for relating consumer quantities first to mass units of constituent plant and animal products, then to equivalent domestically-producible foodstuffs, and finally to land areas. Chapter 4 presents results from the analysis, discusses how Canada's current efforts to monitor agri-environmental sustainability could be augmented by consumer characterization, and offers insight into and choices for the future path of sustainable agricultural development. Finally, chapter 5 delivers some conclusions. 


\subsection{Literature Review}

Discussions of sustainable systems require fixed definitions, specific contexts, and defined spatial scales for any element of the system under consideration. Sustainable agricultural development approaches consider the integration of environmental, social and economical elements so that a cultural ecosystem from which food and fibre resources are extracted may continue to function. Indicators provide information about the functioning of agroecosystems; particularly useful are indicators from which inferences about difficult-to-measure properties of the system can be made. Frameworks combine multiple indicators to provide a more complete picture of the health of a system. Many frameworks use indicators of, or are based on, land area demand, but most use production data to demonstrate the impacts of supplying the global markets. Land area demand and human carrying capacity are interrelated and can become more so as yield growth rates stabilize.

\subsection{Sustainable agriculture defined}

It is typical in the literature to begin discussions of sustainable development (SD) by breaking down terms and defining the concepts from within. For example, the term sustainable (or sustainability) has been defined in countless ways. Since fundamentally sustainability "always concerns temporality and [...] longevity" (Costanza \& Patten, 1995: 194), a lexical definition, to continue through time, is invoked with regularity, at least introductorily (Brown, Hanson, Liverman \& Merideth jr., 1987: 713; Costanza \& Patten, 1995: 195; 
Dixon \& Fallon, 1989: 74; Douglass, 1984: 3; Hansen, 1996: 117). Since nothing can last forever, Costanza and Patten suggest a limiting temporal criterion in which the length of time a component within a "nested hierarchy of systems" must endure to be considered sustainable is equal to or greater than the expected lifespan of the component under normal behavioural conditions (1995: 195). For example, a single farm field under a typical three-crop rotation requires a fallow period to regenerate soil fertility and may continue indefinitely under such management. However, if farmer omits the fallow period for this particular field, its fertility may decline over time, although ceteris paribus the whole farm may remain continually productive. Conway sees agricultural systems as such a hierarchical order of systems or as levels of ecological organization ascending from a single field to the watershed or regional scale, each one "nested" within the next (1985: 34). In fact, it has been suggested the hierarchy could include the entire Earth as an agroecosystem (Walter-Toews, 1996: 687). The literal view is a polar one, something is sustainable or it is not. Shearman worries literal usages lead to "self-referential" definitions arising from empirical examples that may be difficult to apply elsewhere (1990: 2 ).

Others have found sustainability too hard to define at all, calling it instead an idealized goal because it cannot be directly measured. However, once the ideal is stated, progress toward or away from, or comparison with it can be made and an indication as to the "level and duration" of the sustainability of the system can be defined (Zinck et al., 2004: 89). Viewing sustainability in this way, 
as a continuum between the polar extremes, is probably more realistic. In developing the ecological footprint methodology, Wackernagel and Rees, too, shied away from a clearly stated meaning, instead saying that reducing the difference between what the global ecosystem can provide and absorb and what humans demand of it in these regards moves us towards "[d]eveloping sustainability" (1996: 159-160). Although they set no explicit upper limits to the world's ecological capacity, a fact for which they have been criticized (van den Bergh \& Verbruggen, 1999: 64), their assertion that a holistic response is necessary to reduce human impact on the environment is a sound one. In any case, what is definably and measurably sustainable at one scale may not be at another (Brown et al., 1987: 717), so perhaps "sustainable" is best defined simply as "the common-sense notion that we don't want to move ahead one step only to slip back two" (Dixon \& Fallon, 1989: 73).

More expansive definitions for agricultural sustainability have been articulated. Conway says formerly natural ecosystems are converted into "hybrid" agroecosystems, which are co-opted to produce food and fibre for human use (1985: 34). Agroecosystem sustainability depends on ecological concepts of resilience and resistance; the former describes the ability of the system to withstand stresses and perturbations without too great a variation in yield, while the latter refers to the time it takes the system to return to its normal state (Power, 1999: 185-186). Stresses can be small and periodic, but are usually continuous, while perturbations are discrete, unusual occurrences of significant 
magnitude (Conway, 1985: 35). Tilman also takes an ecological viewpoint, noting additionally that richer species composition and higher species diversity work towards the continuation of any ecosystem (1999: 5999). Sustainable rice production in Japán can involve a "mutually adaptive" set of integrated cultivation practices, a "management syndrome," that are less effective in maintaining yield in smaller or different groups (Andow \& Hidaka, 1989: 448). At their interface, agriculture has always tested the resilience of nature (Altieri et al., 1984: 175).

For Brown and co-workers, sustainable agriculture is qualitatively conservative of resources like soil and water, respectful of biodiversity, and socio-economically productive (1987: 714$)$. Zinck and colleagues hold that agricultural sustainability is a concept that "implies" continuous preservation of natural ecosystems, maintaining production while minimizing inputs, and ensuring income equity for producers, their families and communities, while providing "basic food needs" (for whom is not specified) (2004: 89). Here again Shearman has concerns: if a system is cast as sustainable, what aspersions will this cast on other existing or "conventional" systems? Using "sustainable" as a modifier to an activity implies the other ways of doing things can lead in socially undesirable directions (1990: 2).

There are three perspectives that have dominated investigations into sustainability for at least 20 years, since the concept was in its nascence (Shearman, 1990: 1). The economic point of view is usually predicated on 
continued economic growth and often struggles to value non-market goods and services, such as those provided by ecosystems. The social viewpoint considers the maintenance of individual well-being, from the basic provision of shelter, food and water to attaining more advanced social rights like "security, freedom, education, employment, and recreation." The social perspective is invoked by those seeking equitable resource allocations or to define the maximum supportable number of people for a given resource pool. Finally, an ecological or environmental assessment takes into account the continuation of ecosystems, including the abiotic components and all aspects of biodiversity. Notably, there is a connection between short-term variability in the biological aspects of diversity, as opposed to the abiotic elements, and longer ecosystem sustainability. It has been observed that pest management that improves the resilience of a cultural ecosystem has possibly decreased its long-term resistance (Brown et al., 1987:716). These three viewpoints, or variations of them, are often combined when creating holistic approaches sustainable development.

\subsection{Approaches to sustainability}

A sustainability concept forms the basis for an "integrating framework" for theoretical and empirical investigations (Smit \& Brklacich, 1989: 411). Once the goals are defined, approaches to assessing the current level of sustainability can be taken and actions setting a trajectory towards meeting the goals can be implemented. Examples of frameworks are provided later after a review of approaches to sustainability. 
In his seminal work, Douglass (1984: 4-6) integrates traditional views and methods of agriculture with new analyses and alternative methods in an effort to give meaning to agricultural sustainability from the disparate voices arguing narrower definitions. He describes three approaches to agriculture that arise in light of growing evidence that agricultural systems are overtaxing the environment, are possibly incapable of meeting future global demand for food and are growing less connected to the farmers, their families and their communities.

The first set of approaches considers agri-food systems sustainable if they are self-sufficient. This viewpoint can support the industrialization of agriculture as the means to feed an ever-growing population in the developing world or to provide meat and other energy-rich foods for the economically more advanced nations (Douglass, 1984: 6). Ensuring food sufficiency for a defined time period requires matching estimates of demand under dynamic socio-economic conditions with estimates of supply under variable climatic conditions for each major food group. These are mostly economical estimations and tend to view any limits not as physical, but as opportunity cost transactions in which resource substitutions are always an option. This overlooks the fact that the fundamental resource of agriculture, the land, is fixed in amount and productively finite if mistreated, and is thus non-substitutable (Douglass, 1984: 7-10).

Douglass' next group of approaches is ecological and sets sustainability as the upper level at which the earth can continually provide the resources that 
support food production and absorb the wastes that it generates. For agricultural systems that depend at least to some degree on natural and renewable sources of power, pest control and fertilization, farmers who engage in unsustainable practices risk declines in land fertility (Douglass, 1984: 11). The use of nonrenewable resources, chiefly fossil fuels and petrochemicals, temporarily boosts the productivity of the land while they are available. This may degrade the stock of renewable resources, either by polluting or structurally altering natural ecosystems irrevocably, or by supporting human population growth that, in turn, causes additional strain on space and resources (Douglass, 1984: 12-13). That environmental degradation may be masked by increasing inputs to the agri-food system or energy to mitigation efforts supports the idea that system sustainability is more prediction in a current context and verifiable only in retrospect (Costanza \& Patten, 1995: 194). Conway observes this too, saying a measured decline in productivity may or may not indicate unsustainability, but in any case, the system can collapse fast and unpredictably (1985: 34).

The final group Douglass recognizes are those who raise social concerns of sustainability, expressing them as community values that encompass the entire agroecosystem, including human members. The resulting paradigm is usually called alternative agriculture because it rejects a competitive model of large-scale industrialized agriculture in favour of a cooperative, locally-focused one. This mutually-supportive model of farming extends to the protection of nature, includes social justice and intergenerational equity, and encourages a 
decentralized power structure that leaves decision-making in the hands of the community, rather than the boardroom (Douglass, 1984: 17-19).

Like Douglass (1984), Dixon and Fallon (1989) also find sustainability concepts can be placed in three groups: the physical accounting of a single resource, the description of physical and environmental interactions among groups of resources and ecosystems, and the accounting of broader socialenvironmental-economic interactions (73-74).

Over a century ago, biologists working in forestry and fishery recognized that over-harvesting one season reduces the yield in subsequent years and conceptualized maximum sustainable yield (harvest) as the amount of growth or reproduction in excess of replacement growth or stock (Brown et al., 1987: 714). This work was limited to the analysis of a single biophysical resource in isolation from socio-economic development, with a view to preserving the status quo (Dixon \& Fallon, 1989: 74). Later, foresters altered their approach, but not the underlying principle of sustained yield, so that the forest would be harvested in a way that guided its development to even-aged stands (Brklacich, Bryant \& Smit, 1991: 3).

Considering a resource in isolation can mask system unsustainability (Smith \& McDonald, 1998: 21), giving rise to methods for describing interactions amongst resource exploitation systems (industries) or how such resource exploitation impacts ecosystems. Accounting for interactions in this way has been useful for achieving constant production in agroecosystems. The example given 
is rubber plantations that replaced the native ecosystems in Malaysia in the early $20^{\text {th }}$ century; it is noted in this case that both ecosystems are sustainable, just not when simultaneously co-located (Dixon \& Fallon, 1989: 75). Like Douglass (1984: 8), Dixon and Fallon (1989: 76) identify in these "trade-offs" opportunity costs, but as the physical usefulness of productive assets against the utility of the original ecosystem, instead of in purely economic terms. The latter authors still appreciate that some valuation system needs to be applied and stress the influence resource managers have through policy- and decision-making. This suggests that ecosystems have more than economic value, which will not necessarily be recognized in a market milieu, but that could be normatively assigned worth on the basis of an intuitive intrinsic value found in nature (Shearman, 1990: 5).

The last group of concepts Dixon and Fallon (1989: 76) recognize are those that describe comprehensively the environmental, social and economic interactions and impacts of resource exploitation activities. When these elements are considered together, they constitute a measure of sustainable development where the goal is not simply the physical maintenance of a resource or continuation of a production system, but the advancement of the individual and collective welfare of society. Most definitions of sustainable development include environmental, social and economical concerns (Costanza \& Patten, 1995: 194). While not defined explicitly by Dixon and Fallon (1989), others have called development "directed social change" intended to harness the beneficial aspects 
of a socio-economic system and guide them to a cooperative equilibrium ( $\mathrm{Niu}, \mathrm{Lu}$ \& Khan, 1993: 180). In this way, development can be conceived as the qualitative advancement of the system, as opposed to its quantitative growth (Daly, 1987: 323).

The World Commission on Environment and Development's (WCED) springboard definition from which many later approaches to sustainable development are launched is often quoted incompletely and simply that fulfilling the needs of the present generation should not obstruct future ones from fulfilling their own. Tellingly, it continues:

The concept of sustainable development does imply limits - not absolute limits but limitations imposed by the present state of technology and social organization on environmental resources and by the ability of the biosphere to absorb the effects of human activities. But technology and social organization can be both managed and improved to make way for a new era of economic growth (WCED, 1987: 8).

Truncation has arguably been necessary to make SD concepts inclusive and applicable to different sectors and interests. Indeed, Caldwell recalls that conflicting priorities between the developed and developing worlds for environmental and economic foci, respectively, nearly derailed the first attempts to define ecologically sustainable development some 40 years ago (1984: 299). That limitless economic growth is desirable is highly debatable; economists who assume growth is both desirable and inevitable tend to ignore sustainability altogether (Brown et al., 1989: 716). This concept is in fact sustainable growth, which is an oxymoron (Daly, 1990: 2). The Commission finishes the paragraph 
appropriately to their mandate, stating the opinion that global poverty can be mostly overcome, proffering a normative statement condemning any poverty, and noting extreme negative economic conditions encourage susceptibility to "ecological and other catastrophes" (WCED, 1987: 8).

An academic approach to sustainable agricultural development suggests as a goal: a system capable of fulfilling human needs for food, fibre, and related products, both now and in the future; one that conserves resources, is economically viable, protects the environment and, to the greatest extent possible, relies on renewable rather than non-renewable resources to ensure long-term societal survival (Bavec, Mlakar, Rozman, Pažek \& Bavec, 2009: 90; Rao \& Rogers, 2006: 441; Reganold, Papendick \& Parr, 1990: 112; Smith \& McDonald, 1998: 15). The definition proposed by Agriculture and Agri-food Canada is similar but decidedly nuanced. To develop sustainably, an agri-food system need only protect those resources on which it depends, although in a manner that is "compatible with surrounding natural systems and processes" (Lefebvre, 2005: 2). While contributions to wider socio-economic conditions are mentioned, of course including the supply of safe and healthful food, protection of the socio-economic status of agri-food businesses, labourers and their families is clearly specified (Lefebvre, 2005: 2). 


\subsection{Sustainability frameworks}

Sustainability frameworks are contextual guides that govern the choice of indicators and influence how the information is viewed and reported (Tomalty et al., 2007: 9). Robèrt and co-workers (1997: 80-81) outline a sustainable development framework based on a theoretical model governed by prerequisites that include:

i.) a rational view of the world,

ii.) a definition of sustainability supported by science,

iii.) a recognition that individuals should not be forced to act against their self-interest,

iv.) straightforward ideas that are easily transmitted to support consensus-building,

v.) ideas that generate the least opposition,

vi.) a path that does not require the complete re-organization of society and offers broad options towards society's new endpoint,

vii.) a potential for evolving the current economic paradigm into one adapted to existing and future scarcities, and

viii.) an assumption that economy is subsumed by environment, a perspective that must be applied to all scales in the system under consideration.

The last point should be stressed here, as the authors go on to say that people must understand how an individual's actions contribute to a cumulative effect 
and how changing one's own behaviour moves society collectively towards the sustainability goal.

In the view of Robèrt and colleagues, the key to any sustainable development model is that it rests solidly on a scientific foundation. Economists struggle to internalize environmental costs and the use of "margin-based valuation" of environmental costs fails to recognize the systemic nature of some problems, the complex interrelationships in ecosystems, and that many environmental effects are not linear, but can for instance be threshold-based (Robèrt et al., 1997: 80). Since the authors assert the moral basis for sustainability is the continuation of nature for its own sake (Robèrt et al., 1997: 79), this means economists must presuppose the biophysical conditions that ensure the survival of the biosphere are sacrosanct and build into models a suite of feedback mechanisms (indicators) that track the movement of society vis-à-vis its sustainability goals (Robèrt et al., 1997: 80, 81, 83).

A Canadian context can be illustrated by the six "key principles" of SD as promulgated for the main sectors of the economy, explicitly including agriculture and food, by the 1991 Ontario Roundtable on Environment and Economy (Lonergan, 1993: 336). First, intergenerational equity means the stock of natural and human capital must be non-declining over time and essential ecological services must remain intact. Second, environmental, social and resource depletion costs are internalized; the polluter pays principle is invoked. Third, a pro-active, rather than reactionary, stance is taken. Where structural analyses of 
the socio-economic system expose sources of pressure from individuals (consumers), businesses or institutions, action is taken to anticipate the cumulative effects and put in place preventative measures. Fourth, fully-informed decision making is important. All stakeholders are empowered in a decentralized, consensus-based model of decision-making. Fifth, depletion of non-renewable resources should be offset by increasing technological efficiency, closing the loop for material use, and the development of finite-resource substitutes for use by future generations. Sixth, quality of development is preferred over quantitative expansion. Consumers are made aware of the impacts of their choices, while product durability, energy efficiency and "a more efficient spatial distribution of activities" and presumably their by-products is stressed for the wider socioeconomic system (Lonergan, 1993: 336-337).

The AEI in use by AAFC are modelled on the driving force-state-response (DSR) framework developed in part by the OECD from original Canadian efforts (Berger \& Hodge, 1998: 256; Dumanski \& Pieri, 1997 14, \#2; Smith \& McRae, 2000: 2). The DSR model has been adopted by agencies of the United Nations and many nations to structure indicator development at discrete scales in a manner compatible with a hierarchical view of agroecosystems (e.g. Conway, 1985: 34). This is the "hard systems view" of agriculture, viewing agroecosystems as repairable mechanisms, where pressures of frequently human origin are identified within a defined boundary, e.g. field or farm, and the state of the system is observed, usually with the notion that outcomes of the pressure 
are undesirable (Walter-Toews, 1996: 686-687). The responses of various actors within the system may then be prescribed in order to effect positive change in the pressure variable, thus setting up a cycle of continuous feedback between humans and the environment (Guy \& Kibert, 1998: 41). Figure 2.1 shows the Canadian variation, driving forces-outcomes-responses, and some of the functions and elements within each category as set out by Smith and McRae (2000: 2) in the initial AEI development.
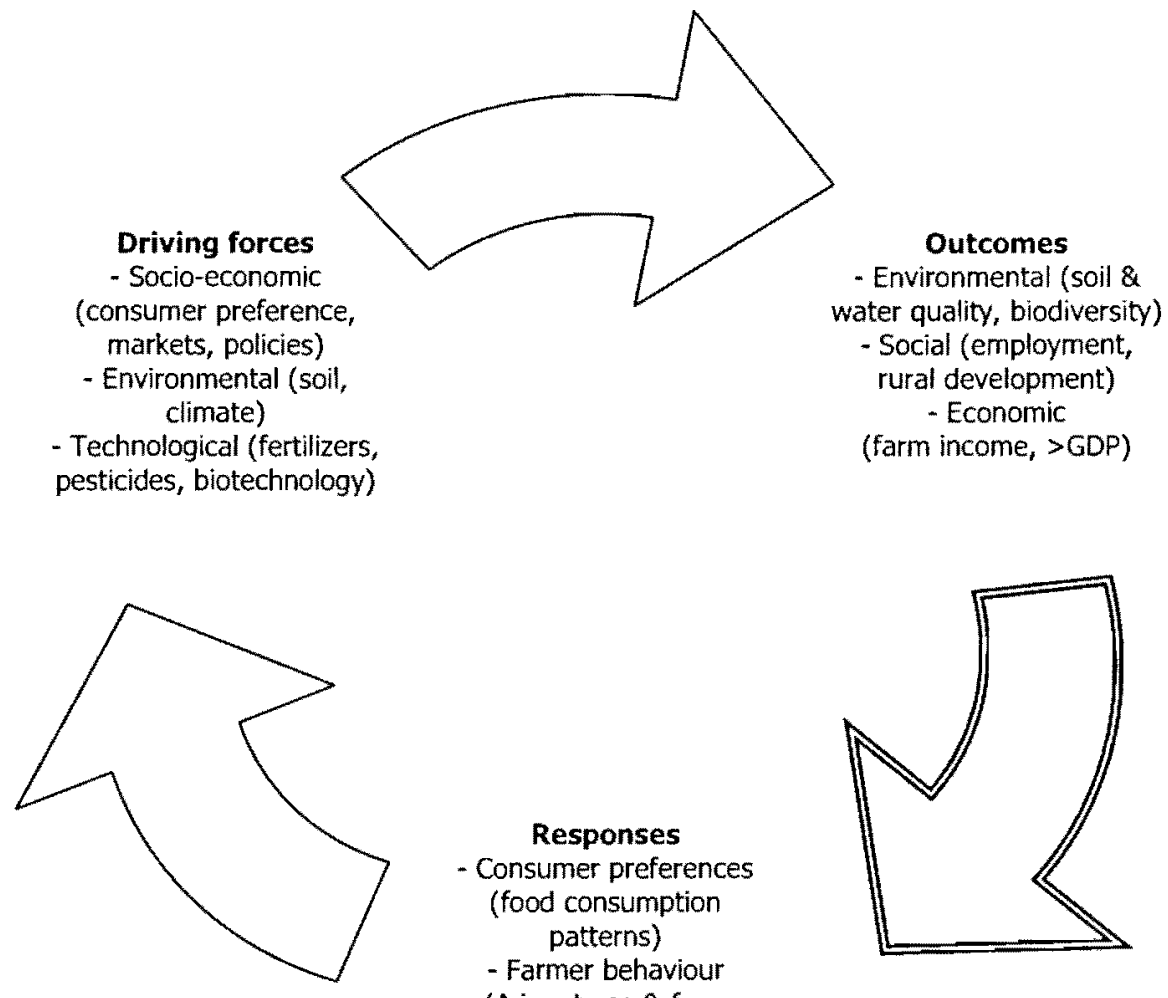

$$
\begin{gathered}
\text { Responses } \\
\text { - Consumer preferences } \\
\text { (food consumption } \\
\text { patterns) } \\
\text { - Farmer behaviour } \\
\text { ( } \Delta \text { input use \& farm } \\
\text { mgmt. practices) } \\
\text { - } \Delta \text { government policies }
\end{gathered}
$$

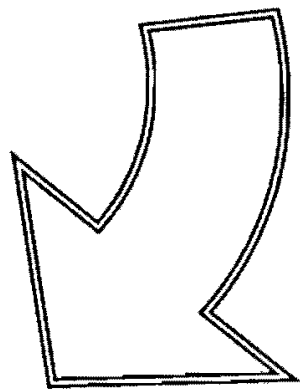

Figure 2.1: Driving force-outcome-response framework framing Canada's AEI (After Smith \& McRae, 2000: 2).

As figure 2.1 illustrates, consumer preference is both a driver of agrienvironmental change and an appropriate target for response options. The highlighted arrow between outcomes and responses denotes the typical 
placement of indicators (Guy \& Kibert, 1998: 41, figure 1). AAFC currently does not explicitly propose indicators that infer consumer preference responses to agroecosystem pressures originating from socio-economic driving forces (see table 1.1) (Lefebvre et al., 2005).

\subsection{Sustainability indicators}

Providing a connection that is meaningful to citizens, policy-makers or educators between activities and their consequences is often done by means of indicators. Indicators are specific measures of environmental, social or economic health that serve as proxies for the overall state of the system, usually with the view of ensuring the system's continuing integrity and sustainability (Maclaren, 1996: 186). Although the complexity of information imparted by an indicator should coincide with the level of understanding of the intended audience, including non-scientists (van den Bergh \& Verbruggen, 1999: 62), in all cases the primary usefulness of indictors is as a communication tool to "simplify a complex reality" (Smeets \& Weterings, 1999: 5). To be useful they must describe key aspects of the system in question, rather than characteristics that are "superficial or isolated" (Moxey, Whitby \& Lowe, 1998: 265). Further, measureable changes in the states, values or direction of movement of indicators must reflect concomitant changes in the system (Moxey et al., 1998: 265). These criteria have been addressed since the initial development of Canada's agrienvironmental indicators (Lefebvre, 2005: 3). 
In essence, an indicator is a specific measure or statistic about a system that infers a behaviour that is hard to observe directly or describes a change in state, condition, or quality of the system (OECD 1993, in Dumanski \& Pieri, 1997: 19; Rigby, Woodhouse, Young \& Burton, 2001: 465). Hansen (1996: 134, table 5) argues that policy-makers need indicators of agricultural sustainability that:

- take the literal view of sustainability: the ability to continue through time;

- are objective properties of the system, rather than a series of prescriptive elements that must be realized for a system to be sustainable;

- are continuous variables that allow comparisons between states or systems;

- enable the description of a future state, not simply the present or past states, and incorporate measures of variability; and

- classify and rank limitations (to sustainability).

Indicators ideally relate environmental, social, and economic issues that may only be apparent at a local scale, to the regional or national scale at which the appropriate political decisions are made (Haberl, Wackernagel \& Wrbka, 2004: 194; Robèrt et al., 1997: 80). Their use has become increasingly prevalent in countries, notably Canada, where research into sustainable agriculture has lead to a concerted effort for their development and use (Smith \& McDonald, 1998: 22). Many indicators of sustainability have been implemented to characterize certain portions of larger systems, sometimes with the intent to obscure negative practices or avoid politically unpalatable choices (Pearce 1998, 
in Rigby et al., 2001: 465), but also oppositely to break complex systems into more manageable units for clearer analysis (Costanza \& Patten, 1995: 195).

Land quality indicators (LQI) are derived from the application of the DSR framework to measure the biophysical characteristics of land, the effects of land management practices, and the socio-economic conditions that contribute pressures and constitute the policy environment within which responses can occur (Dumanski \& Pieri, 1997: $\uparrow 18$ ). With respect to LQI, the quality of land is its instant condition in relation to the expectations of it for a specific use, here agriculture. Land is not only soil, but landscape, climate, flora and fauna, surface- and groundwater, and augmentations that facilitate agriculture, like drainage works and terracing (Dumanski \& Pieri, 2000: 94).

When, as is frequently the case, expert, a priori identification of important system functions forms the basis for indicator development, an iterative process often occurs whereby the indicator is "molded" (sic) to conform to available data (Dumanski \& Pieri, 2000: 95). The danger in this is that rather than measuring system trajectory in relation to defined sustainable development goals (the desired state), the indicators can instead become predictions about the efficacy of responses to alter the driving forces (figure 2.1) (Costanza \& Patten, 1995: 194). The LQI were instead developed after "comprehensive analyses of the complex systems to be described and monitored" (Dumanski \& Pieri, 2000: 95).

There is a class of indicators that appraises the relationship between human demand for ecosystem goods and services and the Earth's ability to 
supply them, or carrying capacity (CC), as defined in the introduction on page 9. Of more interest are CC indicators related to land area availability, rather than yield from the land, which for modern agri-food systems is dynamically dependant on climate, input and pesticide availability, advances in bioengineering and biotechnology, and the lowered resilience of monoculture agroecosystems (Plucknett \& Smith, 1986: 40).

Nonetheless notably, in 1986 a direct connection between land area and yield was made in attempt to ascertain CC as the "human appropriation" of photosynthetic products (Vitousek, Ehrlich, Ehrlich \& Matson, 1986). Drawing together the best estimates of net primary productivity (NPP), the biomass remaining after the plant's own respiration, maintenance and reproductive needs have been met, of the surface, sub-surface and aquatic environments from available literature, the authors' calculate it at 225 petagrams of carbon $(\mathrm{Pg}=$ $10^{9}$ tonnes) (Vitousek et al., 1986: 369 , table 1 ).

Three estimates for usage of NPP for five billion people were made. The low estimate includes only biomass directly consumed as fuel, food, timber and fibre. The intermediate estimate accounts for the productivity of all agroecosystems, rather than just the consumed elements, and activities like using fire to clear land. Finally, the high estimate also includes productivity lost as a result of land use changes, like urbanization, and that lost as a consequence of agricultural mismanagement, for example to desertification and erosion; the high estimate is the one favoured by the authors (Vitousek et al., 1986: 368). 
Acknowledging that errors are likely for global estimates such as theirs, Vitousek and colleagues nevertheless state the results "accurately reflect the magnitude" of human appropriation (1986: 372). They find, as a proportion of terrestrial land, some $40 \%$ is co-opted for human use and the remainder likely suffering considerable impact; because human use of marine ecosystems constitutes a small fraction of its NPP over a wide area, adding the aquatic appropriation lowers the fraction to about $25 \%$. Although the methodology accounts for the crops grown and used in a single year and could thus provide insight on a smaller scale, it does not suggest the distribution of NPP usage and cannot connect domestic supply and demand for agricultural products (Vitousek et al., 1986: 368; 372, table 4).

As humans can use technology, import energy and food, and export waste and by-products, purely ecological estimations of CC useful for animal populations are inappropriate (Rees, 1996: 196). Cohen reviewed six methods acceptable for calculations of human $\mathrm{CC}$, leaving aside "those that are categorical assertions without data" (1995a: 342).

i.) Divide the world into regions defined by the differences in their maximum supportable population densities; multiply density by regional area and sum all regions. This was done by several geographers using fixed density estimates that were not objectively derived. 
ii.) Fit mathematical curves to historical population trends and extrapolate to future population estimates. Since the forces controlling birth and death rates have remained elusive, the rationale for fitting the curves in any particular way is suspect.

iii.) Assume a single constraining factor and calculate maximum human population based on that limit. This lends itself to simple mathematical formulae, for example maximum population $=$ total food supply/individual food needs. This method may be hard to justify because it assumes no other forces or factors will intervene.

iv.) An expanded variant of iii), above, combines multiple constraining factors into a single index; for instance, land area required to provide food, fibre and fuel. The same difficulty justifying constraining factors, also in iii), applies here too.

v.) Rather than an index, several independent factors are modeled as constraints. For example, the simple food equation from above can broken down into food groups, and water or input supply calculations can be introduced. From the various maxima, the smallest is chosen as the largest supportable population.

vi.) Combine several independent factors into large computerized sets of difference equations. The functional relationships between human populations and limiting variables, and the interactions 
between the variables themselves are often assumed and are difficult to quantitatively test.

(Cohen, 1995a: 343-344).

Methods one through five are "deterministic and static" and vulnerable to assumptions about changes in variables and dynamism in the relations between them. The stochastic model implied by method six has been applied on a regional scale and is a good candidate for global modelling if only the enormous number of variables, from climate change to epidemics to ocean temperatures, can be reconciled (Cohen, 1995a: 343).

William Rees defines human carrying capacity as the maximum environmental load that can be sustained "without progressively impairing the productivity and functional integrity of relevant ecosystems wherever the latter may be" (Rees, 1996: 203). As opposed to CC describing the maximum supportable population, he asks the proper question: what area of productive land, irrespective of geographic location, is required to support a specific population, at a given technological level and standard of living (Rees, 1996: 203)? This methodology gave rise to an indicator of CC called the ecological footprint (EF), which was developed by Rees and his student Mathis Wackernagel (Wackernagel \& Rees, 1996: 9).

The EF is a determination of the flow of material and energy in a socioeconomic system expressed as the number of hectares of land globally-averaged for bioproductivity required to support it (Erb, 2004: 247). The EF is a 
representative calculation of all the human goods derived from nature, the wastes and by-products deposited there, and the ecosystem functions impacted, simplified for data management purposes. The generalized procedure involves:

- Assuming industrialized harvesting of ecosystems, namely forests and agroecosystems, is sustainable. This leads to conservative estimation since overharvesting is often the case.

- Including only "basic services of nature" to start, with additions to be made as time for development permits. The original services considered are rate of renewable and non-renewable resource use, capacity for waste absorption, and urban land use change.

- Considering areas for only a single use to avoid double-counting. The use for which an area is accounted is the one with the largest impact.

- Using eight land categories to represent all the ecosystems on Earth.

(Wackernagel \& Rees, 1996: 61-62).

Using aggregate national or sub-national data for production and trade for five main classes of economic activity, food, housing, transportation, consumer goods, and services, and dividing by the contained population provides estimates of individual consumption of goods and services. Dividing these statistics by yield or productivity rate leaves as a remainder the per capita area required to support this consumption. More complex industrial goods, like apparel or automobiles, 
may need step-wise disaggregation to reveal the final area of production. The sum of these individual areal requirements is the EF for a single person to which a factor can be applied scaling it up the desired level of interest, from individual through to national (Wackernagel \& Rees, 1996: 63-67).

The areal estimates are not straight-forward geospatial quantities; rather, they are additive portions of eight conceptual land uses "embodied" in the consumption of the product that fall into one of four general classes:

i.) Energy land is assigned based on the amount of forested land required to assimilate the $1 \mathrm{t}$ of $\mathrm{CO}_{2}$ emitted by the generation of 100 gigajoules of energy from fossil fuel sources, 1.8 hectares.

ii.) Consumed land includes built-up land that is paved over, eroded lands, or those otherwise lost to bioproductive use through human activity.

iii.) Currently used lands are gardens, crop lands, pasture, and managed forests that supply food and fibre needs.

iv.) Limited lands are areas remaining in relatively natural states that should be preserved.

(Wackernagel \& Rees, 1996: 68, table 3.1; 72-73).

For any given product or service, a matrix is constructed allocating the analyzed consumer items under the five general economic headings to the eight land types used. The total area determined in this way is not a fixed area of land, but that expropriated from the ecosystems around the world that supplied 
material, energy, or waste sinks to the final products (Wackernagel \& Rees, 1996: $82-83$, table 3.3 ). The real strength of this sustainability indicator is a product of its use of relatively common data, the easy calculation, and perhaps most importantly the comparability of results (Erb, 2004: 248). Discussions generated by the authors include calculating the EF for the world's population at North American standards of living and determining the EF for several countries and the world and comparing them. In 1991, the global EF was found to be 1.8ha, while that of an Indian citizen was $0.4 \mathrm{ha}$; an American, 5.1 ; and a typical Canadian, 4.3 (Wackernagel \& Rees, 1996: 85, table 3.4; 88).

The EF can be applied to specific industries in defined areas, and then later apportioned to multiple actors within or without the system as a way of allocating CC. Increasingly liberalized global trade simultaneously detaches people from first-hand knowledge of the degradation their consumption causes while ironically increasing their vulnerability to the effects of those impacts. By investigating discrete sectors of the economy, an allocation of environmental loads posed by imports and exports can be made (Kissinger \& Rees, 2009: 2309).

Kissinger and Rees (2009: 2310) combine material flow analysis, a method for indentifying the types, quantifying the amounts, and tracking the progress of material and energy through a defined system, with EF analysis to study the agricultural system of the Canadian Prairies. Specifically, they want to know the share of agro-ecosystem products and services embodied in the export 
of 22 products in 6 categories, grains, legumes, oilseeds, root crops, animal feeds, and animal products, as a time series from 1989 until 2007. Further, they track the fraction of the total export footprint to each of five importing regions around the world (Kissinger \& Rees, 2009: 2311; 2314, figure 4).

Their method takes the following steps: identify and quantify Prairie agricultural products and the share of those for export, determine the "key inputs" used in the agri-food system, and estimate the land area required both for production and for sequestration of the $\mathrm{CO}_{2}$ attributable to it. Using food availability data (i.e. the apparent disappearance of food), the researchers translate processed agri-food products into their basic ingredients through US Department of Agriculture conversion factors and the FAO's technical conversion guide. They assign actual land areas based on the fraction exports represent of the total production for each commodity. Likewise for assigning a share of the energy (and then $\mathrm{CO}_{2}$ land) used to supply the total water, pesticide, fertilizer inputs to the system (Kissinger \& Rees, 2009: 2311; 2311, footnote 4).

The study reveals the production of 22 commodities considered required the support of over 55 million bio-productive hectares of land, the total ecological footprint for the system. Of that, just over $51 \%$ was exported, averaged over the study period. Broken down, the export share of the EF ranges from $72.5 \%$ embodied as grain exports, to $39.5 \%$ for beef cattle. By region, $37 \%$ of the Prairie agricultural EF went to the US, $26 \%$ to Asia, and $11 \%$ to Latin 
America, with the remainder going to the EU and "other countries" (Kissinger \& Rees, 2009: 2312-2313; 2313, table 2).

The popularity and subsequent usage of the EF method is such that the term "footprint" has entered the vernacular, but it is not without its detractors. The method of aggregation used in the calculation, often billed as a strong point, makes it difficult for an individual or policy-maker to decide which aspect of a system is unsustainable (van den Bergh \& Verbruggen, 1999: 63). The aggregated EF areas may need to be complemented with real areal requirements and the availability of that land to properly determine sustainability (Erb, 2004: 248). Additionally, related still to aggregation methods, it is hard to choose responses at the regional or national scales that are based on pressures felt at the local scale because while the EF observes ecological tenets and thermodynamic laws, it lacks a weighting scheme for social factors (van den Bergh \& Verbruggen, 1999: 64). For example, the different abundances of renewable energy supplies across Canada may not be accurately reflected if a national decision is taken to reduce fossil fuel use to reduce the country's EF. This is not trivial, since van den Bergh and Verbruggen (1999: 65) assert over $50 \%$ of developed nations' EF derives from the use of fossil fuels.

An adaptation of Wackernagel and Rees' (1996) indicator relates a nation's EF to its domestic biocapacity in a time-series analysis. This variant attempts to capture imported goods in domestic land use estimations, which is especially useful for products a country may not be able to grow or produce, by 
incorporating "complimentary" data about actual land availability and its spatial distribution (Erb, 2004: 248). In applying his method to Austria, Erb analyzes each component of national apparent consumption by dividing country-specific yields into domestic production, imports, and exports to derive real areas that he then assigns domestically to the land classes accounted for by the EF method. Taking agriculture as an example, Erb creates a 207-country list of yields for 61 products, including 39 primary products (crops), that he assigns to Austrian pasture land and arable land (Erb, 2004: 249-250).

Since the productivity of Austrian land is higher than the global average, the areal demand based on this method is lower by half than the conventional EF analysis (Erb, 2004: 253-254). Using country-specific yields also unmasks other possibly counterintuitive results, such as the declining share of per capita pasture land required to provide meat, milk, etc., in the face of a constant rate of consumption owing to yield increases. Erb asserts the simple summation of shares of land globally-averaged for productivity results in the loss of "huge amount[s] of information" contained in, say, the mix of yields within a particular nation's trading partners or the qualitative differences in soils requiring different amounts of irrigation or input use. Neither the conventional EF nor Erb's modification assesses sustainability, but in using real, spatially-assigned areas the latter method can be integrated into an indicator framework (2004: 255).

Cowell and Parkinson (2003: 221-222) recently presented a method to examine the ability of only local areas to satisfy the consumption requirements of 
the United Kingdom. The authors observe that the globalization of the agri-food sector could be seen as a benefit to society by inducing wider competition and thereby lowering prices and broadening consumer choice or as a disbenefit by reducing countries' food security (self-sufficiency) and masking environmental and social harms caused by exploitative practises in places far from final consumption. By contrast, localisation, defined as domestic production, is seen as a way of at least illuminating the negative aspects of agricultural production and reducing the transportation-related impacts of importation. In part, their purpose is to assess the possibilities for localising production, since they note there is no point to policies advocating localisation if it is infeasible.

Land area is chosen as an indicator because increasing populations lead to increased competition for use of this finite resource and because consumption within these populations is generally increasing. They deem the country level appropriate because in the UK, as in Canada, agricultural policy is mostly driven by the central government. Their method uses actual data on specific food groups, rather than the grain-equivalents or estimated consumption levels of other studies, which allows "more detailed insights" into the effects of a localisation strategy and avoids criticism over data accuracy (Cowell \& Parkinson, 2003: 224).

Working with 1992 aggregate national data in mass units, Cowell and Parkinson (2003: 225) begin by determining consumption as the residual after adding production and imports and subtracting exports and changes in stock (i.e. 
the apparent disappearance of food). They apply often complex formulae to work from homogenous bulk government and industry agri-food statistics (e.g. tonnes of beef) back to the land required for food crops and for the farmland that supported the consumed animals' lifecycles. Dividing the various consumption quantities by their respective yields leaves the area required for production (Cowell \& Parkinson, 2003: 226-227; 234-235). For food not producible in the UK the authors propose to substitute an "average mix" of similar products without offering details as to its derivation (i.e. by the mix of current areas of production, as proposed here, or similarly by production masses) (226). They do not allow for differences in production practises, which is especially notable for localising foods like livestock under intensive production (227).

The ratio of production to consumption gives Cowell and Parkinson a "selfsufficiency index," which they use only to assess the UK's relative reliance on imports for any given food category (2003: $225 ; 227$, table 2 ). Because part of their method involves calculating tonne-kilometres for energy use analysis, they use mass units for this ratio (2003: 225). Since the index is unitless only the magnitude of (in)sufficiency can be understood and not quantitative differences. The area currently under cultivation for each food category is compared with that required under a localisation policy revealing that animal products take the most area by far, requiring as much as eight times more land than the next category, cereals. In total, the UK requires between $1 \%$ and $16 \%$ more agricultural land 
than it has to supply its consumption and Cowell and Parkinson conclude that in order to meet a localisation strategy, meat consumption must be drastically reduced or plants with significantly higher yields must be substituted for those currently produced or both. They point to UK survey results showing strong preference for locally produced fruits and vegetables and growing vegetarianism and suggest consumption patterns could shift in what is for them a positive direction (Cowell \& Parkinson, 2003: 230-231).

Researchers from the Netherlands have reviewed food security studies and projections of future demand and note that most assume a constant supply of land despite the fact that arable land is being lost at the rate of $7 \%$ per decade. The green revolution has led to the juxtaposition of increasing per capita grain harvest and declining per capita arable land. The land required for food however is dependant on more than just yields and production methods, because of shifting consumer demand for different types of food. This gives rise to areal quantification based on food consumption patterns, which are observable trends in the types and combinations of foods eaten by a given population. These patterns are influenced by culture, religion, personal tastes, food availability, and habit, amongst other things, and can shift over time in the same place. Since an "affluent" diet including animal-based products may require three times the land of a vegetarian diet, the effects of shifting consumption patterns on land requirements are likely of the "same order of magnitude" as the 
combined effects of rising population and changing productivity (GerbensLeenes, Nonhebel \& Ivens, 2002: 47-48).

Gerbens-Leenes and co-workers note that circumstances must be clearly defined for analyses of land requirements because significant differences in consumption patterns occur between nations and because the kinds and quantities of foods grown and the consequent environmental impacts are a result of a close interdependence between agri-food supply and consumer demand (2002: 48). They state the use of household consumption data ("the bottom of the food system") represents a substantial advancement in the quality of land requirement analyses (Gerbens-Leenes et al., 2002: 48).

The method begins with 1990 household expenditure data, rather than with physical quantities, for over 100 foods commonly eaten at home by the Dutch in nine categories. Quantities are derived by applying price data directly (i.e. purchase amount times physical units per unit cost) or via the results of a previous Dutch study describing the relationship between price, nutritional energy, and physical quantity. Processed foods are rendered to constituent ingredients through technical conversions and industrial recipes. For domestically-producible crops, the inverse of the weighted average yield gives area requirement as $\mathrm{m}^{2} / \mathrm{kg}$. For imports, the origins and amounts of products are determined and the inverse of the yields provided by the FAO are applied. Livestock products, here also excluding fish, are grouped into intensive animal production and dairy farming; animal feed statistics are used to find pasture, 
fodder, and roughage areas. Breaking raw milk down into its constituent carbohydrate, protein, and fat components according to fraction of nutritional energy, the area required for each is found; the area required for dairy products, for instance cheese and yoghurt, are found based on the composition of those milk constituents. The sum of the household land area requirements is multiplied by the number of households to give national area needs (Gerbens-Leenes et al., 2002: 50-52).

The results reveal Dutch household consumption is dominated by meat and dairy products and the area required to supply them represents $47 \%$ of the total household requirement, compared to $12 \%$ for fruits, vegetables, and bread. The effects of diet affluence are illustrated by noting the addition of "one mouthful $(10 \mathrm{~g})^{\prime \prime}$ of meat everyday by an individual increases area requirement by about $100 \mathrm{~m}^{2}$, while the same increase in potato consumption increases area by a mere $2 \mathrm{~m}^{2}$ (Gerbens-Leenes et al., 2002: 53, table 2; 54). The Netherlands government also calculates national food availability (apparent disappearance of food) and the authors apply their method to this quantity for comparison. They find congruence between their own results and governmental estimates, asserting this validates the assumptions made in the course of the work (Gerbens-Leenes et al., 2002: 55). 


\subsection{Methods}

Since assessing national self-sufficiency for major food groups is the goal of this study, demand must be expressed in terms that are comparable to those of supply. The subsequent analysis is premised on the work of Cowell and Parkinson (2003), especially their reporting of the real national land areas that would be needed to supply domestic food consumption and comparison to existing areal capacity. Also like their work and that of Gerbens-Leenes and colleagues (2002) and Kissinger and Rees (2009), this study uses commonly available government, technical, and industry information (e.g. FAO, n.d.; StatsCan, 2009) to relate the original masses of primary agricultural products to their processed counterparts. However, unlike Cowell and Parkinson and studies based on the EF methodology (Erb, 2003: 247) that use the apparent consumption of food and resources as the basis, the method employed here begins with surveyed consumption (StatsCan, 2003b).

Total Canadian food consumption is determinable by the following process. The 2001 Food Expenditure Survey (FES) (StatsCan, 2003b) estimates food expenditures and quantities for the over 11.5 million households (StatsCan, 2005a). These are listed as household weekly averages for 195 different broad food groups, like cuts of beef, fresh apples, and jams and preserves, which are in turn aggregations of almost 2000 individual types of food or brand names (StatsCan, 2003b). StatsCan lists these foods broadly into the following groups: 
- Meat (including meat preparations)

- Fish and other marine products

- Dairy products and eggs

- Bakery and other cereal products

- Fruits and nuts (including fruit juices, jams, etc.)

- Vegetables (including vegetable products and juices)

- Condiments, spices and vinegar

- Sugar and sugar preparations

- Coffee and tea

- Fats and oils

- Other foods, non-alcoholic beverages, food materials \& preparations

The survey was administered as two, one-week diaries completed by 5,643 urban and rural households in all Provinces, as well as households in the cities of Iqaluit, Whitehorse and Yellowknife; as not all households completed both, the sample comprises 11,034 diary-weeks for a response rate of almost $98 \%$. This is the eighteenth such survey to be completed since they began in 1953, the sixth in a row to include smaller communities and thus claim to be nationally representative. The stated "primary reason" for conducting the survey is as an economic tool to help adjust the consumer price index, but other reasons include market analysis and nutritional studies (StatsCan, 2003b: User Guide, 4). The User Guide states the samples are weighted so that the detailed 
food list reflects differences in "sampling and response rates among geographic areas and household types," but gives no further details (StatsCan, 2003b: User Guide, 11). There are six appendices to the survey that list statistical information like frequency counts or provide data summaries; Appendices $C($ iii), detailed quantities, and $E$, food codes, are useful here. The former contains the values transformed by the method, while the latter provides complete details of foods in all categories and is included herein as Appendix 1 (StatsCan, 2003b).

Multiplying the number of households in Canada in 2001 by the average quantities consumed per week as found in the FES gives the national consumption for each foodstuff. These weekly values are then transformed into yearly amounts, which may be in metric mass or volume units, like kilograms of apples or litres of strawberries, and thus directly usable, or shown as quantities that need further transformations. For those food items reported as a number consumed, for instance the number of ears of corn eaten (StatsCan, 2003b), an equivalent measure in the appropriate metric units is found using accepted technical conversion factors.

The 2001 Canadian data for field crops, fruits and vegetables, data regarding animal feed requirements and other information are obtained from governmental resources, predominantly from Statistics Canada's Canadian Socioeconomic Information Management system (CANSIM) II database (2009) and Agriculture and Agri-food Canada (AAFC), as well as the United Nations Food and Agriculture Organization (FAO). These quantities are often in imperial measures, 
likely reflecting farmers' usage, and must be converted; conversion factors are utilized where required (StatsCan, 2002: 11).

Some foods cannot be produced in Canada due to climatic or geophysical factors. In the case of items such as tropical fruit, a representation of Canadianproduced fruit is established and substituted (Cowell \& Parkinson, 2003: 226); likewise for rice or other staples not appreciably produced in Canada. Aquaculture was not included in Cowell and Parkinson's study because fish farms "do not occupy terrestrial land areas" (2003: 227). However, farmed fish are fed from terrestrially-grown grains (StatsCan, 2005b), and the industry exists in all provinces and Yukon and Northwest Territories (AAFC, 2003). Therefore, the feed requirements are calculated to meet the household consumption averages (StatsCan, 2003a) with substitution made for non-farmed fish by the major farmed fish in Canada, salmon (see 3.1.2, below).

Studies that refer to national production data to estimate areas dedicated to domestic food consumption or to calculate the EF of food utilize categories based on sectors of primary agricultural production, including, for example, meat, vegetables, fruit, and cereals. Because such studies begin with bulk agricultural materials they account for all end uses regardless of the degree of subsequent processing (Cowell \& Parkinson, 2003: 225, table 1; White, 2000: 151). Studies examining environmental impact from the consumption perspective can examine prescribed diets. The life cycle assessment of the "predominantly plant-based Mediterranean diet" on which recommended nutrition guidelines for 
the US and other nations are based is an example (Duchin, 2005: 104). As the method here is applied to Canada and uses a consumer survey that is akin to a dietary estimation, only foods suggested by Canada's Food Guide (Health Canada, 2008a: 1) will be included in the study. Thus, for nutritionally nonessential items that cannot be grown in Canada, such as cocoa, tea and coffee, no substitution will be made. Likewise, no accounting will be made for other foods such as ice cream, sweets and cakes.

\subsection{Reconciling quantities in the FES}

The explanation of the method generally follows the numerical order of the food codes. As noted, the detailed food codes and descriptions are found as Appendix 1. The FES Appendix C(ii) reports results in an electronic spreadsheet to at least two (2) significant figures, the same number as the conversion factors and yields (StatsCan, 2003b; 2009). Although the numbers were not rounded in the model for the calculations, they are reported here rounded simply to three whole numbers; more than three significant figures is not implied.

\subsubsection{Meat (including poultry)}

In the FES meat is given as kilograms consumed per household for the various primal ${ }^{5}$ cuts of beef, including hip, loin, rib, and chuck cuts, and of pork, including leg, loin, belly, and shoulder cuts; lamb, mutton and other animal meats and chicken, turkey and other poultry meats are not sub-divided according

\footnotetext{
${ }^{s}$ The edible portion of an animal (not poultry) is prepared by cutting the eviscerated carcass in half lengthwise through the spine and subsequently each half into four or more primal cuts from which servingsized portions are prepared (Potter \& Hotchkiss, 1998: 317).
} 
to cut (StatsCan, 2003b). In the case of beef and pork, these cuts must be aggregated into their equivalent whole animals to determine necessary grazing land. Farm animals slaughtered for meat are valued on the basis of the edible portion, usually called cold dressed weight or dressed carcass weight (DCW) when the meat is ready for sale; this is the fraction remaining after removal of the hide or feathers, head, blood, feet and guts (Government of Alberta, 2008).

For beef Potter and Hotchkiss (1998: 331-332, figure 14.11) provide a reference for approximate yields from a dressed beef carcass. Table 3.1 reproduces their summary table showing common wholesale beef cuts and the corresponding percent share of a carcass; where it differs, the term for a cut as used in the FES is provided in brackets (Appendix 1).

Table 3.1: The approximate yield of typical cuts of beef from a dressed carcass.

\begin{tabular}{||l|c|c|l|c|c||}
\hline \hline FOREQUARTER CUTS & $\begin{array}{c}\text { YIELD } \\
\%{ }^{*}\end{array}$ & $\begin{array}{c}\text { DCW } \\
\text { (KG) }\end{array}$ & $\begin{array}{c}\text { HINDQUARTER } \\
\text { CUTS }\end{array}$ & $\begin{array}{c}\text { YIELD } \\
\%\end{array}$ & $\begin{array}{c}\text { DCW } \\
(\mathrm{KG})\end{array}$ \\
\hline Chuck & 26 & 91.7 & Round (Hip cuts) & 23 & 81.1 \\
\hline Ribs & 9 & 31.8 & Sirloin (Loin cuts) & 9 & 31.8 \\
\hline Fore Shank (Other beef) & 4 & 14.1 & $\begin{array}{l}\text { Short loin (Loin } \\
\text { cuts) }\end{array}$ & 8 & 28.2 \\
\hline Brisket (Other beef) & 5 & 17.6 & Flank (Other beef) & 5 & 17.6 \\
\hline Short plate (Other beef) & 8 & 28.2 & Offal & 3 & 10.7 \\
\hline Total & 52 & 183.4 & Total & 48 & 169.4 \\
\hline
\end{tabular}

Also shown, in order to estimate the number of cattle accounted for in the FES, are the yield percentages applied against the average DCW for Canadian cattle for 2001: $352.8 \mathrm{~kg}$ (StatsCan, 2009: survey 003-0026). The average mass yields for each cut of meat are divided into the corresponding yearly quantities of those cuts from the FES to give the number of animals that would have been 
slaughtered to provide each cut; the largest number is used. However, there are several steps taken in advance of the final result.

Beef is unique in the FES as the only meat for which "ground" is a special category (Appendix 1). Potter and Hotchkiss state it is derived from every cut, but not from offal (1998: 332). Therefore, the quantity of ground beef will be distributed against the respective cuts after the yields from table 3.1 have been re-weighted to remove the $3 \%$ offal from the calculation. The offal is treated later as a stand-alone category.

Several categories of prepared foods containing products made from different animals are listed in the FES; among others, these include sausages, canned meats, ready-to-eat items, and restaurant take-out foods. Where the FES category contains items made from the meat of different animals the quantity will be distributed according to the preference for each meat in the FES. Bologna is made entirely from ground beef and is added there (Potter \& Hotchkiss, 1998:

\section{7; Appendix 1).}

Table 3.2 shows the portions of prepared, cured and canned meats, and sausages that are made from almost 160,000 tonnes of ground beef. The total mass from table 3.2 is added to the total ground beef, which is then allocated to the cuts shown in table 3.1 after re-weighting to exclude offal. The re-weighting is shown in table 3.3 and the ground beef calculations in table 3.4 . 
Table 3.2: Share of listed categories supplied by ground beef.

\begin{tabular}{|l|c|}
\hline FES CATEGORY & MASS OF GROUND BEEF (KG) \\
\hline Other cured meat & $2,500,000$ \\
\hline Uncooked sausage & $25,200,000$ \\
\hline Bologna & $17,900,000$ \\
\hline Wieners & $20,000,000$ \\
\hline Other cooked or cured sausage & $37,800,000$ \\
\hline Other ready-cooked meat & $32,400,000$ \\
\hline Other meat preparations & $7,490,000$ \\
\hline Meat stews and hams & $8,410,000$ \\
\hline Other canned meats $(\ldots)$ & $6,940,000$ \\
\hline Total & $159,000,000$ \\
\hline
\end{tabular}

Table 3.3: Ground beef allocation table.

\begin{tabular}{|l|c|c|}
\hline CUT & $\%$ (TABLE 3.1) & RE-WEIGHTING \\
\hline Round & 23.0 & 23.7 \\
\hline Ribs & 9.0 & 9.3 \\
\hline Sirloin \& short loin & 17.0 & 17.5 \\
\hline Foreshank, brisket, short plate, flank & 22.0 & 22.7 \\
\hline Chuck & 26.0 & 26.8 \\
\hline Total & 97 & 100 \\
\hline
\end{tabular}

Table 3.4: Allocation of ground beef to specific cuts.

\begin{tabular}{|l|r|r|}
\hline \hline CUT & RE-WEIGHTED \% & MASS (KG) \\
\hline Ground beef from FES & $203,000,000$ \\
\hline Addition from table 3.2 & $159,000,000$ \\
\hline Sub-total allocated to cuts, below & $362,000,000$ \\
\hline Hip cuts & 23.7 & $85,800,000$ \\
\hline Rib cuts & 9.3 & $33,600,000$ \\
\hline Loin cuts & 17.5 & $63,400,000$ \\
\hline Other beef cuts & 22.7 & $82,000,000$ \\
\hline Chuck cuts & 26.8 & $97,000,000$ \\
\hline
\end{tabular}

Once the weight of ground beef has been re-proportioned, it is added to the starting FES consumption for the respective cuts. This constitutes an addition of between $47 \%$ for hip cuts and $84 \%$ for chuck cuts. Despite having a lower fraction of the DCW than chuck cuts and the lowest addition of ground beef 
mass, the consumption of hip cuts is still the highest and requires the slaughter of over 2.23 million cattle. The FES cuts, 2001 consumption amounts, additions from table 3.4, mass per cut as a fraction of the 2001 DCW from table 3.1 and number of animals required to provide the total for each cut are shown in table 3.5. The bold typeface indicates how many cattle were fed to support 2001 consumption.

Table 3.5: Calculation of required slaughter cattle.

\begin{tabular}{|l|r|r|r|r|r||}
\hline $\begin{array}{l}\text { BEEF } \\
\text { CUT }\end{array}$ & $\begin{array}{l}\text { FES } \\
\text { CONSUMPTION } \\
\text { (KG) }\end{array}$ & $\begin{array}{l}\text { MASS FROM } \\
\text { TABLE 3.4 }\end{array}$ & $\begin{array}{l}\text { TOTAL } \\
\text { CONSUMED } \\
\text { MASS (KG) }\end{array}$ & $\begin{array}{l}\text { DCW } \\
\text { MASS/ } \\
\text { CUT } \\
\text { (KG) }\end{array}$ & $\begin{array}{l}\text { NUMBER OF } \\
\text { ANIMALS }\end{array}$ \\
\hline $\begin{array}{l}\text { Hip } \\
\text { Cuts }\end{array}$ & $95,500,000$ & $85,800,000$ & $181,000,000$ & 81.1 & $\mathbf{2 , 2 4 0 , 0 0 0}$ \\
\hline $\begin{array}{l}\text { Rib } \\
\text { cuts }\end{array}$ & $35,800,000$ & $33,600,000$ & $69,400,000$ & 31.8 & $2,180,000$ \\
\hline $\begin{array}{l}\text { Loin } \\
\text { cuts }\end{array}$ & $23,900,000$ & $63,400,000$ & $87,300,000$ & 60.0 & $1,450,000$ \\
\hline $\begin{array}{l}\text { Other } \\
\text { beef } \\
\text { Cuts }\end{array}$ & $23,900,000$ & $82,000,000$ & $106,000,000$ & 77.6 & $1,520,000$ \\
\hline $\begin{array}{l}\text { Chuck } \\
\text { cuts }\end{array}$ & $17,900,000$ & $97,000,000$ & $115,000,000$ & 91.7 & $1,250,000$ \\
\hline Offal & $11,900,000$ & \multicolumn{1}{|l|}{0} & $11,900,000$ & 10.6 & $1,130,000$ \\
\hline
\end{tabular}

Dairy cows must reproduce each year to perpetuate lactation. Female calves are generally kept to replenish the herd, while males are slaughtered when they reach $205-318 \mathrm{~kg}$ live weight to be sold as veal (Ontario Veal Association, 2003). Canadian grading regulations state the DCW of veal must be between $80-180 \mathrm{~kg}$ (Department of Justice Canada [DOJC], 2009a). StatsCan (2009: survey 003-0026) found the 2001 average DCW for veal was $118.3 \mathrm{~kg}$. Unlike their parents, calves are not disaggregated into cuts in the FES (StatsCan, 
2003b) so simply dividing the veal DCW into the FES average consumption gives the number of calves required. The FES cuts, 2001 consumption weights, 2001 DCW for veal and number of animals that were fed to support this consumption (bolded) are shown in table 3.6.

Table 3.6: Calculation of required slaughter calves.

\begin{tabular}{|l|r|r|r|}
\hline MEAT & FES CONSUMPTION (KG) & DCW (KG) & NUMBER OF ANIMALS \\
\hline Veal & $11,900,000$ & 118.3 & $\mathbf{1 0 1 , 0 0 0}$ \\
\hline
\end{tabular}

Hog carcass yields are given in cold trimmed weight (CTW), the bled, eviscerated pig with the rear feet on and excess fat trimmed (for rendering, see section 3.1.7) (StatsCan, 2009: survey 003-0028, footnote 5). The average CTW for Canadian swine in 2001 was $83.6 \mathrm{~kg}$ (StatsCan, 2009: survey 003-0028) against which the yield percentages are distributed. Approximately the same procedure is followed for pork as for beef using yield percentages obtained from Canadian Pork International [CPI], a producer, processor and exporter promoting organization. CPI and AAFC conducted a joint study in 1992 to determine yields of various cuts (CPI, n.d.) and those against the CTW the results are reported in table 3.7.

Table 3.7: The yield of typical cuts of pork from a cold trimmed carcass.

\begin{tabular}{|l|c|c|}
\hline CUT & SHARE OF CARCASS (\%) & CTW \\
\hline Leg & 27.6 & 22.6 \\
\hline Loin & 24.7 & 20.8 \\
\hline Belly & 23.9 & 20.1 \\
\hline Shoulder & 23.8 & 20.1 \\
\hline Total & 100 & 83.6 \\
\hline
\end{tabular}

Source: (CPI, n.d.). 
The FES has an "other pork" category that lists whole animals, sides and quarters that nominally follow the cuts from table 3.7; therefore, this quantity will be divided into the cuts from table 3.7 in proportion to consumer preference from the FES (StatsCan, 2003b). The 17,900 tonnes of other pork is allocated across all the pork cuts according to their fraction of the DCW shown in table 3.7. The distribution is shown in table 3.8 .

Table 3.8: Share of selected categories added to pork cuts.

\begin{tabular}{|l|c|c|}
\hline \hline CUT & $\begin{array}{l}\text { AMOUNT CONSUMED } \\
\text { FROM FES (\%) }\end{array}$ & $\begin{array}{l}\text { MASS OF "OTHER } \\
\text { PORK" (KG) }\end{array}$ \\
\hline Loin cuts & 73 & $13,100,000$ \\
\hline Shoulder cuts & 11 & $2,070,000$ \\
\hline Belly cuts & 8 & $1,380,000$ \\
\hline Leg cuts & 8 & $1,380,000$ \\
\hline
\end{tabular}

Pork used in sausages and prepared foods is typically from the shoulder cut (Manitoba Pork Council [MPC], 2004) and is added there. The application of the method to processed pork products follows the same process as for beef except, with the meat products and sausages apportioned to shoulder cuts according to table 3.9 .

Table 3.9: Share of selected categories added to pork shoulder cuts.

\begin{tabular}{|l|r|}
\hline \hline FES CATEGORY & MASS OF PORK SHOULDER (KG) \\
\hline Other cured meat & $1,050,000$ \\
\hline Uncooked sausage & $10,600,000$ \\
\hline Wieners & $8,400,000$ \\
\hline Other cooked or cured sausage & $15,900,000$ \\
\hline Other ready-cooked meat & $13,600,000$ \\
\hline Other meat preparations & $3,150,000$ \\
\hline Meat stews and hams & $3,530,000$ \\
\hline Other canned meats (...) & $2,920,000$ \\
\hline Total & $59,200,000$ \\
\hline
\end{tabular}


Ham is derived from leg cuts and bacon is distributed to loin cuts and belly cuts according to the consumer preference for the two (MPC, 2004). Ham is apportioned to leg cuts as shown in table 3.10.

Table 3.10: Share of ham categories added to pork leg cuts.

\begin{tabular}{|l|c|}
\hline FES CATEGORY & MASS OF PORK LEG (KG) \\
\hline Ham (excluding cooked ham) & $59,700,000$ \\
\hline Cooked ham & $30,000,000$ \\
\hline Total & $89,700,000$ \\
\hline
\end{tabular}

The weighting to apportion bacon is a simple 90:10 split between loin and belly cuts and is shown in table 3.11

Table 3.11: Share of bacon added to pork loin and belly cuts.

\begin{tabular}{|l|c|c|}
\hline CUT & $\%$ SHARE & MASS OF BACON (KG) \\
\hline Bacon (from FES) & 100 & $41,800,000$ \\
\hline Loin cuts & 90 & $37,600,000$ \\
\hline Belly cut & 10 & $4,180,000$ \\
\hline
\end{tabular}

Pork cuts, 2001 consumption amounts, addition of values from tables 3.8, $3.9,3.10$, and $3.11, \mathrm{~kg}$ per cut as a fraction of the DCW from table 3.7, and the number of animals required to provide the total for each cut are shown in table 3.12. The bold typeface indicates the number of swine that were fed to support 2001 consumption.

Table 3.12: Calculation of required slaughter pigs.

\begin{tabular}{|l|r|r|r|r|r||}
\hline $\begin{array}{l}\text { PORK } \\
\text { CUTS }\end{array}$ & $\begin{array}{l}\text { FES } \\
\text { CONSUMPTION } \\
\text { (KG) }\end{array}$ & $\begin{array}{l}\text { MASS FROM } \\
\text { TABLES 3.8, } \\
3.9,3.10 \text { \& } \\
3.11(\mathrm{KG})\end{array}$ & $\begin{array}{l}\text { TOTAL } \\
\text { CONSUMED } \\
\text { MASS (KG) }\end{array}$ & $\begin{array}{l}\text { DCW } \\
\text { MASS } \\
\text { /CUT } \\
\text { (KG) }\end{array}$ & $\begin{array}{l}\text { NUMBER OF } \\
\text { ANIMALS }\end{array}$ \\
\hline Leg cuts & $11,900,000$ & $91,100,000$ & $103,000,000$ & 22.6 & $4,550,000$ \\
\hline $\begin{array}{l}\text { Loin cuts } \\
\begin{array}{l}\text { Belly } \\
\text { cuts }\end{array}\end{array}$ & $113,000,000$ & $50,700,000$ & $164,000,000$ & 20.9 & $\mathbf{7 , 8 6 0 , 0 0 0}$ \\
\hline $\begin{array}{l}\text { Shoulder } \\
\text { cuts }\end{array}$ & $11,900,000$ & $5,560,000$ & $17,500,000$ & 20.1 & 861,000 \\
\hline
\end{tabular}


Lamb and mutton headline a category that includes goat, deer, buffalo, caribou, horse and rabbit meats as well as frog's legs (Appendix 1). As lamb and mutton are singled out and the distribution of other meats within the category is unknown, the StatsCan average DCW for sheep and lamb, $21.1 \mathrm{~kg}$, will be divided into the FES quantity to give an equivalent number of ovine animals (StatsCan, 2009: survey 003-0028).

Not as many prepared meats and sausages start with lamb or mutton as with beef, pork or chicken in Canada. Table 3.13 lists those FES categories apportioned in addition to the 2001 consumption.

Table 3.13: Share of listed categories added to lamb and mutton.

\begin{tabular}{|l|r|}
\hline FES CATEGORY & MASS OF SHEEP (KG) \\
\hline Other ready-cooked meat & 939,000 \\
\hline Other canned meats (...) & 201,000 \\
\hline Total & $1,140,000$ \\
\hline
\end{tabular}

The quantities from table 3.13 amount to nearly $10 \%$ of the 2001 Canadian consumption of ovine meat. This is shown, along with the 2001 average DCW of sheep and the number of animals slaughtered to support the total in table 3.14. The bold typeface indicates the number of sheep that were fed to support 2001 consumption.

Table 3.14: Calculation of required slaughter sheep.

\begin{tabular}{|c|c|c|c|c|c|}
\hline \hline MEAT & $\begin{array}{l}\text { FES STARTING } \\
\text { MASS (KG) }\end{array}$ & $\begin{array}{l}\text { MASS FROM } \\
\text { TABLES 3.13 } \\
\text { (KG) }\end{array}$ & $\begin{array}{l}\text { TOTAL } \\
\text { CONSUMED } \\
\text { MASS (KG) }\end{array}$ & $\begin{array}{l}\text { DCW } \\
\text { (KG) }\end{array}$ & $\begin{array}{l}\text { NUMBER OF } \\
\text { ANIMALS }\end{array}$ \\
\hline Sheep & $11,900,000$ & $1,140,000$ & $13,000,000$ & 21.1 & $\mathbf{6 2 0 , 0 0 0 0}$ \\
\hline
\end{tabular}


In Canada chickens are slaughtered and mechanically processed at a rate of about 25000 broilers (meat animals) per hour (AAFC, 2008b), mainly in Ontario and Quebec where some $60 \%$ of production takes place (StatsCan, 2009: survey 003-0018). After being electrically stunned, killed by bleeding from the neck, scalded in hot water, and plucked of feathers, the birds are mechanically eviscerated, then cleaned and prepared for consumption whole or for further processing (Barker, Lankhaar \& Stals, 2004: 94-96, 97-98). The average dressed weight for birds is not supplied directly by StatsCan, as it is for cattle and swine, but is found by dividing the individual Provinces' meat production by their respective number of birds slaughtered and taking the weighted mean as the National average. StatsCan suppresses data where it might identify the survey participants; due to this, no poultry data are available for Prince Edward Island (P.E.I.) or Newfoundland and Labrador, representing 2\% of Canada's production (StatsCan, 2009: survey 003-0018).

Table 3.15 lists the percent share from each Province of the total National production, the carcass weights, and the final DCW. The Canadian average weight of a dressed chicken was $1.53 \mathrm{~kg}$ in 2001 . Chickens are used in a variety of prepared and cooked foods that are simply allocated to whole chickens according to this meat's share of consumer preference, as shown in table 3.16 . Prepared chicken products add almost $17 \%$ to the total eaten by Canadians in 2001. Chicken consumption in 2001, the addition of prepared food, the 
calculated 2001 DCW for chicken and the number of animals required to support the total (bolded) are shown in table 3.17.

Table 3.15: Percent share of chicken production and average dressed weight, Provincially and Nationally, 2001 data.

\begin{tabular}{|l|c|c|}
\hline AREA & SHARE (\%) & AVERAGE DRESSED WEIGHT (KG) \\
\hline Quebec & 27 & 1.58 \\
\hline Ontario & 32 & 1.57 \\
\hline Manitoba & 5 & 1.41 \\
\hline Saskatchewan & 3 & 1.40 \\
\hline Alberta & 9 & 1.47 \\
\hline British Colombia & 16 & 1.44 \\
\hline New Brunswick & 3 & 1.54 \\
\hline Nova Scotia & 3 & 1.52 \\
\hline P.E.I. & $\mathrm{x}$ & - \\
\hline Nfld. \& Labrador & $\mathrm{x}$ & - \\
\hline National & 98 & 1.53 \\
\hline
\end{tabular}

Note: $\mathrm{x}=$ suppressed $\quad$ Source: (StatsCan, 2009: survey 003-0018)

Table 3.16: Share of listed categories added to chickens.

\begin{tabular}{|l|r|}
\hline \hline FES CATEGORY & MASS OF CHICKEN (KG) \\
\hline Other cured meat & $2,420,000$ \\
\hline Wieners & $19,400,000$ \\
\hline Other ready-cooked meat & $31,500,000$ \\
\hline Other meat preparations & $7,270,000$ \\
\hline Other canned meats (...) & $6,740,000$ \\
\hline Total & $67,300,000$ \\
\hline
\end{tabular}

Table 3.17: Calculation of required slaughter chickens.

\begin{tabular}{|l|l|l|l|l|l|}
\hline MEAT & $\begin{array}{l}\text { FES } \\
\text { STARTING } \\
\text { MASS (KG) }\end{array}$ & $\begin{array}{l}\text { MASS } \\
\text { FROM } \\
\text { TABLE 3.16 } \\
\text { (KG) }\end{array}$ & $\begin{array}{l}\text { TOTAL } \\
\text { CONSUMED } \\
\text { MASS (KG) }\end{array}$ & $\begin{array}{l}\text { DCW } \\
\text { (KG) }\end{array}$ & $\begin{array}{l}\text { NUMBER OF } \\
\text { ANIMALS }\end{array}$ \\
\hline Chickens & $400,000,000$ & $67,300,000$ & $467,000,000$ & 1.53 & $\mathbf{3 0 5 , 0 0 0 , 0 0 0}$ \\
\hline
\end{tabular}

Turkey production data are also suppressed for P.E.I. and Newfoundland and Labrador, but since the missing data account for less than a tenth of a percent of National production (StatsCan, 2009: survey 003-0018), the 
discrepancy can be safely ignored in this case. Using the same method as displayed in table 3.15 , the 2001 Canadian average DCW for turkeys is found to be $7.40 \mathrm{~kg}$ (StatsCan, 2009: survey 003-0018). Turkeys are used in some prepared foods and the distribution of those is shown in table 3.18 .

Table 3.18: Share of listed categories added to turkeys.

\begin{tabular}{|l|c|}
\hline FES CATEGORY & MASS OF TURKEY (KG) \\
\hline Other ready-cooked meat & $5,170,000$ \\
\hline Other canned meats $(. .)$. & $1,110,000$ \\
\hline Total & $6,280,000$ \\
\hline
\end{tabular}

Turkey products from table 3.18 add just less than $10 \%$ to the total eaten by Canadians in 2001. Turkey consumption in 2001, the additional mass from prepared food, the calculated 2001 DCW for turkey and the number of animals required to support the total, in bold type, are shown in table 3.19 .

Table 3.19: Calculation of required slaughter turkeys.

\begin{tabular}{|l|l|l|l|l|l|}
\hline MEAT & $\begin{array}{l}\text { FES } \\
\text { STARTING } \\
\text { MASS (KG) }\end{array}$ & $\begin{array}{l}\text { MASS } \\
\begin{array}{l}\text { FROM } \\
\text { TABLE 3.18 } \\
(\text { KG) }\end{array}\end{array}$ & $\begin{array}{l}\text { TOTAL } \\
\text { CONSUMED } \\
\text { MASS (KG) }\end{array}$ & $\begin{array}{l}\text { DCW } \\
\text { (KG) }\end{array}$ & $\begin{array}{l}\text { NUMBER OF } \\
\text { ANIMALS }\end{array}$ \\
\hline Turkeys & $65,700,000$ & $6,280,000$ & $72,000,000$ & 7.4 & $\mathbf{9 , 7 2 0 , 0 0 0}$ \\
\hline
\end{tabular}

There are other commercially important birds produced in Canada, including geese, ducks, ostriches, emus, rheas and small game birds, like pheasants, raised for food (AAFC, 2009a). In the FES, the consumption category for these birds also includes the offal and livers from chickens and turkeys. Together they constitute about $0.8 \%$ of poultry meat consumed in 2001 and will not be considered further. 


\subsubsection{Fish and other marine products}

Fish is an important part of Canadians' diet. Although in 2001 almost three times the pork, over three and a half times the chicken and well over seven times the beef were eaten (StatsCan, 2003b), fish are nonetheless important to this accounting because the global wild fish harvest has peaked, so aquaculture will be increasingly called upon to provide this food (AAFC, 2003). Salmon and other ocean fish account for the vast majority of fish consumed in 2001 (StatsCan, 2003b). When farmed, salmon are fed a pelletized diet that simulates a natural one of crustaceans and fish; since salmon are the most-farmed fish in Canada (AAFC, 2008c), it can be assumed their diet is represented by any generalized feed calculations.

StatsCan (2005b: table 23A) has determined 3.452t of "complete grainbased rations" were required to feed 1000 farmed fish in 2001 . Of that, $2.495 \mathrm{t}$ is in fact not grain based, but consists of minerals, fats, sweeteners, supplements and animal by-products (StatsCan, 2005b: 9), while the remainder is made up of $0.666 \mathrm{t}$ wheat and $0.292 \mathrm{t}$ soybean meal (StatsCan, 2005b: table 23K). As the proportions of the constituents of the non-grain based diet are unknown, and it is not possible to accurately re-integrate generically described "animal byproducts" back into whole animals in any case, this part of the analysis will be incomplete. 
Other considerations for this category include:

- Freshwater fish account for less than $5 \%$ of consumption in Canada and will be included with marine fish (StatsCan, 2003b).

- The weight of canned fish, mostly salmon and tuna, and that of cured and pickled fish will be considered equivalent to live-weight fish; they account for almost $26 \%$ of consumption (StatsCan, 2003b).

- Shellfish represent $18.5 \%$ of fish consumption (StatsCan, 2003b) and are ocean farmed in Canada, but since they feed naturally they make no demand on land area (AAFC, 2008c).

StatsCan based feed quantity estimations on average weights for salmon of $8 \mathrm{lbs}(3.6 \mathrm{~kg})$ and trout of $5 \mathrm{lbs}(2.3 \mathrm{~kg})(2005 \mathrm{~b}: 8)$; the higher number will be adopted since, as noted, salmon account for the preponderance of both farmed and consumed fish. Table 3.20 shows the 2001 consumption of all fresh, frozen and canned fish, the average weight of salmon and the number of thousands of farmed fish required to meet those quantities, again in bold type.

Table 3.20: Calculation of required farmed fish.

\begin{tabular}{|l|c|c|c|}
\hline FISH & $\begin{array}{l}\text { FES STARTING } \\
\text { MASS (KG) }\end{array}$ & $\begin{array}{l}\text { WEIGHT OF } \\
\text { FISH (KG) }\end{array}$ & $\begin{array}{l}\text { NUMBER OF FARMED } \\
\text { FISH }\end{array}$ \\
\hline Fresh or frozen & $90,000,000$ & 3.6 & $25,000,000$ \\
\hline Canned & $42,000,000$ & 3.6 & $11,000,000$ \\
\hline Total & $130,000,000$ & 3.6 & $\mathbf{3 6 , 0 0 0 , 0 0 0}$ \\
\hline
\end{tabular}




\subsubsection{Dairy products and eggs}

The first post-natal nutrition all mammals receive is milk (Early, 1998: 1), an emulsion of fat globules (lipids collectively called milkfat or butterfat) interspersed with a colloidal suspension of large proteins in an aqueous solution (serum) containing minerals, enzymes, acids, lactose and vitamins (Goff, 2009a). The main source of milk in North America is bovines (Potter \& Hotchkiss, 1998: 279) and the Canadian dairy herd is predominantly the Holstein breed at over 90\% (AAFC, 2009b). Dairy producers in Canada, like those in other nations with industrialized dairy industries, use common milk collection and pooling systems (Early, 1998: 11). This compensates for any variability in the composition of milk, even among cows of the same breed, owing to inter alia age, feed and season (Lane, 1998: 165; Potter \& Hotchkiss, 1998: 279-280) and makes possible the determination of averages for lipid and protein content (Potter \& Hotchkiss, 1998: 280). Butterfat and proteins are the substrates for most dairy products derived from milk or cream.

Regular beverage milk is marketed according to its fat content and is listed in the FES as fluid whole milk (homogenized), $2 \%$ butterfat, $1 \%$ butterfat and skim (Appendix 1); homogenized milk has a butterfat content of $3.25 \%$ and that of skim milk is not more than $0.5 \%$ (Dairy Producers Association of Canada, n.d.). Whole milk is mechanically separated using centrifugal cream separators that act on the density difference between the skim milk and the butterfat (Potter \& Hotchkiss, 1998: 291). Two methods exist for manufacturing milk with 
a particular fat content. The first is to simply separate the skim milk from the fat entirely and later reintroduce the quantity of butterfat required to reach the content desired (Early, 1998: 22); the second is to control the rate of separation so that the output is not skim, but milk with the desired fat content (Potter \& Hotchikiss, 1998: 291). Both methods are used in Canada (Goff, 2009b) and in either case it is the serum that accounts for the volume.

Specialty milks listed in the FES include lactose-reduced, sterilized, acidophilus bacterium-enhanced and lactose-free milks and must also be added to the total volume. Cream is listed with beverage milk in the FES and will also be added to it. Neither ice cream nor ice milk are a recommended part of nutrition and are not accounted (Health Canada, 2008a).

Milk separated to make cream containing $30-35 \%$ fat forms the basis for butter-making (Potter and Hotchkiss, 1998: 369). Cream is an oil-in-water emulsion; water is said to be the continuous phase, while droplets of fat encased in protective phospholipid coats float as the discontinuous phase. Agitating the emulsion, or churning, breaks the oil droplets and causes them to adhere to one another until they begin to form larger and larger clumps of fat. The liquid must be drained and may be consumed as buttermilk, although buttermilk is more commonly produced through fermentation as yoghurt (Goff, 2009c), see below. The final product is the reversed, water-in-oil emulsion containing at least $80 \%$ fat called butter (Potter and Hotchkiss, 1998: 370). 
It is reasonable to assume that cream (milkfat) extracted from the production of beverage milk supplies some part of butter production, but some butter manufacturers begin with whole milk and "usually" send the skim for drying into milk powder (Goff, 2009d: 111). A complete exposition of the dairy industry to determine such specifics is beyond the scope of this work. It will therefore be assumed that butter is made from milk produced specially for that purpose, although this may lead to an estimation of the dairy herd that is higher than actually required. Potter and Hotchkiss approximate $22.8 \mathrm{~L}$ of milk for every kilogram of butter (1998: 281, table 13.3). The volume of milk required to manufacture the butter consumed in 2001 is calculated in table 3.21 . Almost 1.5 million kilolitres of whole milk was centrifuged to separate enough butterfat for this amount.

Table 3.21: Calculation of milk volume required to supply butter.

\begin{tabular}{|c|c|c|c|}
\hline $\begin{array}{c}\text { FES } \\
\text { ITEM }\end{array}$ & $\begin{array}{c}\text { FES STARTING } \\
\text { VOLUME (KG) }\end{array}$ & $\begin{array}{c}\text { FES CONVERSION FACTOR } \\
\text { (KL/KG) }\end{array}$ & $\begin{array}{c}\text { MILK VOLUME } \\
(\mathrm{KL})\end{array}$ \\
\hline Butter & $65,700,000$ & 0.023 & $1,500,000$ \\
\hline
\end{tabular}

Yoghurt is milk that has undergone lactic acid fermentation and is likely the oldest example of bioengineered food preservation (Jaros \& Rohm, 1998: 156). Most, if not all, of the yoghurt available in Canada is made from cow's milk (Staff, 1998: 124). A review of literature does not indicate that a change in volume occurs after fermentation (Goff, 2009c; Jaros \& Rohm, 1998; Potter \& Hotchkiss, 1998; Staff, 1998), although Staff notes that fruit concentrate may be added between $15-25 \%$ of volume (1998: 143). Yoghurt is listed in the FES in both fresh and frozen forms, but there is no other subdivision for additives like 
fruit (StatsCan, 2003b); therefore, the volume of fresh and frozen yoghurt will be considered as an equivalent volume of milk and added to its total.

Cheese making uses about $35 \%$ of the world's milk production (Banks, 2007: 100). The FES lists: cheddar cheese; grated cheese, including cheddar, mozzarella, parmesan and romano; process cheese, which includes Gruyere, cheese slices and prepared cheese snacks; cottage cheese, including ricotta; and other cheese, which includes some 36 other named cheeses (Appendix 1). As previously mentioned, the protein content of milk is important to dairy manufacturers, especially as the principal substrate for cheese-making (Potter \& Hotchkiss, 1998: 300) and the standardization of milk that ensures uniformity of content allows for generalizations in the relationship between inputs and outputs. Cheese is described as what remains "after coagulation and whey separation" of milk, cream, or both (Goff, 2009e). Whey constitutes about $90 \%$ of milk volume, as it includes the serum, and contains whey proteins (which may be recovered in the cheese) and minerals. Once considered an environmental threat, mostly due to heightened biological oxygen demand in receiving water bodies, whey products have growing value in some markets (Kelly, 2007: 163). That said, whey products are not explicitly mentioned in the FES (Appendix 1) so any Canadian consumption will be assumed as a by-product of cheese production.

Banks suggests production of $1 \mathrm{~kg}$ of cheddar cheese requires about $10 \mathrm{~L}$ of milk (2007: 102). Both Emmons and colleagues (1990: 1384) and Hill (2009) use the Van Slyke and Price formula to arrive at $9.885 \mathrm{~kg}$ and $9.945 \mathrm{~kg}$ cheddar 
cheese yield per 100kg milk, respectively, while Potter and Hotchkiss (1998: 281) aver $10 \mathrm{~kg}$ milk generally produces $1 \mathrm{~kg}$ of any cheese. Since milk has a density of about $1.03 \mathrm{~kg} / \mathrm{L}$ at $20^{\circ} \mathrm{C}$ (Goff, 2009a) $100 \mathrm{~kg}$ milk displaces $97.1 \mathrm{~L}$. These numbers are compared in table 3.22 .

Table 3.22: Relationship between milk quantity and cheese yield.

\begin{tabular}{|l|c|c|c|}
\hline \hline AUTHOR & CHEESE (KG) & MILK (L) & CHEESE: MILK (KG/L) \\
\hline Banks (2007) & 1.0 & 10.0 & 0.10 \\
\hline Emmons, et.al. (1990) & 9.985 & 97.1 & 0.10 \\
\hline Potter \& Hotchkiss (1998) & 9.945 & 97.1 & 0.10 \\
\hline
\end{tabular}

Therefore, for all the cheeses except cottage cheese the relationship of $10 \mathrm{~L}$ milk to produce $1 \mathrm{~kg}$ cheese will be adopted. For cottage cheese, Potter and Hotchkiss (1998:281) suggest $6.3 \mathrm{~kg}$, or $6.5 \mathrm{~L}$, milk makes $1 \mathrm{~kg}$. The milk required to make the nearly 46,000 tonnes of cheese consumed is calculated in table 3.23 .

Table 3.23: Calculation of milk required to supply cheese consumption.

\begin{tabular}{|l|c|c|c|}
\hline \multicolumn{1}{|c|}{ FES ITEM } & $\begin{array}{c}\text { FES STARTING } \\
\text { MASS (KG) }\end{array}$ & $\begin{array}{c}\text { VOLUME OF } \\
\text { MILK (L/KG) }\end{array}$ & $\begin{array}{c}\text { REQUIRED VOLUME } \\
\text { OF MILK (KL) }\end{array}$ \\
\hline $\begin{array}{l}\text { Cheese (except } \\
\text { cottage cheese) }\end{array}$ & $22,100,000$ & 10 & 221,000 \\
\hline Cottage cheese & $23,900,000$ & 6.5 & 155,000 \\
\hline Total & $46,000,000$ & n/a & 376,000 \\
\hline
\end{tabular}

Condensed and evaporated milk are listed together in the FES (Appendix 1) and Potter and Hotchkiss (1998: 281) suggest $2.3 \mathrm{~kg}$ and $2.4 \mathrm{~kg}$ milk, respectively, makes $1 \mathrm{~kg}$ of each product. The slightly higher value is used here and is converted using the milk density relationship, $1.03 \mathrm{~kg} / \mathrm{L}$ (Goff, 2009a), to 2.5L milk per litre of product. The starting volume of milk evaporated or 
condensed to provide for those categories in the amounts consumed in 2001 is displayed in table 3.24 .

Table 3.24: Calculation of milk required to supply evaporated milk consumption.

\begin{tabular}{|l|c|c|c|}
\hline FES ITEM & $\begin{array}{l}\text { FES STARTING } \\
\text { VOLUME (KL) }\end{array}$ & $\begin{array}{l}\text { RELATIONSHIP } \\
\text { TO MILK (L:L) }\end{array}$ & $\begin{array}{l}\text { REQUIRED } \\
\text { VOLUME OF MILK } \\
\text { (KL) }\end{array}$ \\
\hline $\begin{array}{l}\text { Evaporated and } \\
\text { condensed milk }\end{array}$ & 23,800 & $2.5: 1$ & 59,700 \\
\hline
\end{tabular}

Once the milk required to support the 2001 Canadian diet is known, the size of the dairy herd can be found. A "dairy year" runs from August 1 until the following July 31 so a figure must be derived from both the 2000-2001 and 2001-2002 reports. The former says an average Canadian dairy cow produced 9,152kg of milk, while in 2001-2002 the figure was 9,242 (Canadian Dairy Commission [CDC], 2001; CDC, 2002). Taking the median, 9,197kg, and using the same milk density relationship as for cheese, above (Goff, 2009a), the yield is found to be equivalent to 8,929 litres of milk per cow per annum.

The totals from the tables $3.21,3.23$, and 3.24 are added to the FES quantities of liquid milk, milk specialty products, and yoghurt products to provide the total quantity of milk and dairy products consumed in 2001. This is shown, along with the average annual milk production from a single Canadian cow and the number of animals required to produce the total, in bold type, in table 3.25 .

Table 3.25: Calculation of total milk and the animals required for its supply.

\begin{tabular}{|l|l|l|l|l|l||}
\hline $\begin{array}{l}\text { FES } \\
\text { ITEM }\end{array}$ & $\begin{array}{l}\text { FES } \\
\text { STARTING } \\
\begin{array}{l}\text { VOLUME } \\
(\text { KL })\end{array}\end{array}$ & $\begin{array}{l}\text { VOLUME FROM } \\
\text { TABLES 3.21, } \\
3.23 \& 3.24 \\
(\mathrm{KL})\end{array}$ & $\begin{array}{l}\text { TOTAL } \\
\text { CONSUMED } \\
\text { VOLUME (KL) }\end{array}$ & $\begin{array}{l}\text { MILK PER } \\
\text { COW } \\
(\mathrm{KL} / \mathrm{YR})\end{array}$ & $\begin{array}{l}\text { NUMBER } \\
\text { OF } \\
\text { ANIMALS }\end{array}$ \\
\hline Milk & $2,340,000$ & $1,940,000$ & $4,280,000$ & 8.929 & $\mathbf{4 7 9 , 0 0 0}$ \\
\hline
\end{tabular}


There is an "other dairy products" category in the FES that contains powdered and chocolate milk, buttermilk, eggnog and other beverage milks and drinkable yoghurt, alongside sour cream and various creamy spreads, such as chip dip, garlic spreads and whip cream (Appendix 1). This presents some difficulty for analysis in that accounting for the milk and yoghurt products is appropriate, but for the cream-based products would constitute double counting and there is no way to disaggregate the two. Given the available data, there does not appear to be an argument that justifies apportioning any fraction to the milk volume, while it is arguable that very little of the list are nutritionally essential foods (Health Canada, 2008a). Therefore these data are not used in the analysis.

Eggs are listed with dairy in the FES, but are largely supplied by chickens. StatsCan found the average number of eggs produced by a chicken in 2001 to be 270 (StatsCan, 2009: survey 003-0020). The number of eggs per chicken will be divided into the total in the FES to give the number of chickens required to support this consumption. The total eggs consumed, the average number of eggs produced by a Canadian chicken in 2001, and the number of chickens fed to supply the eggs, in bold type, are shown in table 3.26 .

Table 3.26: Calculation of eggs and the chickens required for their supply.

\begin{tabular}{|l|l|l|l||}
\hline $\begin{array}{l}\text { FES } \\
\text { ITEM }\end{array}$ & $\begin{array}{l}\text { FES STARTING } \\
\text { QUANTITY }\end{array}$ & $\begin{array}{l}\text { EGGS PER CHICKEN } \\
\text { PER YEAR }\end{array}$ & $\begin{array}{l}\text { NUMBER OF } \\
\text { ANIMALS }\end{array}$ \\
\hline Eggs & $3,300,000,000$ & 270 & $\mathbf{1 2 , 2 0 0 , 0 0 0}$ \\
\hline
\end{tabular}




\subsubsection{Bakery and other cereal products}

Cereal goods fall into three broad areas in the FES: baked goods, including bread, rolls and buns, and crackers; pasta products; and rice, breakfast cereals, flours and flour-based mixes. Within these broad groups there are nineteen categories comprising 280 individual foods (Appendix 1). The main constituent of most baked goods and pasta is wheat flour (Potter \& Hotchkiss, 1998: 388) and fortunately most recipes for baked goods express ingredients as a percentage of the weight of flour used (Gisslen, 1985: 5), while pasta is generally $12 \%$ moisture by weight when finished (Potter \& Hotchkiss, 1998: 388) making calculation of grain requirement relatively facile. Rice is not grown in Canada (FAO, 2009) and must be substituted for. There are several categories, like cookies, doughnuts, and other baked goods, that are almost entirely nonessential.

Grinding flour evolved from a simple process for crushing seeds. Each grain has a complicated structure designed to protect the seed until germination and growth conditions are right. A hard, multi-layered outer casing, the bran, protects the nutritious interior, including the starchy endosperm that initially feeds the new plant, and the germ, which carries the genetic material (Potter \& Hotchkiss, 1998: 383; 385, figure 17.1$)$. In the earliest innovation after natural stones, original millers pounded the whole grain in a pestle-and-mortar arrangement to make whole grain flour; mechanized flour milling, grinding whole grain between two rotating circular stones, dates back perhaps 7500 years. The 
process for separating the darker bran from the lighter endosperm to make socalled white flour, called the gradual reduction process, developed over the last three hundred years. The modern mill begins with the break process that passes grain through a series of progressively smaller, fluted cast-iron rollers that crack and flake off the bran and the germ, each pass followed by sieving through progressively smaller screens that separates the endosperm (Catterall \& Cauvain, 2007: 333-335). The endosperm fragments, called semolina, are then passed through the reduction system. This series of smooth rollers produces finished flour of different grades, in declining quality from beginning to end (Catterall \& Cauvain, 2007: 345) The bran can also be ground and added to produce different types of brown flour (Catterall \& Cauvain, 2007: 347), but is mostly destined for animal feed (Canadian Wheat Board, 2008). If the mill is set to make white flour, only the endosperm is used and represents between $76-78 \%$ of the mass of wheat, called the extraction rate. Blended brown flours have an extraction rate of approximately $90 \%$ and whole wheat $100 \%$ (Catterall \& Cauvain, 2007: 347). Flours made from rye and other grains, while milled in the same fashion, do not have the proteins (glutens) required for breadmaking and must be blended with wheat flour; for example, light rye bread is made using $60 \%$ wheat flour and $40 \%$ rye flour (Cauvain, 2007: 372, 375). The extraction rate applied will depend on the item in question; these are explained below.

Bread is a standalone category in the FES with no distinction made between white or whole wheat varieties and no mention of breads made from 
other grasses like rye or those made from lesser-known grains such as spelt, kamut or quinoa (Canadian Grain Commission [CGC], 2009; Appendix 1). However, since breads made from any of these grains will be functionally similar as food and since the 2001 Canadian average yield for both wheat and rye was identical (StatsCan, 2009: survey 001-0010), assuming all rye breads are made from wheat does not change the analysis of land area. Yield data for spelt, kamut and quinoa are not readily available for Canada (FAO, 2009; StatsCan, 2009), although they are all grown commercially here (CGC, 2009); it will be assumed that wheat is an acceptable substitute for these grains in bread.

As mentioned, bread formulae are related to the mass of flour, so if a typical recipe can be established and a reasonable estimate of weight lost to dehydration and processing can be made, the flour used can be calculated from the mass of the finished product. Gisslen (1985: 34) addresses scaling commercial dough recipes, noting that evaporative weight loss is $10-13 \%$, or 50 $65 \mathrm{~g}$ per $500 \mathrm{~g}$, and later suggests adding $50 \mathrm{~g}$ of dough for every $450 \mathrm{~g}$ finished product, or $11 \%$ extra, to account for "baking loss" (1985: 73). Wiggins and Cauvain (2007: 171, figure 5.18), in a more detailed consideration of losses throughout a processing plant, arrive at the same figure, $11 \%$. Some of the loss must be dough adhering to preparation and cooking surfaces and mixing and cutting blades, but most is lost as water is evaporated during baking. Due to numerical agreement $11 \%$ total loss is accepted. Perhaps somewhat arbitrarily a loss of $10 \%$ will be accounted; this represents an attempt at realism in 
acknowledging material loss (minus $1 \%$ from $11 \%$ ), while maintaining a conservative estimate by attributing most of the loss to evaporation.

Further assumed is an extraction rate for flour from wheat of $90 \%$, as for brown flour, above, because although it leads to a less conservative estimate than the extraction rate for white flour $(\sim 77 \%)$, it is realistic. One hundred percent whole wheat flour includes the milled germ, which contains much fat and becomes rancid in storage, so is less used commercially. Also, the milled bran and germ in whole grain flour have other effects that detract from the quality of the bread and so the use of whole wheat flour is usually augmented with other flour (Gisslen, 1985: 13). To allocate all bread using white flour extraction rates would ignore easily available information that a great many bread products for sale in Canada are made from some kind of blended flour (e.g. Canada Bread Company Limited, 2005).

Table 3.27 shows the commercial formulations of white and whole wheat breads if 100 units of flour are used, the application of a $10 \%$ loss of water by mass, the change in the percent share of flour, and the factor used to convert the mass of bread consumed to its equivalent grain at a $90 \%$ flour extraction rate. The masses of bread, rolls, and the like consumed in Canada in 2001 are multiplied by 0.64 , deterrnined in table 3.27 , to obtain the amount of wheat required for production (StatsCan, 2003b). Before calculating the wheat required for bread and related products, the quantities from several categories must be transformed to usable units. 
Table 3.27: Comparison of contributions (by mass and percent) of ingredients in bread and calculation of conversion factor.

\begin{tabular}{|l|r|r|}
\hline INGREDIENT & WHITE & WHOLE WHEAT \\
\hline Flour & $100 \mathrm{~g}$ & $100 \mathrm{~g}$ \\
\hline Water & $60 \mathrm{~g}$ & $62 \mathrm{~g}$ \\
\hline Yeast & $3.75 \mathrm{~g}$ & $3 \mathrm{~g}$ \\
\hline Salt & $2.5 \mathrm{~g}$ & $2 \mathrm{~g}$ \\
\hline Sugar/ malt syrup & $3.75 \mathrm{~g}$ & $4 \mathrm{~g}$ \\
\hline Non-fat milk solids & $5 \mathrm{~g}$ & $3 \mathrm{~g}$ \\
\hline Shortening & $3.75 \mathrm{~g}$ & $4 \mathrm{~g}$ \\
\hline Yield & $178.75 \mathrm{~g}$ & $178 \mathrm{~g}$ \\
\hline \% flour & 56 & 56 \\
\hline$\%$ flour (-10\% water) & 58 & 57 \\
\hline $\begin{array}{l}\text { Conversion for FES (90\% } \\
\text { extraction; unitless) }\end{array}$ & 0.64 & 0.64 \\
\hline
\end{tabular}

Source for masses: (Gisslen, 1985: 47; 48).

The FES category "unsweetened rolls and buns" includes scones, tea biscuits, bagels and other buns traditionally eaten for breakfast, Kaisers and other buns used for sandwiches, and dinner rolls and hamburger and hotdog buns (Appendix 1). As these are given as a number of dozen rolls consumed an equivalent mass of finished product must be determined. Rolls and buns begin with as little as $45 \mathrm{~g}$ of dough for dinner rolls to $60 \mathrm{~g}$ for Kaisers and $50-55 \mathrm{~g}$ for bagels (Gisslen, 1985: 50,66, 68). As the numbers of each item are unknown, the mean is an inappropriate measure as it cannot be realistically weighted. Therefore the median of the range $45-60 \mathrm{~g}, 52.5 \mathrm{~g}$ per unit (also the median of the range for bagels alone) is chosen and the calculation is shown in table 3.28.

Table 3.28: Calculation of the mass of rolls from initial FES numerical quantity.

\begin{tabular}{|l|l|c|c|}
\hline $\begin{array}{l}\text { FES } \\
\text { ITEM }\end{array}$ & $\begin{array}{l}\text { FES STARTING } \\
\text { QUANTITY }\end{array}$ & $\begin{array}{l}\text { AVERAGE MASS OF DOUGH } \\
\text { PER ROLL (T) }\end{array}$ & $\begin{array}{l}\text { MASS OF } \\
\text { ROLLS (T) }\end{array}$ \\
\hline Rolls & $3,370,000,000$ & 0.0000525 & 177,000 \\
\hline
\end{tabular}


Buns and rolls are prepared using the same manufacturing processes and the same flour as bread, above, so the same derivations apply for weight loss and flour extraction rate. The recipes are again expressed as a percentage of the flour used and table 3.29 gives those for hard rolls, like Kaisers, soft rolls, like dinner rolls, and bagels.

Table 3.29: Comparison of contributions (by mass and percent) of ingredients in various rolls and calculation of conversion factor.

\begin{tabular}{|l|r|r|r||}
\hline \hline INGREDIENT & $\begin{array}{c}\text { SOFT } \\
\text { ROLLS }\end{array}$ & HARD ROLLS & BAGELS \\
\hline Flour & $100 \mathrm{~g}$ & $100 \mathrm{~g}$ & $100 \mathrm{~g}$ \\
\hline Water & $57 \mathrm{~g}$ & $55 \mathrm{~g}$ & $50 \mathrm{~g}$ \\
\hline Yeast & $3.5 \mathrm{~g}$ & $3.5 \mathrm{~g}$ & $3 \mathrm{~g}$ \\
\hline Salt & 1.75 & $2.25 \mathrm{~g}$ & $1.5 \mathrm{~g}$ \\
\hline Sugar/ malt syrup & 9.5 & $2.25 \mathrm{~g}$ & $6 \mathrm{~g}$ \\
\hline Egg whites & - & $2.25 \mathrm{~g}$ & - \\
\hline Shortening & $4.75 \mathrm{~g}$ & $2.25 \mathrm{~g}$ & (oil) $0.8 \mathrm{~g}$ \\
\hline Butter & $4.75 \mathrm{~g}$ & - & - \\
\hline Yield & $186.0 \mathrm{~g}$ & $167.5 \mathrm{~g}$ & $161.0 \mathrm{~g}$ \\
\hline$\%$ flour & 54 & 60 & 62 \\
\hline$\%$ flour (-10\% water) & 55 & 62 & 64 \\
\hline $\begin{array}{l}\text { Conversion for FES (90\% } \\
\text { extraction; unitless) }\end{array}$ & 0.62 & 0.69 & 0.71 \\
\hline
\end{tabular}

Source for masses: (Gisslen, 1985: 44; 48; 50).

The mean of the three conversion factors, 0.67 , is adopted to convert the mass of buns consumed to wheat grains needed.

Crackers and crisp breads follow in the FES and include soda crackers (saltines), soup crackers, Melba toast, and crisp breads with brand names like Stoned Wheat Thins ${ }^{\top M}$ and Triscuit ${ }^{\top M}$ (Appendix 1). Crackers and their ilk are made with dough that is similar to bread, though with slightly less water and with a different cooking process (Manley, 2001: 41). Crisp breads are also similar 
to regular bread, but are made with much more water, later removed (Manley, 2001: 28; 30). Again as above, formulations are made against 100 units of brown wheat flour extracted as $90 \%$ of the mass of whole grain. In the case of these products, however, the final product is dried to $5 \%$ moisture (Manley, 2001: 30).

Table 3.30 shows the commercial formulations of crackers and crisp bread if 100 units of flour are used, the application of a $95 \%$ loss of water by mass, the change in the percent share of flour and the factor used to convert the mass of product consumed to its equivalent grain at a $90 \%$ flour extraction rate.

Table 3.30: Comparison of contributions (by mass and percent) of ingredients in crackers and crisp breads and calculation of conversion factor.

\begin{tabular}{|l|r|r|}
\hline \hline INGREDIENT & CRACKERS & CRISP BREAD \\
\hline Flour & $100 \mathrm{~g}$ & $100 \mathrm{~g}$ \\
\hline Water & $29.5 \mathrm{~g}$ & $129 \mathrm{~g}$ \\
\hline Yeast & $0.15 \mathrm{~g}$ & - \\
\hline Salt & $1.62 \mathrm{~g}$ & $1.15 \mathrm{~g}$ \\
\hline Soda & $0.89 \mathrm{~g}$ & - \\
\hline Non-fat milk solids & $3.7 \mathrm{~g}$ & - \\
\hline Shortening & $11.82 \mathrm{~g}$ & - \\
\hline Yield & $147.68 \mathrm{~g}$ & $230.15 \mathrm{~g}$ \\
\hline$\%$ flour & 68 & 43 \\
\hline$\%$ flour (-95\% water) & 84 & 88 \\
\hline $\begin{array}{l}\text { Conversion for FES (90\% } \\
\text { extraction; unitless) }\end{array}$ & 0.93 & 0.98 \\
\hline
\end{tabular}

Source: (Manley, 2001: 30; 41).

Both the mean and the median of the conversion factor are 0.955 , so this number will be used.

While cookies, sweet biscuits, doughnuts, and other sweet goods are not essential and are not accounted here, the same cannot be said for muffins. 
Muffins are made with similar ingredients and in much the same fashion as bread (Gisslen, 1985: 85) and experience the same 10\% moisture loss during baking.

Table 3.31 shows a typical muffin recipe and the calculation of the conversion factor.

Table 3.31: Ingredients in muffins and calculation of conversion factor.

\begin{tabular}{|l|r|}
\hline INGREDIENT & MUFFINS \\
\hline Flour & $100 \mathrm{~g}$ \\
\hline Sugar & $30 \mathrm{~g}$ \\
\hline Baking powder & $6 \mathrm{~g}$ \\
\hline Salt & $1.25 \mathrm{~g}$ \\
\hline Eggs & $20 \mathrm{~g}$ \\
\hline Water & $80 \mathrm{~g}$ \\
\hline Shortening & $30 \mathrm{~g}$ \\
\hline Yield & $267.25 \mathrm{~g}$ \\
\hline$\%$ flour & 37 \\
\hline$\%$ flour (-10\% water) & 39 \\
\hline $\begin{array}{l}\text { Conversion for FES (90\% } \\
\text { extraction; unitless) }\end{array}$ & 0.44 \\
\hline \multicolumn{2}{|l|}{ Source for mses: (GSTen $1985:$} \\
\hline
\end{tabular}

Source for masses: (Gisslen, 1985: 90).

Muffins are also listed in the FES as number eaten and must be converted to mass before the application of the conversion factor. Gisslen (1985: 90) directs bakers to use approximately $60 \mathrm{~g}$ of dough per muffin, which will be adopted here.

Pastes of semolina and water formed into sheets and cut into dumplings called noodles have been produced nearly as long as bread, perhaps as long as 6000 years in China. In Europe evidence from ancient art and text indicates the Romans had developed pasta in 600 BCE. Production was artisanal until the Industrial Revolution brought mechanization, extruders and hydraulic presses; the first fully modernized plant, with continuous extrusion and drying producing 
ready-to-eat pasta, began operating in 1946 (Dexter, 2004: 249-250). In the FES pasta is listed in three groups: canned pasta products; fresh or dry pasta; and dry pasta mixes (Appendix 1). The latter two are mostly dry pasta and canned pasta start with it, so a general discussion of the derivation of the wheat equivalent will be made followed by details specific to the canned product. Both Italian pasta and Asian noodles are described in all three groups; Dexter notes that while the processing steps are quite different the recipes and final moisture contents are similar $(2004: 257 ; 264)$, so they are accounted for in the same fashion.

Italian pasta is made from semolina, the course particles of the endosperm, rather than ground flour, and preferably obtained from high-quality wheat (Dexter, 2004: 250). Since the bran is removed completely for semolina, the extraction rate for semolina is the same as that for white flour, between 76$78 \%$ or $77 \%$ (Catterall \& Cauvain, 2007: 346 ), as will be used here. Potter and Hotchkiss (1998: 388) state simply that pasta should be dried to "about 12\%", while Dexter (2004: 257 ) is no more specific in his long overview of the multistage, controlled drying process in the modern plant, suggesting "approximately $12.5 \%$." Since a higher moisture value leads arithmetically to lesser quantities of wheat required and is thus a conservative measure, $12.5 \%$ moisture will be used. The formula for pasta is 30 units of water for every 100 of semolina. Asian noodles are made not from semolina, but from a variety of flours, mostly wheat 
flour $^{6}$ free of bran, i.e. extracted at a rate of 77\% (Dexter, 2004: 259). Table 3.32 shows the calculations determining the conversion of pasta to wheat.

Table 3.32: Comparison of contributions (by mass and percent) of ingredients in pasta.

\begin{tabular}{|l|c|}
\hline INGREDIENT & PASTA \\
\hline Flour & $100 \mathrm{~g}$ \\
\hline Water & $30 \mathrm{~g}$ \\
\hline Salt & - \\
\hline Yield & $130 \mathrm{~g}$ \\
\hline \% flour & 77 \\
\hline$\%$ flour (-87.5\% water) & 96 \\
\hline Conversion for FES (unitless) & 1.25 \\
\hline
\end{tabular}

Source for masses: (Dexter, 2004: 251).

As can be seen, whole wheat must be produced to account for the milling loss of the bran, resulting in a conversion factor of 1.25 .

Canned pasta includes a variety of ready-to-eat noodle types and shapes in a sauce (Appendix 1). Lopez discusses the procedure for canning spaghetti, which will be assumed here to be typical of all canned pasta. As the pasta is cooked prior to canning it is fully hydrated, weighs about 2.5 times its dry mass, and takes up from $33-50 \%$ of the volume of the package (Lopez: 1987a: 316$317)$. Assuming the density of fully hydrated pasta is about $1 \mathrm{~kg} / \mathrm{L}$, a conservative estimation of the dry weight of pasta from a can is $33 \% \div 2.5=13 \%$ of the volume given in the FES. As its constituency cannot be determined, the sauce will not be accounted for. Table 3.33 shows the steps in converting litres of canned pasta to the mass equivalent.

\footnotetext{
${ }^{6}$ Perhaps 30-40\% of all wheat flour in Southeast Asia is used for making noodles (Dexter, 2004: 258).
} 
Table 3.33: Calculation of mass of pasta from canned volume.

\begin{tabular}{|l|c|c|c||}
\hline FES ITEM & $\begin{array}{l}\text { FES STARTING } \\
\text { QUANTITY }(L)\end{array}$ & $\begin{array}{l}\text { \% DRY MASS OF } \\
\text { PASTA }\end{array}$ & $\begin{array}{l}\text { MASS OF PASTA } \\
(\text { KG })\end{array}$ \\
\hline $\begin{array}{l}\text { Canned pasta } \\
\text { products }\end{array}$ & $29,900,000$ & 13 & $3,880,000$ \\
\hline
\end{tabular}

The mass of wheat accounted for by pasta consumption, including the result from table 3.33, is determined in table 3.34 .

Table 3.34: Total mass of pasta.

\begin{tabular}{|l|r||}
\hline FES ITEM & FES STARTING QUANTITY (T) \\
\hline Canned pasta products & 3,880 \\
\hline Dry or fresh pasta & 149,000 \\
\hline Pasta mixes & 35,800 \\
\hline Total & 189,000 \\
\hline
\end{tabular}

In table 3.35 the totals from tables 3.28 and 3.34 are listed with bread, crackers and crisp breads, their respective conversion factors, and the resulting quantities of wheat ascribed to their production; the final quantity of wheat is in bold type.

Table 3.35: Calculation of wheat required for bread, rolls, crackers and pasta.

\begin{tabular}{|c|c|c|c|}
\hline FES ITEM & $\begin{array}{l}\text { QUANTITY FROM FES, } \\
\text { TABLES } 3.28 \& 3.34(\mathrm{~T})\end{array}$ & $\begin{array}{l}\text { CONVERSION } \\
\text { FACTOR (UNITLESS) }\end{array}$ & $\begin{array}{l}\text { MASS OF } \\
\text { WHEAT }(T)\end{array}$ \\
\hline Bread & 573,000 & 0.64 & 367,000 \\
\hline Rolls & 177,000 & 0.67 & 118,000 \\
\hline $\begin{array}{l}\text { Crackers and } \\
\text { crisp breads }\end{array}$ & 53,500 & 0.995 & 53,200 \\
\hline Pasta & 189,000 & 1.25 & 236,000 \\
\hline Total & $n / a$ & $\mathrm{n} / \mathrm{a}$ & 774,000 \\
\hline
\end{tabular}

In the FES rice is found as white, brown, parboiled and prepared types (Appendix 1) and, as mentioned above, is not a commercially grown cereal in Canada (FAO, 2009). A substitution must therefore be made to account for the land area represented by its consumption. Beside rice, cereals also include 
wheat, rye, barley, oats and corn (GCG, 2009; Potter \& Hotchkiss, 1998: 381). As it is reasonable to assume some substitution by grain corn in the event rice is unavailable, accounting for rice consumption is proportional to the fraction of produced amounts for wheat, rye barley, oats and corn using CANSIM II data and calculated in table 3.36 (StatsCan, 2009: survey 001-0010).

Table 3.36: Calculation of production proportions for cereals, 2001.

\begin{tabular}{|l|c|c|}
\hline GRAIN & 2001 PRODUCTION (T) & $\%$ OF TOTAL \\
\hline Barley & $10,800,000$ & 25.4 \\
\hline Corn (grain) & $8,390,000$ & 19.6 \\
\hline Oats & $2,690,000$ & 6.3 \\
\hline Rye & 228,000 & 0.5 \\
\hline Wheat & $20,600,000$ & 48.2 \\
\hline Total & $42,800,000$ & 100 \\
\hline
\end{tabular}

Source: (StatsCan, 2009: survey 001-0010).

The amount of rice consumed, given as mass units in the FES, will be converted to equivalent land areas of each above grain in proportion to the percentages found in table 3.36. While it is beyond the scope of this work to evaluate the nutritional values of foods, a straight substitution in this case is plausible, at least on the grounds of energy equivalency. Equal amounts of rice, whole wheat, and potato flours and corn meal contain between $1000 \mathrm{~kJ}$ and $1300 \mathrm{~kJ}$ of energy. A serving of cooked white or brown rice yields about the same energy as a slice of white or whole wheat bread or cooked barley (Health Canada, 2008b: 4-6). Table 3.37 shows the distribution of the 119,000 tonnes of rice consumed in 2001 as if it were Canadian-grown grains. Domesticallyproduced grain totals are in bold type. 
Table 3.37: Calculation for rice as Canadian-grown grain.

\begin{tabular}{|l|c|c|}
\hline \multicolumn{1}{|c|}{ GRAIN } & \% OF TOTAL & RICE AS GRAIN (T) \\
\hline Total & 100 & $\mathbf{1 1 9 , 0 0 0}$ \\
\hline Barley & 25.4 & $\mathbf{3 0 , 3 0 0}$ \\
\hline Corn & 19.6 & $\mathbf{2 3 , 4 0 0}$ \\
\hline Oats & 6.3 & $\mathbf{7 , 5 1 0}$ \\
\hline Rye & 0.5 & $\mathbf{6 3 6}$ \\
\hline Wheat & 48.2 & $\mathbf{5 7 , 6 0 0}$ \\
\hline
\end{tabular}

Flour is listed as a standalone category in the FES, encompassing wheat, rice, rye, oat, corn, buckwheat, and potato flours, amongst others (Appendix 1). The task here is to find a reasonable substitute for such a disparate blend when the proportions of each are unknown. As a comprehensive analysis of the manufacturing techniques and extraction rates for all the flours listed and the subsequent calculation of a single conversion factor is beyond the scope of this work, the $90 \%$ extraction rate applied to bread flour, above, will be applied, as will the average yield for all wheat, $1900 \mathrm{~kg} / \mathrm{ha}$ (StatsCan, 2009: survey 0010010). The weight of all the flour consumed in 2001 is listed in table 3.38 , along with the conversion factor derived from the $90 \%$ extraction rate of flour from wheat, and the addition to the final mass of wheat, in bold type.

Table 3.38: Calculation of wheat required to supply flour.

\begin{tabular}{|l|c|c|c|}
\hline FES ITEM & $\begin{array}{l}\text { FES STARTING } \\
\text { MASS }(T)\end{array}$ & $\begin{array}{l}\text { CONVERSION FACTOR } \\
\text { (UNITLESS) }\end{array}$ & MASS OF WHEAT (T) \\
\hline Flour & 143,000 & 1.11 & $\mathbf{1 5 9 , 0 0 0}$ \\
\hline
\end{tabular}

"Other cereal grains" is a catch-all category of foods like natural bran, bulgur, wheat germ, couscous, hominy grits, oatmeal and corn meal (Appendix 1), again in undeterminable proportions. As these foods are cereals the proportions found in table 3.36 are applied here. Table 3.39 shows this for the 
nearly 18 thousand tonnes of other milled and unmilled grains. Domesticallyproduced grain totals are in bold type.

Table 3.39: Calculation for flour as Canadian-grown grain.

\begin{tabular}{|l|c|c|}
\hline \hline GRAIN & \% OF TOTAL & FLOUR AS GRAIN (T) \\
\hline Total & 100 & 17,900 \\
\hline Barley & 25.4 & $\mathbf{4 , 5 4 0}$ \\
\hline Corn & 19.6 & $\mathbf{3 , 5 1 0}$ \\
\hline Oats & 6.3 & $\mathbf{1 , 1 3 0}$ \\
\hline Rye & 0.5 & $\mathbf{9 5}$ \\
\hline Wheat & 48.2 & $\mathbf{8 , 6 4 0}$ \\
\hline
\end{tabular}

Breakfast cereals are another unknown mix of grain-based foods found in the FES (Appendix 1). Wheat, rice, corn and oats are the predominant grains and for most cereals only the endosperm are used, either mashed and reformed, or mechanically aerated or "puffed" (Potter \& Hotchkiss, 1998: 394-395). Finished breakfast cereals are dried to $3-5 \%$ moisture from the original moisture content of the grains of about $11 \%$ (Potter \& Hotchkiss, 1998: 382, table $17.2 ; 395$ ) and so a conversion factor must be found by dividing the mean moisture content by the finished content before the $77 \%$ extraction rate for endosperm from grain can be applied; the calculation of this is shown in table 3.40 .

Table 3.40: Calculation of the average moisture content and conversion factor for breakfast cereals.

\begin{tabular}{|l|c|}
\hline GRAIN & MOISTURE CONTENT \\
\hline Corn & $11 \%$ \\
\hline Oats & $13 \%$ \\
\hline Wheat & $11 \%$ \\
\hline Mean & $11.7 \%$ \\
\hline Cereal moisture content & $5 \%$ \\
\hline FES conversion factor & 2.34 \\
\hline
\end{tabular}

Source: (Potter \& Hotchikiss, 1998: 382, table 17.2). 
After the converted amount is determined it is apportioned according to table 3.36 as for rice and other cereal grains, above. Breakfast cereals must undergo a two-step process to find the final demand they pose on land area. First, the moisture content is increased to its original proportion using the conversion factor from table 3.40; second, it is apportioned as for rice and other grains, above, based on table 3.36. The results are shown in tables 3.41 and 3.42 , respectively, with the masses to be added to the final grains quantities in the latter table in bold type.

Table 3.41: Calculation of grain required for breakfast cereal consumption.

\begin{tabular}{||c|c|c|c|}
\hline \hline FES ITEM & $\begin{array}{c}\text { FES STARTING } \\
\text { MASS }(T)\end{array}$ & $\begin{array}{c}\text { FES CONVERSION FACTOR } \\
\text { (UNITLESS) }\end{array}$ & $\begin{array}{c}\text { MASS OF } \\
\text { GRAINS }(T)\end{array}$ \\
\hline $\begin{array}{l}\text { Breakfast } \\
\text { cereals }\end{array}$ & 143,000 & 2.34 & 335,000 \\
\hline
\end{tabular}

Table 3.42: Calculation for breakfast cereals as Canadian-grown grain.

\begin{tabular}{|l|c|c|}
\hline \hline \multicolumn{1}{|c|}{ GRAIN } & $\%$ OF TOTAL & $\begin{array}{c}\text { BREAKFAST CEREALS } \\
\text { AS GRAIN (T) }\end{array}$ \\
\hline Total & 100 & 335,000 \\
\hline Barley & 25.4 & $\mathbf{8 5 , 0 0 0}$ \\
\hline Corn & 19.6 & $\mathbf{6 5 , 8 0 0}$ \\
\hline Oats & 6.3 & $\mathbf{2 1 , 1 0 0}$ \\
\hline Rye & 0.5 & $\mathbf{1 , 7 9 0}$ \\
\hline Wheat & 48.2 & $\mathbf{1 6 2 , 0 0 0}$ \\
\hline
\end{tabular}

The remaining cereal products are cake mixes and cereal-based snack foods that are not considered nutritional and are not accounted here (Health Canada, 2008a). The totals from tables $3.35,3.37,3.38,3.39$, and 3.42 are collected in table 3.84, where the final areal demand for such land is determined. 


\subsubsection{Fruit and nuts}

Over 170 kinds of fresh, frozen, preserved and juiced fruits from around the world were eaten in Canada in 2001 (Appendix 1). Only five orchard fruits, five berries, both sweet and sour cherries, and melons (in small quantities) are produced commercially in Canada (FAO, 2009; StatsCan, 2009: survey 0010009). Not orly must consumption of domestically-produced fruits be satisfied by 2001 Canadian fruit production, but in order to satisfy this analysis the areas required to provide substitutes for imported species must be as well.

There are several fruits listed in the FES in litres, like strawberries, or as the number consumed rather than as a mass, like grapefruits and melons, and thus require conversion (StatsCan, 2003b). The United States Department of Agriculture's (USDA) Food and Nutrition Service publishes commodity fact sheets for many foods including grapefruit (USDA, 2007: 123). The USDA's National Agricultural Statistics Service (NASS) provides some conversions in annual statistical reports including for strawberries and watermelon (2009: vi, vii). The following table relates the number of grapefruits and litres of strawberries from the FES to equivalent mass according to the above-noted sources.

Table 3.43: Calculation of per unit mass for selected fruits.

\begin{tabular}{|l|c|c|c||}
\hline FRUIT & UNIT & MASS (KG) & CONVERSION FACTOR \\
\hline Grapefruit & $27-32$ large fruit & $15.4-17.7$ & $0.56 \mathrm{~kg} / \mathrm{single}$ fruit \\
\hline Strawberries & Crate $(26.4 \mathrm{~L})$ & 16.3 & $0.68 \mathrm{~kg} / \mathrm{L}$ \\
\hline
\end{tabular}


Grapefruit are given as a range of weights that for single fruits corresponds to $0.55-0.57 \mathrm{~kg}$; both the mean and the median are $0.56 \mathrm{~kg}$ and this value is used. For strawberries the value is essentially a bulk density measurement, $0.68 \mathrm{~kg} / \mathrm{L}$.

Melons create an additional complication in that they have myriad harvest weights, dependant on the variety or species. Complimentary here to the USDA data for watermelons (2009: vii), a document has been prepared by Penn State University (n.d.) covering the production and marketing of cantaloupes that lists the harvest weights of 11 cultivars. The range is listed and the mean is calculated, as shown in table 3.44. As there is a significant difference in the values and there is no way to know the distribution of melon types in the FES (StatsCan, 2003b), an average weighted by Canadian production, $64 \%$ melons like cantaloupe and $36 \%$ watermelon $(F A O, 2009)$ is calculated and also shown in table 3.44 .

Table 3.44: Calculation of per unit mass for melons.

\begin{tabular}{|l|l|r|c||}
\hline \hline \multicolumn{1}{|c|}{ FRUIT } & \multicolumn{1}{|c|}{ CRITERION } & MASS (KG) & $\begin{array}{c}\text { MASS/MELON } \\
\text { (KG) }\end{array}$ \\
\hline Cantaloupe & Range (11 varieties) & $1.8-3.2$ & 2.5 \\
\hline Watermelon & Single average melon & 11.3 & 11.3 \\
\hline Weighted cantaloupe & 64\% production area & 2.5 & $-1.6-$ \\
\hline Weighted watermelon & 22\% production area & 11.3 & $-4.1-$ \\
\hline Mean melon weight & $100 \%$ production area & - & 2.9 \\
\hline
\end{tabular}

Source: (FAO, 2009; Penn State, n.d.: 2, table 1; USDA, 2009: vii)

Although the accuracy of this result, $2.9 \mathrm{~kg}$, is somewhat questionable, an alternative applicable measure of central tendency, the median, $6.7 \mathrm{~kg}$, is equally unsatisfactory in that it is likely too high. Since the lower measure is more conservative, it is adopted. Melons were produced in such small quantities in 
2001 Canada that StatsCan does not collect data, although the FAO (2009) has estimated planted area, production and yield. The mass of fruits given in numeric quantities in the FES must be first converted and this is shown in table 3.45 .

Table 3.45: Calculation of the mass of fruits from initial FES numerical quantities.

\begin{tabular}{|l|c|c|c|}
\hline FES ITEM & $\begin{array}{l}\text { FES STARTING QUANTITY } \\
\text { (\# UNLESS NOTED) }\end{array}$ & $\begin{array}{l}\text { CONVERSION } \\
\text { FACTOR (T/UNIT) }\end{array}$ & $\begin{array}{l}\text { MASS OF } \\
\text { FRUIT (T) }\end{array}$ \\
\hline Grapefruits & $155,000,000$ & 0.00056 & 86,900 \\
\hline Melons & $102,000,000$ & 0.00290 & $\mathbf{2 9 4 , 0 0 0}$ \\
\hline Strawberries & $47,800,000 \mathrm{~L}$ & 0.00068 & $\mathbf{3 2 , 5 0 0}$ \\
\hline
\end{tabular}

After fresh fruit is accounted for, frozen fruits are analyzed in much the same manner. There is a similar mix of domestic and imported fruits, both berries and tree fruits, in an unknown distribution in the FES (Appendix 1) that will be apportioned against table 3.53 , below. Although they are $85-90 \%$ water, fruits are not dehydrated prior to freezing except for some osmotic dehydration caused by the syrup or powdered sugar used mainly as preservative (De Ancos, Sánchez-Moreno, De Pascual-Teresa \& Cano, 2006: 59, 65).

Dried fruit does occur in the FES as a single group comprising raisins and an "other dried fruit/preserves" category (Appendix 1). Drying involves the removal of free and bound water from fruits using either natural or mechanical methods involving warm-air convection, surface conduction, infrared radiation, or (microwave) molecular excitation. Regardless of the method and process the drying effects of fruit are similar and thus may be discussed generally (Barta, 2006: 82-84).

The main variety of grape used for raisin production in North America, primarily in the US, is the Thompson seedless variety and raisin-making is the 
second most common use for grapes in the world after wine-making (Bhat, Desai \& Suleiman, 2006: 439). Grapes have an initial moisture content of around $86 \%$ by mass and are dried to $14 \%$ moisture by mass (Bhat et al., 2006: 442); this will be arithmetically reversed to find the starting mass. The mass of grapes is obtained by initially multiplying the mass of raisins found in the FES by 0.14 to find a mass of water. This is subtracted from the starting mass to find the mass of solids. The mass of dried solids is increased by a factor of $6.14(0.86 / 0.14)$ to an approximate initial water content of $31,530 \mathrm{~kg}$, which is in turn divided into the mass of solids, giving a starting dried solids percentage of grapes, $16.3 \%$. The divisor is increased until the result is $14 \%$ ( $86 \%$ moisture). As suggested above, different grapes are eaten fresh, used for making raisins or for beverage purposes. However, no distinction is made for grape variety in this study, so the mass is added to the total for grapes.

The list of dried and preserved fruit includes both domestic and imported items, as well as items like fruit bars that are processed beyond drying and candied fruits and cherries in syrup; since over $80 \%$ of the list is simply dried fruit the entire category is analyzed as such (Appendix 1). All fruits begin, as mentioned, with a moisture content of $85-90 \%$ (De Ancos et al., 2006: 59) and all are dried to between 12-16\% (Pátaki, 2006: 219). The median of both ranges, $87.5 \%$ and $14 \%$, respectively, will be applied as for grapes, immediately above, as will the iteration process. The final mass will be apportioned to domestic fruits' land area using table 3.53. The mass of fresh fruit that went into 
the manufacture of raisins and dried fruit is shown in table 3.46. The amount to be added to the final total for grapes is in bold type. The total for dried fruit is distributed against domestic production in table 3.56, below.

Table 3.46: Mass of fruit as raisins and dried fruits.

\begin{tabular}{|c|c|c|c|c|c|}
\hline $\begin{array}{l}\text { FES } \\
\text { ITEM }\end{array}$ & $\begin{array}{l}\text { FES } \\
\text { STARTING } \\
\text { MASS (T) }\end{array}$ & $\begin{array}{l}\text { FES } \\
\text { STARTING } \\
\text { MOISTURE } \\
(\%) \\
\end{array}$ & $\begin{array}{l}\text { FES } \\
\text { STARTING } \\
\text { DRY } \\
\text { MASS (T) }\end{array}$ & $\begin{array}{l}\text { FINAL } \\
\text { MOISTURE } \\
\text { CONTENT } \\
(\%)\end{array}$ & $\begin{array}{l}\text { FINAL } \\
\text { MASS OF } \\
\text { FRUIT } \\
\text { (T) }\end{array}$ \\
\hline Raisins & 5,970 & 14.0 & 5,130 & 86.0 & 36,700 \\
\hline $\begin{array}{l}\text { Dried } \\
\text { fruit }\end{array}$ & 11,900 & 14.0 & 10,300 & 87.5 & 82,200 \\
\hline
\end{tabular}

Fruit juice not from concentrate includes apple, orange and grapefruit juices and also contains an "other" category that lists the juices of 17 distinct domestic and imported fruits. Juices are either clear, like apple juice, or cloudy, like orange juice, but the process for extracting the juice is the same; clear juices additionally undergo filtration during processing (Horváth-Kerkai, 2006: 205).

Commercial extraction of fruit juices in North America is done by the "squeezer-type" and "reamer-type" extractors (Hui, 2004: 367). Unfortunately, Hui (2004: 368) only gives the extraction rate for the squeezer-type, stating the average production capacity is $500 \mathrm{~L}$ orange juice per tonne oranges, which amounts to $50 \%$ extraction by mass. The FAO value is slightly higher at $54 \%$ extraction rate for oranges, $75 \%$ for grapes, $48 \%$ for grapefruits, $33 \%$ for lemons and $72 \%$ for apples in the US, and $70 \%$ for Canadian apples (FAO, n.d.: 195, 272-273). Other literature did not provide more than qualitative statements of extraction rates (Horváth-Kerkai, 2006: 209; Pátaki, 2006: 222; Potter \& Hotchkiss, 1998), although Potter and Hotchkiss aver that, equipment differences 
notwithstanding, all the elements of juice processing are common for all fruits (1998: 432). For the juices specifically named in the FES the respective FAO (n.d.) extraction rates are applied, using the Canadian value for apples, and the result added to domestic production for apples and apportioned against table 3.43 for the others. For the other juice category, the median of the range 54$70 \%, 62 \%$, will be used and the result apportioned according to table 3.53 .

Concentrated fruit juice is mostly orange juice, both as found in the FES and produced globally (Hui, 2006: 376; StatsCan, 2003b), followed by "other concentrated fruit juices." The FAO (n.d.: 272) lists the extraction rate for American orange juice concentrate as $21 \%$ and grapefruit juice concentrate at $12 \%$. Orange juice will be assessed at $21 \%$ and the other juice category at the median of the above range, $16.5 \%$; both will be apportioned against table 3.53 . Using the FAO (n.d.) extraction rates given in above, a conversion factor from litres of juice to tonnes of fruit is derived and applied in table 3.47.

Table 3.47: Calculation of mass of fruit required to make an initial volume of fruit juice.

\begin{tabular}{|l|c|c|r|}
\hline \hline FES ITEM & $\begin{array}{l}\text { FES STARTING } \\
\text { QUANTITY }(\mathrm{L})\end{array}$ & $\begin{array}{l}\text { CONVERSION } \\
\text { FACTOR (T/L) }\end{array}$ & MASS OF FRUIT (T) \\
\hline Apple juice & $143,000,000$ & 0.0014 & $\mathbf{2 0 1 , 0 0 0}$ \\
\hline Grapefruit juice & $23,900,000$ & 0.0021 & 50,200 \\
\hline Orange juice & $251,000,000$ & 0.0019 & 476,000 \\
\hline Other juice & $388,000,000$ & 0.0016 & 621,000 \\
\hline Total (excl. apples) & $663,000,000$ & n/a & $1,150,000$ \\
\hline
\end{tabular}

The mass of fruit required to supply concentrated fruit juice is found is the same manner as in table 3.47 and is displayed in table 3.48 . The mass of apples from table 3.47 is added directly to domestic consumption, while the total from 
the other juices in that table and the total from table 3.48 are distributed against domestic production in table 3.56 .

Table 3.48: Calculation of starting mass of fruit from an iritial volume of concentrated fruit juice.

\begin{tabular}{|l|c|c|c||}
\hline \hline FES ITEM & $\begin{array}{l}\text { FES STARTING } \\
\text { QUANTITY }(L)\end{array}$ & $\begin{array}{l}\text { CONVERSION } \\
\text { FACTOR }(T / L)\end{array}$ & MASS OF FRUIT (T) \\
\hline Orange juice & $41,800,000$ & 0.0048 & 201,000 \\
\hline Other fruit juice & $71,700,000$ & 0.0061 & 437,000 \\
\hline Total & $114,000,000$ & $\mathrm{n} / \mathrm{a}$ & 638,000 \\
\hline
\end{tabular}

Canned peaches, pineapples, mixed fruit (mostly fruit salads) and fruit cocktails, and "other fruit" are listed in the FES as volume units (StatsCan, 2003b) and so must be converted. The Canadian Agricultural Products Act regulations mandate minimum net and drained weights for five standardized can sizes making estimation of mass equivalence reasonably straight-forward. For peaches and pineapples, for each can size produced ${ }^{7}$ the lowest drained weight percentage, i.e. the most conservative estimate, will be adopted. The regulations include fruit salad, which is essentially the mixed fruit category and will thus be used. These figures are found in table 3.49.

Table 3.49: Canned fruits consumed and $\mathrm{m} / \mathrm{v}$ ratio.

\begin{tabular}{|l|c|}
\hline CANNED ITEM & $\%$ MASS/VOLUME \\
\hline Peaches & $60^{\mathrm{a}}$ \\
\hline Pineapple & $53^{\mathrm{b}}$ \\
\hline Fruits for salad & $61^{\mathrm{c}}$ \\
\hline \hline
\end{tabular}

Notes: a) 10fl.oz., sliced, quartered, halves; in water or syrup.

b) 10 fl.oz. all styles but crushed; in water.

c) $28 f$ floz. in water or syrup.

Source: (DOJC, 2009b).

\footnotetext{
${ }^{7}$ Not all fruits are sold in every can size.
} 
These ratios will be applied against their respective categories in the FES. For peaches the amount is applied directly against production area. Both pineapples and mixed fruit are apportioned according to table 3.53 .

For the remaining category, "other canned fruit," which includes domestic and imported kinds in an unknown distribution, an average for those domestically produced fruit for which there are canning regulations will be determined. All these values and the calculation can be found in table 3.50. The mass of other canned fruit is found by multiplying the volume by 0.54 ; the result is apportioned according to table 3.53. Conversion factors derived from the regulated minimum drained weights of canned fruit are shown in table 3.51 with the starting volume of the cans and the final mass of fruit. The result for peaches, in bold, is added directly to domestic consumption, while the rest are added to table 3.57 .

Table 3.50: Other canned fruits, $\mathrm{m} / \mathrm{v}$ ratio and mean of the ratio.

\begin{tabular}{|l|c|}
\hline \hline CANNED ITEM & $\%$ MASS/VOLUME \\
\hline Blueberries & $53^{\mathrm{a}}$ \\
\hline Cherries (sweet) & $57^{\mathrm{b}}$ \\
\hline Pears & $61^{\mathrm{c}}$ \\
\hline Plums & $57^{\mathrm{d}}$ \\
\hline Raspberries & $50^{\mathrm{e}}$ \\
\hline Strawberries & $43^{\mathrm{f}}$ \\
\hline Average for FES & 54 \\
\hline
\end{tabular}

Notes: a) $19 f 1.0 z$. , in water or syrup.

b) $28 f$ l.oz., not pitted; in syrup or water.

c) 10 fl.oz., sliced, quartered, halves; in water or syrup.

d) 28 fl.oz., in water or syrup.

e) 14 fl.oz., in water or syrup.

f) $14 f$ l.oz., in water or syrup.

Source: (DOJC, 2009b) 
Table 3.51: Mass of fruit required to provide the initial canned volume.

\begin{tabular}{|l|c|c|c||}
\hline \hline FES ITEM & $\begin{array}{l}\text { FES STARTING } \\
\text { QUANTITY (L) }\end{array}$ & $\begin{array}{l}\text { CONVERSION } \\
\text { FACTOR (T/L) }\end{array}$ & $\begin{array}{l}\text { MASS OF } \\
\text { FRUIT (T) }\end{array}$ \\
\hline Peaches & $11,900,000$ & 0.00060 & $\mathbf{7 , 1 7 0}$ \\
\hline Pineapple & $17,900,000$ & 0.00053 & 9,490 \\
\hline Mixed fruit & $29,900,000$ & 0.00061 & 18,200 \\
\hline Other canned fruit & $23,900,000$ & 0.00054 & 12,900 \\
\hline Total (excl. peaches) & $71,700,000$ & $\mathrm{n} / \mathrm{a}$ & 40,600 \\
\hline
\end{tabular}

The final two fruit categories in the FES, "jams, jellies and other preserves" and "fruit pie fillings," are similar products given in volume units that must be converted to mass (StatsCan, 2003b). Canadian standards for fruit content of jam vary by fruit and according to whether or not pectin, a gelling agent, is added ${ }^{8}$. The range is as little as $27 \%$ fruit by mass in jam with pectin added, to $35 \%$ in jams with apple or rhubarb and some other fruit, to $45 \%$ in pectin-free jams (DOJC, 2009c). Jelly and marmalade are made with juice extracted from fruit, rather than the whole fruit itself, as is jam (Vibhakara \& Bawa, 2006: 197-198). As neither the starting quantity of fruit nor the amount of jelly within the category can be accurately determined (StatsCan, 2003b), jelly and marmalade will be treated as jam. Pie fillings contain about $30 \%$ fruit by mass (Pátaki, 2006: 226). Since the only products mentioned by name in the FES are low-pectin fruits (StatsCan, 2003b; Vibhakara \& Bawa, 2006: 191), since pie fillings contain an amount of fruit similar to that of jam, and since the fruit by mass in pectin-added jam is the most conservative measure, it will be assumed that products in this category contain $27 \%$ fruit by mass, apportioned through

\footnotetext{
${ }^{8}$ Pectin is found naturally in fruits; apples and citrus fruits are examples of fruits high in pectin, while peaches, berries and pineapple are examples with low amounts (Vibhakara \& Bawa, 2006; 191).
} 
table 3.53. The results are in table 3.52 and the total is distributed to domestic production in table 3.57 .

Table 3.52: Mass of fruit required to manufacture the volume of jam, jelly, other preserves and fruit pie filling.

\begin{tabular}{|l|c|c|c|}
\hline \hline FES ITEM & $\begin{array}{l}\text { FES STARTING } \\
\text { QUANTITY }(L)\end{array}$ & $\begin{array}{l}\text { CONVERSION } \\
\text { FACTOR (T/L) }\end{array}$ & MASS OF FRUIT (T) \\
\hline Jams et.al. & $23,800,000$ & 0.00027 & 6,430 \\
\hline Pie filling & $5,970,000$ & 0.00027 & 1,610 \\
\hline Total & $29,800,000$ & $\mathrm{n} / \mathrm{a}$ & 8,040 \\
\hline
\end{tabular}

Nuts are not commercially produced in Canada (FAO, 2009: StatsCan, 2009) and there are no obvious substitutes short of nutritional comparison, which is beyond the scope of this work.

The mix of domestic fruit that will take the place of imports is proportional to the 2001 tonnes of production for apples, apricots, blueberries, two kinds of cherries, cranberries, grapes, melons, peaches, pears, raspberries, and strawberries (Cowell \& Parkinson, 2003: 226; StatsCan, 2009: survey 001-0009). The produced amount for the two types of cherry production is combined. The distribution is shown in table 3.53. Table 3.54 shows the distribution of equivalent masses of various domestic fruit substituting for bananas and citrus fruits, whose FES quantities are shown in the top row. Table 3.55 shows the distribution of equivalent masses of various domestic fruit substituting for other fresh fruit, other tropical fruit and frozen fruit, again with the FES quantities in the top row (Cowell \& Parkinson, 2003: 226). 
Table 3.53: Calculation of production proportions for fruit, 2001.

\begin{tabular}{|l|c|c|}
\hline \hline FRUIT & 2001 PRODUCTION (T) & \% OF TOTAL AREA \\
\hline Apples & 488,000 & 63.0 \\
\hline Apricots & 1,370 & 0.2 \\
\hline Blueberries & 67,700 & 8.6 \\
\hline Cherries & 11,100 & 1.4 \\
\hline Cranberries & 34,800 & 4.5 \\
\hline Grapes & 67,200 & 8.7 \\
\hline Melons & 12,400 & 1.6 \\
\hline Peaches & 30,500 & 3.9 \\
\hline Pears & 17,500 & 2.3 \\
\hline Plums & 3,630 & 0.5 \\
\hline Raspberries & 14,600 & 1.9 \\
\hline Strawberries & 26,200 & 3.4 \\
\hline Total & 775,000 & 100 \\
\hline
\end{tabular}

Source: (FAO, 2009; StatsCan, 2009: survey 001-0009).

Table 3.54: Masses of domestic fruits substituting for bananas and citrus fruit.

\begin{tabular}{|l|r|r|r|r|r||}
\hline \multicolumn{1}{|c|}{ FRUIT } & \multicolumn{1}{c|}{$\%$} & $\begin{array}{c}\text { BANANAS } \\
(\mathrm{T})\end{array}$ & $\begin{array}{c}\text { GRAPEFRUIT } \\
(\mathrm{T})\end{array}$ & $\begin{array}{c}\text { ORANGES } \\
(\mathrm{T})\end{array}$ & $\begin{array}{r}\text { LEMONS \& } \\
\text { LIMES }(T)\end{array}$ \\
\hline FES totals & 100 & 358,000 & 86,900 & 233,000 & 17,900 \\
\hline Apples & 63.0 & $\mathbf{2 2 6 , 0 0 0}$ & $\mathbf{5 4 , 8 0 0}$ & $\mathbf{1 4 7 , 0 0 0}$ & $\mathbf{1 1 , 3 0 0}$ \\
\hline Apricots & 0.2 & $\mathbf{6 3 3}$ & $\mathbf{1 5 4}$ & $\mathbf{4 1 1}$ & $\mathbf{3 2}$ \\
\hline Blueberries & 8.6 & $\mathbf{3 1 , 3 0 0}$ & $\mathbf{7 , 5 9 0}$ & $\mathbf{2 0 , 3 0 0}$ & $\mathbf{1 , 5 6 0}$ \\
\hline Cherries & 1.4 & $\mathbf{5 , 1 2 0}$ & $\mathbf{1 , 2 4 0}$ & $\mathbf{3 , 3 3 0}$ & $\mathbf{2 5 6}$ \\
\hline Cranberries & 4.5 & $\mathbf{1 6 , 1 0 0}$ & $\mathbf{3 , 9 0 0}$ & $\mathbf{1 0 , 4 0 0}$ & $\mathbf{8 0 3}$ \\
\hline Grapes & 8.7 & $\mathbf{3 1 , 1 0 0}$ & $\mathbf{7 , 5 4 0}$ & $\mathbf{2 0 , 2 0 0}$ & $\mathbf{1 , 5 5 0}$ \\
\hline Melons & 1.6 & $\mathbf{5 , 7 4 0}$ & $\mathbf{1 , 3 9 0}$ & $\mathbf{3 , 7 3 0}$ & $\mathbf{2 8 7}$ \\
\hline Peaches & 3.9 & $\mathbf{1 4 , 1 0 0}$ & $\mathbf{3 , 4 3 0}$ & $\mathbf{9 , 1 7 0}$ & $\mathbf{7 0 6}$ \\
\hline Pears & 2.3 & $\mathbf{8 , 0 7 0}$ & $\mathbf{1 , 9 6 0}$ & $\mathbf{5 , 2 4 0}$ & $\mathbf{4 0 3}$ \\
\hline Plums & 0.5 & $\mathbf{1 , 6 8 0}$ & $\mathbf{4 0 7}$ & $\mathbf{1 , 0 9 0}$ & $\mathbf{8 4}$ \\
\hline Raspberries & 1.9 & $\mathbf{6 , 7 4 0}$ & $\mathbf{1 , 6 4 0}$ & $\mathbf{4 , 3 8 0}$ & $\mathbf{3 3 7}$ \\
\hline Strawberries & 3.4 & $\mathbf{1 2 , 1 0 0}$ & $\mathbf{2 , 9 4 0}$ & $\mathbf{7 , 8 7 0}$ & $\mathbf{6 0 5}$ \\
\hline
\end{tabular}


Table 3.55: Masses of domestic fruits substituting for other fresh fruit, other tropical fruit and frozen fruit.

\begin{tabular}{|l|r|r|r|r|}
\hline \multicolumn{1}{|c|}{ FRUIT } & \multicolumn{1}{c|}{$\%$} & $\begin{array}{r}\text { OTHER } \\
\text { FRESH } \\
\text { FRUIT (T) }\end{array}$ & $\begin{array}{c}\text { OTHER } \\
\text { TROPICAL } \\
\text { FRUIT (T) }\end{array}$ & $\begin{array}{r}\text { FROZEN } \\
\text { FRUIT (T) }\end{array}$ \\
\hline FES totals & 100 & 41,800 & $\mathbf{7 7 , 6 0 0}$ & 5,970 \\
\hline Apples & 63.0 & $\mathbf{2 6 , 3 0 0}$ & $\mathbf{4 8 , 9 0 0}$ & $\mathbf{3 , 7 6 0}$ \\
\hline Apricots & 0.2 & $\mathbf{7 4}$ & $\mathbf{1 3 7}$ & $\mathbf{1 1}$ \\
\hline Blueberries & 8.6 & $\mathbf{3 , 6 5 0}$ & $\mathbf{6 , 7 7 0}$ & $\mathbf{5 2 1}$ \\
\hline Cherries & 1.4 & $\mathbf{5 9 8}$ & $\mathbf{1 , 1 1 0}$ & $\mathbf{8 5}$ \\
\hline Cranberries & 4.5 & $\mathbf{1 , 8 8 0}$ & $\mathbf{3 , 4 8 0}$ & $\mathbf{2 6 8}$ \\
\hline Grapes & 8.7 & $\mathbf{3 , 6 2 0}$ & $\mathbf{6 , 7 3 0}$ & $\mathbf{5 1 8}$ \\
\hline Melons & 1.6 & $\mathbf{6 6 9}$ & $\mathbf{1 , 2 4 0}$ & $\mathbf{9 6}$ \\
\hline Peaches & 3.9 & $\mathbf{1 , 6 5 0}$ & $\mathbf{3 , 0 6 0}$ & $\mathbf{2 3 5}$ \\
\hline Pears & 2.3 & $\mathbf{9 4 1}$ & $\mathbf{1 , 7 5 0}$ & $\mathbf{1 3 4}$ \\
\hline Plums & 0.5 & $\mathbf{1 9 6}$ & $\mathbf{3 6 4}$ & $\mathbf{2 8}$ \\
\hline Raspberries & 1.9 & $\mathbf{7 8 6}$ & $\mathbf{1 , 4 6 0}$ & $\mathbf{1 1 2}$ \\
\hline Strawberries & 3.4 & $\mathbf{1 , 4 1 0}$ & $\mathbf{2 , 6 2 0}$ & $\mathbf{2 0 2}$ \\
\hline
\end{tabular}

Table 3.56 displays the distribution of equivalent masses of various domestic fruit substituting for the amounts of other dried fruit, fruit juices and fruit juices from concentrate, their consumption values shown in the top row. Table 3.57 shows the distribution of equivalent masses of various domestic fruit substituting for other canned fruit and jams, jellies and preserve, with the amounts from the above tables shown in the top row (Cowell \& Parkinson, 2003: 226). The mass totals in bold type from tables $3.45,3.46,3.47,3.51,3.54,3.55$, 3.56, and 3.57 are carried forward to table 3.85 . 
Table 3.56: Masses of domestic fruits substituting for other dried fruit, other fruit juice and concentrated fruit juice.

\begin{tabular}{||l|r|r|r|r||}
\hline \hline FRUIT & \multicolumn{1}{l|}{$\%$} & $\begin{array}{l}\text { OTHER DRIED } \\
\text { FRUIT (T) }\end{array}$ & $\begin{array}{l}\text { OTHER FRUIT } \\
\text { JUICE }(T)\end{array}$ & CONC. JUICE (T) \\
\hline FES totals & 100 & 82,200 & $1,150,000$ & 638,000 \\
\hline Apples & 63.0 & $\mathbf{5 1 , 7 4 7}$ & $\mathbf{7 2 3 , 0 0 0}$ & $\mathbf{4 0 2 , 0 0 0}$ \\
\hline Apricots & 0.2 & $\mathbf{1 4 5}$ & $\mathbf{2 , 0 3 0}$ & $\mathbf{1 , 1 3 0}$ \\
\hline Blueberries & 8.6 & $\mathbf{7 , 1 6 8}$ & $\mathbf{1 0 0 , 0 0 0}$ & $\mathbf{5 5 , 6 0 0}$ \\
\hline Cherries & 1.4 & $\mathbf{1 , 1 7 5}$ & $\mathbf{1 6 , 4 0 0}$ & $\mathbf{9 , 1 2 0}$ \\
\hline Cranberries & 4.5 & $\mathbf{3 , 6 8 5}$ & $\mathbf{5 1 , 5 0 0}$ & $\mathbf{2 8 , 6 0 0}$ \\
\hline Grapes & 8.7 & $\mathbf{7 , 1 2 3}$ & $\mathbf{9 9 , 5 0 0}$ & $\mathbf{5 5 , 3 0 0}$ \\
\hline Melons & 1.6 & $\mathbf{1 , 3 1 6}$ & $\mathbf{1 8 , 4 0 0}$ & $\mathbf{1 0 , 2 0 0}$ \\
\hline Peaches & 3.9 & $\mathbf{3 , 2 3 6}$ & $\mathbf{4 5 , 2 0 0}$ & $\mathbf{2 5 , 1 0 0}$ \\
\hline Pears & 2.3 & $\mathbf{1 , 8 4 9}$ & $\mathbf{2 5 , 8 0 0}$ & $\mathbf{1 4 , 4 0 0}$ \\
\hline Plums & 0.5 & $\mathbf{3 8 5}$ & $\mathbf{5 , 3 8 0}$ & $\mathbf{2 , 9 9 0}$ \\
\hline Raspberries & 1.9 & $\mathbf{1 , 5 4 5}$ & $\mathbf{2 1 , 6 0 0}$ & $\mathbf{1 2 , 0 0 0}$ \\
\hline Strawberries & 3.4 & $\mathbf{2 , 7 7 5}$ & $\mathbf{3 8 , 8 0 0}$ & $\mathbf{2 1 , 5 0 0}$ \\
\hline \hline
\end{tabular}

Table 3.57: Masses of domestic fruits substituting for other canned fruit and jams, jellies and preserves.

\begin{tabular}{|l|r|r|r||}
\hline \multicolumn{1}{|c|}{ FRUIT } & \multicolumn{1}{c|}{$\%$} & $\begin{array}{c}\text { OTHER CANNED } \\
\text { FRUIT }(\mathrm{T})\end{array}$ & $\begin{array}{c}\text { JAMS, JELLIES AND } \\
\text { PRESERVES }(\mathrm{T})\end{array}$ \\
\hline FES totals & 100 & 40,600 & 8,060 \\
\hline Apples & 63.0 & $\mathbf{2 5 , 6 0 0}$ & $\mathbf{5 , 0 8 0}$ \\
\hline Apricots & 0.2 & $\mathbf{7 2}$ & $\mathbf{1 4}$ \\
\hline Blueberries & 8.6 & $\mathbf{3 , 5 4 0}$ & $\mathbf{7 0 3}$ \\
\hline Cherries & 1.4 & $\mathbf{5 8 1}$ & $\mathbf{1 1 5}$ \\
\hline Cranberries & 4.5 & $\mathbf{1 , 8 2 0}$ & $\mathbf{3 6 2}$ \\
\hline Grapes & 8.7 & $\mathbf{3 , 5 2 0}$ & $\mathbf{6 9 9}$ \\
\hline Melons & 1.6 & $\mathbf{6 5 0}$ & $\mathbf{1 2 9}$ \\
\hline Peaches & 3.9 & $\mathbf{1 , 6 0 0}$ & $\mathbf{3 1 8}$ \\
\hline Pears & 2.3 & $\mathbf{9 1 4}$ & $\mathbf{1 8 1}$ \\
\hline Plums & 0.5 & $\mathbf{1 9 0}$ & $\mathbf{3 8}$ \\
\hline Raspberries & 1.9 & $\mathbf{7 6 4}$ & $\mathbf{1 5 2}$ \\
\hline Strawberries & 3.4 & $\mathbf{1 , 3 7 0}$ & $\mathbf{2 7 2}$ \\
\hline
\end{tabular}




\subsubsection{Vegetables}

Canadians enjoy about 200 different fresh, frozen, dried and carıned vegetables (Appendix 1). CANSIM II and AAFC provides data for 22 vegetables under cultivation in Canada in 2001 that closely match those consumed, as listed in the FES, although in the catch-all, "other" categories there are items not grown here that will be accounted for in much the same manner as imported fruit (AAFC, 2009c; StatsCan, 2003b; StatsCan, 2009: survey 001-0013). Also like fruit, domestic consumption is accounted for and a representation of imported vegetables made from the FES (Cowell \& Parkinson, 2003: 226).

There are several field vegetables listed in the FES as a number consumed, rather than as mass, thus requiring conversion. StatsCan publishes the conversion factors it uses for corn, cucumbers and lettuce in annual reports (StatsCan, 2002: 10). The USDA's NASS also publishes conversion factors for cauliflower and celery, as for fruit, above (USDA, 2009: v). The following table relates those vegetables listed numerically in the FES to equivalent mass according to StatsCan and the NASS.

Table 3.58: Calculation of per unit mass for selected fresh vegetables.

\begin{tabular}{|l|c|c|c|}
\hline VEGETABLE & UNIT & $\begin{array}{c}\text { MASS } \\
\text { (KG) }\end{array}$ & $\begin{array}{c}\text { MASS/SINGLE } \\
\text { VEGETABLE (KG) }\end{array}$ \\
\hline Cauliflower & Crate (24 heads) & 22.7 & 0.95 \\
\hline Celery & Crate (3-4 dozen); median 42 & 27.2 & 0.65 \\
\hline Corn & Dozen & 2.7 & 0.23 \\
\hline Cucumber & Dozen & 5.9 & 0.49 \\
\hline Lettuce & Dozen & 6.8 & 0.57 \\
\hline \hline
\end{tabular}

Source: (StatsCan, 2002: 10; USDA, 2009: v) 
There is a range given for celery in table 3.58 of $3-4$ dozen plants per crate; the median is chosen for this calculation. Lettuce is listed in the FES as iceberg lettuce, or head lettuce as in table 3.58 , as well as varieties including romaine, leaf and Boston lettuce. As there is no way to disaggregate the types from the FES quantities (Appendix 1), the value given in the table is used. The conversion factors derived in table 3.58 are applied to the FES quantities (StatsCan, 2003b) in table 3.59 and the resulting mass of each, shown in bold type, is added to domestic consumption in table 3.86 .

Table 3.59: Calculation of the mass of vegetables from initial FES numerical quantities.

\begin{tabular}{|l|c|c|c|}
\hline FES ITEM & $\begin{array}{l}\text { FES STARTING } \\
\text { QUANTITY }(\#)\end{array}$ & $\begin{array}{l}\text { CONVERSION FACTOR } \\
(\text { UNIT/T) }\end{array}$ & $\begin{array}{l}\text { MASS OF } \\
\text { VEGETABLE (T) }\end{array}$ \\
\hline Cauliflower & $47,800,000$ & 0.00095 & $\mathbf{4 5 , 4 0 0}$ \\
\hline Celery & $95,500,000$ & 0.00065 & $\mathbf{6 2 , 1 0 0}$ \\
\hline Corn & $209,000,000$ & 0.00023 & $\mathbf{4 8 , 1 0 0}$ \\
\hline Cucumber & $197,000,000$ & 0.00049 & $\mathbf{9 6 , 6 0 0}$ \\
\hline Lettuce & $269,000,000$ & 0.00057 & $\mathbf{1 5 3 , 0 0 0}$ \\
\hline
\end{tabular}

Most of the vegetables listed in the FES are domestically produced and are accounted for directly, but some require additional or special treatment. The first category is "other leaf and stalk vegetables" and includes such things as asparagus, chard, alfalfa sprouts, Asian vegetables, and fresh herbs. Next is "other seed and gourd vegetables" and this list includes lima beans, okra, squash, zucchini, and Asian vegetables. Finally, "other root vegetables" comprises such things as sweet potatoes, water chestnuts, parsnips, horseradish, ginger and garlic (Appendix 1). These will be apportioned directly against table 3.66 . 
Frozen vegetables include corn, peas, potato products and a catch-all category called "other frozen vegetables" (Appendix 1). The FAO (n.d.: 193-195) states Canadian frozen potatoes lose $40 \%$ of their fresh weight, corn only $10 \%$, and generic frozen vegetables 10\%; these figures will be used, the last value serving for both peas and other vegetables. The weights of the first three are added to the totals for those vegetables. The results for "other vegetables" are apportioned according to the distribution in table 3.66. The initial mass of fresh vegetables that supplied the consumption of frozen vegetables in 2001 is shown in table 3.60. The bolded values are added directly to domestic consumption in table 3.85 , while the total for other frozen vegetables is re-distributed in table 3.68 .

Table 3.60: Mass of vegetables required for frozen vegetables.

\begin{tabular}{|l|c|c|r|}
\hline FES ITEM & $\begin{array}{l}\text { FES STARTING } \\
\text { QUANTITY (KG) }\end{array}$ & $\begin{array}{l}\text { FAO CONVERSION } \\
\text { FACTOR (T/KG) }\end{array}$ & $\begin{array}{l}\text { MASS OF } \\
\text { VEGETABLE (T) }\end{array}$ \\
\hline Corn & $11,900,000$ & 0.0011 & $\mathbf{1 3 , 1 0 0}$ \\
\hline Peas & $17,900,000$ & 0.0011 & $\mathbf{1 9 , 7 0 0}$ \\
\hline Potatoes & $89,600,000$ & 0.0017 & $\mathbf{1 5 2 , 0 0 0}$ \\
\hline Other veg. & $41,800,000$ & 0.0011 & 46,000 \\
\hline
\end{tabular}

There are both dried potatoes and "other dried vegetables" in the FES; the latter includes mostly beans and yam, lotus root, onions, garlic and mushrooms in unknown proportions (Appendix 1). The FAO (n.d.: 272) states the dried mass of vegetables is $15 \%$ of fresh mass, although offers nothing for potatoes specifically. The same conversion factor will be applied to both categories, with the mass of potatoes applied directly to the total for potatoes and the other vegetables apportioned according to table 3.66. After conversion in 
table 3.61 , the mass of fresh potatoes is added to domestic consumption, while the initial mass of other dried vegetables is re-distributed in table 3.68.

Table 3.61: Mass of vegetables from dried potatoes and other dried vegetables.

\begin{tabular}{|l|c|c|c||}
\hline \hline FES ITEM & $\begin{array}{l}\text { FES STARTING } \\
\text { QUANTITY (KG) }\end{array}$ & $\begin{array}{l}\text { FAO CONVERSION } \\
\text { FACTOR (T/KG) }\end{array}$ & $\begin{array}{l}\text { MASS OF VEGETABLE } \\
(T)\end{array}$ \\
\hline $\begin{array}{l}\text { Potatoes - } \\
\text { dried }\end{array}$ & $5,970,000$ & 0.0067 & $\mathbf{4 0 , 0 0 0}$ \\
\hline $\begin{array}{l}\text { Other veg. - } \\
\text { dried }\end{array}$ & $11,900,000$ & 0.0067 & 80,000 \\
\hline
\end{tabular}

Canned vegetables, tomato juice and other vegetable juice are found in the vegetable section of the FES as volume units, i.e. litres, consumed (StatsCan, 2003b) and so must be converted. Canned products must be made with fresh vegetables (Lopez, 1987b: 103) so the yearly consumption conceptually represents a constant demand on the land, even if products may be stored for some time after canning.

Canadian agricultural product regulations mandate minimum net and drained weights for five standardized can sizes making estimation of the mass equivalent reasonably straight-forward. For each item, for each can size produced ${ }^{9}$ the lowest drained weight percentage, i.e. the most conservative estimate, will be adopted, except in the following cases or with the following assumptions. Baked beans uses the lowest net weight, rather than drained weight. Canned corn will be assumed to be kernels, rather than creamed. Drained canned tomatoes are assumed to be Canada Fancy grade $65 \%$ solids (the highest grade) (DOJC, 2009b).

\footnotetext{
${ }^{9}$ Not all vegetables are sold in every can size.
} 
Some 20 vegetables are listed as "other canned vegetables" in the FES, but not all are described in the regulation; the average drained weights (i.e. except baked beans) of those that are regulated will be used. The result will be apportioned against table 3.66 (DOJC, 2009b; StatsCan, 2003b). The FAO (n.d.: 272 ) says US extraction of tomato juice occurs at a rate of $65 \%$ and vegetable juice generally at $60 \%$; the latter will be used for "other juice." In Canada tomato juice is extracted at $90 \%$ efficiency (FAO, n.d.: 194) and although this is not the most conservative choice, it is the most realistic and will be adopted. Table 3.62 lists the consumption items from the FES (StatsCan, 2003b) and the percent mass per unit volume, both in ounces, from the regulation.

Table 3.62: Canned vegetables consumed and mass/volume ratio.

\begin{tabular}{||l|c|}
\hline \hline CANNED ITEM & $\%$ MASS/VOLUME \\
\hline Green or wax beans & $54^{\mathrm{a}}$ \\
\hline Baked beans & $102^{\mathrm{b}}$ \\
\hline Other beans & $60^{\mathrm{c}}$ \\
\hline Corn & $64^{\mathrm{d}}$ \\
\hline Mushrooms & $52^{\mathrm{e}}$ \\
\hline Peas & $61^{\mathrm{f}}$ \\
\hline Tomatoes & $66^{\mathrm{g}}$ \\
\hline Other canned veg. & $60^{\mathrm{h}}$ \\
\hline Tomato juice & 90 \\
\hline Other veg. juice & 60 \\
\hline \hline
\end{tabular}

Notes: a) 14fl.oz., short cut.

b) $28 f$ f.oz., vegetarian beans ( $c f$ pork and beans).

c) $28 f$.oz., lima beans

d) 28 fl.oz., whole kernel in brine.

e) $28 f$ f.oz., stems and pieces.

f) 28 fl.oz., peas.

g) $28 f$ floz., Canada Fancy Grade, $65 \%$ drained solids.

h) Mean of values $a, c, d, e, f$, and $g$, above.

Source: (DOJC, 2009b; Matthews, Phillips \& Augustine, 1980: 297, table 4)

In table 3.63 canned vegetables are transformed from a volume measure to equivalent mass with canned, domestically-produced vegetables added 
directly to table 3.85 and other canned vegetables apportioned against table 3.68 .

Table 3.63: Mass of vegetables required to provide the initial canned volume.

\begin{tabular}{|l|c|c|c|}
\hline \hline FES ITEM & $\begin{array}{l}\text { FES STARTING } \\
\text { QUANTITY }(L)\end{array}$ & $\begin{array}{l}\text { CONVERSION } \\
\text { FACTOR (T/L) }\end{array}$ & $\begin{array}{l}\text { MASS OF } \\
\text { VEGETABLE (T) }\end{array}$ \\
\hline Green or wax beans & $17,900,000$ & 0.00054 & $\mathbf{9 , 6 7 0}$ \\
\hline Baked beans & $23,900,000$ & 0.00102 & $\mathbf{2 4 , 4 0 0}$ \\
\hline Other beans & $23,900,000$ & 0.00060 & $\mathbf{1 4 , 3 0 0}$ \\
\hline Corn & $35,800,000$ & 0.00064 & $\mathbf{2 2 , 9 0 0}$ \\
\hline Mushrooms & $17,900,000$ & 0.00052 & $\mathbf{9 , 3 2 0}$ \\
\hline Peas & $17,900,000$ & 0.00061 & $\mathbf{1 0 , 9 0 0}$ \\
\hline Tomatoes & $89,600,000$ & 0.00066 & $\mathbf{5 9 , 1 0 0}$ \\
\hline Other canned veg. & $23,900,000$ & 0.00060 & 14,300 \\
\hline
\end{tabular}

After determining the mass of fresh vegetables processed into juice in table 3.64 , the value for tomatoes is added to the total consumed in table 3.85 and other vegetable juice is re-distributed in table 3.69.

Table 3.64: Calculation of mass of vegetables required to make an initial volume of juice.

\begin{tabular}{|l|c|c|l|}
\hline \hline FES ITEM & $\begin{array}{l}\text { FES STARTING } \\
\text { QUANTITY }(L)\end{array}$ & $\begin{array}{l}\text { CONVERSION } \\
\text { FACTOR (T/L) }\end{array}$ & $\begin{array}{l}\text { MASS OF } \\
\text { VEGETABLE (T) }\end{array}$ \\
\hline Tomato juice & $41,800,000$ & 0.0011 & $\mathbf{4 6 , 0 0 0}$ \\
\hline Other veg. juice & $65,700,000$ & 0.0017 & 112,000 \\
\hline
\end{tabular}

In the FES pickles include eggs, pimentos, walnuts, onions, olives, beets and different cucumber varieties (Appendix 1). The FAO (n.d.: 195) gives a $90 \%$ extraction rate for "vegetables prepared by vinegar" that will be used for this category, while other literature is silent on the matter (Nip, 2004: 53; 76, table 3.52: Potter \& Hotchkiss, 1998: 271-274). The above-noted mix of pickled items presents a problem with respect to allocation, as it includes eggs and nuts with vegetables. As the solutions are limited without knowing the fraction of each 
constituent, the results of this conversion will simply be apportioned against table 3.66. The transformation of pickles to a final mass is displayed in table 3.65 and the total is re-distributed in table 3.69 .

Table 3.65: Calculation of starting mass of vegetables from an initial volume of pickles.

\begin{tabular}{|l|c|c|c|}
\hline FES ITEM & $\begin{array}{l}\text { FES STARTING } \\
\text { QUANTITY }(L)\end{array}$ & $\begin{array}{l}\text { CONVERSION } \\
\text { FACTOR (T/L) }\end{array}$ & $\begin{array}{l}\text { MASS OF } \\
\text { VEGETABLE }(T)\end{array}$ \\
\hline Pickles & $51,400,000$ & 0.0011 & 56,500 \\
\hline
\end{tabular}

The proportions of domestic vegetables that will replace imports are proportional to the $2001 \mathrm{mix}$ of the produced quantities of asparagus, beansgreen and wax, beans-dry, broccoli, cabbage, carrots, cauliflower, corn (sweet), cucumbers, lettuce, onions, peas, potatoes, and tomatoes (Cowell \& Parkinson, 2003: 226; StatsCan, 2009: survey 001-0013). The distribution is shown in table 3.66. Like fruit, imported vegetables and juiced, canned, frozen, pickled and dried vegetables converted in the tables above are apportioned against the distribution table, 3.66. This begins in table 3.67 , which apportions the FES quantities of various "other" categories, found in the top row, to equivalent domestic consumption. These values are later compiled in table 3.85. Table 3.68 collects the totals from the tables above for other canned, other frozen and other dried vegetables and considers them as domestic consumption. The numbers in bold are then carried to table 3.85 . 
Table 3.66: Calculation of production proportions for vegetables, 2001.

\begin{tabular}{|l|c|c|}
\hline VEGETABLE & 2001 PRODUCTION (T) & $\begin{array}{c}\% \text { OF TOTAL } \\
\text { AREA }\end{array}$ \\
\hline Asparagus & 3,040 & 0.1 \\
\hline Beans (dry) & 300,000 & 4.5 \\
\hline Beans (green) & 47,800 & 0.7 \\
\hline Beets & 20,700 & 0.3 \\
\hline Broccoli & 65,900 & 1.0 \\
\hline Cabbage & 142,000 & 2.1 \\
\hline Carrots & 332,000 & 5.0 \\
\hline Cauliflower & 46,300 & 0.7 \\
\hline Celery & 35,800 & 0.5 \\
\hline Corn & 306,000 & 4.6 \\
\hline Cucumbers & 75,500 & 1.1 \\
\hline Lettuce & 87,700 & 1.3 \\
\hline Mushrooms & 86,400 & 1.3 \\
\hline Onions & 192,000 & 2.9 \\
\hline Parsnips & 4,070 & 0.1 \\
\hline Peas & 74,200 & 1.1 \\
\hline Peppers & 30,700 & 0.5 \\
\hline Potatoes & $4,220,000$ & 63.6 \\
\hline Radishes & 6,790 & 0.1 \\
\hline Spinach & 4,170 & 0.1 \\
\hline Tomatoes & 499,000 & 7.6 \\
\hline Turnips & 52,800 & 0.8 \\
\hline Total & $6,630,000$ & 100 \\
\hline \hline
\end{tabular}

Source: (AAFC, 2009c; StatsCan, 2009: survey 001-0013). 
Table 3.67: Masses of domestic vegetables substituting for other leaf and stalk vegetables, other seed and gourd vegetables, and other root vegetables.

\begin{tabular}{|l|r|r|r|r||}
\hline VEGETABLE & $\begin{array}{l}2001 \\
\text { PLANTED } \\
\text { AREA (\%) }\end{array}$ & $\begin{array}{l}\text { OTHER LEAF } \\
\text { \& STALK } \\
\text { VEG. (T) }\end{array}$ & $\begin{array}{l}\text { OTHER SEED \& } \\
\text { GOURD VEG. (T) }\end{array}$ & $\begin{array}{l}\text { OTHER ROOT } \\
\text { VEG. (T) }\end{array}$ \\
\hline FES totals & 100 & 65,700 & 47,800 & 35,800 \\
\hline Asparagus & 0.1 & $\mathbf{3 0}$ & $\mathbf{2 2}$ & $\mathbf{1 6}$ \\
\hline Beans (dry) & 4.5 & $\mathbf{2 , 9 7 0}$ & $\mathbf{2 , 1 6 0}$ & $\mathbf{1 , 6 2 0}$ \\
\hline Beans (green) & 0.7 & $\mathbf{4 7 3}$ & $\mathbf{3 4 4}$ & $\mathbf{2 5 8}$ \\
\hline Beets & 0.3 & $\mathbf{2 0 5}$ & $\mathbf{1 4 9}$ & $\mathbf{1 1 2}$ \\
\hline Broccoli & 1.0 & $\mathbf{6 5 3}$ & $\mathbf{4 7 5}$ & $\mathbf{3 5 6}$ \\
\hline Cabbage & 2.1 & $\mathbf{1 , 4 0 0}$ & $\mathbf{1 , 0 2 0}$ & $\mathbf{7 6 5}$ \\
\hline Carrots & 5.0 & $\mathbf{3 , 2 8 0}$ & $\mathbf{2 , 3 9 0}$ & $\mathbf{1 , 7 9 0}$ \\
\hline Cauliflower & 0.7 & $\mathbf{4 5 8}$ & $\mathbf{3 3 3}$ & $\mathbf{2 5 0}$ \\
\hline Celery & 0.5 & $\mathbf{3 5 4}$ & $\mathbf{2 5 8}$ & $\mathbf{1 9 3}$ \\
\hline Corn & 4.6 & $\mathbf{3 , 0 3 0}$ & $\mathbf{2 , 2 1 0}$ & $\mathbf{1 , 6 5 0}$ \\
\hline Cucumbers & 1.1 & $\mathbf{7 4 8}$ & $\mathbf{5 4 4}$ & $\mathbf{4 0 8}$ \\
\hline Lettuce & 1.3 & $\mathbf{8 6 9}$ & $\mathbf{6 3 2}$ & $\mathbf{4 7 4}$ \\
\hline Mushrooms & 1.3 & $\mathbf{8 5 5}$ & $\mathbf{6 2 2}$ & $\mathbf{4 6 7}$ \\
\hline Onions & 2.9 & $\mathbf{1 , 9 0 0}$ & $\mathbf{1 , 3 8 0}$ & $\mathbf{1 , 0 4 0}$ \\
\hline Parsnips & 0.1 & $\mathbf{4 0}$ & $\mathbf{2 9}$ & $\mathbf{2 2}$ \\
\hline Peas & 1.1 & $\mathbf{7 3 5}$ & $\mathbf{5 3 4}$ & $\mathbf{4 0 1}$ \\
\hline Peppers & 0.5 & $\mathbf{3 0 4}$ & $\mathbf{2 2 1}$ & $\mathbf{1 6 6}$ \\
\hline Potatoes & 63.6 & $\mathbf{4 1 , 8 0 0}$ & $\mathbf{3 0 , 4 0 0}$ & $\mathbf{2 2 , 8 0 0}$ \\
\hline Radishes & 0.1 & $\mathbf{6 7}$ & $\mathbf{4 9}$ & $\mathbf{3 7}$ \\
\hline Spinach & 0.1 & $\mathbf{4 1}$ & $\mathbf{3 0}$ & $\mathbf{2 3}$ \\
\hline Tomatoes & 7.6 & $\mathbf{4 , 9 4 0}$ & $\mathbf{3 , 5 9 0}$ & $\mathbf{2 , 6 9 0}$ \\
\hline Turnips & 0.8 & $\mathbf{5 2 3}$ & $\mathbf{3 8 0}$ & $\mathbf{2 8 5}$ \\
\hline & & & & \\
\hline
\end{tabular}


Table 3.68: Masses of domestic vegetables substituting for other canned vegetables, other frozen vegetables, and other dried vegetables.

\begin{tabular}{|c|c|c|c|c|}
\hline VEGETABLE & $\begin{array}{l}2001 \\
\text { PLANTED } \\
\text { AREA (\%) }\end{array}$ & $\begin{array}{l}\text { OTHER } \\
\text { CANNED } \\
\text { VEG. (T) }\end{array}$ & $\begin{array}{l}\text { OTHER FROZEN } \\
\text { VEG. } \\
\text { (T) }\end{array}$ & $\begin{array}{l}\text { OTHER } \\
\text { DRIED VEG. } \\
\text { (T) }\end{array}$ \\
\hline FES totals & 100 & 14,300 & 46,000 & 80,000 \\
\hline Asparagus & 0.1 & 7 & 21 & 37 \\
\hline Beans (dry) & 4.5 & 648 & 2,080 & 3,620 \\
\hline Beans (green) & 0.7 & $10 \overline{3}$ & 331 & 576 \\
\hline Beets & 0.3 & 45 & 144 & 250 \\
\hline Broccoli & 1.0 & 142 & 457 & 796 \\
\hline Cabbage & 2.1 & 306 & 981 & 1,710 \\
\hline Carrots & 5.0 & 716 & 2,300 & 4,000 \\
\hline Cauliflower & 0.7 & 100 & 321 & 558 \\
\hline Celery & 0.5 & 77 & 248 & 432 \\
\hline Corn & 4.6 & 662 & 2,120 & 3,700 \\
\hline Cucumbers & 1.1 & 163 & 523 & 911 \\
\hline Lettuce & 1.3 & 190 & 608 & 1,060 \\
\hline Mushrooms & 1.3 & 187 & 599 & 1,040 \\
\hline Onions & 2.9 & 414 & 1,330 & 2,310 \\
\hline Parsnips & 0.1 & 9 & 28 & 49 \\
\hline Peas & 1.1 & 160 & 514 & 895 \\
\hline Peppers & 0.5 & 66 & 213 & 371 \\
\hline Potatoes & 63.6 & 9,120 & 29,300 & 50,900 \\
\hline Radishes & 0.1 & 15 & 47 & 82 \\
\hline Spinach & 0.1 & 9 & 29 & 50 \\
\hline Tomatoes & 7.6 & 1,080 & 3,460 & 6,020 \\
\hline Turnips & 0.8 & 114 & 366 & 637 \\
\hline
\end{tabular}

Finally, other vegetable juice and pickles and apportioned against domestic consumption in table 3.69 , with the equivalent values added to total vegetable consumption in table 3.85 . 
Table 3.69: Masses of domestic vegetables substituting for other vegetable juice and pickles.

\begin{tabular}{|l|r|r|r||}
\hline VEGETABLE & $\begin{array}{l}\text { 2001 PLANTED } \\
\text { AREA (\%) }\end{array}$ & $\begin{array}{l}\text { OTHER VEG. } \\
\text { JUICE (T) }\end{array}$ & PICKLES. (T) \\
\hline Total & 100 & 112,000 & 56,500 \\
\hline Asparagus & 0.1 & $\mathbf{5 1}$ & $\mathbf{2 6}$ \\
\hline Beans (dry) & 4.5 & $\mathbf{5 , 0 5 0}$ & $\mathbf{2 , 5 6 0}$ \\
\hline Beans (green) & 0.7 & $\mathbf{8 0 4}$ & $\mathbf{4 0 7}$ \\
\hline Beets & 0.3 & $\mathbf{3 4 9}$ & $\mathbf{1 7 7}$ \\
\hline Broccoli & 1.0 & $\mathbf{1 , 1 1 0}$ & $\mathbf{5 6 2}$ \\
\hline Cabbage & 2.1 & $\mathbf{2 , 3 8 0}$ & $\mathbf{1 , 2 1 0}$ \\
\hline Carrots & 5.0 & $\mathbf{5 , 5 8 0}$ & $\mathbf{2 , 8 3 0}$ \\
\hline Cauliflower & 0.7 & $\mathbf{7 7 9}$ & $\mathbf{3 9 4}$ \\
\hline Celery & 0.5 & $\mathbf{6 0 3}$ & $\mathbf{3 0 5}$ \\
\hline Corn & 4.6 & $\mathbf{5 , 1 6 0}$ & $\mathbf{2 , 6 1 0}$ \\
\hline Cucumbers & 1.1 & $\mathbf{1 , 2 7 0}$ & $\mathbf{6 4 3}$ \\
\hline Lettuce & 1.3 & $\mathbf{1 , 4 8 0}$ & $\mathbf{7 4 8}$ \\
\hline Mushrooms & 1.3 & $\mathbf{1 , 4 5 0}$ & $\mathbf{7 3 6}$ \\
\hline Onions & 2.9 & $\mathbf{3 , 2 3 0}$ & $\mathbf{1 , 6 3 0}$ \\
\hline Parsnips & 0.1 & $\mathbf{6 8}$ & $\mathbf{3 5}$ \\
\hline Peas & 1.1 & $\mathbf{1 , 2 5 0}$ & $\mathbf{6 3 2}$ \\
\hline Peppers & 0.5 & $\mathbf{5 1 7}$ & $\mathbf{2 6 2}$ \\
\hline Potatoes & 63.6 & $\mathbf{7 1 , 1 0 0}$ & $\mathbf{3 6 , 0 0 0}$ \\
\hline Radishes & 0.1 & $\mathbf{1 1 4}$ & $\mathbf{5 8}$ \\
\hline Spinach & 0.1 & $\mathbf{7 0}$ & $\mathbf{3 6}$ \\
\hline Tomatoes & 7.6 & $\mathbf{8 , 4 0 0}$ & $\mathbf{4 , 2 5 0}$ \\
\hline Turnips & 0.8 & $\mathbf{8 8 9}$ & $\mathbf{4 5 0}$ \\
\hline \hline
\end{tabular}

\subsubsection{Margarine, fats, and oils}

The final FES category to be considered comprises lard, margarine, shortening, and cooking/salad oil (Appendix 1). Lard is "meat scraps" heated in vats of water until the fat melts and floats to the surface in a process called rendering (Potter \& Hotchkiss, 1998: 365). In Canada, Federal regulations state lard must be rendered from hogs (DOJC, 2009c). The FAO (n.d.: 196) states Canadian slaughter hog yield just over $6 \mathrm{~kg}$ fat per head, or 130,000 tonnes in 2001 (StatsCan, 2009: survey 003-0028). Lard represented less than 3\% of fat 
consumed as an agri-food product in Canada in 2001 (StatsCan, 2003b), which was easily produced through the above-noted yield of hogs; thus the data will not be included to avoid potential double-counting.

Fats and oils are derived from plants and terrestrial and marine animals. The choice for any given use may depend on an imparted flavour, perceived health benefit, or possessed functional characteristic, but in the globalized market is more likely dependant on cost and availability. Most fats and oils can be substituted for one another (Potter \& Hotchkiss, 1998: 361, 363), so the method of comparison is straight-forward.

Margarine and shortening are somewhat functionally interchangeable, which is not surprising since they are manufactured in much the same way (Potter \& Hotchkiss, 1998: 372, 374). Since shortening, like lard, only represents about $3 \%$ of fats consumed it will be combined with margarine for this analysis. Margarine is made from vegetable oil that has been hydrogenated to raise its melting point above room temperature and is then used as the basis for a waterin-oil emulsion not unlike butter, as described above on page 72 (Potter \& Hotchkiss, 1998: 371, 373). Margarine (and shortening) will be converted to an equivalent volume of oil, which will, in turn, be apportioned against the sources of its production.

The density of Canadian-produced oils must be found to convert the mass of margarine into a volume measure that can be applied against the average extraction rate. Table 3.70 shows the density ranges and their medians for corn, 
soybean, and sunflower oils acceptable in Canada (DOJC, 2009c). The value for corn and sunflower, $0.921 \mathrm{~kg} / \mathrm{L}$, is representative of the densities found in this table and is selected.

Table 3.70: Calculation of oil density.

\begin{tabular}{|l|c|c|}
\hline \hline ITEM & DENSITY (KG/L) & MEDIAN (KG/L) \\
\hline Corn & $0.917-0.925$ & 0.921 \\
\hline Soybean & $0.919-0.925$ & 0.922 \\
\hline Sunflower & $0.918-0.923$ & 0.921 \\
\hline
\end{tabular}

Source: (DOJC, 2009C)

Table 3.71 shows the extraction rates for Canadian-grown oil crops and the weighted mean of the rate (FAO, n.d. 193, 194), which will be used for both margarine and for the FES cooking/salad oil category.

Table 3.71: Calculation of extraction rate for vegetable oil.

\begin{tabular}{|l|c|c|c|}
\hline OILSEED & $\begin{array}{c}2001 \text { PRODUCTION } \\
(\%)\end{array}$ & $\begin{array}{c}\text { EXTRACTION RATE } \\
(\%)\end{array}$ & $\begin{array}{l}\text { WEIGHTED } \\
\text { RATE }(\%)\end{array}$ \\
\hline Canola & 33 & 41 & 13.5 \\
\hline Corn (grain) & 55 & 45 & 24.8 \\
\hline Soybean & 11 & 17 & 1.9 \\
\hline Sunflower & 1 & 41 & 0 \\
\hline Total & 100 & $\mathrm{n} / \mathrm{a}$ & 40.2 \\
\hline
\end{tabular}

Source: (FAO, n.d.: 193, 194; StatsCan, 2009: survey 001-0010)

The regulated minimum oil content, $80 \%$, multiplied by the density from table $3.70,0.921 \mathrm{~kg} / \mathrm{L}$, provides the conversion factor in table 3.72 .

Table 3.72: Volume of oil from initial mass of margarine and shortening.

\begin{tabular}{|l|c|c|c|}
\hline FES ITEM & $\begin{array}{l}\text { FES STARTING } \\
\text { QUANTITY (KG) }\end{array}$ & $\begin{array}{l}\text { CONVERSION } \\
\text { FACTOR } \\
(\text { L/KG) }\end{array}$ & $\begin{array}{l}\text { VOLUME OF } \\
\text { VEGETABLE } \\
\text { OIL (L) }\end{array}$ \\
\hline Margarine & $102,000,000$ & 0.736 & $59,800,000$ \\
\hline Shortening & $5,970,000$ & 0.736 & $3,520,000$ \\
\hline Total fats as oils & $108,000,000$ & 0.736 & $63,300,000$ \\
\hline
\end{tabular}


The total volume of oil from table 3.72 is added with the consumed volume of salad/cooking oil from the FES (StatsCan, 2003b) and the inverse of the weighted extraction rate from table 3.71 is applied. This is shown in table 3.73.

Table 3.73: Calculation of masses of oilseeds from oil volumes.

\begin{tabular}{|l|c|c|c|}
\hline \multicolumn{1}{|c|}{ FES ITEM } & $\begin{array}{c}\text { FES STARTING } \\
\text { QUANTITY (L) }\end{array}$ & $\begin{array}{c}\text { CONVERSION } \\
\text { FACTOR (T/L) }\end{array}$ & $\begin{array}{c}\text { MASS OF } \\
\text { OILSEEDS (T) }\end{array}$ \\
\hline $\begin{array}{l}\text { Total fats as oils } \\
\text { (table 3.72), }\end{array}$ & $63,300,000$ & 0.0025 & 158,000 \\
\hline Salad or cooking oils & $77,600,000$ & 0.0025 & 194,000 \\
\hline Total & $141,000,000$ & 0.0025 & 352,000 \\
\hline
\end{tabular}

The mass of oil-bearing seeds from table 3.73 is apportioned against the quantities of Canadian-produced oilseeds in proportions shown in the following table.

Table 3.74: Calculation of production proportions for oilseeds, 2001.

\begin{tabular}{|l|c|c|}
\hline \hline ITEM & 2001 PRODUCTION (T) & \% OF TOTAL PRODUCED \\
\hline Canola & $5,020,000$ & 33 \\
\hline Corn & $8,390,000$ & 55 \\
\hline Soybean & $1,640,000$ & 11 \\
\hline Sunflower & 104,000 & 1 \\
\hline Total & $15,100,000$ & 100 \\
\hline
\end{tabular}

Source: (StatsCan, 2009: survey 001-0010)

The fractions of domestically-produced canola, corn, soybean, and sunflower from table 3.74 are applied against the total amount of oil consumed from table 3.73 and shown in table 3.75. The totals, displayed in bold, are added directly to total consumption in table 3.83 to find the cropping area. 
Table 3.75: Masses of domestic oil crops used in the manufacture cooking/salad oil and margarine.

\begin{tabular}{|l|c|c|}
\hline \multicolumn{1}{|c|}{ OIL CROP } & \% OF TOTAL & OILSEEDS (T) \\
\hline Total (table 3.73) & 100 & 352,000 \\
\hline Canola & 33 & $\mathbf{1 1 7 , 0 0 0}$ \\
\hline Corn & 55 & $\mathbf{1 9 5 , 0 0 0}$ \\
\hline Soybean & 11 & $\mathbf{3 8 , 0 0 0}$ \\
\hline Sunflower & 1 & $\mathbf{2 , 4 1 0}$ \\
\hline
\end{tabular}

\subsubsection{Area for animal feed requirements}

The 2001 feed requirements for animals, poultry and fish were estimated by StatsCan based on information from the actual 1999 feed used, Provincial livestock experts, feed producers, marketing boards, and the Animal Nutrition Association of Canada (StatsCan, 2005b: 73, table 23K). These coefficients were reported as tornes per year for wheat, oats, barley, corn, dry peas, soy and canola meal, pasture, dry hay, and silage. Listed without further explanation are "other small grains," which will be interpreted as the "mixed grains" category from the CANSIM II database (StatsCan, 2009: survey 001-0010) and "other roughages," which will be added to hay. Mill screen is also part of the diet, but is accounted for as the by-product of flour production.

Consideration must be made that the production of veal may require the feeding of an additional, maternal parent. ${ }^{10}$ Cows and bulls are put together in the spring or early summer; if a cow becomes pregnant, it is fed over the winter until the calf is born early in the next year. If it does not, the cow will be sold for

\footnotetext{
${ }^{10}$ As a bull services many females, its contribution to each calf is minimal (Cowell \& Parkinson, 2003: 234, footnote 4).
} 
slaughter (Canadian Cattlemen's Association, n.d.). It is therefore assumed that for every calf, an additional heifer was fed for one year. However, as mentioned previously, dairy cattle are impregnated to ensure lactation (Ontario Veal Association, 2003); therefore, the number of calves slaughtered for veal plus the number of replacement dairy calves is compared against the dairy cows required. If the number of calves is less, it will be assumed all the 2001 Canadian consumption was met from this source; this is realistic since users of a sustainable system will make use of all available materials before producing new materials. If the number of calves exceeds the number of dairy cows, area for feeding beef heifers equal to the difference will added. Some 1.07 million dairy heifers were on farms in Canada in 2001, while replacement calves numbered nearly 520,000 and the number slaughtered for consumption was calculated in table 3.6 is about 101,000 (StatsCan, 2009: survey 003-0032. Therefore, veal consumption is met by the dairy herd in excess of the required replacements.

The numbers of animals fed to support Canadians in 2001 found in sections 3.1.1, 3.1.2, and 3.1.3 are compiled in the following series of tables. Table 3.76 displays barley, corn, and wheat in tonnes. The totals in bold type are added directly to domestic consumption, but the others must undergo further transformation. Oats and mixed grains are not fed to pigs, chickens, turkeys, or fish and are omitted from table 3.77, which shows the quantities that supported the other animals. Table 3.78 shows tonnes of legumes and canola, which was fed to all animals. 
Table 3.76: Barley, corn, and wheat grown to support 2001 Canadian meat, dairy and fish consumption.

\begin{tabular}{|l|r|r|r|r|}
\hline \hline ANIMAL & NUMBER FED & \multicolumn{1}{|c|}{ BARLEY (T) } & CORN (T) & WHEAT (T) \\
\hline Beef cattle & $2,240,000$ & $2,150,000$ & 382,000 & 78,200 \\
\hline Calves & 101,000 & 8,180 & 48,200 & 1,110 \\
\hline Dairy cattle & 479,000 & 358,000 & 24,900 & 436,000 \\
\hline Sheep & 620,000 & 16,100 & 3,100 & 620 \\
\hline Swine & $7,860,000$ & 574,000 & 944,000 & 220,000 \\
\hline $\begin{array}{l}\text { Chickens } \\
\text { (layers) }\end{array}$ & $12,200,000$ & 0 & 125,000 & 138,000 \\
\hline $\begin{array}{l}\text { Chickens } \\
\text { (broilers) }\end{array}$ & $305,000,000$ & 91,600 & 428,000 & 214,000 \\
\hline Turkeys & $9,720,000$ & 0 & 68,100 & 51,500 \\
\hline Aquaculture & $36,000,000$ & 0 & 0 & 21,600 \\
\hline \multicolumn{1}{r|}{ Total } & n/a & $\mathbf{3 , 2 0 0 , 0 0 0}$ & $\mathbf{2 , 0 2 0 , 0 0 0}$ & $\mathbf{1 , 1 6 0 , 0 0 0}$ \\
\hline
\end{tabular}

Table 3.77: Mixed grain and oats grown to support 2001 Canadian meat, dairy and fish consumption.

\begin{tabular}{||l|r|c|r|}
\hline ANIMAL & NUMBER FED & MIXED GRAIN (T) & OATS (T) \\
\hline Beef cattle & $2,240,000$ & 53,700 & 841,000 \\
\hline Calves & 101,000 & 101 & 8,380 \\
\hline Dairy cattle & 479,000 & 24,900 & 9,570 \\
\hline Sheep & 620,000 & 620 & 3,720 \\
\hline Swine & $7,860,000$ & 0 & 0 \\
\hline Total & n/a & $\mathbf{7 9 , 3 0 0}$ & $\mathbf{8 6 2 , 0 0 0}$ \\
\hline
\end{tabular}

Table 3.78: Legumes and canola grown to support 2001 Canadian meat, dairy and fish consumption.

\begin{tabular}{|l|r|r|r|r|}
\hline \multicolumn{1}{|c|}{ ANIMAL } & NUMBER FED & CANOLA MEAL (T) & PEAS (T) & $\begin{array}{r}\text { SOYBEAN } \\
\text { MEAL (T) }\end{array}$ \\
\hline Beef cattle & $2,240,000$ & 58,100 & 51,400 & 130,000 \\
\hline Calves & 101,000 & 2,520 & 606 & 5,450 \\
\hline Dairy cattle & 479,000 & 45,500 & 1,440 & 127,000 \\
\hline Sheep & 620,000 & 620 & 620 & 1,240 \\
\hline Swine & $7,860,000$ & 94,400 & 55,000 & 252,000 \\
\hline Chickens - layers & $12,200,000$ & 25,600 & 0 & 41,500 \\
\hline $\begin{array}{l}\text { Chickens - } \\
\text { broilers }\end{array}$ & $305,000,000$ & 30,500 & 0 & 153,000 \\
\hline Turkeys & $9,720,000$ & 5,830 & 0 & 36,000 \\
\hline Aquaculture & $36,000,000$ & 0 & 0 & 8,790 \\
\hline Total & $\mathrm{n} / \mathrm{a}$ & 263,000 & $\mathbf{1 0 9 , 0 0 0}$ & $\mathbf{7 5 4 , 0 0 0}$ \\
\hline
\end{tabular}


Peas are added directly to their consumption total for vegetables, but soybean and canola meals must be further converted to their equivalent whole masses, which are then added to domestic consumption in table 3.83. The inverse of the soybean meal extraction rate of $76 \%$ and the canola rate of $61 \%$ provide the final values (FAO, n.d.: 194), as shown in table 3.79.

Table 3.79: Calculation of mass of canola and soybeans required to supply animal feed meal.

\begin{tabular}{|l|c|c|c||}
\hline MEAL TYPE & $\begin{array}{l}\text { QUANTITY } \\
\text { FROM TABLE } \\
3.78(\mathrm{~T})\end{array}$ & $\begin{array}{l}\text { CONVERSION } \\
\text { FACTOR } \\
\text { (UNITLESS) }\end{array}$ & $\begin{array}{l}\text { MASS OF } \\
\text { SEEDS OR } \\
\text { BEANS (T) }\end{array}$ \\
\hline Canola meal & 263,000 & 1.64 & $\mathbf{4 3 2 , 0 0 0}$ \\
\hline Soybean meal & 754,000 & 1.32 & $\mathbf{9 9 6 , 0 0 0}$ \\
\hline
\end{tabular}

The production of soybean and canola meal is also a by-product of food oil extraction or vice versa. Since the amounts of these crops required for animal feed exceed those required for the extraction of food oil, the oil for human use is dropped from the calculation to avoid double-counting.

An alternative storage method for grain involves harvesting the entire plant, cutting it finely and packing it quickly in air-tight structures to undergo anaerobic lactic acid fermentation. Fermentation lasts from three to four weeks, after which the $\mathrm{pH}$ of the environment is too low for microbial activity, thus preserving the feed (Tremblay, 2008: 1). This is called silage and in Canada in 2001 over $85 \%$ of cereals devoted to silage was barley (Helm \& Salmon, 2002: 1). This grain is preferred because of the higher average quality of the finished product noted by producers, but other grains used include corn, oats, and triticale (a hybrid of wheat and rye) (Helm \& Salmon, 2002: 1). 
According to AAFC (2009d), of some 21 million hectares of land devoted to grazing beef and dairy cattle and sheep ${ }^{11} 6$ million hectares is planted forage, or tame hay, and the rest is wild rangeland. As accurate yield data for wild plants are not readily available, the total area of pasture land will be determined by applying the yield for tame hay.

Table 3.80 shows the hay and pasture forage, added directly to tame hay consumption in table 3.83 , and the silage consumed by cattle and sheep. Silage requires further transformation.

Table 3.80: Hay, pasture and silage required to support 2001 Canadian meat and dairy consumption.

\begin{tabular}{|l|r|r|r|r||}
\hline \multicolumn{1}{|c|}{ ANIMAL } & NUMBER FED & $\overline{\text { DRY HAY }}(\mathrm{T})$ & PASTURE $(T)$ & SILAGE (T) \\
\hline Beef cattle & $2,240,000$ & 919,000 & $2,700,000$ & $2,720,000$ \\
\hline Calves & 101,000 & 4,950 & 16,400 & 2,520 \\
\hline Dairy cattle & 479,000 & 492,000 & 156,000 & $1,420,000$ \\
\hline Sheep & 620,000 & 146,000 & 106,000 & 21,300 \\
\hline Total & $\mathrm{n} / \mathrm{a}$ & $\mathbf{1 , 5 6 0 , 0 0 0}$ & $\mathbf{3 , 0 0 0 , 0 0 0}$ & $4,170,000$ \\
\hline
\end{tabular}

For silage, a weighted average of the 2001 produced masses for barley, corn, and oats is applied against the silage requirement to apportion the share to each grain. As silage yields are not available from StatsCan (2009), studies conducted at an Alberta research farm provide a series of yield results for these grains grown under optimum conditions that are applied against their respective shares of silage (Baron, Okine \& Dick, 2000: table $1 \&$ table 6b). Table 3.81 shows the areas and resulting percent share. Barley, corn, and oats are applied directly to table 3.83 .

\footnotetext{
"The remaining animals of concern here do not utilize pasture (StatsCan, 2005b).
} 
Table 3.81: Calculation of production proportions for silage crops, 2001.

\begin{tabular}{|l|c|c|}
\hline SILAGE & 2001 PRODUCTION (T) & \% OF TOTAL PRODUCTION \\
\hline Barley & $10,800,000$ & 55 \\
\hline Corn & $6,080,000$ & 31 \\
\hline Oats & $2,690,000$ & 14 \\
\hline Total & $19,600,000$ & 100 \\
\hline
\end{tabular}

Source: (StatsCan, 2009: survey 001-0010)

The area of grains required to produce the silage requirement determined in table 3.80 is calculated in table 3.82 and added to the total for that crop when cereals, legumes, and oilseed crops area gathered in table 3.83 .

Table 3.82: Distribution of production required for silage crops.

\begin{tabular}{|l|c|r||}
\hline GRA.IN & \% OF TOTAL PRODUCTION & SILAGE (T) \\
\hline Silage & 100 & $\mathbf{4 , 1 7 0 , 0 0 0}$ \\
\hline Barley & 55 & $\mathbf{2 , 3 1 0 , 0 0 0}$ \\
\hline Corn & 31 & $\mathbf{1 , 2 9 0 , 0 0 0}$ \\
\hline Oats & 14 & $\mathbf{5 7 2 , 0 0 0}$ \\
\hline
\end{tabular}

Source: (StatsCan, 2009: survey 001-0010)

\subsection{Calculation of areas required to support 2001 household food consumption}

The total masses of primary crops, the collection of all the bolded values from the tables in section 3.1 , are found in tables $3.83,3.84$, and 3.85 . The final areas that support domestic consumption are found by dividing the mass totals for each crop by the 2001 Canadian yields, as found in StatsCan (2009) and FAO (2009) resources. Table 3.83 shows the cereals, legumes, and oilseeds grown to support livestock production separately from those grown to supply people directly with those vegetable products. The total required area in table 3.83 is found by summing those columns (not shown) and applying the appropriate 
yield. The corn listed in table 3.83 is grain corn, which is accounted as animal feeds, as a source of cooking oil, for processed grain foods like breakfast cereals, and as the substitute for grains not grown in Canada, particularly rice.

Table 3.83: Final area calculations for 2001 consumption of cereals, legumes and oilseeds.

\begin{tabular}{|l|r|r|r|r||}
\hline \hline CROP & $\begin{array}{l}\text { TOTALS FOR } \\
\text { ANIMAL NEEDS } \\
\text { FROM TABLES } \\
(T)\end{array}$ & $\begin{array}{l}\text { TOTALS FOR } \\
\text { HUMAN NEEDS } \\
\text { FROM FES \& } \\
\text { TABLES (T) }\end{array}$ & $\begin{array}{l}\text { CROP } \\
\text { YIELDS } \\
(T / H A)\end{array}$ & $\begin{array}{l}\text { TOTAL AREA } \\
(\mathrm{HA})\end{array}$ \\
\hline Barley & $3,200,000$ & 120,000 & 2.6 & $\mathbf{1 , 2 8 0 , 0 0 0}$ \\
\hline Barley (silage) & $2,310,000$ & $\mathrm{n} / \mathrm{a}$ & 11.7 & $\mathbf{1 9 8 , 0 0 0}$ \\
\hline Canola & 432,000 & See 3.1 .7 & 1.3 & $\mathbf{3 3 2 , 0 0 0}$ \\
\hline Corn (grain) & $2,020,000$ & 288,000 & 6.6 & $\mathbf{4 4 2 , 0 0 0}$ \\
\hline Corn (silage) & $1,290,000$ & $\mathrm{n} / \mathrm{a}$ & 14.1 & $\mathbf{9 1 , 6 0 0}$ \\
\hline $\begin{array}{l}\text { Dry hay } \\
\text { (and pasture) }\end{array}$ & $4,540,000$ & $\mathrm{n} / \mathrm{a}$ & 3.1 & $\mathbf{1 , 4 9 0 , 0 0 0}$ \\
\hline Mixed grains & 79,300 & 0 & 2.8 & $\mathbf{2 8 , 3 0 0}$ \\
\hline Oats & 862,000 & 29,700 & 2.2 & $\mathbf{4 4 9 , 0 0 0}$ \\
\hline Oats (silage) & 572,000 & $\mathrm{n} / \mathrm{a}$ & 13.1 & $\mathbf{4 3 , 7 0 0}$ \\
\hline Rye & 0 & 2,520 & 1.9 & $\mathbf{1 , 3 3 0}$ \\
\hline Soybean & 996,000 & See 3.1 .7 & 1.5 & $\mathbf{6 6 4 , 0 0 0}$ \\
\hline Sunflower & 0 & 2,410 & 1.6 & $\mathbf{1 , 5 6 0}$ \\
\hline Wheat & $1,160,000$ & $1,170,000$ & 1.9 & $\mathbf{1 , 2 3 0 , 0 0 0}$ \\
\hline Total & $17,500,000$ & $1,610,000$ & $\mathrm{n} / \mathrm{a}$ & $\mathbf{6 , 2 7 0 , 0 0 0}$ \\
\hline
\end{tabular}

NOTES: i) n/a - not applicable.

ii) totals may not add due to rounding.

For tables 3.84 and 3.85 all of the primary crops listed are produced for human consumption with the exception of peas, which includes those used for livestock. The total areas are carried forward to the following section, where the final results are presented and discussed. The corn required to support consumption determined in section 3.1.6, vegetables, is listed in table 3.85 as sweet corn. 
Table 3.84: Final area calculations for 2001 fruit consumption.

\begin{tabular}{|l|r|r|r||}
\hline FRUIT & $\begin{array}{l}\text { TOTALS FROM } \\
\text { FES \& TABLES (T) }\end{array}$ & $\begin{array}{l}\text { CROP } \\
\text { YIELDS } \\
(\text { T/HA })\end{array}$ & \multicolumn{1}{l|}{$\begin{array}{l}\text { TOTAL AREA } \\
(\mathrm{HA})\end{array}$} \\
\hline Apples & $2,200,000$ & 8.4 & $\mathbf{2 6 2 , 0 0 0}$ \\
\hline Apricots & 4,840 & 6.6 & $\mathbf{7 3 3}$ \\
\hline Blueberries & 239,000 & 1.5 & $\mathbf{1 5 9 , 0 0 0}$ \\
\hline Cherries & 39,100 & 5.8 & $\mathbf{6 , 7 5 0}$ \\
\hline Cranberries & 123,000 & 14.6 & $\mathbf{8 , 4 1 0}$ \\
\hline Grapes & 370,000 & 6.4 & $\mathbf{5 7 , 8 0 0}$ \\
\hline Melons & 338,000 & 22.6 & $\mathbf{1 5 , 0 0 0}$ \\
\hline Peaches & 169,000 & 9.3 & $\mathbf{1 8 , 1 0 0}$ \\
\hline Pears & 127,000 & 11.1 & $\mathbf{1 1 , 5 0 0}$ \\
\hline Plums & 36,700 & 4.5 & $\mathbf{8 , 1 6 0}$ \\
\hline Raspberries & 51,500 & 3.8 & $\mathbf{1 3 , 5 0 0}$ \\
\hline Strawberries & 125,000 & 4.4 & $\mathbf{2 8 , 4 0 0}$ \\
\hline Total & $3,820,000$ & $\mathrm{n} / \mathrm{a}$ & $\mathbf{5 8 9 , 0 0 0}$ \\
\hline
\end{tabular}

NOTES: i) n/a - not applicable.

ii) totals may not add due to rounding. 
Table 3.85: Final area calculations for 2001 vegetable consumption.

\begin{tabular}{||l|c|r|r||}
\cline { 2 - 4 } & $\begin{array}{l}\text { TOTALS FROM } \\
\text { FES \& TABLES (T) }\end{array}$ & $\begin{array}{l}\text { CROP YIELDS } \\
(T / H A)\end{array}$ & $\begin{array}{r}\text { REQUIRED } \\
\text { AREA (HA) }\end{array}$ \\
\hline Asparagus & 210 & 2.4 & $\mathbf{8 7}$ \\
\hline Beans (dry) & 59,400 & 1.8 & $\mathbf{3 3 , 7 0 0}$ \\
\hline Beans (green) & 30,900 & 4.3 & $\mathbf{7 , 1 8 0}$ \\
\hline Beets & 1,430 & 18.6 & $\mathbf{7 7}$ \\
\hline Broccoli & 124,000 & 8.0 & $\mathbf{1 5 , 5 0 0}$ \\
\hline Cabbage & 63,500 & 24.5 & $\mathbf{2 , 5 9 0}$ \\
\hline Carrots & 190,000 & 35.4 & $\mathbf{5 , 3 7 0}$ \\
\hline Cauliflower & 48,600 & 16.4 & $\mathbf{2 , 9 6 0}$ \\
\hline Celery & 64,600 & 45.6 & $\mathbf{1 , 4 2 0}$ \\
\hline Corn (sweet) & 105,000 & 9.2 & $\mathbf{1 1 , 4 0 0}$ \\
\hline Cucumbers & 102,000 & 14.9 & $\mathbf{6 , 8 3 0}$ \\
\hline Lettuce & 159,000 & 25.1 & $\mathbf{6 , 3 4 0}$ \\
\hline Mushrooms & 57,100 & 217.0 & $\mathbf{2 6 3}$ \\
\hline Onions & 168,000 & 36.0 & $\mathbf{4 , 6 8 0}$ \\
\hline Parsnips & 281 & 14.6 & $\mathbf{1 9}$ \\
\hline Peas & 145,000 & 4.4 & $\mathbf{3 2 , 9 0 0}$ \\
\hline Peppers & 67,800 & 12.2 & $\mathbf{5 , 5 6 0}$ \\
\hline Potatoes & $1,090,000$ & 25.0 & $\mathbf{4 3 , 7 0 0}$ \\
\hline Radishes & 12,400 & 6.9 & $\mathbf{1 , 8 0 0}$ \\
\hline Spinach & 12,200 & 6.6 & $\mathbf{1 , 8 5 0}$ \\
\hline Tomatoes & 313,000 & 52.3 & $\mathbf{5 , 9 8 0}$ \\
\hline Turnips & 33,500 & 23.7 & $\mathbf{1 , 4 1 0}$ \\
\hline Total & $2,850,000$ & $\mathrm{n} / \mathrm{a}$ & $\mathbf{1 9 2 , 0 0 0}$ \\
\hline \hline
\end{tabular}

NOTES: i) $n / a-$ not applicable.

ii) totals may not add due to rounding. 


\subsection{Results and discussion}

The areas actually under cultivation in 2001 for each crop are found in StatsCan (2009) and FAO (2009) resources. The self-sufficiency indicator (SSI) is found by determining the ratio of the areas actually under cultivation for primary agricultural production in Canada to those conceptually required to fulfill the dietary demands of its citizens. This is done for the consumption pattern evinced by the 2001 food expenditure survey (FES), as determined above.

\subsection{The areas of Canadian self-sufficiency}

In 2001, Canada had approximately 50,000,000 hectares of land suitable to agriculture, or about 5\% of the total land mass (Hoffman et al., 2005: 4; 5, table 1; Kissinger \& Rees, 2009: 2310). At that time, about $65 \%$ of that land, some $32,000,000$ hectares, was under cultivation for cereals, legumes, and oilseeds (StatsCan, 2009). Table 4.1 shows the SSI results for these crops.

Table 4.1: Final areas for cereals, legumes and oilseeds, 2001.

\begin{tabular}{|l|c|c|r|}
\hline \hline CROP & CONSUMPTION AREA (HA) & PRODUCTION AREA (HA) & SSI \\
\hline Barley & $1,470,000$ & $4,700,000$ & 3.2 \\
\hline Canola & 332,000 & $3,830,000$ & 11.5 \\
\hline Corn & 442,000 & $1,290,000$ & 2.9 \\
\hline Hay \& pasture & $1,490,000$ & $7,660,000$ & 5.2 \\
\hline Mixed grains & 28,300 & 364,000 & 12.9 \\
\hline Oats & 449,000 & $1,910,000$ & 4.3 \\
\hline Rye & 1,330 & 181,000 & 137 \\
\hline Soybean & 664,000 & $1,080,000$ & 1.6 \\
\hline Sunflower & 1,560 & 72,800 & 46.7 \\
\hline Wheat & $1,230,000$ & $11,000,000$ & 8.9 \\
\hline Total & $6,100,000$ & $32,000,000$ & 5.3 \\
\hline
\end{tabular}

NOTE: numbers may not add due to rounding. 
Table 4.1 shows that after conceptually supplying Canadian food consumption over five times the land in question supports crops destined for other uses, mostly trade, but also building materials, biofuels, bioplastics, and other novel uses (Junkins et al., 2005: 18). This is unsurprising since Canada is a major supplier of agricultural products to the world market, in 2001 especially as the largest exporter of oats and canola, second-largest of wheat, third of rye, and fifth of barley (FAO, 2009); exports of raw grain crops alone accounted for $15 \%$ of the value of all exports of domestic agri-food products in 2001 (Industry Canada, 2008).

Since calculation of the SSI for crops is in part a function of market forces at work within the country, with respect that conceptually required areas are extrapolated from existing producer choices, and country-specific yields, it can be more illustrative of the usage of productive lands than methods better suited to cross-country comparison. In their application of the EF to Prairie agriculture, Kissinger and Rees find $62 \%$ of cropland and about $45 \%$ of meat footprints, totalling about 28 million hectares or half of the total footprint, are exported ${ }^{12}$ (2009: 2312-2313). However, this is not a real area and danger exists that if it is seen that way then, for example, efforts to make Prairie agriculture more sustainable may be equally directed towards influencing Canadian consumption patterns as towards increasing the food security of those nations dependant on Canadian exports. The possibility of assigning such " false concreteness"' to EF

\footnotetext{
${ }^{12}$ On average for the years between 1989-2007 (Kissinger \& Rees, 2009: 2311).
} 
results has been recognized as a concern not only of the lay public and politicians, but apparently also of trained environmentalists and scholars (van den Bergh \& Verbruggen, 1999: 64, single quotes in the original).

Through integration with the AEI, the SSI can reveal the impacts of Canada's contributions to the global agri-food market. The implementation of AAFC's indicator set positively shows long-underway declines in risk of water, wind, and tillage soil erosion (Lobb, 2005: 103, table 13-3; Rostad \& Padbury, 2005: 98, table 13-2; van Vliet, Padbury, Rees \& Matin, 2005: 92, table 13-1), improvements in soil organic carbon content (McConkey, Hutchinson, Smith, Grant \& Desjardins, 2005: 108; 110, table 14-1), and declines in soil salinity (Wiebe, Eilers, Eilers \& Brierley, 2005: 116, table 15-1). However, there is a worrying on-going trend towards increased risk of nutrient run-off causing nitrogen contamination to ground- and surface waters, a consequence of agricultural intensification and changing producer choices (Drury et al., 2005: 72, table 9-2).

The trend towards further converting summerfallow land to intensive monoculture (Eilers \& Huffman, 2005: 44) and generally switching from cereal crops to legumes or row crops are economically enhancing strategies that result in soil nutrient accumulation, nonetheless both are supported by government policies and marketing efforts (Junkins et al., 2005: 19). The oversupply of field crops, from the point of view of potential domestic requirements, revealed by the SSI in table 4.1 suggests that producers could be further influenced to adopt 
production of novel foods for domestic markets. As an instance, the intensive corn production in Ontario and Quebec, which together comprise over $95 \%$ of the Canadian growing area, and the increase in legumes planted in those provinces are thought greatly responsible for the dramatic increase in farms at higher risk of nitrogen run-off (Drury et al., 2005: 72, 74; StatsCan, 2009: survey 001-0010). Since self-sufficient production can be recognized easily in table 4.1 , some fraction of production could be identified as superfluous and price supports or greater marketing and promotion can be designed to encourage diversification or new crop development. For example, this could provide the impetus to bring "un-official" grains like kamut, spelt, and quinoa into the Canada Grain Act so producers can obtain the same income guarantees that traditional commercial grains enjoy (CGC, 2009: ף10).

Indeed, AAFC suggests producers should exploit the desire that more affluent peoples have for a diet that is increasingly guided by personal taste, variety, convenience, and an enhanced awareness that less intensive production practises such as organic agriculture can improve the immediate environment (Gerbens-Leenes et al., 2002: 48; Junkins et al., 2005: 18-19, 20). As diets become more affluent, consumption of fresh fruits and vegetables rises (Gerbens-Leenes et al., 2002: 55). There is thus both reason and opportunity to increase fruit and vegetable production in an effort to achieve a sustainable agrifood system, as shown in table 4.2 and 4.3 , respectively. 
Table 4.2 shows self-sufficiency in fruit can be achieved by switching just $1 \%$ of the 2001 total area under cultivation in Canada from some other use. The SSI reveals Canadians consumed fruit in amounts that if produced by domestically cultivatable species would require 1.1 million hectares, over 10 times the area actually under cultivation for fruit in 2001. Despite this, in 2001 there was in fact a decline in cultivated area of about $1 \%$ from the previous year, although the farm-gate value of production was up 7\% (StatsCan, 2002: $5)$.

Table 4.2: Final areas for fruits, 2001.

\begin{tabular}{|l|c|c|c|}
\hline \hline CROP & CONSUMPTION AREA (HA) & PRODUCTION AREA (HA) & SSI \\
\hline Apples & 262,000 & 25,800 & 0.10 \\
\hline Apricots & 733 & 208 & 0.28 \\
\hline Blueberries & 159,000 & 44,000 & 0.28 \\
\hline Cherries & 6,750 & 1,930 & 0.29 \\
\hline Cranberries & 8,410 & 2,380 & 0.28 \\
\hline Grapes & 57,800 & 10,600 & 0.18 \\
\hline Melons & 15,000 & 550 & 0.04 \\
\hline Peaches & 18,100 & 3,300 & 0.18 \\
\hline Pears & 11,500 & 1,570 & 0.14 \\
\hline Plums & 8,160 & 801 & 0.10 \\
\hline Raspberries & 13,500 & 3,840 & 0.28 \\
\hline Strawberries & 28,400 & 6,000 & 0.21 \\
\hline Total & 589,000 & 101,000 & 0.17 \\
\hline
\end{tabular}

NOTE: numbers may not add due to rounding.

There is little overt mention of whether or not AAFC's AEI are applied specifically to fruit production in Canada and considering the relatively low area under cultivation shown in table 4.2 compared to that shown in table 4.1 , a focus on field crops is understandable. One goal of this work is to incorporate additional social aspects into Canada's sustainable agricultural development 
polices. An imperative to effect positive changes in society as a whole is implied by the word "development" (Daly, 1987: 323; Niu et al., 1993: 180) and suggests another use for the SSI: linking the impact of agricultural land use change to agri-food sustainability.

Canadians have historically been among the world's largest consumers of fruit and fruit juice, for instance consuming about twice as much of the latter as Americans do (Lee, Brown \& Seale jr., 1992: 255). Yet if the mass of fruit consumed domestically in 2001 were re-distributed proportionately to currently produced species, not a single crop could meet the demand (table 4.2). The distribution of fruit-growing areas in 2001 was limited to four main regions in the following proportions: $30 \%$ grown in Ontario, $27 \%$ in Quebec, $21 \%$ in British Columbia, and $12 \%$ in Nova Scotia (StatsCan, 2005: 5). There is a long-term decline in the areas devoted to fruits in Canada (AAFC, 2008b: 2-3, table 1; Krueger, 1978: 179), as urbanization continues to claim the higher-quality farm land most suitable to its cultivation (Hoffman et al., 2005: 8). This is of particular concern in Ontario, which contains $56 \%$ of the premier agricultural land in Canada, as a high proportion of that land is in the south-western Golden Horseshoe region that is also home to most of Canada's urban lands (Hoffman et al., 2005: 5, 7).

There is here a confluence of social and environmental issues. Urban sprawl is especially contentious where some fruit is grown since those areas possess specialized conditions that do not exist elsewhere (Hoffman et al., 2005: 
8). However, urbanization continues apace increasing reliance on imports, the chief supplier of which is the US at about $80 \%$, followed by nations of the Southern Hemisphere who typically supply when domestic crops are out of season (AAFC, 2007b: 9, 14). Together, this means as Canada permanently loses fruit production capacity to possibly unsustainable land use changes, there is an increasing reliance on foreign sources. As importation rises, along with the associated pollution and GHG emissions, so does the general unsustainability of the agri-food system as it becomes less self-sufficient.

Table 4.3 shows that for the most part, Canada is self-sufficient in vegetable production, with production about 2.5 times total conceptual demand. Although there are several individual items that are potentially under-supplied, this methodology extrapolates producer response to market forces, not consumer demand for specific products and so should not necessarily suggest heightening production of particular items. However, as a great many vegetables are row crops that provide less surface cover, growing them at all raises the risk of erosion (Huffman et al., 2006: 67). The SSI should be seen here as cautionary; if AEI results tend to prescribe against vegetable cultivation as a mitigation measure for certain impacts (e.g. Lobb, 2005: 106, 15), it should be considered only until it impinges on self-sufficiency. The long-term economic costs of import-reliance can be balanced against those of other mitigation measures or research into practices that, for instance, increase soil cover like 
intercropping. Finally, since vegetables are grown in many of the same areas as fruits, they are at similar risk to urbanization.

Table 4.3: Final areas for vegetables, 2001.

\begin{tabular}{|l|r|r|r|}
\hline CROPS & CONS. AREA (HA) & PROD. AREA (HA) & SSI \\
\hline Asparagus & 87 & 1,630 & 18.6 \\
\hline Beans (dry) & 33,700 & 185,000 & 5.47 \\
\hline Beans (green) & 7,180 & 12,100 & 1.69 \\
\hline Beets & 77 & 1,160 & 15.0 \\
\hline Broccoli & 15,500 & 4,050 & 0.26 \\
\hline Cabbage & 2,590 & 6,250 & 2.41 \\
\hline Carrots & 5,370 & 9,380 & 1.75 \\
\hline Cauliflower & 2,960 & 2,880 & 0.97 \\
\hline Celery & 1,420 & 794 & 0.56 \\
\hline Corn (sweet) & 11,400 & 35,400 & 3.09 \\
\hline Cucumbers & 6,830 & 12,800 & 1.88 \\
\hline Lettuce & 6,340 & 3,500 & 0.55 \\
\hline Mushrooms & 263 & 398 & 1.51 \\
\hline Onions & 4,680 & 5,420 & 1.16 \\
\hline Parsnips & 19 & 288 & 15.0 \\
\hline Peas & 32,900 & 17,200 & 0.52 \\
\hline Peppers & 5,560 & 2,590 & 0.47 \\
\hline Potatoes & 43,700 & 169,000 & 3.88 \\
\hline Radishes & 1,800 & 983 & 0.55 \\
\hline Spinach & 1,850 & 646 & 0.35 \\
\hline Tomatoes & 5,980 & 13,600 & 2.28 \\
\hline Turnips & 1,410 & 2,270 & 1.60 \\
\hline Total & 192,000 & 487,000 & 2.54 \\
\hline
\end{tabular}

NOTE: numbers may not add due to rounding.

\subsection{Inclusiveness of results}

The 2001 FES contains the consumption records for some 1995 different agri-food products. This analysis attempts to capture as many as realistically possible, especially those conforming to the recommendations of Canada's food guide (Health Canada, 2008b). Table 4.4 shows the FES food categories, the totals consumed and the totals accounted for by the SSI, listed according to 
whether the item is reported in volume units (millions of litres) or mass (millions of tonnes).

Table 4.4: Total volumes and masses from the FES and accounted by the SSI.

\begin{tabular}{|l|r|r|r|r|r|r||}
\hline FES ITEM & FES (ML) & SSI (ML) & SSI (\%) & FES (MT) & SSI (MT) & SSI (\%) \\
\hline Meat \& fish & 0 & 0 & 0 & 1,700 & 1,700 & 99 \\
\hline Dairy & 2,700 & 2,400 & 87 & 310 & 310 & 100 \\
\hline Cereals & 30 & 30 & 100 & 1,600 & 1,200 & 77 \\
\hline Fruit & 1,100 & 1,000 & 96 & 1,300 & 1,300 & 100 \\
\hline Vegetables & 710 & 450 & 64 & 1,800 & 1,800 & 100 \\
\hline Fats \& oils & 78 & 78 & 100 & 110 & 107 & 95 \\
\hline Nuts & 0 & 0 & 0 & 42 & 0 & 0 \\
\hline Sugar & 18 & 0 & 0 & 310 & 0 & 0 \\
\hline Coffee \& tea & 0 & 0 & 0 & 72 & 0 & 0 \\
\hline Other & 2,600 & 0 & 0 & 600 & 140 & 24 \\
\hline Total & 7,200 & 3,900 & 55 & 7,800 & 6,500 & 84 \\
\hline
\end{tabular}

There are a number of factors affecting the seemingly low inclusion of volume-measured foodstuffs. Mainly it is the "other" category, which accounts for about $36 \%$ of the total volume and is made up of soups that do not belong elsewhere (cream soups, turtle soup, cheddar cheese soup, etc.), infant foods and formulas, carbonated beverages, and fruit drinks (liquor mixes, lemonade, Gatorade ${ }^{\circledR}$, etc.). The low apparent response for volume-measured vegetables is explained in that this group comprises prepared salad dressings, "other condiments," which includes vinegar, and "other sauces" (guacamole, rib and wing sauces, taco, teriyaki and soya sauces, etc.), the latter of which alone accounts for $36 \%$ of the total volume of vegetables. The cereals and dairy unaccounted for are sweetened products, such as cakes and ice cream respectively, that are not part of the analysis. Numerically, 1225 items were 
included in the analysis, or $61 \%$. If "non-food" items like beverages, spices, salt, herbs, jelly powders, gelatine and infant formulas are removed from the count, the share rises to $66 \%$.

In calculating the number of animals required from the mass of cuts of meat there are considerable differences in the numbers; for example, half the number of cattle is required to supply offal as hip cuts (table 3.5 ) and over nine times the number of swine are required to supply loin cuts as to supply the mass of belly cuts (table 3.12 ). This is mainly an artefact of the FES in that the ordinal rank of each cut from the survey is the same as that of the required animals before the addition of masses as determined by the method (i.e. the additional masses from prepared meat products, etc.). Accounting for the disposition of the discrepancy is beyond the scope of this work, but possible explanations include exports and pet foods. 


\subsection{Conclusions}

Canada does not grow what it eats. There is, on first glance, a surfeit of land available to conceptually supply its citizens with food. Some foodstuffs derived from the field crops listed in table 4.1 could be consumed from domestic sources in amounts at least $50 \%$ greater than in 2001 and table 4.3 shows there was over $60 \%$ more vegetable area available than "required." The unsustainability of the current Canadian consumption pattern is highly apparent from table 4.2, which shows over 5 times the current area would need to be brought under cultivation to meet consumption levels with domestically produced fruit. Although this only amounts to $1 \%$ of the available agricultural land, the land most suited to fruit farming is also that most at risk of loss to land use change (Hoffman et al., 2005: 7-8) and has long be declining (Krueger, 1978: 179). This is a permanent loss of carrying capacity and represents increasing Canadian dependence on the globalized agri-food system, which is thought by many to be unsustainable.

Of course, Canada's farmers should and do exploit the nation's comparative advantage for field crop production, primarily in the Prairies but also increasingly in the Central provinces, and so with good reason the initial AEI are focused on ascertaining the impacts of that production. The sustainable development definition on which AAFC bases its choice of indicators (Lefebvre, 2005: 2) specifies the natural resources that agriculture depends on as needing protection. Without including domestic demand in the decision-making process 
the AEI results can have a prescriptive effect on cropping choices while protecting that advantage or those resources; this, in turn, can cause Canadian consumers to become more reliant on foreign sources of food for a nutritionally complete diet. Likewise, the AEI are not likely to be influential on policies that affect land loss, namely urbanization.

Recognizing consumer demand as a pressure variable highlights socially desirable outcomes, such as preserving prime land, and incorporating national agri-food self-sufficiency into the AEI broadens the options for environmental, social, and economic responses within the DSR framework used in most OECD countries, including Canada. Douglass' (1984: 07) caution that sustainability requires a delimited temporal scale within which agricultural supply and demand for a given socio-economic system are closely matched is complemented by Conway's (1985: 34) assertion that due to the hierarchical nature of agroecosystems a response at one level in the system cannot easily predict the outcomes at another one. However, the SSI uses average household consumption and can therefore be disaggregated to agree with intervening spatial scales.

One hoped-for contribution of this study to the methodology is in using surveyed consumer preferences for food as a way to help construct more realistic assessments of agri-food system sustainability. A nationally-weighted dataset was used here, which may not be representative of some urban centres that have large, culturally distinct populations whose dietary preference is 
markedly different. However, resting the method on surveyed data is claimed as an improvement since applying re-weighted or new data is easily done if the scale or the scope of the study changes. This is unlike studies using the apparent disappearance residuals, which are derived from highly aggregated data mostly influenced by collective producer decisions and international trade conditions. Further, with respect to such top-down assessments, as the primary crops move through the processing chain they are subject to wastage or process losses; accounting all losses for the same number of final products as analyzed here is likely to be immensely complicated and introduce additional uncertainty.

Nonetheless, there are several points in this study where uncertainty is introduced, including the following: Prepared meat products were assumed to consist solely of meat, but meat pies, for instance, have a dough crust. An exploration of the exact variability in yields of dairy products was not made; this may be important for, say, cheese made from the milk of animals other than cattle. The fate of laying hens is uncertain; reputable information about if or where layers enter the food chain was not forthcoming, although since layers amount to less than $4 \%$ of the birds required for meat (tables $3.17 \& 3.21$ ) this is not an egregious instance of double-counting in any case. There are certainly innumerable bread recipes and it is likely that there is enough variation in ingredient proportions among them to produce a range of input quantities, rather than the single values used here. There is an assumption that 2001 yields were 
not unusual and that there was no radical shift in production choices from past years.

There are two methods by which the distributional proportions shown in tables $3.36,3.53,3.66,3.74$, and 3.81 could be calculated. After the final masses of foodstuffs are calculated, those crops that are not domestically grown are allocated to those that are according to the fraction of the mass of each crop that was produced in 2001. Allocating those fractions according to area provides quite different results because yields vary considerably between crops. A farmer has to devote a larger area to a low-yield crop than to higher-yielding one to obtain the same mass of both, thus area is not a reflection of market share. Thus, for example, using area leads to the conclusion that 800,000 hectares of blueberries, almost 6 times that of apples, would be required for that crop's share, while using the mass fraction suggests apples be produced in amounts 1.6 times that of blueberries. The mass of apples produced in 2001 was almost 7 times that of blueberries (StatsCan, 2002: 18, table 2), suggesting there is still a limitation with this aspect of the method.

Canada is a large country and regional trading with proximate American states in many cases is more desirable than cross-country transport of similar foods. Care is taken here not to imply that self-sufficiency within an artificial border is a necessary condition of sustainability, but rather that those cases where Canada is far, or is moving away, from self-sufficiency deserve extra attention. 


\section{References}

Agriculture and Agri-Food Canada, (1997). Agriculture in harmony with nature: strategy for environmentally sustainable agriculture and agri-food development in Canada. Retrieved May 9, 2009 from: http://www4.agr.gc.ca/AAFC-

AAC/display-afficher.do?id=1175526032952\&lang=eng

Agriculture and Agri-Food Canada, (2003). Fish and seafood. Aquaculture atlas of Canada. Retrieved May 31, 2009 from:

http://www.ats.agr.gc.ca/seafood/aquaculture-e.htm

Agriculture and Agri-Food Canada, (2005). Agriculture in harmony with nature: Agriculture and Agri-Food Canada's sustainable development strategy 20012004. Retrieved June 3, 2009 from: http://www4.agr.gc.ca/AAFC-AAC/displayafficher.do?id=1175526032952\&lang=eng

Agriculture and Agri-Food Canada, (2007a). Changing consumer demands. Retrieved May 4, 2009 from: http://www4.agr.gc.ca/AAFC-AAC/displayafficher.do?id=1185451287432\&lang=e\#tphp

Agriculture and Agri-Food Canada, (2007b). 2002/2003 Canadian fruit situation and trends including apples, tender fruits, grapes (Vinifera) and berries.

Retrieved August 4, 2009 from: http://www4.agr.gc.ca/AAFC-AAC/displayafficher.do?id=1184695056095\&lang=eng

Agriculture and Agri-Food Canada, (2008a). Canada land inventory level-I digital data. Retrieved May 9, 2009 from: http://sis.agr.gc.ca/cansis/nsdb/cli/class.html Agriculture and Agri-Food Canada, (2008b). Canada's poultry industry ... at a glance. Retrieved May 26, 2009 from:

http://www.ats.agr.gc.ca/supply/3315_e.htm

Agriculture and Agri-Food Canada, (2008c). Fish and seafood fact sheets: farmed salmon. Retrieved May 31, 2009 from:

http://www.ats.agr.gc.ca/seafood/farmed_salmon-e.htm

Agriculture and Agri-Food Canada, (2009a). Poultry marketplace. Retrieved May 27, 2009 from: http://www.agr.gc.ca/poultry/index_eng.htm

Agriculture and Agri-Food Canada, (2009b). Dairy industry at a glance. Retrieved May 28, 2009 from: http://www4.agr.gc.ca/AAFC-AAC/displayafficher.do?id=1182522993907\&lang=eng

Agriculture and Agri-Food Canada, (2009c). Crop profile for cabbage and broccoli in Canada. Retrieved June 8, 2009 from: http://www4.agr.gc.ca/AAFC-

AAC/display-afficher.do?id=1181584838944\&lang=eng 
Agriculture and Agri-Food Canada, (2009d). Land managers - soil and land - land management through grazing. Retrieved June 11, 2009 from:

http://www4.agr.gc.ca/AAFC-AAC/displayafficher.do?id=1187188747887\&lang=eng

Agriculture and Agri-Food Canada, (2009e). Economic and market information. Retrieved June 11, 2009 from: http://www4.agr.gc.ca/AAFC-AAC/displayafficher.do?id $=1177676316971$ \&lang=eng\&menupos $=1$

Altieri, M.A., Letourneau, D.K. \& Davis, J.R. (1984). The requirements of sustainable agroecosystems. In Douglass G.K. (Ed.), Agricultural sustainability in a changing world order (pp. 147-157). Boulder, CO: Westview Press.

Andow, D.A. \& Hidaka, K. (1989). Experimental natural history of sustainable agriculture: syndromes of production. Agriculture, Ecosystems \& Environment, $27(1-4), 447-464$.

Bavec, M., Mlakar, S.G., Rozman, C., Pažek, K. \& Bavec, F. (2009). Sustainable agriculture based on integrated and organic guidelines: understanding terms. Outlook on Agriculture, 38(1), 89-95.

Banks, J.M. (2007). Cheese yield. In McSweeney, P.L.H. (Ed.), Cheese problems solved (pp.100-114). Boca Raton, FL: CRC Press LLC.

Barker, D., Lankhaar, J. \& Stals, P. (2004). Primary processing of poultry. In Mead, G.C. (Ed.) Poultry meat processing and quality (pp. 90-107). Boca Raton, FL: CRC Press LLC.

Baron, V.S., Okine, E. \& Dick, A.C. (2000). Optimizing yield and quality of cereal silage. Retrieved July 28, 2009 from:

http://www.wcds.afns.ualberta.ca/Proceedings/2000/Chapter30.htm

Barta, J. (2006). Fruit drying principles. In Hui, Y.H. (Ed.) Handbook of fruits and fruit processing (pp. 81-94). Ames, IA: Blackwell Publishing Professional.

Beaulieu, M.S., MacDonald, T., \& Mineau, P. (2005). Pesticide use and pest management practices of Canadian apple growers. Ottawa, ON: Statistics Canada, Agriculture Division.

Berger, A.R. \& Hodges, R.A. (1998). Natural change in the environment: a challenge to the pressure-state-response concept. Social Indicators Research, $44(2), 255-265$.

Bhat, N.R., Desai, B.B. \& Suleiman, M.K. (2006). Grapes and raisins. In Hui, Y.H. (Ed.) Handbook of fruits and fruit processing (pp. 439-452). Ames, IA: Blackwell Publishing Professional. 
Blake, D.E. (2001). Contextual effects on environmental attitudes and behavior. Environment and Behavior, 33(5), 708-725.

Boivin, G., Grimard, J. \& Olivier, C. (2005) Integrated pest management In Lefebvre, A., Eilers, W., \& Chunn, B. (Eds.). Environmental sustainability of Canadian agriculture: agri-environmental indicator report series - report \#2 (pp.85-87). Ottawa, ON: Agriculture and Agri-Food Canada.

Braidwood, R.J. (1954). From cave to village in Iraq. Agricultural History, 28(2), 41-43.

Brainard, D.C. \& Bellinder, R.R. (2004). Weed suppression in a broccoli-winter rye intercropping system. Weed Science, 52(2), 281-290.

Brklacich, M., Bryant, C.R. \& Smit, B. (1991). Review and appraisal of concept of sustainable food production systems. Environmental Management, 15(1), 1-14.

Brown, B.J., Hanson, M.E., Liverman, D.M. \& Meredith Jr., R.W., (1987). Global sustainability: Toward definition. Environmental Management, 11(6), 713-719.

Cain, P.J. \& Hopkins, A.G. (2002). British imperialism, 1688-2000. Essex, UK: Pearson Education Limited.

Caldwell, L.K. (1984). Political aspects of ecologically sustainable development. Environmental Conservation, 11(4), 299-308.

Canada Bread Company Limited, (2005). About Dempster's bread. Retrieved June 3, 2009 from: http://www.dempsters.ca/Products_Breads.html

Canadian Cattlemen's Association, (n.d.). About cow-calf operations. Retrieved June 3, 2009 from: http://cowcalf.cattle.ca/the-bull-factor/

Canadian Dairy Commission, (2001). The Canadian Dairy Commission annual report 2000-2001. Retrieved June 3, 2009 from: http://www.cdcccl.gc.ca/CDC/index_en.asp?caId $=832$

Canadian Dairy Commission, (2002). The Canadian Dairy Commission annual report 2001-2002. Retrieved June 3, 2009 from: http://www.cdcccl.gc.ca/CDC/index_en.asp?caId $=832$

Canadian Grain Commission, (2009). Grains of Canada. Retrieved June 1, 2009 from: http://www.grainscanada.gc.ca/grainsc-cgrains/ogc-goc-eng.htm

Canadian Pork International, (n.d.) Industry information: meat yield. Retrieved May 25, 2009 from:

http://www.canadapork.com/english/pages/frmsts/page03.html 
Canadian Wheat Board, (2008). From wheat to bread. Retrieved May 30, 2009 from:

http://www.cwb.ca/public/en/library/research/popups/wheat_From_wheat.jsp

Carpenter, S., Caraco, N.F., Correll, D.L., Horwath, R.W., Sharpley, A.F. \& Smith, V.H. (1998). Nonpoint pollution of surface waters with phosphorus and nitrogen. Issues in Ecology, 3, 1-14.

Cassman, K.G. (1999). Ecological intensification of cereal production systems: yield potential, soil quality, and precision agriculture. Proceedings of the National Academy of Sciences, 96(11), 5952-5959.

Catterall, P. \& Cauvain, S.P. (2007). Flour milling. In Cauvain, S.P \& Young, L.S. (Ed.s) [Electronic version]. Technology of breadmaking (pp. 333-369). Springer US.

Cauvain, S.P. (2007). Other cereals in breadmaking. In Cauvain, S.P \& Young, L.S. (Ed) [Electronic version]. Technology of breadmaking (pp. 371-388). Springer US.

Chambers, N., Simmons, C. \& Wackernagel, M. (2000). Sharing nature's interest: ecological footprints as an indicator of sustainability. London, UK: Earthscan Publications Ltd.

Chambers, P.A., Guy, M., Roberts, E.S., Charlton, M.N., Kent, R., Gagnon, C., Grove, G., \& Foster. N. (2001). Nutrients and their impact on the Canadian environment. Ottawa, ON: Agriculture and Agri-Food Canada, Environment Canada, Fisheries and Oceans Canada, Health Canada and Natural Resources Canada.

Cohen, J.E. (1995a). Population growth and Earth's human carrying capacity. Science, 269(5222), 341-346.

Cohen, J.E. (1995b). How many people can the earth support? New York, NY: W.W. Norton \& Company Inc.

Coltro, L., Mourad, A.L., Kletecke, R.M., Mendonça, T.A. \& Germer, S.P.M. (2009). Assessing the environmental profile of orange production in Brazil. The International Journal of Lifecycle Assessment, [on-line]. Retrieved March 25, 2009 from: http://www.springerlink.com/index/Im578136kp776x30.pdf

Conway, G.R. (1985). Agroecosystem analysis. Agricultural Administration, 20, 31-55.

Costanza, R. \& Patten, B.C., (1995). Defining and predicting sustainability. Ecological Economics, 15, 193-196. 
Cowell, S.J. \& Parkinson, S. (2003). Localization of UK food production: an analysis using land area and energy as indicators. Agriculture, Ecosystems and Environment, 94, 221-236.

Csillag, C. (2000). Turning point: environmental health in Brazil. Environmental Health Perspectives, 108(11), A504-A511.

Dairy Producers Association of Canada, (n.d.). Industry statistics. Retrieved May 25, 2009 from: http://www.dpac-atlc.ca/english/processors/statistics.cfm

Daly, H.E. (1987). The economic growth debate: what some economists have learned, but many have not. Journal of Environmental Economics and Management, 14, 323-336.

Daly, H.E. (1990). Toward some operational principles of sustainable development. Ecological Economics, 2, 1-6.

De Ancos, B., Sánchez-Moreno, C., De Pascual-Teresa, S. \& Cano, M.P. (2006). Fruit freezing principles. In Hui, Y.H. (Ed.) Handbook of fruits and fruit processing (pp. 59-80). Ames, IA: Blackwell Publishing Professional.

De Jong, R., Yang, J.Y., Drury, C.F., Huffman, E., Kirkwood, V. \& Yang, X.M. (2005). Nitrogen In Lefebvre, A., Eilers, W., \& Chunn, B. (Eds.). Environmental sustainability of Canadian agriculture: agri-environmental indicator report series - report \#2 (pp.124-130). Ottawa, ON: Agriculture and Agri-Food Canada.

Department of Justice Canada, (2009a). Livestock and poultry carcass grading regulations (SOR/92-541). Retrieved May 27, 2009 from:

http://laws.justice.gc.ca/en/showdoc/cr/SOR-92-541/bo-ga:I_V::boga:I_VI/20090527?command=search\&caller=SI\&search_type $=$ all\&shorttitle $=$ Live stock $\% 20$ Carcass $\% 20$ Grading $\% 20$ Regulations $\&$ day $=27 \&$ month $=5 \&$ year $=2009 \& \mathrm{~s}$ earch_domain $=c r \&$ showall $=L \&$ statuteyear $=$ all\&lengthannual $=50 \&$ length $=50 \& p a$ ge $=3$

Department of Justice Canada, (2009b). Schedule IV, table 1B. Retrieved June, 10, 2009 from: http://laws.justice.gc.ca/en/showdoc/cr/C.R.C.-

c.291/sc:4/20090601/en\#anchorsc:4

Department of Justice Canada, $(2009 \mathrm{c})$. Food and drug regulations. Retrieved June 10, 2009 from: http://laws.justice.gc.ca/en/showdoc/cr/C.R.C.-c.870/boga:I_B-gb:I_11/20090602/en\#anchorbo-ga:I_B-gb:I_11

Dexter, J.E. (2004). Grain, paste products: pasta and Asian noodles. In Smith, J.S. \& Hui, Y.H. (Ed) Food processing-principles and applications. Ames, IA:

Blackwell Publishing

Dixon, J.A. \& Fallon, L.A. (1989). The concept of sustainability: origins, extensions and usefulness for policy. Society and Natural Resources, 2, 73-84. 
Douglass, G.K. (1984). The meanings of agricultural sustainability. In Douglass G.K. (Ed.), Agricultural Sustainability in a changing world order (pp. 3-29). Boulder, CO: Westview Press.

Downs, P. (2008, April 23). CanGro closing will mark end of Niagara fruit-canning industry. The Record [on-line]. Retrieved July 2, 2009 from:

http://news.therecord.com/Business/article/340579

Drury, C.F., Yang, J.Y., De Jong, R., Huffman, P., Kirkwood, V., Yang, X.M. \& Reid, K. (2005). Nitrogen use efficiency. In Lefebvre, A., Eilers, W., \& Chunn, B. (Eds.). Environmental sustainability of Canadian agriculture: agri-environmental indicator report series - report \#2 (pp.18-23). Ottawa, ON: Agriculture and AgriFood Canada.

Duchin, F. (2005). Sustainable consumption of food: a framework for analyzing scenarios about changes in diets. Journal of Industrial Ecology, 9(1-2), 99-114.

Dumanski, J. \& Pieri, C. (1997). Application of the pressure-state-response framework for the land quality indicators (LQI) prograrnme. In Land quality indicators and their use in sustainable agriculture and rural development. Retrieved May 23, 2009 from: http://www.fao.org/docrep/W4745E/w4745e00.htm\#Contents

Dumanski, J., Desjardins, R.L., Tarnocai, C., Monreal, C., Gregorich, E.G. \& Kirkwood, V. (1998). Possibilities for future carbon sequestration in Canadian agriculture in relation to land use changes. Climatic Change, 40, 81-103.

Dumanski, J. \& Pieri, C. (2000).Land quality indicators: research plan. Agriculture, Ecosystems and Environment, 81(2), 93-102.

Duvick, D.N. \& Cassman, K.G. (1999). Post-Green Revolution trends in yield potential of temperate maize in the north-central United States. Crop Science, $39,1622-1630$.

Dyer, J. (1982). Sustainability in the Canadian agr-food system. Canadian Farm Economics, 17(3), 23-28.

Early, R. (1998). Liquid milk and cream. In Early, R., (Ed.), The Technology of Dairy Products (2 ${ }^{\text {nd }}$ Ed.) (pp. 1-49). London, UK: Blackie Academic \& Professional.

Eilers, W. \& Huffman, T. (2005). Agricultural land use change. In Lefebvre, A., Eilers, W., \& Chunn, B. (Eds.). Environmental sustainability of Canadian agriculture: agri-environmental indicator report series - report \#2 (pp.42-48). Ottawa, ON: Agriculture and Agri-Food Canada. 
Eilers, W. \& Lefebvre, A. (2005a). Assessing the sustainability of agriculture. In Lefebvre, A., Eilers, W., \& Chunn, B. (Eds.). Environmental sustainability of Canadian agriculture: agri-environmental indicator report series - report \#2 (pp.7-13). Ottawa, ON: Agriculture and Agri-Food Canada.

Eilers, W. \& Lefebvre, A. (2005b). National and regional summary. In Lefebvre, A., Eilers, W., \& Chunn, B. (Eds.). Environmental sustainability of Canadian agriculture: agri-environmental indicator report series - report \#2 (pp.190-201). Ottawa, ON: Agriculture and Agri-Food Canada,.

Emmons, D.B., Ernstrom, C.A., Lacroix, C. \& Verret, P. (1990). Predictive formulas for yield of cheese from composition of milk: a review. Journal of Dairy Science, 73(6), 1365-1394.

Erb, K-H. (2004). Actual land demand of Austria 1926-2000: a variation on ecological footprint assessments. Land Use Policy, 21(3), 247-259.

Evenson, R.E. \& Gollin, D. (2003). Assessing the impact of the Green Revolution, 1960-2000. Science, 300(5620), 758-762.

Federico, G. (2005). Feeding the world: an economic history of agriculture, 18002000. Princeton, NJ: Princeton University Press.

Food and Agriculture Organization, (n.d.) Technical conversion factors for agricultural commodities. Retrieved September 21, 2008 from:

http://www.fao.org/es/ess/tcf.asp

Food and Agriculture Organization, (1997). Land quality indicators and their use in sustainable agriculture and rural development: table of contents - Application of the pressure-state-response framework for the land quality indicators (LQI) programme. Retrieved March 12, 2009 from:

http://www.fao.org/docrep/W4745E/w4745e00.htm \#Contents

Food and Agriculture Organization, (2001). Human energy requirements.

Retrieved May 13, 2009 from:

http://www.fao.org/docrep/007/y5686e/y5686e00.htm

Food and Agriculture Organization, (2009). FAOSTAT-ProdSTAT-crops. Retrieved June 1, 2009 from: http://faostat.fao.org/site/567/default.aspx\#ancor

Gerbens-Leenes, P.W., Nonhebel, S. \& Ivens, W.P.M.F. (2002). A method to determine land requirements relating to food consumption patterns. Agriculture, Ecosystems and Environment, 90(1), 47-58.

Gisslen, W. (1985). Professional baking. Toronto, ON: John Wiley \& Sons.

Goff, D. (2009a). Dairy chemistry and physics. Retrieved May 30, 2009 from: http://www.foodsci.uoguelph.ca/dairyedu/chem.html 
Goff, D. (2009b). Clarification and cream separation. Retrieved May 30, 2009 from: http://www.foodsci.uoguelph.ca/dairyedu/clarification.html

Goff, D. (2009c). Yoghurt. Retrieved May 30, 2009 from: http://www.foodsci.uoguelph.ca/dairyedu/yogurt.html

Goff, D. (2009d). Butter manufacture. Retrieved July 30, 2009 from: http://www.foodsci.uoguelph.ca/dairyedu/butter.html

Goff, D. (2009e). Cheese. Retrieved July 30, 2009 from: http://www.foodsci.uoguelph.ca/dairyedu/cheese.html\#treatment

Government of Alberta, (2008). Economics and marketing: understanding dressing percentage of slaughter cattle. Retrieved May 23, 2009 from: http://www1.agric.gov.ab.ca/\$department/deptdocs.nsf/all/sis12389

Government of Manitoba, (2009). Blueberry production in Manitoba. Retrieved May 13, 2009 from: http://www.gov.mb.ca/agriculture/crops/fruit/blf01s00.html

Government of Ontario, (2007). Population counts: Canada, Ontario and regions. Retrieved June 8, 2009 from:

http://www.fin.gov.on.ca/english/economy/demographics/census/cenhi06-1.html

Graedel, T.E. \& Allenby, B.R. (2003) Industrial ecology (2 ${ }^{\text {nd }}$ Ed.). Upper Saddle River, N]: Pearson Education Inc.

Guvenc, I. \& Yildirim, E. (2006). Increasing productivity with intercropping systems in cabbage production. Journal of Sustainable Agriculture, 28(4), 29-44.

Guy, G.B., Kibert, C.J., (1998). Developing indicators of sustainability: US experience. Building Research and Information, 26(1), 39-45.

Haberl, H., Wackernagel, M. \& Wrbka, T. (2004). Land use and sustainability indicators. An introduction. Land Use Policy, 21(3), 193-198.

Hansen, J.W. (1996). Is agricultural sustainability a useful concept? Agricultural Systems, 50(2), 117-143.

Health Canada, (2008a). Canada's food guide: get your copy. Retrieved July 29, 2009 from: http://www.hc-sc.gc.ca/fn-an/food-guide-aliment/ordercommander/index-eng.php\# 1

Health Canada, (2008b). Nutrient value of some common foods. Retrieved August 4, 2009 from: http://www.hc-sc.gc.ca/fn-an/nutrition/fiche-nutridata/nutrient_value-valeurs_nutritives-eng.php

Helbaek, H. (1959). The domestication of food plants in the Old World. Science, 130(3372), 365-372. 
Helm, J.H. \& Salmon, D.F. (2002). Cereal silage options for Western Canada. Retrieved June 6, 2009 from: http://www.wcds.afns.ualberta.ca/Proceedings/ 2002/Chapter\%2019\%20Helm.htm

Hill, A.R. (2009). The cheese site. Retrieved May 30, 2009 from: http://www.foodsci.uoguelph.ca/cheese/sectione.htm\#yieldefficiency

Hofmann, N, Filoso, G. \& Schofield, M. (2005). The loss of dependable agricultural in Canada. Retrieved July 8, 2008 from:

http://www.statcan.gc.ca/bsolc/olc-cel/olc-cel?catno=21-006-

XIE2005001\&lang=eng

Horváth-Kerkai, E. (2006). Manufacturing fruit beverages. In Hui, Y.H. (Ed.) Handbook of fruits and fruit processing (pp. 205-216). Ames, IA: Blackwell Publishing Professional.

Hui, Y.H. (2004). Fruits: orange juice production. In Smith, J.S. \& Hui, Y.H. (Ed.s) Food processing - principles and applications (pp.361-390). Ames, IA: Blackwell Publishing Professional.

Industry Canada, (2008). Trade data online (TDO). Retrieved June 19, 2009 from: http://www.ic.gc.ca/epic/site/tdo-dcd.nsf/en/Home

Iyengar, G.V. \& Nair, P.P. (2000). Global outlook on nutrition and the envirorıment: meeting the challenges of the next millennium. The Science of the Total Environment, 249(1-3), 331-346.

Jaros, D. \& Rohm, H. (1998). Controlling the texture of fermented dairy products: the case of yoghurt. In Smit, G. (Ed.) Dairy processing-improving quality. Boca Raton, FL: CRC Press LLC.

Javorek, S.K., Antonowitsch, R., Callaghan, C., Grant, M. \& Weins, T. (2005). Wildlife habitat on farmland. In Lefebvre, A., Eilers, W., \& Chunn, B. (Eds.). Environmental sustainability of Canadian agriculture: agri-environmental indicator report series - report \#2 (pp.158-164). Ottawa, ON: Agriculture and Agri-Food Canada.

Junkins, B, Clark, H., MacGregor, R.J. \& McRae, T. (2005). Driving forces affecting the environmental sustainability of agriculture. In Lefebvre, A., Eilers, W., \& Chunn, B. (Eds.). Environmental sustainability of Canadian agriculture: agri-environmental indicator report series - report \#2 (pp.18-23). Ottawa, ON: Agriculture and Agri-Food Canada.

Kelly, A.L. (2007). Whey processing. In McSweeney, P.L.H. (Ed.). Cheese problems solved. Boca Raton, FL: CRC Press LLC.

Kendall, H.W. \& Pimentel, D. (1994). Constraints on the expansion of the global food supply. Ambio, 23(3), 198-205. 
Khush, G.S. (1999). Green revolution: preparing for the $21^{\text {st }}$ century. Genome, $42,646-655$.

Kissinger, M. \& Rees, W.E. (2009). Footprints in the prairies: degradation and sustainability of Canadian agricultural land in a globalizing world. Ecological Economics, 68(8-9), 2309-2315.

Koroluk, R. Piau, A., Grimard, J., Bourque, L. \& Korol, M. (2005). Farm environmental management practices. In Lefebvre, A., Eilers, W., \& Chunn, B. (Eds.). Environmental sustainability of Canadian agriculture: agri-environmental indicator report series - report \#2 (pp.49-60). Ottawa, ON: Agriculture and AgriFood Canada.

Krueger, R.R. (1978). Urbanization of the Niagara fruit belt. Canadian Geographer, 22(3), 179-194.

Lane, R. (1998). Butter and mixed fat spreads. In Early, R., (Ed.), The Technology of dairy products ( $2^{\text {nd }}$ ed.) (pp. 158-197). London, UK: Blackie Academic \& Professional.

Lee, J-Y, Brown, M.G. \& Seale jr., J.L. (1992). Demand relationships among fresh fruit and juices in Canada. Review of Agricultural Economics, 14(2), 255-262.

Lefebvre, A. (2005). Introduction. In Lefebvre, A., Eilers, W., \& Chunn, B. (Eds.). Environmental sustainability of Canadian agriculture: agri-environmental indicator report series - report \#2 (pp.2-6). Ottawa, ON: Agriculture and Agri-Food Canada.

Lefebvre, A., Eilers, W., \& Chunn, B. (eds.), (2005). Environmental sustainability of Canadian agriculture: agri-environmental indicator report series - report \#2. Ottawa, ON: Agriculture and Agri-Food Canada.

Liebman, M. \& Dyck, E. (1993). Crop rotation and intercropping strategies for weed management. Ecological Applications, 3(1), 92-122.

Lobb, D. (2005). Tillage erosion. In Lefebvre, A., Eilers, W., \& Chunn, B. (Eds.). Environmental sustainability of Canadian agriculture: agri-environmental indicator report series - report \#2 (pp.101-107). Ottawa, ON: Agriculture and Agri-Food Canada.

Lonergan, S. (1993). Sustainable regional development. Canadian Journal of Resource Science, 16(3), 335-339.

Lopez, A. (1987a). A complete course in canning and related processes. Book III - processing procedures for canned food products. Baltimore, MD: The Canning Trade Inc. 
Lopez, A. (1987b). A complete course in canning and related processes, Book Ibasic information on canning. Baltimore, MD: The Canning Trade Inc.

Luna, J.M. \& House, G.J. (1990). Pest management in sustainable agricultural systems. In Edwards, C.A., Lal, R., Madden, P., Miller, R.H. \& House, G.J. (ed.s). Sustainable agricultural systems (pp. 157-173). Boca Raton, FL: St. Lucie Press.

Maclaren, V.W., (1999). Urban sustainability reporting. Journal of the American Planning Association, 62(2), 184-202.

Manley, D. (2001). Biscuit, cracker and cookie recipes for the food industry. [Electronic resource.] Woodhead Publishing Retrieved June 3, 2009 from: http://knovel.com/web/portal/browse/display?_EXT_KNOVEL_DISPLAY_bookid= $541 \&$ VerticalID $=0$

Manitoba Pork Council, (2004). Pick pork: buying guide. What are the characteristics of pork cuts? Retrieved May 25, 2009 from:

http://www.pickpork.com/buying.php

McConkey, B., Hutchinson, J., Smith, W., Grant, B., \& Desjardins, P. (2005). Soil organic carbon. In Lefebvre, A., Eilers, W., \& Chunn, B. (Eds.). Environmental sustainability of Canadian agriculture: agri-environmental indicator report series - report \#2 (pp.108-113). Ottawa, ON: Agriculture and Agri-Food Canada.

McRae, T., Smith, C.A.S., and Gregorich, L.J. (Eds). 2000. Environmental sustainability of Canadian agriculture: report of the agri-environmental indicator project. A summary. Ottawa, ON: Agriculture and Agri-Food Canada.

Matthews, R.F., Phillips, P.E. \& Augustine, J.J. (1980). Evaluation of Florida tomatoes for juice processing. Proceedings of the Florida State Horticultural Society, 93, 296-298.

Milbrath, L.W., (1984). A proposed value structure for a sustainable society. The Environmentalist, 4(2), 113-124.

Moxey, A., Whitby, M. \& Lowe, P. (1998). Agri-environmental indicators: issues and choices. Land Use Policy, 15(4), 265-269.

Nepstad, D.C., Stickler, C.M. \& Almeida, O.T. (2006). Globalization of the Amazon soy and beef industries: opportunities for conservation. Conservation Biology, 20(6), 1595-1603.

Nip, W.-K., (2004). Fermented product manufacturing. In Smith, J.S. \& Hui, Y.H. (Ed.s) Food processing - principles and applications (pp.45-78). Ames, IA:

Blackwell Publishing Professional. 
Niu, N. \& Proux, S. (2005). Overview of agriculture in Canada. In Lefebvre, A., Eilers, W., \& Chunn, B. (Eds.). Environmental sustainability of Canadian agriculture: agri-environmental indicator report series - report \#2 (pp.24-35). Ottawa, ON: Agriculture and Agri-Food Canada.

Niu, W., Lu, J.J. \& Khan, A.A. (1993). Spatial systems approach to sustainable development: a conceptual framework. Environmental Management, 17(2), 179186.

Ontario Veal Association, (2003). What is Veal and other frequently asked questions. Retrieved May 27, 2009 from:

http://www.ontarioveal.on.ca/all_about_veal/vealquestions.html

Opara, L.U. (2003). Traceability in agriculture and food supply chain: a review of basic concepts, technological implications, and future prospects. Food, Agriculture \& Environment, 1(1), 101-106.

Osterhammel, J. (2005). Colonialism: a theoretical overview. (S. Frisch, Trans.). Princeton, N]: Markus Weiner Publishers.

Parry, J.H. (1996). The establishment of the European hegemony: 1425-1715. New York, NY: Harper Torchbooks.

Pátaki, G. (2006) Fruit as an ingredient in a fruit product. In Hui, Y.H. (Ed.) Handbook of fruits and fruit processing (pp. 217-230). Ames, IA: Blackwell Publishing Professional.

Penn State University, (n.d.). Agricultural alternatives - cantaloupe production. Retrieved May 25, 2009 from: http://horticulture.psu.edu/files/hort/extension/cantelupe.pdf

Pfeiffer, D.A. (2006). Eating fossil fuels. Gabriola Island, BC: New Society Publishers.

Pierce, J.T. \& Furuseth, O.J., (1986). Constraints to expanded food production: a North American perspective. Natural Resources Journal, 26(Winter), 15-39.

Plucknett, D.L. \& Smith, N.J.H. (1986). Sustaining agricultural yields. BioScience, $36(1), 40-45$.

Potter, N.N., \& Hotchkiss, J.H. (1998) Food Science (5 $5^{\text {th }}$ Ed.). New York, NY: Springer Science + Media, Inc.

Power, A.G., (1999). Linking ecological sustainability and world food needs. Environment, Development and Sustainability, 1, 185-196.

Rao, N.H. \& Rogers, P.P. (2006). Assessment of agricultural sustainability. Current Science, 91(4), 439-448. 
Rees, W. (1996). Revisiting carrying capacity: area-based indicators of sustainability. Population and Environment: A Journal of Interdisciplinary Studies, 17(3), 195-215.

Reganold, J.P., Papendick, R.I. \& Parr, J.F. (1990). Sustainable agriculture. Scientific American, 262(6), 112-120.

Rigby, D., Woodhouse, P., Young, T. \& Burton, M. (2001). Constructing a farm level indicator of sustainable agricultural practice. Ecological Economics, 39(3), 463-478.

Robèrt, K-H, Daly, H., Hawken, P. \& Holmberg, J. (1997). A compass for sustainable development. International Journal for Sustainable Development and Ecology, 4, 79-92.

Rostad, H. \& Padbury, G. (2005). Wind erosion. In Lefebvre, A., Eilers, W., \& Chunn, B. (Eds.). Environmental sustainability of Canadian agriculture: agrienvironmental indicator report series - report \#2 (pp.97-100). Ottawa, ON: Agriculture and Agri-Food Canada.

Seidl, I. \& Tisdell, C.A. (1999). Carrying capacity reconsidered: from Malthus' population theory to cultural carrying capacity. Ecological Economics, 31(3), 395408.

Semple, E.C. (1928). Ancient Mediterranean agriculture: part I. Agricultural History, 2(2), 61-98.

Senanayake, R. (1984). The ecological, energetic and agronomic systems of ancient and modern Sri Lanka. In Douglass G.K. (Ed.), Agricultural sustainability in a changing world order (pp. 227-237). Boulder, CO: Westview Press.

Sharpley, A.N., Daniels, T., Sims, T., Lemunyon, J., Stevens, R. \& Parry, R. (2003). Agricultural phosphorus and eutrophication ( $2^{\text {nd }}$ Ed.). US Department of Agriculture, University Park PA: Agricultural Research Service, ARS-149.

Shearman, R. (1990). The meaning and ethics of sustainability. Environmental Management, 14(1), 1-8.

Sheppard, S.C., Bittman, S. \& Tait, J. (2005). Ammonia. In Lefebvre, A., Eilers, W., \& Chunn, B. (Eds.). Environmental sustainability of Canadian agriculture: agri-environmental indicator report series - report \#2 (pp.149-152). Ottawa, ON: Agriculture and Agri-Food Canada.

Smeets, E. \& Weterings, R. (1999). Environmental indicators: typology and overview. Retrieved August 29, 2008 from:

http://www.ambiente.provincia.foggia.it/Aree $\% 20$ tematiche/Aree $\% 20$ protette $\% 2$ 0e\%20paesaggio/documenti1/10_EnvIndic.pdf 
Smit, B. \& Brklacich, M. (1989). Sustainable development and the analysis of rural systems. Journal of Rural Studies, 5(4), 405-414.

Smit, B. \& Smithers, J. (1993). Sustainable agriculture: interpretations, analyses and prospects. Canadian Journal of Regional Science, 16(3), 499-524.

Smith, A.K. (1991). Creating a world economy: merchant capital, colonialism and world trade, 1400-1825. Boulder, CO: Westview Press.

Smith, B.D. (1995). The emergence of agriculture. New York, NY: W.H. Freeman and Company.

Smith, C.S. \& McDonald, G.T. (2002). Assessing the sustainability of agriculture at the planning stage. Journal of Environmental Management, 52(1), 15-37.

Smith, C.A.S. \& McRae, T. (2000). Understanding and assessing the sustainability of agriculture. In McRae, T., Smith, C.A.S., and Gregorich, L.J. (Eds). 2000. Environmental sustainability of Canadian agriculture: report of the agrienvironmental indicator project. A summary (pp. 2). Ottawa, ON: Agriculture and Agri-Food Canada.

Staff, M.C. (1998). Cultured milk and fresh cheeses. In Early, R., (Ed.), The Technology of Dairy Products (2 ${ }^{\text {nd }}$ ed.) (pp. 123-157). London, UK: Blackie Academic \& Professional.

Statistics Canada, (n.d.). Population and dwelling counts, for Canada, Provinces and Territories, 2001 and 1996 censuses - 100\% data. Retrieved July 3, 2009 from:

http://www12.statcan.ca/english/census01/products/standard/popdwell/TablePR.cfm

Statistics Canada, (2002). Fruit and vegetable production, volume 70(2). Retrieved June 1, 2009 from: http://dsp-psd.tpsgc.gc.ca/Collection-R/Statcan/22003-XIB/22-003-XIB-e.html

Statistics Canada, (2003a). Sub-provincial population dynamics: the continuing urbanization of Canada. Retrieved May 4, 2009 from:

http://geodepot.statcan.ca/Diss/Highlights/Page7/Page7_e.cfm

Statistics Canada, (2003b). Family food expenditure survey-2001. Retrieved May 8, 2008 from: http://www.statcan.gc.ca/dli-ild/data-donnees/ftp/foodexdepalim/foodex-depalimentaires2001-eng.htm 
Statistics Canada, (2005a). Profile of marital status, common-law status, families, dwellings and households, for Canada, Provinces, Territories, Census Divisions and Census Subdivisions, 2001 Census. Retrieved May 25, 2009 from:

http://www12.statcan.ca/english/census01/products/standard/profiles/RetrievePr ofile.cfm?Temporal $=2001 \&$ PID $=56146 \& A P A T H=1 \& R L=3 \& I P S=95 F 0487 X C B 2001$ 001

Statistics Canada, (2005b). Livestock feed requirements study. Retrieved July 11, 2008 from: http://dsp-psd.pwgsc.gc.ca/Collection/Statcan/23-501-X/23-501XIE2003001.pdf

Statistics Canada, (2008a). Food consumption in Canada - data sources: additional documentation. Retrieved July 8, 2008 from: http://www.statcan.ca/cgi-bin/imdb/p2SV.pl?Function=getSurvey\&SDDS=3475\& lang $=e n \& d b=\mathrm{I} M D B \& d b g=f \& a d m=8 \& d i s=2$

Statistics Canada, (2008b). Food statistics in Canada. Retrieved July 8, 2008 from: http://www.statcan.gc.ca/cgi$\mathrm{bin} / \mathrm{imdb} / \mathrm{p} 2$ SV.pl?Function $=$ getSurvey\&SDDS $=3475 \&$ lang $=\mathrm{en} \& \mathrm{db}=\mathrm{IMDB} \& \mathrm{dbg}=\mathrm{f}$ \&adm $=8 \&$ dis $=2$

Statistics Canada, (2009). CANSIM II. Retrieved May 25, 2009 from: http://cansim2.statcan.ca/cgi-win/cnsmcgi.exe?CANSIMFile=CII/CII_1_E.HTM\& RootDir $=$ CII/

Swanton, C.J., Harker, K.N. \& Anderson, R.L. (1993). Crop losses due to weeds in Canada. Weed Technology, 7(2), 537-542.

Theunissen, J., Booij, C.J.H., \& Lotz, A.P. (1995). Effects of intercropping white cabbage with clovers on pest infestation and yield. Entomologia Experimentalis et Applicata, 74(1), 7-16.

Thompson, P.B. \& Nardone, A. (1999). Sustainable livestock production: methodological and ethical challenges. Livestock Production Science, 61(2-3), 111-119.

Tilman, D. (1999). Global environmental impacts of agricultural expansion: the need for sustainable and efficient practices. Proceedings of the National Academy of Sciences, 96(11), 5995-6000.

Tilman, D., Cassman, K.G., Matson, P.A., Naylor, R. \& Polasky, S. (2002). Agricultural sustainability and intensive production practices. Nature, 418(6898), 671-677. 
Tomalty, R., Alexander, D., Anielski, M., Wilson, J., Jozsa, A., Haider, M., CartinArtega, F. \& Casey, D. (2007). Ontario community sustainability report, 2007. Drayton Valley, AB: The Pembina Institute. Retrieved March 18, 2009 from: http://www.pembina.org/pub/1512

Topp, E., van Bochove, E., Thériault, G., Dechmi, F. \& Lapin, D. (2005). Pathogens. In Lefebvre, A., Eilers, W., \& Chunn, B. (Eds.). Environmental sustainability of Canadian agriculture: agri-environmental indicator report series - report \#2 (pp.138-139). Ottawa, ON: Agriculture and Agri-Food Canada.

Tremblay, M. (2008). Silage storage techniques. Retrieved June 6, 2009 from: http://www.agriculture.gov.sk.ca/Default.aspx?DN=0f4ad0a5-6733-4472-9e1195cf79108918

United Nations Population Division, (2009). World population prospects: the 2008 revision population database. Sri Lanka, 1950-2005. Retrieved March 18, 2009 from: http://esa.un.org/unpp/index.asp

United States Department of Agriculture, (2007). Food and Nutrition Service USDA commodity food fact sheet for schools \& child nutrition institutions. Retrieved May 25, 2009 from: http://www.fns.usda.gov/fdd/schfacts/rpts/allfacts_bycode_veg-fruits.pdf

United States Department of Agriculture, (2009). National Agricultural Statistics Service: publications - 2001 agricultural statistics. Retrieved August, 2008 from: http://www.nass.usda.gov/Publications/Ag_Statistics/2001/index.asp

van Bochove, E., Thériault, G., Dechmi, F. \& Leclerc, M-L. (2005). Phosphorus. In Lefebvre, A., Eilers, W., \& Chunn, B. (Eds.). Environmental sustainability of Canadian agriculture: agri-environmental indicator report series - report \#2 (pp.131-135). Ottawa, ON: Agriculture and Agri-Food Canada.

van den Bergh, J.C.J.M. \& Verbruggen, H. (1999). Spatial sustainability, trade and indicators: an evaluation of the 'ecological footprint.' Ecological Economics, $29(1), 61-72$.

van Vliet, L.J.P., Padbury, G.A., Rees, H.W. \& Matin, M.A. (2005). Water erosion. In Lefebvre, A., Eilers, W., \& Chunn, B. (Eds.). Environmental sustainability of Canadian agriculture: agri-environmental indicator report series - report \#2 (pp.90-96). Ottawa, ON: Agriculture and Agri-Food Canada.

Vibhakara, H.S. \& Bawa, A.S. (2006) Manufacturing jams and jellies. In Hui, Y.H. (Ed.) Handbook of fruits and fruit processing (pp. 189-204). Ames, IA: Blackwell Publishing Professional.

Vitousek, P.M., Ehrlich, P.R., Ehrlich, A.H. \& Matson, P.A. (1986). Human appropriation of the products of photosynthesis. BioScience, 36(6), 368-373. 
Wackernagel, M. \& Rees, W. (1996). Our ecological footprint. Gabriola Island, BC: New Society Publishers.

Walter-Toews, D. (1996). Ecosystem health: a framework for implementing sustainability in agriculture. BioScience, 46(9), 686-689.

Weiss, H. \& Bradley, R.S. (2001). What drives societal collapse? Science, 291(5504), 609-610.

Welch, R.M. \& Graham, R.D. (1999). A new paradigm for world agriculture: productive, sustainable, nutritious, healthful food systems. Field Crops Research, $60,1-10$.

White, T. (2000). Diet and the distribution of environmental impact. Ecological Economics, 34(1), 145-153.

Wiebe, B.H., Eilers, R.G., Eilers, W.D. \& Brierley, J.A. (2005). Soil salinity. In Lefebvre, A., Eilers, W., \& Chunn, B. (Eds.). Environmenta/ sustainability of Canadian agriculture: agri-environmental indicator report series - report \#2 (pp.114-118). Ottawa, ON: Agriculture and Agri-Food Canada.

Wiggins, C. \& Cauvain, S.P. (2007). Proving, baking and cooling. In Cauvain, S.P \& Young, L.S. (Ed.s) [Electronic resource]. Technology of breadmaking (pp. 141174). Springer US.

World Commission on Environment and Development, (1987). Our common future. New York, NY: Oxford University Press.

Zinck, J.A., Beeroterán, J.L., Farshad, A, Moameni, A., Wokabi, S. \& Van Ranst, E. (2004). Approaches to assessing sustainable agriculture. Journal of Sustainable Agriculture, 23(4), 87-109. 
Appendix 1 
Appendix E Food Code Descriptions

\begin{tabular}{|c|c|}
\hline Food code & Description \\
\hline F004 & Beef hip cuts (except shank cuts) - fresh or frozen \\
\hline F004 & Beef Swiss steaks - fresh or frozen \\
\hline F004 & Minute steak - fresh or frozen \\
\hline F004 & Beef Tournedos - fresh or frozen \\
\hline F004 & Beef sirloin tip cuts - fresh or frozen \\
\hline F004 & Beef sandwich steaks - fresh or frozen \\
\hline F004 & Beef rump cuts - fresh or frozen \\
\hline F004 & Beef round cuts (including eye-of-round) - fresh or frozen \\
\hline F004 & Beef Chinese fondue - fresh or frozen \\
\hline F004 & Beef Boston steaks - fresh or frozen \\
\hline F004 & French beef - fresh or frozen \\
\hline F005 & Beef loin cuts - fresh or frozen \\
\hline F005 & Beef brochettes (fresh or frozen) \\
\hline F005 & Beef t-bone steaks - fresh or frozen \\
\hline F005 & Filet mignon - fresh or frozen \\
\hline F005 & Beef wing/club steaks - fresh or frozen \\
\hline F005 & Beef tenderloin cuts - fresh or frozen \\
\hline F005 & Beef strip/New Yorkttop cuts - fresh or frozen \\
\hline F005 & Beef pin bone steaks - fresh or frozen \\
\hline F005 & Baron of beef - fresh or frozen \\
\hline F005 & Beef porterhouse steaks - fresh or frozen \\
\hline F006 & Beef rib cuts - fresh or frozen \\
\hline F006 & $\begin{array}{l}\text { Beef rib cuts (including standing, rolled, or prime) - fresh or } \\
\text { frozen }\end{array}$ \\
\hline F006 & Beef rib eye/delmonico/spencer cuts - fresh or frozen \\
\hline F006 & Beefeater roast - fresh or frozen beef \\
\hline F007 & Beef chuck cuts (except shank cuts) - fresh or frozen \\
\hline F007 & Beef shoulder cuts - fresh or frozen \\
\hline F007 & Beef short-rib roasts - fresh or frozen \\
\hline F007 & Beef blade cuts - fresh or frozen \\
\hline F007 & Beef chuck cuts - fresh or frozen \\
\hline F007 & Beef cross-cut rib cuts - fresh or frozen \\
\hline F008 & Stewing beef - fresh or frozen \\
\hline F008 & Beef pieces - fresh or frozen \\
\hline Foog & Ground beef (including patties) - fresh or frozen \\
\hline F009 & Beef hamburger - fresh or frozen \\
\hline Foog & Beef patties - fresh or frozen \\
\hline F009 & Beef ground - fresh or frozen \\
\hline F009 & Beef steakettes - fresh or frozen \\
\hline
\end{tabular}




\begin{tabular}{|c|l|}
\hline F015 & Beef carcasses and primal portions - fresh or frozen \\
\hline F015 & $\begin{array}{l}\text { Beef, other (incl. brisket, plate, flank, shank cuts) - fresh or } \\
\text { frozen }\end{array}$ \\
\hline F015 & Beef hinds - fresh or frozen \\
\hline F015 & Beef shank primal portions - fresh or frozen \\
\hline F015 & Beef rib primal portions - fresh or frozen \\
\hline F015 & Beef plate primal portions - fresh or frozen \\
\hline F015 & Beef sides - fresh or frozen \\
\hline F015 & Beef fronts - fresh or frozen \\
\hline F015 & Beef flank primal portions - fresh or frozen \\
\hline F015 & Beef chuck primal portions - fresh or frozen \\
\hline F015 & Beef brisket primal portions - fresh or frozen \\
\hline F015 & Beef hip primal portions - fresh or frozen \\
\hline F015 & Beef loin primal portions - fresh or frozen \\
\hline F015 & Beef brisket cuts - fresh or frozen \\
\hline F015 & Beef shortbraising ribs - fresh or frozen \\
\hline F015 & Beef shank cuts - fresh or frozen \\
\hline F015 & Beef plate cuts - fresh or frozen \\
\hline F015 & Beef flank cuts - fresh or frozen \\
\hline F015 & Beef london broil - fresh or frozen \\
\hline F026 & Pork leg cuts (except hocks) - fresh or frozen \\
\hline F026 & Pork shank end roasts - fresh or frozen \\
\hline F026 & Pork leg roasts - fresh or frozen \\
\hline F026 & Pork centre ham cuts - fresh or frozen \\
\hline F027 & Pork loin cuts - fresh or frozen \\
\hline F029 & Pork shoulder cuts (including New York or Montreal-style) - \\
\hline F027 & Pork riblets - fresh or frozen \\
\hline F027 & Pork steak - fresh or frozen \\
\hline F027 & Pork loin roasts (including crown) - fresh or frozen \\
\hline F027 & Pork loin chops (rib, country-style or butterfly) - fresh or frozen \\
\hline F027 & Pork brochettes - fresh or frozen \\
\hline F027 & Pork back ribs - fresh or frozen \\
\hline F027 & Breaded pork cutlets - fresh or frozen \\
\hline F027 & Pork tenderloin - fresh or frozen \\
\hline So28 pork (belly cuts) - fresh or frozen \\
\hline Pork shoulder cuts (except hocks) - fresh or frozen \\
\hline For frozen \\
\hline
\end{tabular}




\begin{tabular}{|c|c|}
\hline F035 & Pork carcasses and primal portions - fresh or frozen \\
\hline F035 & Pork - other (including hocks) - fresh or frozen \\
\hline F035 & Pork shoulders - fresh or frozen \\
\hline F035 & Hog carcasses - fresh or frozen \\
\hline F035 & Hog sides - fresh or frozen \\
\hline F035 & Pork bellies - fresh or frozen \\
\hline F035 & Pork legs - fresh or frozen \\
\hline F035 & Pork loins - fresh or frozen \\
\hline F035 & Pork hocks - fresh or frozen \\
\hline F035 & Ground pork - fresh or frozen \\
\hline Fo46 & Chicken (including fowl) - fresh or frozen \\
\hline F046 & Boneless chicken - fresh or frozen \\
\hline F046 & Stewers (chicken) - fresh or frozen \\
\hline F046 & Roasters - chicken - fresh or frozen \\
\hline F046 & Cornish hens - fresh or frozen \\
\hline F046 & Fowl - fresh or frozen \\
\hline F046 & Chicken brochettes - fresh or frozen \\
\hline F046 & Capon chicken - fresh or frozen \\
\hline F046 & Breaded chicken cutlets - fresh or frozen \\
\hline F046 & Broiler chicken - fresh or frozen \\
\hline F046 & Chicken wings (except cooked) - fresh or frozen \\
\hline F047 & Turkey - fresh or frozen \\
\hline Fo49 & Poultry meat and offal from poultry - other - fresh or frozen \\
\hline F049 & Quail - fresh or frozen \\
\hline F049 & Ducks - fresh or frozen \\
\hline F049 & Geese - fresh or frozen \\
\hline F049 & Giblets - fresh or frozen \\
\hline F049 & Pheasants - fresh or frozen \\
\hline F049 & Poultry liver - fresh or frozen \\
\hline F061 & Veal - fresh or frozen \\
\hline F061 & Osso bucco - fresh or frozen \\
\hline F061 & Veal scaloppini - fresh or frozen \\
\hline F061 & Ground veal - fresh or frozen \\
\hline Fo71 & Liver from mammals - fresh or frozen \\
\hline Fo74 & Offal from mammals - other - fresh or frozen \\
\hline F074 & Stomachs (tripe) - fresh or frozen \\
\hline F074 & Ox tails - fresh or frozen \\
\hline F074 & Tongues - fresh or frozen \\
\hline F074 & Sweetbreads - fresh or frozen \\
\hline F074 & Soup bones \\
\hline F074 & Knuckles - fresh or frozen \\
\hline F074 & Feet - fresh or frozen \\
\hline Fo74 & Kidneys - fresh or frozen \\
\hline Fo74 & Tails - fresh or frozen \\
\hline F074 & Hearts - fresh or frozen \\
\hline F074 & Marrow bones - fresh or frozen \\
\hline
\end{tabular}




\begin{tabular}{|c|c|}
\hline F076 & Lamb and mutton - fresh or frozen \\
\hline F076 & Meat (except poultry) - other - fresh or frozen \\
\hline F076 & Lamb - fresh or frozen \\
\hline F076 & Mutton - fresh or frozen \\
\hline F076 & Goat meat - fresh or frozen \\
\hline F076 & Venison - fresh or frozen \\
\hline F076 & Horse meat - fresh or frozen \\
\hline F076 & Frogs legs - fresh or frozen \\
\hline F076 & Caribou meat - fresh or frozen \\
\hline F076 & Buffalo meat - fresh or frozen \\
\hline F076 & Rabbit meat - fresh or frozen \\
\hline F082 & Bacon \\
\hline F082 & Peameal bacon (back bacon) \\
\hline F083 & Ham (except cooked ham) \\
\hline F083 & Cottage rolls \\
\hline F083 & Picnic ham \\
\hline F083 & Uncooked ham \\
\hline F083 & Smoked ham \\
\hline F083 & Picnic shoulder ham \\
\hline F083 & Ham slices (steaks) \\
\hline F083 & Ham shanks \\
\hline F083 & Ham - pickled (except canned) \\
\hline F083 & Ham butts - uncooked \\
\hline F085 & Cured meat - other \\
\hline F085 & Smoked poultry meat \\
\hline F085 & Corned beef - brisket \\
\hline F085 & Corned beef - sweet pickled \\
\hline F085 & Cured bacon rinds \\
\hline F085 & Cured pigs feet (edible offal) \\
\hline F085 & Jerked meat - (jerky) (except canned) \\
\hline F085 & Pail salt beef \\
\hline F085 & Pork hocks (edible offal), (except canned) - pickled \\
\hline F085 & Salted pork \\
\hline F085 & Smoked beef, except pre-cooked \\
\hline F085 & Sunrise Salt Meat (TM) \\
\hline F091 & Uncooked sausage \\
\hline F091 & Beef and pork sausage - uncooked, chilled or frozen \\
\hline F091. & Beef sausage - uncooked, chilled or frozen \\
\hline F091 & Breakfast sausage - uncooked \\
\hline F091 & Country-style sausage - uncooked \\
\hline F091 & English bangers - uncooked \\
\hline F091 & Farmer style sausage uncooked - chilled or frozen \\
\hline F091 & Link sausage - uncooked \\
\hline F091 & Longanisa - uncooked \\
\hline F091 & Oktoberfest sausage - uncooked \\
\hline F091 & Pork sausage - uncooked, chilled or frozen \\
\hline
\end{tabular}




\begin{tabular}{|c|c|}
\hline F092 & Bologna \\
\hline F093 & Wieners (except canned) \\
\hline F093 & Wieners (made with chicken) - except canned \\
\hline F093 & BBQ wieners - except canned \\
\hline F093 & Frankfurters (except canned) \\
\hline F093 & Campfire garlic - except canned \\
\hline F096 & Cooked/cured sausage - other \\
\hline F096 & Pancetta \\
\hline F096 & Liver cheese (liver loaf) \\
\hline F096 & Leona style sausage \\
\hline F096 & Liver sausages (except canned) \\
\hline F096 & Liverwurst sausage \\
\hline F096 & Lunenburg pudding \\
\hline F096 & Merguez \\
\hline F096 & Milano sausage \\
\hline F096 & Mortadella sausage \\
\hline F096 & White pudding sausage (except canned) \\
\hline F096 & Pastrami sausage (except canned) \\
\hline F096 & Bratwurst sausage \\
\hline F096 & Pepperoni sausage \\
\hline F096 & Polish/summer sausage \\
\hline F096 & Salami \\
\hline F096 & Saveloy sausage \\
\hline F096 & Vienna sausage \\
\hline F096 & Kolbassa sausage \\
\hline F096 & Summer sausage \\
\hline F096 & Black pudding sausage - cooked or cured (except canned) \\
\hline F096 & Brockwurst sausage \\
\hline F096 & Andouillettes (except canned) \\
\hline F096 & Bavarian sausage \\
\hline F096 & Knackwurst sausage (except canned) \\
\hline F096 & Beer sausage \\
\hline F096 & Blood pudding sausage \\
\hline F096 & Braunschweiger sausage \\
\hline F096 & Capicolla sausage \\
\hline F096 & Holsteiner sausage \\
\hline F096 & Beef smokies sausage - cooked or cured \\
\hline F096 & Hot italian sausage \\
\hline F096 & Chinese sausage \\
\hline F096 & Har coil sausage \\
\hline F096 & Goteborg sausage \\
\hline F096 & Genoa sausage \\
\hline F096 & Garlic ring sausage \\
\hline FO96 & Dry sausage \\
\hline F096 & Mastro (TM) \\
\hline
\end{tabular}




\begin{tabular}{|c|c|}
\hline F097 & Cooked (boiled) ham \\
\hline F097 & Luncheon ham \\
\hline F097 & Prosciutto (except canned) \\
\hline F097 & Sliced ham \\
\hline F100 & Ready-cooked meat - hot - other \\
\hline F100 & Other ready-cooked meat (except hot) (includes cold cuts) \\
\hline F100 & Fried chicken - hot \\
\hline F100 & Chicken wings (hot) \\
\hline F100 & Turkey pieces - hot \\
\hline F100 & Meat loaf - hot \\
\hline F100 & Cooked whole turkey - hot \\
\hline F100 & Chicken nuggets (hot) \\
\hline$F 100$ & Chicken burgers - hot \\
\hline$F 100$ & Barbequed or roasted poultry meat - hot \\
\hline F100 & Chicken strips (hot) \\
\hline$F 100$ & Barbequed or roasted meats - hot \\
\hline F100 & Roast chicken - hot (excluding whole bbq) \\
\hline F100 & Roast chicken - frozen \\
\hline F100 & Luncheon loaf (except canned) \\
\hline F100 & Luncheon meats (including sliced and prepackaged) \\
\hline F100 & $\begin{array}{l}\text { Macaroni and cheese loaf (mainly meat) (including sliced and } \\
\text { prepackaged) }\end{array}$ \\
\hline F100 & Turkey rolls - pre-cooked - frozen \\
\hline F100 & Meat (except canned) - pre-cooked - frozen \\
\hline F100 & Meat and olive loaf (except canned) \\
\hline F100 & Meat loaves and jellied meats (except canned) \\
\hline F100 & Mock chicken (except canned) \\
\hline F100 & Pimento loaf (except canned) - pickled \\
\hline F100 & Scotch eggs \\
\hline F100 & Smoked beef - pre-cooked \\
\hline$F 100$ & Spiced beef (including sliced and prepackaged) \\
\hline F100 & Jellied veal (except canned) \\
\hline F100 & Chicken wings - cooked (except heated) \\
\hline$F 100$ & Pickle and pimento ham loaf (except canned) \\
\hline F100 & Cooked pork roast \\
\hline F100 & Ham loaf (except canned) \\
\hline F100 & Fried chicken - frozen \\
\hline F100 & Corned beef (except canned) \\
\hline F100 & Cooked turkey pieces \\
\hline F100 & Chicken strips \\
\hline $\mathrm{F} 100$ & Chicken nuggets - ready-cooked \\
\hline F100 & Chicken burgers \\
\hline F100 & Chicken - frozen cooked \\
\hline F100 & Cha sui (barbequed pork) - hot or cold \\
\hline F100 & Boil-in-a-bag meat (except ham) (except canned) \\
\hline
\end{tabular}




\begin{tabular}{|c|c|}
\hline F100 & Barbequed or roasted poultry meat (except canned) \\
\hline F100 & Barbequed or roasted meats (except hot) \\
\hline F100 & Jellied tongue (except canned) \\
\hline F100 & Cooked whole turkey or sliced turkey \\
\hline F101 & Meat preparations (except hot) - other \\
\hline F101 & Meat preparations - hot - other \\
\hline F101 & Sweet and sour spareribs (except hot) \\
\hline F101 & Solid meat essences \\
\hline F101 & Skillet strips \\
\hline F101 & Sausage meat - fresh or frozen \\
\hline F101 & Sausage rolls - fresh \\
\hline F101 & Tourtiere \\
\hline F101 & Reuben \\
\hline F101 & Powdered meat essences \\
\hline F101 & Poultry pastes (except canned) \\
\hline F101 & Potted meats (except canned) \\
\hline F101 & Meat soup stock (excepl canned) \\
\hline F101 & Meat salads \\
\hline F101 & Chicken pot pies (except pre-cooked frozen) \\
\hline F101 & Meat pies (including poultry) - fresh \\
\hline F101 & Scrapple (except canned) \\
\hline F101 & Beef stew - dried \\
\hline F101 & Cooked meat offal in aspic or coated with fat (except canned) \\
\hline F101 & Dongo-dongo \\
\hline F101 & Haggis \\
\hline F101 & Head cheese (cretons) and scrapple (except canned) \\
\hline F101 & Jamaican patty \\
\hline F101 & Meat loaf mix (beef, pork, veal) \\
\hline F101 & Meat pastes (except canned) \\
\hline F101 & Meat pates (except canned) \\
\hline F101 & Beef and kidney pies (except canned) \\
\hline F101 & Beef \& kidney pie - hot \\
\hline F101 & Poultry pastes (hot) \\
\hline F101 & Tourtiere - hot \\
\hline F101 & Sweet \& sour spareribs - hot \\
\hline F101 & Sausage rolls - hot \\
\hline F101 & Sausage meat - hot \\
\hline F101 & Meat soup stock - hot \\
\hline F101 & Meat pies (including poultry) - hot \\
\hline F101 & Meat pastes (hot) \\
\hline F101 & Chicken pot pies - hot \\
\hline F101 & Jamaican patty (hot) \\
\hline
\end{tabular}




\begin{tabular}{|c|c|}
\hline F108 & Hams - canned \\
\hline F108 & Meat stews - canned \\
\hline F108 & Prosciutto-canned \\
\hline F108 & Picnic hams - canned \\
\hline F108 & Beef ragout - canned \\
\hline F108 & Beef stew - canned \\
\hline F108 & Irish stew - canned \\
\hline F108 & Meat ball stew - canned \\
\hline F110 & $\begin{array}{l}\text { Meat and meat preparations (except infant foods) - other - } \\
\text { canned }\end{array}$ \\
\hline F110 & Meat-filled cannelloni - canned \\
\hline F110 & Pate de foie gras - canned \\
\hline F110 & Oxtails - canned \\
\hline F110 & Ox (beef) tongues - canned \\
\hline F110 & Pork sausage - canned \\
\hline F110 & Meat-filled ravioli - canned \\
\hline F110 & Spiced pork and ham - canned \\
\hline F110 & Meat balls and gravy (beef) - canned \\
\hline F110 & Meat balls and gravy, n.e.s. - canned \\
\hline F110 & Mutton or lamb (except infant foods) - canned \\
\hline F110 & Pork spread - canned \\
\hline F110 & Spiced beef - canned \\
\hline F110 & Steak and kidney pie - canned \\
\hline F110 & Truffles with pate de foie de gras - canned \\
\hline F110 & Turkeys - canned \\
\hline F110 & Veal spread - canned \\
\hline F110 & Wieners and beans - canned \\
\hline F110 & Wieners or frankfurters - canned \\
\hline $\mathrm{F} 110$ & Liver paste - canned \\
\hline F110 & Smoked bacon rinds - canned \\
\hline F110 & Boned chicken - canned \\
\hline F110 & Ham spread - canned \\
\hline F110 & Bacon - canned \\
\hline F110 & Beef dinners - canned \\
\hline F110 & Beef fluid (meat extract) - canned \\
\hline F110 & Beef hash (except infant foods) - canned \\
\hline F110 & Beef steak and onions - canned \\
\hline F110 & Braised steak - canned \\
\hline F110 & Brawn - canned \\
\hline$F 110$ & Chicken loaves - canned \\
\hline F110 & Flakes of ham - canned \\
\hline F110 & Flakes of turkey - canned \\
\hline F110 & Beef paste - canned \\
\hline$F 110$ & Meat gravy - canned \\
\hline F110 & Chicken-a-la-king - canned \\
\hline
\end{tabular}




\begin{tabular}{|c|c|}
\hline $\mathrm{F} 110$ & Flakes of corned beef - canned \\
\hline $\mathrm{F} 110$ & Flakes of chicken - canned \\
\hline F110 & Deviled ham - canned \\
\hline F110 & Corned beef - canned \\
\hline $\mathrm{F} 110$ & Cooked fancy meats (edible offal) (except infant foods) - canned \\
\hline F110 & Cocktail sausages - canned \\
\hline F114 & Cod - fresh or frozen \\
\hline $\mathrm{F} 114$ & Atlantic cod - fresh or frozen \\
\hline F114 & Bakala fish (cod) - fresh or frozen \\
\hline F114 & Gray cod - fresh or frozen \\
\hline F114 & Rock cod - fresh or frozen \\
\hline $\mathbf{F 1 1 5}$ & Flounder and sole - fresh or frozen \\
\hline F115 & Petrale - fresh or frozen \\
\hline F115 & Brill - fresh or frozen fish \\
\hline F115 & Plaice - fresh or frozen \\
\hline F115 & Arrowtooth - fresh or frozen \\
\hline F115 & Dab - fresh or frozen fish \\
\hline F115 & Pacific turbot - fresh or frozen \\
\hline F116 & Haddock - fresh or frozen \\
\hline F123 & Salmon - fresh or frozen \\
\hline$F 123$ & Kokanees - fresh or frozen \\
\hline$F 123$ & Salmon fillets - fresh or frozen \\
\hline F125 & Sea fish - other - fresh or frozen \\
\hline F125 & Sea smelt - fresh or frozen \\
\hline F125 & Sea bass - fresh or frozen \\
\hline F125 & Sardines (sardina) - fresh or frozen \\
\hline F125 & Sablefish - fresh or frozen \\
\hline F125 & Rosefish - fresh or frozen fish \\
\hline $\mathrm{F} 125$ & Shad - fresh or frozen fish \\
\hline$F 125$ & Pollock (bluefish) - fresh or frozen \\
\hline F125 & Steelhead trout - fresh or frozen \\
\hline F125 & Ocean perch - fresh or frozen fish \\
\hline F125 & Redfish - fresh or frozen fish \\
\hline F125 & Shark - fresh or frozen \\
\hline F125 & Silverfish \\
\hline F125 & Snappers - fresh or frozen \\
\hline F125 & Ocean catfish (wolf fish) - fresh or frozen \\
\hline F125 & Swordfish (brandbill) - fresh or frozen \\
\hline F125 & Tilapia \\
\hline F125 & Tomcod - fresh or frozen fish \\
\hline F125 & Tuna - fresh or frozen sea fish \\
\hline $\mathrm{F} 125$ & Turbot (Greenland halibut) - fresh or frozen \\
\hline F125 & Pilchard - fresh or frozen fish \\
\hline $\mathrm{F} 125$ & Skate (wings) - fresh or frozen fish \\
\hline F125 & Fish piece (log cut) \\
\hline F125 & Allantic silverside \\
\hline
\end{tabular}




\begin{tabular}{|c|c|}
\hline $\mathrm{F} 125$ & Billfish (skipper) - fresh or frozen \\
\hline F125 & Blue runner fish \\
\hline F125 & Boccacio - fresh or frozen \\
\hline F125 & Bream - fresh or frozen \\
\hline F125 & Capelin (caplin) - fresh or frozen fish \\
\hline $\mathrm{F} 125$ & Capucettes \\
\hline $\mathrm{F} 125$ & Cultus cod - fresh or frozen fish \\
\hline F125 & Mikfish \\
\hline F125 & Eulachon (candlefish) - fresh or frozen \\
\hline F125 & Alewife (gasparot, gaspareau, kyak) - fresh or frozen fish \\
\hline F125 & Flatfish - fresh or frozen fish \\
\hline F125 & Groundfish - fresh or frozen \\
\hline $\mathrm{F} 125$ & Hake (ling) - fresh or frozen \\
\hline $\mathrm{F} 125$ & Halibut (flitches) - fresh or frozen \\
\hline F125 & Herring - fresh or frozen fish \\
\hline $\mathrm{F} 125$ & Launce, sand - fresh or frozen fish \\
\hline F125 & Lingcod (cultus cod) - fresh or frozen \\
\hline F125 & Puslier (caesio) fish \\
\hline F125 & Mackerel - fresh or frozen \\
\hline $\mathrm{F} 125$ & Cusk - fresh or frozen fish \\
\hline F129 & Freshwater fish - fresh or frozen \\
\hline F129 & Char - fresh or frozen fish \\
\hline F129 & Menominee - fresh or frozen fish \\
\hline F129 & Mooneye - fresh or frozen fish \\
\hline F129 & Mullet - fresh or frozen fish \\
\hline F129 & Muskellunge (maskinonge, lunge) - fresh or frozen \\
\hline $\mathrm{F} 129$ & Pickerel (blue pike, pikeperch, dore, walleye) - fresh or frozen \\
\hline F129 & Pike - fresh or frozen freshwater fish \\
\hline F129 & Pilot fish - fresh or frozen \\
\hline F129 & Powan - fresh or frozen fish \\
\hline$F 129$ & Redfin - fresh or frozen fish \\
\hline $\mathrm{F} 129$ & Waterbelly - fresh or frozen fish \\
\hline F129 & Redhorse - fresh or frozen fish \\
\hline F129 & Roundfish - fresh or frozen fish \\
\hline F129 & Sauger - fresh or frozen fish \\
\hline$F 129$ & Smelt - fresh or frozen \\
\hline F129 & Sturgeon - fresh or frozen \\
\hline F129 & Sucker - fresh or frozen fish \\
\hline F129 & Sunfish (pumpkinseed) - fresh or frozen \\
\hline$F 129$ & Trout (togue, touladi) - fresh or frozen \\
\hline$F 129$ & $\begin{array}{l}\text { Tullibee (cisco, lake chub, lake herring, kiyi, blueback)- fresh or } \\
\text { frozen }\end{array}$ \\
\hline$F 129$ & Ling - fresh or frozen \\
\hline F129 & Whitefish - fresh or frozen \\
\hline F129 & Chub - fresh or frozen fish \\
\hline F129 & Yellow perch - fresh or frozen fish \\
\hline
\end{tabular}




\begin{tabular}{|c|c|}
\hline F129 & Barbotte - fresh or frozen \\
\hline F129 & Bass (black crappie, calico, redeye)-fresh or frozen \\
\hline $\mathrm{F} 129$ & Bloat (bloater) - fresh or frozen \\
\hline F129 & Bluegill - fresh or frozen \\
\hline F129 & Blues - fresh or frozen \\
\hline F129 & Buffalofish - fresh or frozen \\
\hline F129 & Bulhead - fresh or frozen fish \\
\hline F129 & Coregone - fresh or frozen fish \\
\hline $\mathrm{F} 129$ & Buffalofish (carpsucker) - fresh or frozen fish \\
\hline F129 & Laurette - fresh or frozen fish \\
\hline F129 & Crappies - fresh or frozen fish \\
\hline $\mathrm{F} 129$ & Drum (sheephead) - fresh or frozen fish \\
\hline $\mathrm{F} 129$ & Frost fish - fresh or frozen \\
\hline $\mathrm{F} 129$ & Gizzard - fresh or frozen fish \\
\hline $\mathrm{F} 129$ & Goldeye - fresh or frozen fish \\
\hline F129 & Grayling - fresh or frozen fish \\
\hline $\mathrm{F} 129$ & Greaser - fresh or frozen fish \\
\hline F129 & Inconnu (connie) - fresh or frozen fish \\
\hline $\mathrm{F} 129$ & Lamprey (lamper) - fresh or frozen \\
\hline F129 & Carp - fresh or frozen fish \\
\hline F135 & Fish portions - pre-cooked frozen \\
\hline F135 & Breaded fish portions - pre-cooked frozen \\
\hline $\mathrm{F} 135$ & Fish ball - pre-cooked frozen \\
\hline $\mathrm{F} 135$ & Fish burgers - pre-cooked frozen \\
\hline F135 & Fish portions in batter - pre-cooked frozen \\
\hline F135 & Fish sticks - pre-cooked frozen \\
\hline $\mathrm{F} 135$ & Lemon fillets - pre-cooked frozen \\
\hline F135 & High Liner fish (TM) \\
\hline F140 & Cured fish \\
\hline F140 & Ragoonb \\
\hline F140 & Mackerel - smoked, salted, dried, vinegar cured or pickled \\
\hline F140 & Tullibee - smoked, salted, dried, vinegar cured or pickled \\
\hline $\mathrm{F} 140$ & Trout - smoked, salted, dried, vinegar cured or pickled \\
\hline F140 & Sprats - smoked, salted, dried, vinegar cured or pickled \\
\hline F140 & Sablefish - smoked, salted, dried, vinegar, cured or pickled \\
\hline $\mathrm{F} 140$ & Pollock - smoked, salted, dried, vinegar cured or pickled fish \\
\hline F140 & Mudfish - smoked \\
\hline $\mathrm{F} 140$ & Turbot (greeriland halibut) - smoked, salted, dried or pickled \\
\hline F140 & Hake-smoked, salted, dried, vinegar cured or pickled \\
\hline F140 & Haddock - smoked, salted, dried, vinegar cured or pickled \\
\hline F140 & Alewife-smoked, salted, dried, vinegar cured or pickled \\
\hline F140 & Goldeye - smoked, salted, dried, vinegar cured or pickled \\
\hline $\mathrm{F} 140$ & Eel-smoked, salted, dried, vinegar cured or pickled \\
\hline F140 & Cusk - smoked, salted, dried, vinegar cured or pickled \\
\hline F140 & Cod-smoked, salted, dried, vinegar cured or pickled \\
\hline $\mathrm{F} 140$ & Anchovies - smoked, salted, dried, vinegar cured or pickled \\
\hline
\end{tabular}




\begin{tabular}{|l|l|}
\hline F140 & $\begin{array}{l}\text { Herring (kippers) - smoked, salted, dried, vinegar cured or } \\
\text { pickled }\end{array}$ \\
\hline F140 & Salmon - smoked, salted, dried, vinegar cured or pickled \\
\hline F142 & Salmon - canned \\
\hline F143 & Tuna - canned \\
\hline F143 & Albacore (tuna) - canned \\
\hline F143 & Yellowfin (tuna) - canned \\
\hline F143 & Skipjack or striped-bellied bonito (tuna) - canned \\
\hline F143 & Longfin (tuna) - canned \\
\hline F143 & Bluefin (tuna) - canned \\
\hline F146 & Bonito (tuna) - canned \\
\hline F146 & Fish - other - canned \\
\hline F146 & Kippered snacks - canned \\
\hline F146 & Anchovy - canned \\
\hline F146 & Sardines in tomato sauce - canned \\
\hline F146 & Sardines - canned \\
\hline F146 & Pilchard (sardines) - canned \\
\hline F146 & Mexican fish - canned \\
\hline F146 & Mackerel - canned \\
\hline F146 & Gefilte fish - canned \\
\hline F146 & Fish pate (except shellish) - canned \\
\hline F146 & Fish paste - canned \\
\hline F146 & Finnan haddie - canned fish \\
\hline F146 & Creamed salmon with/without peas - canned \\
\hline F146 & Chicken haddie - canned fish \\
\hline F149 & Herring - canned \\
\hline F149 & Shrimps and prawns \\
\hline F149 & Shrimp meat - canned freeze-dried \\
\hline F149 & Shrimp cocktail - frozen \\
\hline F149 & Shrimp and prawn meat - fresh or frozen \\
\hline F149 & Shrimp and prawn meat - canned \\
\hline F149 & Shrimp - frozen cooked \\
\hline F149 & Breaded shrimps - fresh or frozen \\
\hline Shrimps and prawns in shells - fresh or frozen \\
\hline Breaded shrimps - pre-cooked - frozen \\
\hline
\end{tabular}




\begin{tabular}{|c|c|}
\hline F151 & Shellfish - other \\
\hline F151 & Marine products - all other \\
\hline $\mathrm{F} 151$ & Scallop meat - fresh or frozen \\
\hline F151 & Lobsters in shell - fresh or frozen \\
\hline F151 & Mussels - fresh \\
\hline F151 & Octopus \\
\hline$F 151$ & Oyster meat - fresh or frozen \\
\hline F151 & Oysters in the shell - fresh \\
\hline F151 & package seafood \\
\hline F151 & Smoked oysters - canned \\
\hline F151 & Quahogs \\
\hline F151 & Scallops in shells - fresh \\
\hline F151 & Sepia \\
\hline F151 & Squid (Atlantic or Pacific) \\
\hline F151 & Smoked mussels - canned \\
\hline F151 & Calamari - shellfish \\
\hline F151 & Lobster spread \\
\hline F151 & Periwinkle (winkle) \\
\hline F151 & Clams in shells - fresh \\
\hline F151 & Clam meat - fresh \\
\hline F151 & Abalone in shell - fresh \\
\hline F151 & Lobster preparations - canned \\
\hline F151 & Clam meat - frozen \\
\hline F151 & Crab meat - canned \\
\hline F151 & Crab meat - fresh or frozen \\
\hline$F 151$ & Crabs in shell - fresh or frozen \\
\hline F151 & Lobster paste - canned \\
\hline$F 151$ & Escargots (snails) \\
\hline F151 & Fruit de mer \\
\hline F151 & Chocos shellish \\
\hline F151 & Lobster meat - canned \\
\hline F151 & Lobster meat - fresh \\
\hline$F 151$ & Lobster meat - frozen \\
\hline F151 & Cuttlefish (shellfish) \\
\hline F151 & Turtle mieat \\
\hline F151 & $\begin{array}{l}\text { Caviar substitutes (from roe of other fish, except sturgeon) } \\
\text { canned }\end{array}$ \\
\hline F151 & Eel liver \\
\hline F151 & Fish roe \\
\hline F151 & Fish tongues \\
\hline F151 & Pompano \\
\hline F151 & Seal meat \\
\hline F151 & Caviar - canned (prepared from the roe of sturgeon) \\
\hline
\end{tabular}




\begin{tabular}{|c|c|}
\hline F156 & Cream (except sour cream) \\
\hline F156 & Cereal cream (half and half) \\
\hline F156 & Table cream \\
\hline$F 156$ & Whipping cream \\
\hline F157 & Low-fat milk $(1 \%)$ \\
\hline F158 & Fluid whole milk \\
\hline F159 & Low-fat milk $(2 \%)$ \\
\hline F160 & Fluid skim milk \\
\hline F160 & Shape Lite (TM) \\
\hline F161 & Specialty milk products \\
\hline F161 & Lactose reduced milk \\
\hline F161 & Sterilized milk \\
\hline F161 & Acidophilus milk \\
\hline F161 & Lactaid (TM) \\
\hline F162 & Fresh yogurt (any size) \\
\hline F162 & Kefir (TM) (organic milk) \\
\hline F163 & Butter \\
\hline F163 & Creamery butter \\
\hline F163 & Farm made butter (dairy butter) \\
\hline F163 & Reworked butter \\
\hline F166 & Cheddar cheese \\
\hline F166 & Cheddar cheese (mild, medium, old) (except grated) \\
\hline F166 & Cheddar cheese curds \\
\hline F166 & White cheese (cheddar cheese) (except grated) \\
\hline F166 & Lonepine variety pack (cheese) (TM) \\
\hline F167 & Grated cheese \\
\hline F167 & Grated cheddar cheese \\
\hline F167 & Grated mozzarella cheese \\
\hline F167 & Grated parmesan cheese \\
\hline F167 & Grated romano cheese \\
\hline F167 & Shredded mozzarella cheese (light) \\
\hline F168 & Process cheese \\
\hline F168 & Gruyere process cheese \\
\hline F168 & Spray cheese (aerosol) \\
\hline F168 & Process cheese spread \\
\hline F168 & Process cheese food \\
\hline F168 & Cheese mix \\
\hline F168 & Cheddar based process cheese \\
\hline F168 & Process cheese slices \\
\hline F168 & Velveeta (TM) \\
\hline F168 & Cheese Nibblers (TM) \\
\hline F168 & Cheestrings (TM) \\
\hline F168 & Cheez Whiz (TM) \\
\hline F168 & Cheez Whiz Squeez cheese (TM) \\
\hline F168 & Snackeroo's (TM) \\
\hline
\end{tabular}




\begin{tabular}{|c|c|}
\hline F169 & Cottage cheese (creamed or not creamed) \\
\hline F169 & Ricotta cheese $5 \%$ \\
\hline F175 & Cheese - other \\
\hline F175 & Romano cheese (except grated) \\
\hline $\mathrm{F} 175$ & Jarlsberg cheese \\
\hline F175 & Limburger cheese \\
\hline F175 & Mozzarella cheese (except grated) \\
\hline $\mathrm{F} 175$ & Muenster cheese \\
\hline F175 & Neufchatel cheese \\
\hline F175 & Oka cheese \\
\hline F175 & Parmesan cheese (except grated) \\
\hline F175 & Provolone cheese \\
\hline F175 & Roquefort cheese \\
\hline F175 & Samsoe cheese \\
\hline F175 & Skim milk cheese \\
\hline F175 & Swiss cheese \\
\hline F175 & Trappist cheese \\
\hline F175 & Whey cheese \\
\hline F175 & Havarti cheese \\
\hline F175 & Cheshire cheese \\
\hline F175 & Colby cheese \\
\hline$F 175$ & Anfrom cheese \\
\hline F175 & Blue cheese \\
\hline F175 & Bonbel cheese \\
\hline F175 & Brick cheese \\
\hline F175 & Brie cheese \\
\hline F175 & Cream cheeses \\
\hline F175 & Camembert cheese \\
\hline F175 & Gruyere cheese (except processed) \\
\hline F175 & Danbo cheese \\
\hline F175 & Edam cheese \\
\hline F175 & Elbo cheese \\
\hline F175 & Emmentaler (swiss) cheese \\
\hline F175 & Feta cheese \\
\hline F175 & Ficello cheese \\
\hline F175 & Gorgonzola cheese \\
\hline F175 & Gouda cheese \\
\hline F175 & Boursault cheese (TM) \\
\hline F175 & Philadelphia cream cheese (TM) \\
\hline F177 & Condensed or evaporated milk \\
\hline F177 & Condensed skim milk \\
\hline F177. & Condensed whole milk \\
\hline F177 & Evaporated partly skimmed milk \\
\hline F177 & Evaporated skim milk \\
\hline $\mathrm{F} 177$ & Evaporated whole milk \\
\hline
\end{tabular}




\begin{tabular}{|c|c|}
\hline F178 & $\begin{array}{l}\text { Ice cream and ice milk ( } 500 \mathrm{ml} \text { or more portions, except } \\
\text { novelties) }\end{array}$ \\
\hline F178 & $\begin{array}{l}\text { lce cream and ice milk (less than } 500 \mathrm{ml} \text { portions, except } \\
\text { novelties) }\end{array}$ \\
\hline $\mathrm{F} 178$ & lce milk - 500 ml or more \\
\hline $\mathrm{F} 178$ & Ice cream (less than $500 \mathrm{ml}$ ) \\
\hline $\mathrm{F} 178$ & Ice milk - less than $500 \mathrm{ml}$ \\
\hline F179 & Ice cream or ice milk novelties \\
\hline F179 & Ice cream bars \\
\hline $\mathrm{F} 179$ & Ice milk novelties \\
\hline F179 & Ice cream pies \\
\hline F179 & Ice cream novelties \\
\hline F179 & Ice cream cakes \\
\hline F179 & Ice cream cones (containing ice cream) \\
\hline F179 & Revels (TM) \\
\hline F179 & Fudgsicles (TM) \\
\hline $\mathrm{F} 179$ & Numaid (TM) \\
\hline F179 & Nutty buddies (TM) \\
\hline F181 & Frozen yogurt (less than $500 \mathrm{ml}$ ) (including novelties) \\
\hline F181 & Frozen yogurt ( $500 \mathrm{ml}$ or more) \\
\hline F186 & Eggs \\
\hline F186 & Whole eggs - dried \\
\hline F186 & Butter \& Egg \\
\hline F186 & Egg Beaters (TM) \\
\hline F187 & Dairy products - other \\
\hline F187 & Skim milk powder \\
\hline F187 & Unspecified cheese \\
\hline F187 & Malted milk mix \\
\hline F187 & Whole milk powder \\
\hline F187 & Whip cream - canned \\
\hline F187 & Vegetable dip \\
\hline F187 & Tzatziki (dip made with yogurt and cucumber) \\
\hline F187 & Processed sour cream \\
\hline F187 & Omelette pack \\
\hline F187 & Nacho cheese dip \\
\hline$F 187$ & Butter spread (butter base) \\
\hline F187 & Milk sherbets - frozen ( $500 \mathrm{ml}$ and over) \\
\hline F187 & Goats milk \\
\hline F187 & Garlic spread \\
\hline F187 & Cheese for fondue \\
\hline F187 & Mikshake mix \\
\hline$F 187$ & Buttermilk powder \\
\hline F187 & Garlic butter \\
\hline$F 187$ & Chip dips - dairy base \\
\hline F187 & Chocolate drink, fluid, milk base \\
\hline
\end{tabular}




\begin{tabular}{|c|l|}
\hline F187 & Chocolate malted milk \\
\hline F187 & Dairy spreads with herbs \\
\hline F187 & Devon cream - canned fresh \\
\hline F187 & Drinkable yogurt \\
\hline F187 & Eggnog milk \\
\hline F187 & Buttermilk fluid \\
\hline F187 & Danone cheese/yogurt mixed cup (TM) \\
\hline F187 & Minigo (TM) \\
\hline F187 & Wally Dipper (TM) \\
\hline F187 & Yop (TM) \\
\hline F192 & Bread \\
\hline F192 & Raisin bread \\
\hline F192 & Baguettes \\
\hline F192 & Dietary bread \\
\hline F192 & Garlic bread - fresh or frozen \\
\hline F193 & Unsweetened rolls and buns \\
\hline F193 & Kaiser rolls \\
\hline F193 & Scones \\
\hline F193 & Cheese buns \\
\hline F193 & Rye buns \\
\hline F193 & Tea biscuits \\
\hline F193 & Pastry shells \\
\hline F193 & Onion buns \\
\hline F193 & Scotch baps \\
\hline F193 & Hamburger buns \\
\hline F193 & English muffins \\
\hline F193 & Dinner buns and rolls \\
\hline F193 & Croissants \\
\hline F193 & Brioches \\
\hline F193 & Bagels \\
\hline F193 & Hot dog rolls \\
\hline F193 & Crumpets \\
\hline & \\
\hline
\end{tabular}




\begin{tabular}{|c|c|}
\hline F195 & Crackers and crisp breads \\
\hline F195 & Cheese crackers \\
\hline F195 & Zwieback \\
\hline F195 & Soup crackers \\
\hline F195 & Soda crackers / saltines \\
\hline F195 & Rye-king \\
\hline F195 & Rusks \\
\hline F195 & Party crackers \\
\hline F195 & Melba toast \\
\hline F195 & Crisp bread \\
\hline F195 & Bread sticks \\
\hline F195 & Croutons \\
\hline F195 & Stoned Wheat Thins (TM) \\
\hline F195 & Ritz (TM) \\
\hline F195 & Wasa (TM) \\
\hline F195 & Vegetable Thins (TM) \\
\hline F195 & Dutch rusks \\
\hline F195 & Bacon bites (TM) \\
\hline F195 & Cabaret (TM) \\
\hline F195 & Bacon Dippers (TM) \\
\hline F195 & $\operatorname{Triscuit}(T M)$ \\
\hline F197 & Cookies and sweet biscuits \\
\hline F197 & Wafers (biscuits) \\
\hline F197 & Open-faced or coated mallows \\
\hline F197 & Peanut butter cookies \\
\hline F197 & Plain cookies \\
\hline F197 & Pocky sticks \\
\hline F197 & Sandwich-style biscuits \\
\hline F197 & Oatmeal cookies \\
\hline F197 & Sweetened biscuits \\
\hline F197 & Fruit cookies \\
\hline F197 & Shortbread \\
\hline F197 & Graham wafers \\
\hline F197 & Graham wafer crumbs \\
\hline F197 & Fig newtons \\
\hline F197 & Digestives \\
\hline F197 & Coconut cookies \\
\hline F197 & Coated biscuits \\
\hline F197 & Chocolate chip cookies \\
\hline F197 & Bulk purchase of biscuits \\
\hline F197 & Arrowroot biscuits \\
\hline F197 & Graham wafer pie shells \\
\hline F197 & Wagon Wheels (TM) \\
\hline F197 & Oreo Cookie Crumbs (TM) \\
\hline$F 197$ & Oreo cookie pie shells (TM) \\
\hline
\end{tabular}




\begin{tabular}{|c|c|}
\hline F198 & Doughnuts \\
\hline F198 & Fritters (dessert) \\
\hline F199 & Yeast-raised sweet goods (including fruit buns) \\
\hline F199 & Sweet rolls \\
\hline F199 & Butterhorns \\
\hline F199 & Chelsea buns \\
\hline F199 & Cinnamon buns \\
\hline F199 & Coffee cakes \\
\hline F199 & Danish pastries \\
\hline F199 & Easter buns \\
\hline F199 & Hot cross buns \\
\hline F201 & $\begin{array}{l}\text { Dessert pies, cakes, squares and other pastries (except } \\
\text { frozen and meat pies) }\end{array}$ \\
\hline F201 & Fruit and nut bread \\
\hline F201 & Sweet rice $\&$ banana \\
\hline F201 & Strudels \\
\hline F201 & Spanish bar \\
\hline F201 & Queen Elizabeth cake \\
\hline F201 & Rice cake \& mung bean \\
\hline F201 & Pumpkin bread \\
\hline F201 & Persians \\
\hline F201 & Napoleons \\
\hline F201 & Nanaimo bars (fresh) \\
\hline F201 & Jam tarts \\
\hline F201 & Turnovers (fruits) \\
\hline F201 & Butter tarts \\
\hline F201 & Baklavas \\
\hline F201 & Banana bread \\
\hline F201 & Beaver Tails \\
\hline F201 & Eclairs \\
\hline F201 & Brownies \\
\hline F201 & Rice cake \& pork \\
\hline F201 & Com bread \\
\hline F201 & Cream pies \\
\hline F201 & Cream slice \\
\hline F201 & Custard pies \\
\hline F201 & Custard stices \\
\hline F201 & Bismarck \\
\hline F201 & Pop Tarts (TM) \\
\hline F201 & Rose Marie Vanilla (TM) \\
\hline$F 202$ & Muffins \\
\hline $\mathrm{F} 202$ & Bran muffins \\
\hline $\mathrm{F} 202$ & Corn meal muffins \\
\hline F202 & Muffins - store packaged fresh \\
\hline
\end{tabular}




\begin{tabular}{|c|c|}
\hline F205 & Bakery products - other \\
\hline $\mathrm{F} 205$ & Rice snacks \\
\hline $\mathrm{F} 205$ & Wafer roll \\
\hline $\mathrm{F} 205$ & Plum pudding \\
\hline F205 & Poppadums \\
\hline F205 & Poultry stuffing mix \\
\hline F205 & Refrigerated cookie dough \\
\hline F205 & Refrigerated dinner roll dough \\
\hline $\mathrm{F} 205$ & Rice paper of starch or flour \\
\hline F205 & Rice sticks \\
\hline F205 & Taco shells \\
\hline F205 & Tortilla shells \\
\hline F205 & Umpia wrapper \\
\hline F205 & Pita bread \\
\hline F205 & Rice cakes \\
\hline F205 & Fruit and nut roll - canned \\
\hline F205 & Pizza shells - frozen \\
\hline F205 & Bread crumbs \\
\hline F205 & Canned cake \\
\hline F205 & Dietary biscuits \\
\hline F205 & Platina \\
\hline F205 & Egg roll shells \\
\hline F205 & Graham (Polish) \\
\hline F205 & Hardtack (ship's biscuits) \\
\hline F205 & Ice cream cones and wafers \\
\hline F205 & Matzos (unleavened bread) and matzo products \\
\hline F205 & Meringues \\
\hline F205 & Oat cakes \\
\hline F205 & Passover bread \\
\hline F205 & Dough and uncooked pastry (incl. frozen) \\
\hline F211 & Pasta products - canned \\
\hline F211 & Macaroni and cheese - canned pasta \\
\hline F211 & Vermicelli - canned pasta \\
\hline F211 & Spaghetti with meatballs - canned \\
\hline F211 & Noodle numbers - canned \\
\hline F211 & Spaghetti - canned pasta \\
\hline$F 211$ & Alphabets - canned pasta (TM) \\
\hline F211 & Alpha-getti - canned pasta (TM) \\
\hline$F 211$ & Beef-a-roni (TM) \\
\hline F211 & Scarios $(T M)$ - canned pasta \\
\hline F211 & Zoodles (TM) - canned pasta \\
\hline
\end{tabular}




\begin{tabular}{|c|c|}
\hline F212 & Pasta - fresh or dry \\
\hline$F 212$ & Pastina \\
\hline F212 & Penne \\
\hline F212 & Rigatoni - fresh or dry \\
\hline F 212 & Rotini - fresh or dry \\
\hline F212 & Spaghett - fresh or dry pasta \\
\hline $\mathrm{F} 212$ & Spatzel \\
\hline F212 & Spaghettini - fresh or dry pasta \\
\hline F212 & Pasta shapes (bows, stars, elbows) \\
\hline F 212 & Cannelloni - fresh or dry pasta \\
\hline F212 & Pasta - fresh \\
\hline F212 & Vermicelli - fresh or dry \\
\hline $\mathrm{F} 212$ & Chinese noodles - fresh or dry pasta \\
\hline F212 & Egg noodles - fresh or frozen \\
\hline F212 & Farfall \\
\hline F212 & Kielke \\
\hline F212 & Lasagne - fresh or $d y$ \\
\hline F212 & Macaroni shells \\
\hline F 212 & Manicotti \\
\hline F212 & Udon Noodles (TM) \\
\hline F212 & Barilla (TM) \\
\hline F215 & Pasta mixes \\
\hline $\mathrm{F} 215$ & Pasta casserole bases \\
\hline F215 & Lasagne dinner mix \\
\hline $\mathrm{F} 215$ & Noodles Romanoff - pasta mix \\
\hline F215 & Packaged macaroni dinners \\
\hline $\mathrm{F} 215$ & Top Ramer (TM) \\
\hline F215 & Spirals (TM) - pasta mixes \\
\hline F215 & Hamburger Helper (TM) - pasta mixes \\
\hline $\mathrm{F} 215$ & Kraft dinner (TM) - pasta mixes \\
\hline F221 & Rice (including mixes) \\
\hline F221 & Brown rice \\
\hline F221 & Curried rice mix \\
\hline F221 & Fried rice mix \\
\hline F221 & Instant rice \\
\hline F221 & Parboiled rice \\
\hline F221 & Polished and glazed rice \\
\hline F221 & Rice - pre-cooked \\
\hline$F 221$ & Spanish rice mix \\
\hline $\mathrm{F} 221$ & Wild rice \\
\hline F221 & Wild rice mix \\
\hline F221 & Rice-A-Roni (TM) \\
\hline F221 & Minute Rice (TM) \\
\hline
\end{tabular}




\begin{tabular}{|c|c|}
\hline F226 & Flour \\
\hline F226 & Ontario winter wheat flour (soft white) \\
\hline $\mathrm{F} 226$ & Alberta winter wheat flour (hard red) \\
\hline F226 & Sweet rice powder \\
\hline F226 & Rye four \\
\hline$F 226$ & Potato flour \\
\hline F226 & Oat flour \\
\hline F226 & Mixed cereal flour \\
\hline F226 & Gluten and gluten flour \\
\hline F226 & Durum semolina and flour \\
\hline F226 & Corn flour \\
\hline$F 226$ & Cake flour \\
\hline F 226 & Buckwheat flour \\
\hline $\mathrm{F} 226$ & Blended flour \\
\hline F226 & Rice flour \\
\hline$F 226$ & Masa Mixta (TM) \\
\hline F232 & Cereal grains (unmilled or milled) - other \\
\hline F232 & Natural bran \\
\hline F232 & Uncooked rolled oats \\
\hline $\mathrm{F} 232$ & Wheat germ \\
\hline F232 & Uncooked oatmeal \\
\hline F232 & Pearl barley \\
\hline F232 & Malt \\
\hline$F 232$ & Hominy grits \\
\hline$F 232$ & Couscous \\
\hline F232 & Corn meal \\
\hline F232 & Buckwheat meal \\
\hline F232 & Bulgur \\
\hline F236 & Breakfast cereal (except infant cereal) \\
\hline F236 & Puffed rice \\
\hline F236 & Wheat flakes (breakfast cereal) \\
\hline$F 236$ & Shredded wheat cereal \\
\hline F236 & Puffed wheat \\
\hline F236 & Corn flakes \\
\hline $\mathrm{F} 236$ & Instant oatmeal \\
\hline F236 & Cream of wheat \\
\hline F236 & Instant rolled oats \\
\hline F236 & Bran cereal \\
\hline$F 236$ & Granola \\
\hline F236 & Muffets \\
\hline
\end{tabular}




\begin{tabular}{|c|c|}
\hline F237 & Cake and other flour-based mixes \\
\hline F237 & Yorkshire pudding mix \\
\hline F237 & Pancake flour mix \\
\hline F237 & Pie crust mix \\
\hline F237 & Pudding cake mixes \\
\hline F237 & Quick bread mixes \\
\hline F237 & Roll mix \\
\hline F237 & Snacking cake \\
\hline $\mathrm{F} 237$ & Streusel mix \\
\hline F237 & Dumpling mix \\
\hline F237 & Sponge pudding mixes \\
\hline F237 & Brownies (prepared flour mix) \\
\hline F237 & Muffin mix \\
\hline F237 & Biscuit mix \\
\hline F237 & Macaroon mix \\
\hline F237 & Buckwheat mix \\
\hline F237 & Bundt mix \\
\hline F237 & Cheese cake mix \\
\hline F237 & Cookie mix \\
\hline F237 & Dessert bar mixes \\
\hline F237 & Batter mixes \\
\hline F238 & Cereal-based snack foods \\
\hline F238 & Corn sticks \\
\hline F238 & Pretzels \\
\hline F238 & Prepared popcorn (except candied popcorn) \\
\hline F238 & Salted toasted corn \\
\hline F238 & Popping corn \\
\hline F238 & Microwave popcorn \\
\hline F238 & Corn chips \\
\hline F238 & Cheese sticks \\
\hline $\mathrm{F} 238$ & Nacho chips \\
\hline F238 & Popcorn and vegetable oil in packages \\
\hline$F 238$ & Nu Vita hob-nobs \\
\hline F238 & Sun Chips (TM) \\
\hline$F 238$ & Old Time Onion Squares (TM) \\
\hline$F 238$ & Doritos (TM) \\
\hline F238 & Crunchies (TM) \\
\hline$F 238$ & $\mathrm{CH}$ snacks (TM) \\
\hline$F 238$ & Buttons and Bows (TM) \\
\hline F238 & Bugles (TM) \\
\hline$F 238$ & Bagel Chips (TM) \\
\hline F238 & Pita puffs (TM) \\
\hline F238 & Cheetos Twisties (TM) \\
\hline F239 & Cereal products - other \\
\hline F239 & Nuts and Bolts \\
\hline
\end{tabular}




\begin{tabular}{|l|l|}
\hline F243 & Apples - fresh \\
\hline F243 & Crab apples - fresh \\
\hline F244 & Bananas and plantains - fresh \\
\hline F246 & Grapefruit - fresh \\
\hline F247 & Grapes - fresh \\
\hline F247 & Bulk purchase of grapes \\
\hline F248 & Lemons and limes - fresh \\
\hline F249 & Melons - fresh \\
\hline F249 & Honeydew melons - fresh \\
\hline F249 & Muskmelons - fresh \\
\hline F249 & Watermelons - fresh \\
\hline F249 & Cantaloupes - fresh \\
\hline F250 & Oranges and other citrus fruit - fresh \\
\hline F250 & Ugli fruit - fresh \\
\hline F250 & Bergamots \\
\hline F250 & Citrons - fresh \\
\hline F250 & Clementines - fresh \\
\hline F250 & Kumquats - citrus fruit - fresh \\
\hline F250 & Mandarins - fresh \\
\hline F250 & Minneola \\
\hline F250 & Pomelo \\
\hline F250 & Seville oranges \\
\hline F250 & Tangelos \\
\hline F250 & Tangerines \\
\hline F251 & Peaches and nectarines - fresh \\
\hline F252 & Pears - fresh \\
\hline F253 & Plums - fresh \\
\hline F253 & Greengage plums - fresh \\
\hline F253 & Prune plums - fresh \\
\hline
\end{tabular}




\begin{tabular}{|c|c|}
\hline F256 & Tropical fruit - other - fresh \\
\hline F256 & Mangoes - tropical fruit - fresh \\
\hline F256 & Quinces - tropical fruit - fresh \\
\hline F256 & Pomegranates - fresh \\
\hline F256 & Pitted dates \\
\hline F256 & Pineapples - fresh \\
\hline F256 & Persimmons - tropical fruit - fresh \\
\hline$F 256$ & Passion fruit - tropical fruit - fresh \\
\hline F256 & Papayas - tropical fruit - fresh \\
\hline F256 & Lichis - tropical fruit - fresh \\
\hline F256 & Calamansi \\
\hline F256 & Kiwi fruit - fresh \\
\hline F256 & Olives - fresh \\
\hline F256 & Breadfruit \\
\hline F256 & Chinese pear \\
\hline F256 & Durian - fresh \\
\hline F256 & Figs \\
\hline F256 & Guavas - tropical fruit - fresh \\
\hline F256 & Jack fruit \\
\hline F256 & Kaki \\
\hline F256 & Avocados - fresh \\
\hline F258 & Strawberries - fresh \\
\hline F262 & Fruit - other - fresh \\
\hline F262 & Cranberries - fresh \\
\hline $\mathrm{F} 262$ & Raspberries - fresh \\
\hline F262 & Pumpkin - fresh \\
\hline$F 262$ & Mixed fruit (including fruit baskets) \\
\hline F262 & Rhubarb - fresh \\
\hline F262 & Cherries - fresh \\
\hline F262 & Blueberries - fresh \\
\hline$F 262$ & Apricots - fresh \\
\hline F262 & Five berry mix - fresh \\
\hline F262 & Gooseberries - fresh \\
\hline F266 & Fruit - frozen \\
\hline$F 266$ & Blueberries - frozen \\
\hline F266 & Saba bananas (frozen banana) \\
\hline F266 & Rhubarb-frozen \\
\hline F266 & Raspberries - frozen \\
\hline F266 & Pumpkin - frozen \\
\hline F266 & Pineapples - frozen \\
\hline F266 & Pears - frozen \\
\hline F266 & Cherries - frozen \\
\hline F266 & Apples - frozen \\
\hline F266 & Strawberries - frozen \\
\hline F266 & Peaches - frozen \\
\hline
\end{tabular}




\begin{tabular}{|c|c|}
\hline F272 & Raisins - dried \\
\hline F274 & $\begin{array}{l}\text { Fruit (except canned) - other - dried, dehydrated or other } \\
\text { preserved }\end{array}$ \\
\hline F274 & Maraschino cherries in liquid preservative (except canned) \\
\hline F274 & Prunes (dried plums) \\
\hline F274 & Pineapple - dried \\
\hline $\mathrm{F} 274$ & Pears - dried \\
\hline F274 & Mesclum mixture \\
\hline F274 & Fruit peel - dried \\
\hline F274 & Fruit mixtures - dried \\
\hline F274 & Fruit bars - dried, dehydrated or preserved fruit (except canned) \\
\hline $\mathrm{F} 274$ & Figs - dried \\
\hline $\mathrm{F} 274$ & Dragon eye (dried lychee) \\
\hline $\mathrm{F} 274$ & Currants (dried grapes) \\
\hline F274 & Crystallized fruit peel (except canned) \\
\hline F274 & Crystallized and glace cherries (except canned) \\
\hline F274 & Citrus rinds - dried \\
\hline $\mathrm{F} 274$ & Apples - dried \\
\hline F274 & Candied cherries (except canned) \\
\hline $\mathrm{F} 274$ & Peaches - dried \\
\hline $\mathrm{F} 274$ & Berries - dried or dehydrated \\
\hline F274 & Bananas - dried or dehydrated \\
\hline F274 & Apricols - dried \\
\hline F274 & Dates - dried \\
\hline F281 & Apple juice (except concentrated) \\
\hline F281 & Sweet cider (apple juice) \\
\hline F282 & Grapefruit juice (except concentrated) \\
\hline F283 & Orange juice (except concentrated) \\
\hline F286 & Fruit juice (except concentrated) - other \\
\hline $\mathrm{F} 286$ & Pineapple juice (except concentrated) \\
\hline F286 & Unfermented grape juice (except concentrated) \\
\hline F286 & Blended fruit juices (except concentrated) \\
\hline F286 & Pure or natural papaya juice (except concentrated) \\
\hline F286 & Wild berry juices (except concentrated) \\
\hline F286 & Pure or natural citrus fruit juice (except concentrated) \\
\hline F286 & Pure or natural apricot juice (except concentrated) \\
\hline F286 & Prune nectar \\
\hline F286 & Lime juice (except concentrated) \\
\hline F286 & Lemon juice (except concentrated) \\
\hline F286 & Grape nectar - (except concentrated) \\
\hline F286 & Grape juice for wine preparation \\
\hline F286 & Blended orange and grapefruit juice (except concentrated) \\
\hline F286 & Apricot nectar (except concentrated) \\
\hline F286 & Passion fruit juice (except concentrated) \\
\hline F286 & Cranberry juice (except concentrated) \\
\hline F286 & 5 Alive juice (TM) \\
\hline
\end{tabular}




\begin{tabular}{|l|l|}
\hline F288 & Concentrated orange juice \\
\hline F292 & Concentrated fruit juice - other \\
\hline F292 & Concentrated blended fruit juice - frozen \\
\hline F292 & Pure or natural citrus fruit juice concentrates - frozen \\
\hline F292 & Pineapple juice concentrates - frozen \\
\hline F292 & Lime juice concentrates - fresh or frozen \\
\hline F292 & Lemon juice concentrates - fresh or frozen \\
\hline F292 & Concentrated grapefruit juice - frozen \\
\hline F292 & Apple juice concentrates - frozen \\
\hline F292 & Grape juice concentrates - fresh or frozen \\
\hline F292 & Tropical Sun (TM) \\
\hline F295 & Peaches - canned \\
\hline F297 & Pineapple - canned \\
\hline F298 & Mixed fruit - canned \\
\hline F298 & Peaches and pears - canned \\
\hline F298 & Fruit cocktail - canned \\
\hline F298 & Fruit salad - canned \\
\hline F298 & Tropical fruit cocktail - canned \\
\hline F298 & Orange and grapefruit pieces - canned \\
\hline F302 & Fruit - other - canned \\
\hline F302 & Pears - canned \\
\hline F302 & Strawberries - canned \\
\hline F302 & Raspberries - canned \\
\hline F302 & Pumpkin (except pie filling) - canned \\
\hline F302 & Plums - canned \\
\hline F302 & Maraschino cherries - canned \\
\hline F302 & Mandarin oranges - canned \\
\hline F302 & Loganberries - canned \\
\hline F302 & Lichis - canned \\
\hline F302 & Apple sauce - canned \\
\hline F302 & Figs - canned \\
\hline F302 & Cranberries - canned \\
\hline F302 & Crab apples - canned \\
\hline F302 & Prunes - canned \\
\hline F302 & Cherries - canned \\
\hline F302 & Blueberries - canned \\
\hline Apricots - cannerries - canned \\
\hline Fopefruit - canned \\
\hline Snax (TM) \\
\hline
\end{tabular}




\begin{tabular}{|c|c|}
\hline $\mathrm{F} 304$ & Jam, jelly and other preserves (including marmalade) \\
\hline F304 & Mint jelly \\
\hline F304 & Collation Pom \\
\hline F304 & Cranberry jelly - canned \\
\hline $\mathrm{F} 304$ & Cranberry sauce - canned \\
\hline F304 & Crystallized and glace fruits - canned \\
\hline F304 & Jams and other preserves - canned \\
\hline $\mathrm{F} 304$ & Jellies - canned \\
\hline F304 & Marmalades - canned \\
\hline F305 & Fruit pie fillings - canned \\
\hline F305 & Lemon pie filling - canned \\
\hline F305 & Mincemeat (mainly fruit) - canned \\
\hline F305 & Pumpkin pie filling - canned \\
\hline F305 & Rhubarb pie filling - canned \\
\hline F305 & Strawberry/rhubarb pie filling - canned \\
\hline F305 & Apple pie filling - canned \\
\hline F311 & Unshelled nuts (nuts with shells) \\
\hline F311 & Unshelled or unroasted almonds (nuts with shells) \\
\hline F311 & Unshelled walnuts (nuts with shells) \\
\hline F311 & Unshelled sunflower seeds (nuts with shells) \\
\hline F311 & Unshelled pistachio nuts (nuts with shelis) \\
\hline F311 & Unshelled pecans (nuts with shells) \\
\hline F311 & Unshelled peanuts (nuts with shells) \\
\hline F311 & Unshelled or unroasted brazil nuts (nuts with sheils) \\
\hline F311 & Unshelled hazelnuts (nuts with shells) \\
\hline F311 & Unshelled filberts (nuts with shells) \\
\hline F311 & Unshelled coconuts (nuts with shells) \\
\hline F311 & Unshelled chestnuts (except horse chestnuts) (nuts with shells) \\
\hline F311 & Unshelled cashew nuts (nuts with shells) \\
\hline F311 & Mixed unshelled nuts (nuts with shells) \\
\hline F311 & Unshelled marrons (nuts with shells) \\
\hline F311 & Unshelled or unroasted butternuts (nuts with shells) \\
\hline F311 & Spitz (TM) \\
\hline
\end{tabular}




\begin{tabular}{|c|c|}
\hline F312 & Shelled peanuts (except salted) (nuts without shells) \\
\hline $\mathrm{F} 312$ & Salted peanuts (shelled) (nuts without shells) \\
\hline F312 & Dry roasted peanuts \\
\hline F 313 & Salted shelled nuts - other (nuts without shells) \\
\hline F313 & Shelled nuts (except salted) - other (nuts without shells) \\
\hline F313 & Shelled or roasted pecans - salted (nuts without shells) \\
\hline F313 & Slivered nuts - salted (nuts without shells) \\
\hline F313 & Shelled or roasted walnuts - salted (nuts without shells) \\
\hline F313 & Shelled or roasted fiberts - salted (nuts without shells) \\
\hline F313 & Shelled or roasted cashew nuts - salted (nuts without shells) \\
\hline F313 & Shelled or roasted brazil nuts - salted (nuts without shells) \\
\hline F313 & Shelled or roasted almonds - salted (nuts without shells) \\
\hline F313 & Roasted chestnuts - salted (nuts without shells) \\
\hline F313 & Mixed shelled nuts - salted (nuts without shells) \\
\hline F313 & Flaked or ground nuts salted (nuts without shells) \\
\hline F313 & Shelled pistachio nuts - salted (nuts without shells) \\
\hline F313 & $\begin{array}{l}\text { Coconut meat (including shredded and desiccated) unsalted } \\
\text { (nuts without shells) }\end{array}$ \\
\hline F313 & Shelled or roasted brazil nuts (nuts without shells) \\
\hline F313 & Slivered nuts - unsalted (nuts without shells) \\
\hline F 313 & Shelled pistachio nuts (nuts without shells) \\
\hline F313 & Shelled or roasted walnuts (nuts without shells) \\
\hline $\mathrm{F} 313$ & Shelled or roasted pecans (nuts without shells) \\
\hline F313 & Shelled or roasted filberts (nuts without shells) \\
\hline F313 & Shelled or roasted cashew nuts (nuts without shells) \\
\hline F313 & Shelled or roasted almonds (nuts without shells) \\
\hline F313 & Shelled hazelnuts (nuts without shells) \\
\hline F313 & Roasted sunflower seeds (deep fried) (nuts without shells) \\
\hline F 313 & Roasted chestnuts (nuts without shells) \\
\hline F313 & Mixed shelled nuts (nuts without shells) \\
\hline F313 & $\begin{array}{l}\text { Melon, watermelon and pumpkin seeds roasted and salted for } \\
\text { food (nuts without shells) }\end{array}$ \\
\hline F313 & Flaked or ground nuts (nuts without shells) \\
\hline F313 & Sweetened coconut \\
\hline F313 & Macadamian nuts - unsalted (nuts without shells) \\
\hline
\end{tabular}




\begin{tabular}{|c|l|}
\hline F318 & Green or wax beans - fresh \\
\hline F319 & Broccoli - fresh \\
\hline F321 & Cabbage - fresh \\
\hline F322 & Carrots - fresh \\
\hline F323 & Cauliflower - fresh \\
\hline F324 & Celery - fresh \\
\hline F325 & Corn - fresh \\
\hline F326 & Cucumbers - fresh \\
\hline F326 & Gherkins - fresh \\
\hline F326 & Bulk purchase of cucumbers \\
\hline F327 & Lettuce - fresh \\
\hline F327 & Boston lettuce \\
\hline F327 & Cos lettuce \\
\hline F327 & Iceberg lettuce \\
\hline F327 & Leaf lettuce \\
\hline F327 & Mixed lettucelradicchio (musceli) \\
\hline F327 & Romaine lettuce \\
\hline F328 & Mushrooms - fresh \\
\hline F329 & Onions - fresh \\
\hline F329 & Shallots - fresh \\
\hline F329 & Scallions - fresh \\
\hline F330 & Peppers - fresh \\
\hline F330 & Pimentos - fresh \\
\hline F331 & Potatoes - fresh \\
\hline F332 & Radishes - fresh \\
\hline F332 & Daikon \\
\hline F333 & Spinach - fresh \\
\hline F334 & Tomatoes - fresh \\
\hline F334 & Bulk purchase of tomatoes \\
\hline F335 & Turnips and rutabagas \\
\hline F335 & Rabioles (white turnips) \\
\hline F335 & Swedish turnips - fresh \\
\hline & \\
\hline
\end{tabular}




\begin{tabular}{|c|c|}
\hline F344 & Leaf and stalk vegetables - other - fresh \\
\hline F344 & Rapini - fresh \\
\hline F344 & Fennel-fresh \\
\hline F344 & Fiddleheads - fresh \\
\hline F344 & Jicama \\
\hline F344 & Ka-Lan \\
\hline F344 & Leeks \\
\hline F344 & Marjoram - fresh \\
\hline F344 & Water cress - fresh \\
\hline F344 & Nappa \\
\hline F344 & Parsley - fresh \\
\hline $\mathrm{F} 344$ & Sorrel - fresh \\
\hline F 344 & Split mung bean - fresh \\
\hline F344 & Sugar cane \\
\hline F344 & Swiss chard - fresh \\
\hline F344 & Endives - fresh \\
\hline F344 & Beet greens - fresh \\
\hline F344 & Asparagus - fresh \\
\hline F344 & Alfalfa sprouts - fresh \\
\hline F344 & Brussels sprouts - fresh \\
\hline F344 & Arugula - Rocket salad \\
\hline F344. & Dill-fresh \\
\hline F 344 & Basil - fresh \\
\hline F344 & Bean sprouts - fresh \\
\hline F344 & Chicory - fresh \\
\hline F344 & Chinese cabbage \\
\hline F344 & Choi sam \\
\hline F344 & Cilantro-fresh \\
\hline F344 & Coriander - fresh \\
\hline F344 & Curly cabbage \\
\hline F344 & Bok choy \\
\hline F344 & Artichokes - fresh (except Jerusalem artichokes) \\
\hline F 345 & Seed and gourd vegetables - other - fresh \\
\hline F345 & Lima beans - fresh \\
\hline F345 & Okra-fresh \\
\hline F345 & Squash - fresh \\
\hline F345 & Vegetable marrows - fresh \\
\hline F345 & Kang Kong \\
\hline F 345 & Zucchini - fresh \\
\hline F345 & Eggplant - fresh \\
\hline F345 & Green peas - fresh \\
\hline F 345 & China egg plant \\
\hline F345 & Bitter melon \\
\hline F345 & Beinjals - fresh (eggplant) \\
\hline$F 345$ & Gumbo-fresh \\
\hline
\end{tabular}




\begin{tabular}{|c|c|}
\hline F346 & Root vegetables - other - fresh \\
\hline $\mathrm{F} 346$ & Jerusalem artichokes \\
\hline F346 & Water chestnuts - fresh \\
\hline F346 & Taro root \\
\hline F346 & Sweet potatoes and yams - fresh or chilled \\
\hline F 346 & Sweet potatoes \\
\hline F346 & Parsnips - fresh \\
\hline F346 & Horseradish - fresh \\
\hline F 346 & Addoes \\
\hline F346 & Ginger root - fresh \\
\hline F 346 & Salsify - fresh \\
\hline F346 & Garlic-fresh \\
\hline F346 & Elephant garlic \\
\hline F346 & Cassava - fresh \\
\hline F346 & Beets - fresh \\
\hline F346 & Groupings of assorted vegetables for stews/soups \\
\hline F351 & Corn-frozen \\
\hline F352 & Peas - frozen \\
\hline F 353 & Potato products - frozen \\
\hline F353 & Cassava (Kinayod) \\
\hline F353 & French fries - frozen \\
\hline F353 & Hash browns - frozen \\
\hline F353 & Julienne potatoes - frozen \\
\hline F 353 & Potato patties - frozen \\
\hline F353 & Potato puffs - pre-cooked frozen \\
\hline F353 & Tater gems - frozen \\
\hline F353 & Superfries (TM) - frozen \\
\hline F 353 & Beefeater (TM) potatoes - frozen \\
\hline F 353 & Dollar (TM) chips - frozen \\
\hline F 363 & Vegetables - other - frozen \\
\hline F 363 & Squash - frozen \\
\hline F 363 & Zucchini - breaded or battered \\
\hline F363 & Spinach - frozen \\
\hline F363 & Onion rings (in batter) - pre-cooked frozen \\
\hline F 363 & Mushrooms - breaded or battered \\
\hline F363 & Mixed vegetables - frozen \\
\hline F363 & Lima beans - frozen \\
\hline F363 & Fiddleheads - frozen \\
\hline F 363 & Cauliflower - frozen \\
\hline F 363 & Carrots - frozen \\
\hline F363 & Brussels sprouts - frozen \\
\hline F 363 & Broccoli - frozen \\
\hline F363 & Asparagus - frozen \\
\hline F363 & Green or wax beans - frozen \\
\hline
\end{tabular}




\begin{tabular}{|l|l|}
\hline F366 & Potato products - dried \\
\hline F366 & Potatoes au gratin - dried (except canned) \\
\hline F366 & Potatoes with sauce mixes \\
\hline F366 & Instant mashed potatoes \\
\hline F366 & Hash brown potatoes - dried \\
\hline F366 & Scalloped potatoes - dried \\
\hline F367 & Vegetables (except canned) - dried \\
\hline F367 & Navy beans - (except canned) \\
\hline F367 & White pea beans (except seed) - dried \\
\hline F367 & Split peas - dried \\
\hline F367 & Split mung bean - dried \\
\hline F367 & Lima beans (except seed) - dried \\
\hline F367 & Refried beans - powdered \\
\hline F367 & Yam tuber \\
\hline F367 & Red kidney beans (except seed) - dried \\
\hline F367 & Mung beans (except seed) - dried \\
\hline F367 & Lotus root - dried \\
\hline F367 & Lentils - dried \\
\hline F367 & Chopped onions - dried \\
\hline F367 & Chick peas - dried \\
\hline F367 & Minced garlic - dried \\
\hline F367 & Mushrooms - dried (except canned) \\
\hline F371 & Green or wax beans - canned \\
\hline F372 & Baked beans - canned \\
\hline F373 & Beans - other - canned \\
\hline F373 & Faba beans - canned \\
\hline F373 & Refried beans - canned \\
\hline F373 & Navy beans - canned \\
\hline F373 & Lima beans - canned \\
\hline F373 & Kidney beans - canned \\
\hline F373 & Fava beans - canned \\
\hline F373 & Chick peas - canned \\
\hline F373 & Broad beans - canned \\
\hline F373 & Garbanzo beans - canned \\
\hline
\end{tabular}




\begin{tabular}{|l|l|}
\hline F376 & Corn - canned \\
\hline F377 & Mushrooms and truffles - canned \\
\hline F377 & Mushrooms - canned \\
\hline F377 & Mushrooms - pieces and stems - canned \\
\hline F377 & Trufles - canned \\
\hline F378 & Peas - canned \\
\hline F379 & Tomatoes (including paste) - canned \\
\hline F379 & Tomato paste - canned \\
\hline F379 & Tomato sauce - canned \\
\hline F379 & Stewed/crushed/diced/whole tomatoes - canned \\
\hline F388 & Vegetables (except infant foods) - other - canned \\
\hline F388 & Potatoes (except infant foods) - canned \\
\hline F388 & Yams - canned \\
\hline F388 & Water chestnuts - canned \\
\hline F388 & Vine leaves - canned \\
\hline F388 & Sweet potatoes - canned \\
\hline F388 & Squash - canned \\
\hline F388 & Spinach (except infant foods) - canned \\
\hline F388 & Red peppers - canned \\
\hline F388 & Pimentos - canned \\
\hline F388 & Bamboo shoots - canned \\
\hline F388 & Sauerkraut - canned \\
\hline F388 & Asparagus (except infant foods) - canned \\
\hline F388 & Peas and carrots (except infant foods) - canned \\
\hline F388 & Bean sprouts - canned \\
\hline F388 & Beets - canned \\
\hline F388 & Carrots - canned \\
\hline F388 & Green peppers - canned \\
\hline F388 & Macedoine mixed vegetables (except infant foods) - canned \\
\hline F388 & Mixed vegetables (except infant foods) - canned \\
\hline F388 & Okra - canned \\
\hline F390 & Tomato juice - canned \\
\hline F394 & Vegetable juice - other - canned \\
\hline F394 & Carrot juice - canned \\
\hline
\end{tabular}




\begin{tabular}{|c|c|}
\hline F396 & Pickles (including olives) \\
\hline F396 & Pimentos - pickled \\
\hline F396 & Walnuts - pickled \\
\hline F396 & Peppers - pickled \\
\hline F396 & Onions - pickled \\
\hline F396 & Olives in liquid preservative \\
\hline F396 & Olives - canned \\
\hline F396 & Mushrooms - pickled \\
\hline F396 & Mixed pickles \\
\hline F396 & Mango pickles \\
\hline F396 & Bread and butter pickles \\
\hline F396 & Eggs - pickled \\
\hline F396 & Dill pickles \\
\hline F396 & Cocktail onions \\
\hline F396 & Chives - pickled \\
\hline F396 & Chillies - pickled \\
\hline F396 & Capers \\
\hline F396 & Beets - pickled \\
\hline F396 & Gherkins - pickled \\
\hline F400 & Ketchup \\
\hline F400 & Catsup (ketchup) \\
\hline F405 & Other sauces/gravy and sauce mixes \\
\hline F405 & Sparerib sauce \\
\hline F405 & Spaghetti sauce \\
\hline F405 & Seafood sauce \\
\hline F405 & Spaghetti sauce with meat \\
\hline F405 & Spaghetti sauce with mushrooms \\
\hline F405 & Soya sauce \\
\hline F405 & Steak sauce \\
\hline F405 & Stir fry sauce \\
\hline F405 & Taco sauce \\
\hline F405 & Tartar sauce \\
\hline F405 & Worcestershire sauce \\
\hline F405 & Sauce mixes \\
\hline F405 & Pepper steak mix \\
\hline F405 & Teriyaki sauce \\
\hline F405 & Bar-b-que sauce \\
\hline F405 & Pizza sauce \\
\hline F 405 & Oyster sauce \\
\hline F405 & Mushroom sauce \\
\hline F405 & Mint sauce \\
\hline F405 & Meat gravy (except canned) - dried \\
\hline F 405 & Honey garlic sauce \\
\hline F 405 & Hollandaise sauce \\
\hline F405 & Guacamole \\
\hline
\end{tabular}




\begin{tabular}{|l|l|}
\hline F405 & Chili sauce \\
\hline F405 & Bearnaise sauce \\
\hline F405 & Plum sauce \\
\hline F405 & Salsa sauce \\
\hline F405 & Hp Sauce (TM) \\
\hline F405 & Velotine (TM) \\
\hline F405 & A1 Steak Sauce (TM) \\
\hline F405 & Tabasco Sauce (TM) \\
\hline F405 & QH Light Blend (TM) \\
\hline F406 & Mayonnaise and salad dressings \\
\hline F406 & Low calorie dressings \\
\hline F406 & Thousand islands dressing \\
\hline F406 & Italian dressing \\
\hline F406 & French dressing \\
\hline F406 & Blue cheese dressing \\
\hline F408 & Condiments (including vinegar) - other \\
\hline F408 & Vinegar \\
\hline F408 & Vegetable sandwich spreads \\
\hline F408 & Specialty vinegars - other \\
\hline F408 & Rice wine vinegar \\
\hline F408 & Prepared mustard \\
\hline F408 & Prepared horseradish relish \\
\hline F408 & Prepared horseradish \\
\hline F408 & Pickle relish \\
\hline F408 & Mustard sauce \\
\hline F408 & Horseradish mustard \\
\hline F408 & Chutney relish \\
\hline F408 & Balsamic vinegar \\
\hline F408 & Chow chow relish \\
\hline & \\
\hline
\end{tabular}




\begin{tabular}{|c|c|}
\hline F410 & Herbs and spices \\
\hline F410 & Pepper \\
\hline F410 & Parsley - dried \\
\hline $\mathrm{F} 410$ & Paprika \\
\hline F410 & Oregano \\
\hline F410 & Mustard - dried \\
\hline $\mathrm{F} 410$ & Pimento - dried \\
\hline F410 & Marjoram - dried \\
\hline F410 & Sesame seeds \\
\hline F410 & Mace and nutmegs \\
\hline F410 & Mixed pickling spices \\
\hline F410 & Rosemary \\
\hline F410 & Saffron \\
\hline F410 & Savoury \\
\hline $\mathrm{F} 410$ & Grape cardamoms \\
\hline F410 & Spice mixtures \\
\hline F410 & Spnint leaves \\
\hline F410 & Tarragon \\
\hline F410 & Thyme \\
\hline$F 410$ & Turmeric \\
\hline F410 & Vanilla beans \\
\hline$F 410$ & Sage \\
\hline F410 & Chill pepper \\
\hline F410 & Allspice \\
\hline F410 & Anise seeds \\
\hline F410 & Bay leaves - dried \\
\hline$F 410$ & Caraway seeds \\
\hline F 410 & Juniper \\
\hline F 410 & Celery seeds \\
\hline F410 & Horseradish root - dried \\
\hline F410 & Chili powder \\
\hline F410 & Cinnamon \\
\hline F410 & Garam masala \\
\hline F410 & Celery powder \\
\hline F 410 & Ginger \\
\hline F 410 & Citrotin \\
\hline F410 & Fennel - dried \\
\hline F410 & Dill \\
\hline F410 & Curry powder \\
\hline F410 & Cumin \\
\hline F410 & Coriander \\
\hline F410. & Cloves \\
\hline F410 & Goberg Lemon pepper (TM) \\
\hline F410 & Keen's Ground Mustard (TM) \\
\hline
\end{tabular}




\begin{tabular}{|c|c|}
\hline F422 & Sugar \\
\hline F422 & Maple sugar \\
\hline F422 & Loaf sugar from beet or cane \\
\hline F422 & Icing sugar \\
\hline F422 & Dextrose \\
\hline F422 & Cubed sugar \\
\hline F422 & Brown sugar \\
\hline F422 & Fructose (fruit sugar) \\
\hline F423 & Syrups and molasses \\
\hline F423 & Table syrup \\
\hline F423 & Treacle \\
\hline F423 & Sugar syrup \\
\hline F423 & Molasses \\
\hline F423 & Maple syrup \\
\hline $\mathrm{F} 423$ & Corn syrup \\
\hline F423 & Cane syrup \\
\hline F423 & Blackstrap molasses \\
\hline F423 & Blackstrap syrup \\
\hline F423 & Waffe syrup \\
\hline F 423 & Glucose (unmixed corn syrup) \\
\hline F427 & Gum \\
\hline $\mathrm{F} 427$ & Chewing gum \\
\hline F427 & Bubble gum \\
\hline F427 & Chiclets (TM) \\
\hline $\mathrm{F} 427$ & Trident sugar-free gum (TM) \\
\hline F428 & Candy bars \\
\hline $\mathrm{F} 428$ & Chocolate bars \\
\hline $\mathrm{F} 430$ & Chocolate confections - other \\
\hline $\mathrm{F} 430$ & Easter eggs (chocolate-covered marshmallow) \\
\hline F430 & Chocolate-coated fruits \\
\hline F430 & Packaged chocolates \\
\hline F430 & Liqueur-filled chocolates \\
\hline $\mathrm{F} 430$ & Italian chocolate \\
\hline$F 430$ & Boxed chocolates \\
\hline F430 & Chocolate novelties (Easter, Christmas) \\
\hline F 430 & Chocolate hollow goods \\
\hline F430 & Bulk chocolates \\
\hline F430 & Chocolate-covered nuts \\
\hline $\mathrm{F} 430$ & Chocolate-covered raisins \\
\hline F430 & Smarties (TM) \\
\hline
\end{tabular}




\begin{tabular}{|l|l|}
\hline F431 & Sugar candy \\
\hline F431 & Dietetic candy (sugarless) \\
\hline F431 & Tangy taffy \\
\hline F431 & Sugar novelties \\
\hline F431 & Small sugar candy (penny goods) \\
\hline F431 & Mints \\
\hline F431 & Lollipops \\
\hline F431 & Jujubes \\
\hline F431 & Hard drops (candy) \\
\hline F431 & Cream mints (candy) \\
\hline F431 & Christmas candy (including canes) \\
\hline F431 & Caramels (candy) \\
\hline F431 & Candy lozenges \\
\hline F431 & Bonbons (candy) \\
\hline F431 & Jelly beans \\
\hline F431 & Spinners (TM) \\
\hline F431 & Squirmies (TM) \\
\hline F431 & Gummie worms (TM) \\
\hline F431 & Sodalicious (TM) \\
\hline F431 & Satin mix (TM) \\
\hline F431 & Lifesavers (TM) \\
\hline F431 & Gushers (TM) \\
\hline F431 & Ganong chews (TM) \\
\hline F431 & Fruit rollups (TM) \\
\hline F431 & Fruit leather (TM) \\
\hline F431 & Fruit by the Foot (TM) \\
\hline F431 & Frisk (TM) \\
\hline F431 & Cherry blaster \\
\hline F431 & Gummie Bears (TM) \\
\hline & \\
\hline
\end{tabular}




\begin{tabular}{|l|l|}
\hline F434 & Sugar confections - other \\
\hline F434 & Cereal bars \\
\hline F434 & Nougat, not containing chocolate \\
\hline F434 & Yogurt covered raisins \\
\hline F434 & Twists (licorice) \\
\hline F434 & Toffee \\
\hline F434 & Tire d'erable \\
\hline F434 & Sesame seed snaps \\
\hline F434 & Peanut brittle \\
\hline F434 & Yogurt malt candy \\
\hline F434 & Marshmallows \\
\hline F434 & Licorice confectionery \\
\hline F434 & Fudge \\
\hline F434 & Fondant \\
\hline F434 & Candied popcorn \\
\hline F434 & Candied nuts \\
\hline F434 & Popsicles \\
\hline F434 & Granola bars \\
\hline F434 & Nutribar (TM) \\
\hline F434 & Nutri-grain bars (TM) \\
\hline F434 & Sun-ups (TM) \\
\hline F435 & Sugar preparations - other \\
\hline F435 & Sugar preparations for drinks \\
\hline F435 & Candied ginger \\
\hline F435 & Soda fountain syrups, toppings and fruits \\
\hline F435 & Marshmallow topping \\
\hline F435 & Edible cake decorations \\
\hline F435 & Chocolate syrup \\
\hline F435 & Cake icing \\
\hline F435 & Dessert topping \\
\hline F4335 & Root beer syrups \\
\hline F435 & Left drink concentrates and syrups \\
\hline Limeade syrups \\
\hline
\end{tabular}




\begin{tabular}{|c|l|}
\hline F439 & Roasted or ground coffee \\
\hline F440 & Coffee - other \\
\hline F440 & Specialty coffee \\
\hline F440 & Instant coffee \\
\hline F440 & Camp coffee \\
\hline F440 & De-caffeinated coffee \\
\hline F442 & Tea (including herbal) \\
\hline F442 & Tea extracts, essences and preparations \\
\hline F442 & Black tea in tea bags \\
\hline F442 & Thermo tea \\
\hline F442 & Tea substitutes \\
\hline F442 & Green tea \\
\hline F442 & Black tea \\
\hline F442 & Instant iced tea \\
\hline F442 & Red Zinger (herbal tea) (TM) \\
\hline F446 & Margarine \\
\hline F446 & Butter spreads (margarine base) \\
\hline F447 & Shortening \\
\hline F448 & Lard \\
\hline F448 & Leaflard \\
\hline F448 & Tenderflake (TM) \\
\hline F449 & Cooking/salad oil \\
\hline F449 & Peanut oil \\
\hline F449 & Saflower oil \\
\hline F449 & Sesame oil \\
\hline F449 & Sunflower oil \\
\hline F449 & Corn oil \\
\hline F449 & Canola oil \\
\hline F449 & Blended vegetable oils \\
\hline F449 & Soya oil \\
\hline F449 & Olive oil \\
\hline F449 & Pam (TM) \\
\hline
\end{tabular}




\begin{tabular}{|c|c|}
\hline F466 & Soup - chilled, frozen or canned \\
\hline F466 & Cheddar cheese soup - canned \\
\hline F466 & Won ton soup - canned \\
\hline F466 & Turtle soup - canned \\
\hline F466 & Seafood chowders - canned \\
\hline F466 & Fish chowder mix \\
\hline F466 & Cream soups \\
\hline F466 & Consomme/broth - canned \\
\hline F466 & Chowder mix \\
\hline F 466 & Borsch (soup) - canned \\
\hline F466 & Clam chowder - canned \\
\hline F466 & Chunky soups (TM) - canned \\
\hline F467 & Soup-dried \\
\hline F467 & Soup powders \\
\hline F467 & Cup-a-noodles (TM) \\
\hline F467 & Cup-a-soup (TM) \\
\hline F467 & Ichiban (TM) \\
\hline F467 & Instant snack in a cup (TM) \\
\hline F467 & Souptime (TM) \\
\hline F467 & Beef in Mug \\
\hline F469 & Infant or junior foods - canned \\
\hline F469 & Infant foods, dairy produce \\
\hline F469 & Infant vegetables - canned \\
\hline F469 & Infant soups and dinners - canned \\
\hline F469 & Infant meats - canned \\
\hline F469 & Infant fruit juice - canned \\
\hline F469 & Infant fruits, puddings and custards - canned \\
\hline F472 & Infant cereals and biscuits \\
\hline F472 & Teething biscuits \\
\hline $\mathrm{F} 472$ & Farley's baby biscuits (TM) \\
\hline F472 & Pablum (TM) \\
\hline F475 & Infant formula \\
\hline F475 & Formula milk \\
\hline F475 & Good Start (TM) \\
\hline F475 & Isomil (TM) \\
\hline F475 & Pediasure (TM) \\
\hline F 475 & Prosobee (TM) \\
\hline F475 & Similac (TM) \\
\hline F475 & Enfalac (TM) \\
\hline
\end{tabular}




\begin{tabular}{|c|c|}
\hline F477 & Dinners - pre-cooked frozen \\
\hline F 477 & Dinners, principally of meat - pre-cooked frozen \\
\hline F477 & Vegetarian dinners - pre-cooked frozen \\
\hline F477 & Tortellini dinners - pre-cooked frozen \\
\hline F477 & TV dinners - pre-cooked frozen \\
\hline F477 & Shellfish dinners - pre-cooked frozen \\
\hline F477 & Fish with vegetables and sauces - pre-cooked frozen \\
\hline F477 & Entrees - precooked - frozen \\
\hline F 477 & Chinese food dinners - pre-cooked frozen \\
\hline F477 & Fish and chips - pre-cooked frozen \\
\hline F480 & Dessert pies, cakes, squares and other pastries - frozen \\
\hline F 480 & Nanaimo bars (frozen) \\
\hline F480 & French toast - frozen \\
\hline F480 & Chocolate eclairs - frozen \\
\hline F480 & Cream pies - pre-cooked frozen \\
\hline F480 & Waffles - frozen \\
\hline F480 & Eggo (TM) \\
\hline F484 & Meat or poultry pies - frozen \\
\hline F484 & Sausage rolls - pre-cooked frozen \\
\hline F484 & Ron Dine Italien (TM) \\
\hline F 490 & Other prepared food - pre-cooked frozen \\
\hline F490 & Pogo \\
\hline F490 & Pork riblets - pre-cooked frozen \\
\hline F490 & Quiche - pre-cooked frozen \\
\hline F490 & Ravioli-precooked - frozen \\
\hline F490 & Rice preparations - pre-cooked frozen \\
\hline F490 & Seafood casseroles - pre-cooked frozen \\
\hline F490 & Smoked meatballs - frozen \\
\hline F490 & Souvlaki-pre-cooked frozen \\
\hline $\mathrm{F} 490$ & Spring rolls - pre-cooked frozen \\
\hline F490 & Tortellini - pre-cooked frozen \\
\hline F490 & Burritos - pre-cooked frozen \\
\hline F490 & Vegetable preparations - pre-cooked frozen \\
\hline F490 & Welsh rarebit - pre-cooked frozen \\
\hline F490 & Pizza pops \\
\hline F490 & Submarine sandwiches - frozen \\
\hline F490 & Corned beef hash - pre-cooked frozen \\
\hline F 490 & Cabbage rolls - pre-cooked frozen \\
\hline F490 & Cheeseburgers - pre-cooked frozen \\
\hline F490 & Chicken nuggets - pre-cooked frozen \\
\hline F490 & Caulffower with cheese sauce - pre-cooked frozen \\
\hline F490 & Chinese food dishes - pre-cooked frozen \\
\hline F490 & Pizza pies - pre-cooked frozen \\
\hline F 490 & Egg-rolls - pre-cooked frozen \\
\hline F490 & Fish cakes - pre-cooked frozen \\
\hline
\end{tabular}




\begin{tabular}{|c|l|}
\hline F490 & Knishes - precooked - frozen \\
\hline F490 & Lasagne - pre-cooked frozen \\
\hline F490 & Macaroni and cheese - pre-cooked frozen \\
\hline F490 & Perogies - pre-cooked frozen \\
\hline F490 & Chicken wings - pre-cooked frozen \\
\hline F490 & Pizza pockets (TM) \\
\hline F490 & Capio double cheese (TM) \\
\hline F491 & Materials for food preparation \\
\hline F491 & Gelatin \\
\hline F491 & Yogurt starter \\
\hline F491 & Yeast \\
\hline F491 & Unsweetened cooking chocolate, in blocks and cakes \\
\hline F491 & Textured soy protein \\
\hline F491 & Tapioca (including starch) \\
\hline F491 & Synthetic chocolate \\
\hline F491 & Sweetened chocolate in blocks, cakes, crumbs or granules \\
\hline F491 & Sesame powder \\
\hline F491 & Rice starch \\
\hline F491 & Prepared rennet \\
\hline F491 & Potato starch \\
\hline F491 & Pectin \\
\hline F491 & Grated soya \\
\hline F491 & Cream of tartar \\
\hline F491 & Corn starch \\
\hline F491 & Coconut milk \\
\hline F491 & Coconut cream \\
\hline F491 & Cocoa or chocolate powder \\
\hline F491 & Chocolate chips \\
\hline F491 & Carob chips and powder \\
\hline F491 & Beef suet \\
\hline F491 & Baking soda \\
\hline F491 & Baking powder \\
\hline F491 & Artificial sweeteners \\
\hline F491 & Arrowroot - dried \\
\hline No-gr-colour \\
\hline Aspartame (TM) \\
\hline Certo (TM) \\
\hline
\end{tabular}




\begin{tabular}{|c|c|}
\hline F497 & Honey \\
\hline F498 & Peanut butter \\
\hline F499 & Dairy product substitutes \\
\hline F499 & Cream substitutes \\
\hline F499 & Milk substitutes \\
\hline F499 & Rice drink \\
\hline F499 & Soya bean milk \\
\hline F499 & Whipped cream substitutes \\
\hline F499 & Reddi-wip (TM) \\
\hline F499 & Coffee Rich (TM) \\
\hline F499 & Coffee-mate (TM) \\
\hline F499 & Cool Whip (TM) \\
\hline F499 & Dream Whip (TM) \\
\hline F499 & Nutrifil (TM) \\
\hline F500 & Flavouring extracts and essences \\
\hline F500 & Liquid non-alcoholic cocktail mixes \\
\hline F500 & Almond extract \\
\hline F500 & Vanilla extract \\
\hline F501 & Flavouring powders and crystals \\
\hline F501 & Fruit-flavoured powders \\
\hline F501 & Powdered cocktail mixes \\
\hline F501 & Electrolyte replacement powders (including Gatorade (TM)) \\
\hline F501 & Gatorade (TM) - powdered \\
\hline F501 & Kool-aid (TM) \\
\hline F501 & Quench (TM) \\
\hline F501 & Tang (TM) \\
\hline F502 & Food seasonings (except spices, but including table salt) \\
\hline F502 & Monosodium glutamate (seasoning) \\
\hline F502 & Onion powder \\
\hline $\mathrm{F} 502$ & Vietnamese soup \\
\hline F502 & Table salt \\
\hline F502 & Seasoning salt \\
\hline F502 & Onion salt \\
\hline F502 & Celery salt \\
\hline F502 & Gravy improver \\
\hline $\mathrm{F} 502$ & Salt substitute \\
\hline F502 & Garlic powder \\
\hline F502 & Garlic and onion salt seasonings \\
\hline F502 & Dry bouillon extracts, (except canned) \\
\hline $\mathrm{F} 502$ & Meat improver (food seasoning) \\
\hline $\mathrm{F} 502$ & Shake 'n bake (TM) \\
\hline F502 & Taco Joe seasoning (TM) \\
\hline F502 & Oxo cubes (TM) \\
\hline $\mathrm{F} 502$ & Mrs. Dash (TM) \\
\hline F502 & Insta bake \\
\hline
\end{tabular}




\begin{tabular}{|c|c|}
\hline $\mathrm{F} 502$ & Bovril in liquid form (TM) - canned \\
\hline F502 & Chicken Bouquet \\
\hline $\mathrm{F} 502$ & Kitchen Bouquet (TM) \\
\hline F497 & Honey \\
\hline F504 & Prepared dessert powders \\
\hline $\mathrm{F} 504$ & Custard powders \\
\hline $\mathrm{F} 504$ & Lemon pie fillings \\
\hline F504 & Butterscotch pie fillings \\
\hline $\mathrm{F} 505$ & Potato-based snack foods \\
\hline F505 & Julienne potatoes - dried \\
\hline F505 & Prawn chips \\
\hline F505 & Rippled potato chips \\
\hline $\mathrm{F} 505$ & Shoestring potatoes \\
\hline F506 & Food drink powders \\
\hline $\mathrm{F} 506$ & Dietary food drink preparations \\
\hline F506 & Chocolate food drink powders \\
\hline F506 & Cereal grain drink powders \\
\hline F506 & Hot chocolate powders \\
\hline F506 & Instant breakfast (TM) \\
\hline F506 & Ovaltine (TM) \\
\hline F506 & Postum (TM) \\
\hline F506 & Quik (TM) \\
\hline F507 & Puddings and custards - canned \\
\hline F507 & Rice pudding - canned \\
\hline F507 & Tapioca puddings - canned \\
\hline F507 & Gelatin-based puddings - canned \\
\hline F507 & Custard puddings - canned \\
\hline F507 & Coco-jel \\
\hline F507 & Chocolate puddings - canned \\
\hline $\mathrm{F} 507$ & Caramel puddings - canned \\
\hline F507 & Cornstarch puddings - canned \\
\hline F518 & Sandwiches and hot food preparation \\
\hline F518 & Fresh or 'deli' salads \\
\hline F518 & Prepared or 'deli' foods (fresh or canned) - other \\
\hline F518 & Other spreads, pastes and butters (n.e.s.) \\
\hline F518 & All other food preparations (n.e.s.) \\
\hline F518 & Hot egg rolls \\
\hline F518 & Sandwiches (incl. submarines) \\
\hline F518 & Potato wedges \\
\hline F518 & Party tray of sandwiches \\
\hline F518 & Hot quiches \\
\hline F518 & Hot pizza \\
\hline F518 & Hot fried rice \\
\hline F518 & Hot chow mein \\
\hline F518 & Hot chop suey \\
\hline F518 & Hot chile con carne \\
\hline
\end{tabular}




\begin{tabular}{|c|c|}
\hline F518 & Hot cabbage rolls \\
\hline F518 & Hot pasta dishes \\
\hline F518 & Tabouli \\
\hline F518 & Vegetable salad \\
\hline F518 & Stew pack \\
\hline F518 & Sauerkraut (except canned) \\
\hline F518 & Salad mix - fresh \\
\hline F518 & Macaroni salad \\
\hline F518 & Fruit salad - fresh \\
\hline F518 & Cole slaw in package \\
\hline F518 & Caesar salad mix - fresh \\
\hline F518 & Bean salad \\
\hline F518 & Potato salad \\
\hline F518 & Salmon pate - fresh \\
\hline F518 & Fried bean ball \\
\hline F518 & Fried rice (prepared) - fresh or canned (except hot) \\
\hline F518 & Hats-n-hams \\
\hline F518 & Kishke - fresh \\
\hline F518 & Knishes - fresh \\
\hline F518 & Pakoras \\
\hline F518 & Pasta and sauces - fresh \\
\hline F518 & Perogies - fresh or canned \\
\hline $\mathrm{F} 518$ & Quiches (except pre-cooked frozen) \\
\hline F518 & Pizza - fresh (except hot) \\
\hline F518 & Egg rolls - fresh \\
\hline F518 & Pasta dishes - prepared (except frozen or canned) \\
\hline F518 & Baked beans, fresh (except hot) \\
\hline F518 & Dried dinners \\
\hline F518 & Basket Snack \\
\hline F518 & Cabbage rolls - canned \\
\hline F518 & Cabbage rolls - fresh \\
\hline F518 & Canacella \\
\hline F518 & Dehydrated dinners \\
\hline F518 & Chili con carne - canned \\
\hline F518 & Chili con carne (except hot) \\
\hline F518 & Chop suey - fresh or canned \\
\hline F518 & Salmon mousse - fresh \\
\hline F518 & Chow mein - fresh or canned \\
\hline F518 & Carne Assaba \\
\hline F518 & Lemon cheese \\
\hline F518 & Hazelnut butter \\
\hline F518 & Tahini \\
\hline F518 & Sesame spread \\
\hline F518 & Red bean paste \\
\hline F518 & Peanut butter and jelly \\
\hline F518 & Nut butters (except peanut) \\
\hline
\end{tabular}

- xlviii - 


\begin{tabular}{|c|c|}
\hline F518 & Maple butter \\
\hline F518 & Almond paste \\
\hline F518 & Hummus \\
\hline F518 & Lemon butter \\
\hline F518 & Halvah (sesame seed spread) \\
\hline F518 & Chestnut puree \\
\hline$F 518$ & Cashew butter \\
\hline$F 518$ & Caramel spread \\
\hline F518 & Apple butter \\
\hline F518 & Oven melts \\
\hline F518 & Bean thread noodles \\
\hline F518 & Tofu hot dogs \\
\hline F518 & Tofu \\
\hline F518 & Tempeh \\
\hline F518 & Stir fry vegetable mix - fresh \\
\hline $\mathrm{F} 518$ & Roasted hot green peas \\
\hline F518 & Red bean bar \\
\hline F518 & Potato toppers \\
\hline$F 518$ & Pizza mix \\
\hline F518 & Pancake batter - frozen \\
\hline F518 & Tofu burgers \\
\hline F518 & Chicory (coffee substitute) \\
\hline$F 518$ & Nacho cheese mix \\
\hline F518 & Burrito kit \\
\hline F518 & California mix - excluding frozen \\
\hline F518 & Cheese melts \\
\hline F518 & Dietary food powders \\
\hline F518 & Dulse \\
\hline F518 & Food colourings \\
\hline F518 & Fruit and nut mixtures \\
\hline F518 & Gravy mixes \\
\hline F518 & Mountain mix \\
\hline F518 & Cheese \& crackers, packaged together \\
\hline F518 & Magic pantry entrees (excepl pasta) (TM) \\
\hline F518 & Magic pantry cabbage rolls (TM) \\
\hline F518 & Major Gourmet (TM) \\
\hline F518 & Marmite (TM) \\
\hline F518 & Nutella (TM) \\
\hline F518 & Boost liquid (TM) \\
\hline F518 & Tofuti (TM) \\
\hline F518 & Taco trio (TM) \\
\hline F518 & Snack shack \\
\hline F518 & Luncheables (TM) \\
\hline F518 & Juicy Gels (TM) \\
\hline F518 & Bacon Bits (TM) \\
\hline F518 & Kikkoman mix (TM) \\
\hline
\end{tabular}

- xlix - 


\begin{tabular}{|l|l|}
\hline F521 & Carbonated beverages \\
\hline F521 & Soda water \\
\hline F521 & Tonic water \\
\hline F521 & Root beer \\
\hline F521 & Low-calorie carbonated beverages \\
\hline F521 & Cola beverage \\
\hline F521 & Collosal cooler (TM) \\
\hline F521 & Big gulp (TM) \\
\hline F522 & Fruit drinks \\
\hline F522 & Squashes (beverage) \\
\hline F522 & Tropical fruit drink \\
\hline F522 & Orange cordial (non-alcoholic) \\
\hline F522 & Saloa \\
\hline F522 & Orange drink \\
\hline F522 & Lime cordial (non-alcoholic) \\
\hline F522 & Lemonade (including pink lemonade) \\
\hline F522 & Lemonade - frozen \\
\hline F522 & Fruit concentrates - frozen \\
\hline F522 & Apple drink \\
\hline F522 & Limeade - frozen \\
\hline F522 & Honeydew (TM) - frozen \\
\hline F522 & Ribena (TM) \\
\hline F522 & Gatorade (TM) fruit drink \\
\hline F522 & Slurpee (TM) \\
\hline F529 & Non-alcoholic beverages - other \\
\hline F529 & Non-alcoholic beverages (taxable group) - other \\
\hline F529 & Mineral waters, natural and artificial, carbonated or still \\
\hline F529 & Non-alcoholic beer and wine (.5\% or less alcohol) \\
\hline F529 & Liquid iced tea \\
\hline F529 & Cafe lib hot beverage \\
\hline F529 & Lemon barley water \\
\hline F529 & Liquid coffee (hot or iced) \\
\hline F529 & Nantan water (TM) \\
\hline
\end{tabular}

